\title{
Visualização de tags para explicar e filtrar recomendações de músicas
}

\author{
Juliana Sato Yamashita \\ DISSERTAÇূ̃̃O APRESENTADA \\ $\mathrm{AO}$ \\ INSTITUTO DE MATEMÁTICA E ESTATÍSTICA \\ DA \\ UNIVERSIDADE DE SÃo PAULO \\ PARA \\ OBTENÇ̧ÃO DO TÍTULO \\ $\mathrm{DE}$ \\ MESTRE EM CIENCIAS \\ Programa: Ciência da Computação \\ Orientador: Prof. Dr. Flávio S. Corrêa da Silva
}




\section{Visualização de tags para explicar e filtrar recomendações de músicas}

Esta versão da dissertação contém as correções e alterações sugeridas pela Comissão Julgadora durante a defesa da versão original do trabalho, realizada em 02/04/2013. Uma cópia da versão original está disponível no Instituto de Matemática e Estatística da Universidade de Sao Paulo.

Comissão Julgadora:

- Prof. Dr. Flávio Soares Corrêa da Silva (orientador) - IME-USP

- Profa. Dra. Maria Laura Martinez - ECA-USP

- Prof. Dr. Carlos Hitoshi Morimoto - IME-USP 


\section{Agradecimentos}

Eu gostaria de agradecer às pessoas e instituições que contribuíram para tornar este trabalho possível. Agradeço ao Brian e minha família, por toda motivação, carinho e compreensão durante o mestrado.

Ao meu orientador, Prof. Dr. Flávio Soares Corrêa da Silva, pelo apoio, conselhos e amizade, e por aceitar o desafio de orientar uma aluna com graduação em arquitetura.

Agradeço também aos professores do Programa de Pós-Graduação em Ciência da Computação, e aos amigos do IME, em especial do LIDET, por sua ajuda, incentivo e motivação.

Finalmente, agradeço à Universidade de São Paulo, ao Instituto de Matemática e Estatística e ao Departamento da Ciência de Computação, por oferecer a oportunidade de realizar o mestrado.

Muito obrigada a todos! 


\section{Resumo}

Coleções digitais de mídias, tanto pessoais como online, crescem rapidamente. Para que grandes quantidades de músicas sejam acessíveis à usuários, serviços populares como iTunes, Last.fm e Pandora oferecem recomendações. Essa abordagem livra usuários de lembrarem de músicas, e permite a descoberta de canções novas ou esquecidas. Mas recomendações apresentam problemas com usuários, como credibilidade e falta de controle.

A motivação deste trabalho é melhorar a experiência de usuários com recomendações de música através do uso de explicações. Ao usar um sistema de recomendação, a satisfação e aprovação de usuários não depende só da eficácia do algoritmo, mas também de explicações. Pesquisas mostram que estas podem beneficiar sistemas de recomendação, aumentando a credibilidade e satisfação de usuários, ao oferecer mais transparência e formas de correção.

O objetivo deste trabalho é projetar e desenvolver uma nova forma de visualização de tags, e testar sua viabilidade para explicar e filtrar recomendações de músicas. Mais precisamente, investigamos se esta visualização pode favorecer as metas de inspeção (scrutability), eficiência, eficácia e satisfação.

A partir da pesquisa em necessidades de usuários para recomendações e música, a visualização Tag Strings foi projetada e desenvolvida. Tag Strings inclui tanto a interface da visualização, quanto o processo de coleta e cálculo de relevância de tags e músicas.

Para a avaliação da visualização Tag Strings, dois tipos de experimentos foram construídos: a comparação entre uma lista de recomendações com Tag Strings, e a comparação entre o design de referência (baseado nos serviços Last.fm e Pandora) e Tag Strings. A construção desses dois experimentos permitiu a avaliação de Tag Strings como uma forma de explicação para recomendações de música.

Os resultados dos experimentos evidenciam que a nova forma de visualização Tag Strings favorece as metas de inspeção (scrutability), eficiência, eficácia e satisfação, melhorando a usabilidade e experiência de usuários com recomendações de música.

Palavras-chave: Sistemas de Recomendação, Visualização, Interação Homem-Máquina, Design de Interfaces 


\section{Abstract}

Digital media collections, both personal and online, grow rapidly. To make large music collections available to users, popular services such as iTunes, Last.fm and Pandora offer recommendations. This approach frees users from searching for music, and allows for the discovery of new or forgotten items. But recommendations present issues such as user trust and lack of control.

The motivation for this project is to improve user experience with music recommendations through explanations. While using a recommendation system, user acceptance and satisfaction depends not only on the algorithm effectiveness, but also on explanations. Research shows that recommendations benefit from explanations, increasing user trust and satisfaction by offering more transparency and scrutability.

The goal of this project is to design and develop a new form of tag visualization, and test its feasibility to explain and filter music recommendations. We specifically investigate if the visualization can support the aims of scrutability, efficiency, effectiveness and satisfaction.

Based on the user research and needs for music recommendation, the visualization Tag Strings was designed and developed. Tag Strings includes both the visualization interface and the process of collecting and calculation of tag and track relevancy.

To evaluate the visualization Tag String, we designed two types of experiments: comparing Tag Strings with a recommendation list, and comparing Tag Strings with a design reference (based on the services Last.fm and Pandora). The design of these two experiments allowed the evaluation of Tag Strings as a form of explanation to music recommendation.

The experiment results highlight that the new visualization Tag Strings favors the aims of scrutability, efficiency, effectiveness and satisfaction, improving the user experience with music recommendations.

Keywords: Recommendation Systems, Visualization, Human-Computer Interaction, Interface Design 


\section{Sumário}

Lista de Tabelas ........................................................................................................ vii

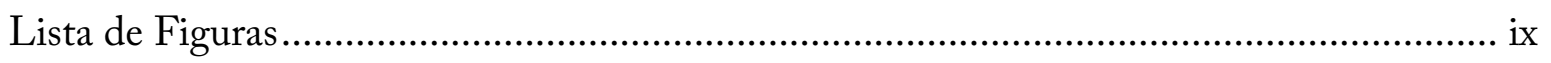

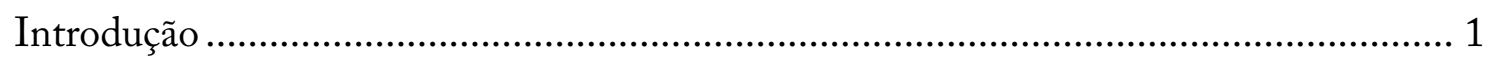

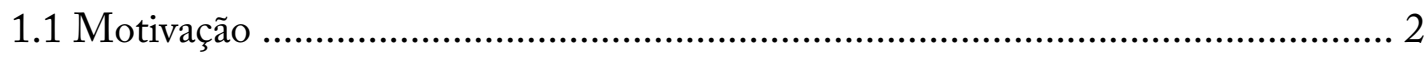

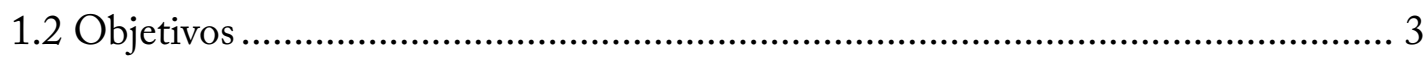

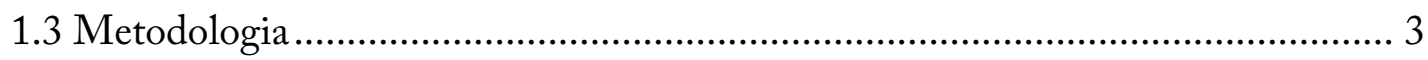

1.4 Contribuições Esperadas .............................................................................. 3

1.5 Estrutura do Trabalho ..................................................................................... 4

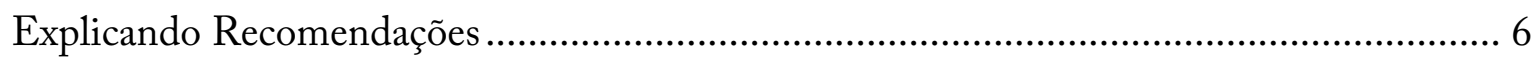

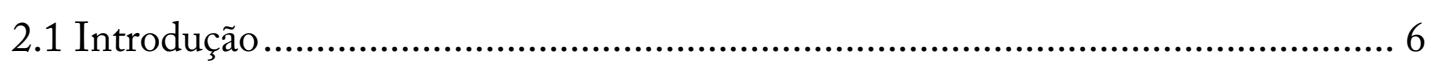

2.2 Metas de Usabilidade e Experiência do Usuário ................................................ 7

2.3 Recomendações, Usabilidade e Experiência do Usuário..................................... 8

2.4 Explicando Recomendações ........................................................................... 9

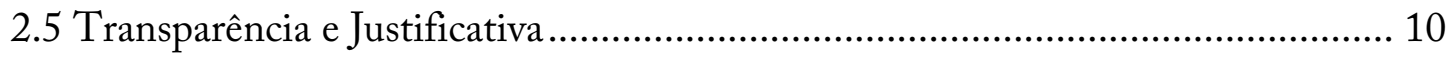

2.6 Metas de Explicação, Usabilidade e Experiência do Usuário ............................... 11

2.7 Processo de Design de Interação ..................................................................... 11

2.7.1 Estudo e Necessidades do Usuário para Música e Recomendação .......... 12

2.7.2 Perfil do Usuário .............................................................................. 17

2.8 Metas de Explicação: Eficiência, Eficácia, Inspeção e Satisfação......................... 17

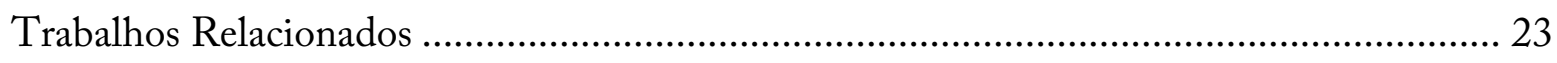

3.1 Explicações de Recomendação que Usam Tags ................................................. 23

3.2 Visualização e Recomendação ......................................................................... 25

3.3 Visualizações de Tags para Coleções de Música................................................ 31

Projetando e Desenvolvendo Visualizações de Tags ............................................................ 34

4.1 Processo de Design de Interação ....................................................................... 34

4.1.1 Perfil do Usuário ..................................................................................... 34

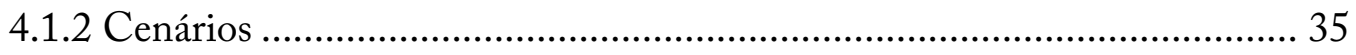

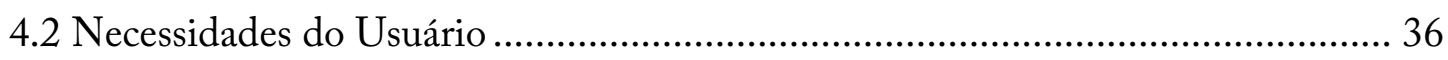

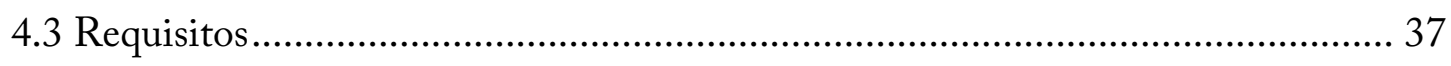




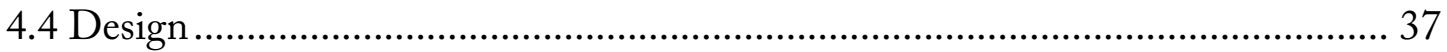

4.5 Exemplos de Designs Conceituais e Critérios de Seleção ...................................... 46

Protótipo para o Espaço de Testes ......................................................................................... 53

5.1 Fluxo do Usuário ............................................................................................. 53

5.2 Implementação de Tag Strings ....................................................................... 54

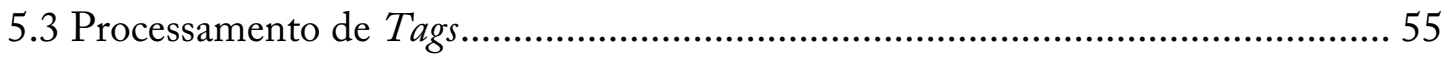

5.4 Melhorando a Relevância de Tags................................................................... 56

5.5 Frequência Inversa de Documentos Aplicada a Relevância de Tags..................... 57

5.5.1 Agrupando Tags Semelhantes .............................................................. 58

5.5.2 Filtrando Recomendações Através de Tags ............................................. 59

5.5.3 Cálculo da Similaridade entre Músicas e o Vetor de Tags:....................... 59

5.6 Experimento com Relevância de Tags................................................................ 60

5.6.1 Métricas para Avaliação ........................................................................ 61

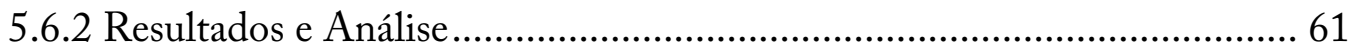

Experimentos com Visualização de Tags .......................................................................... 71

6.1 Avaliando a Interface da Visualização ............................................................... 71

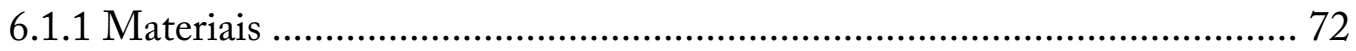

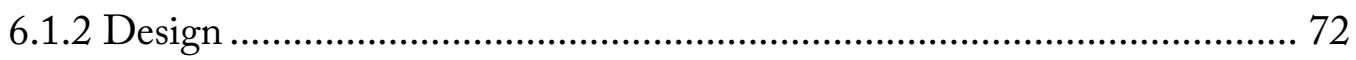

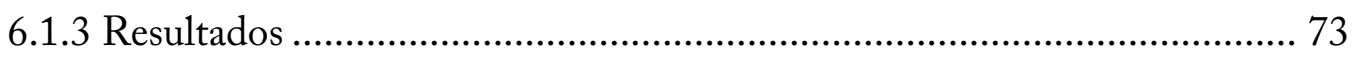

6.2 Experimento 1 - Avaliando Visualizações de Tags como Explicações ................. 74

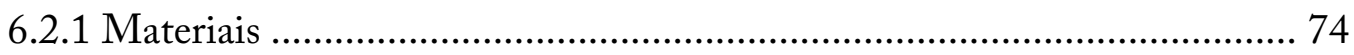

6.2.2 Design do Experimento .................................................................... 77

6.2.3 Hipóteses........................................................................................ 79

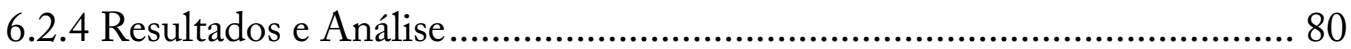

6.3 Experimento 2 - Comparando Tag Strings com Design Base............................. 86

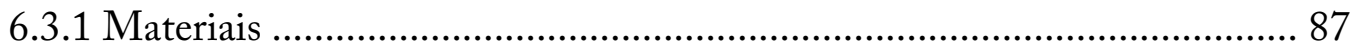

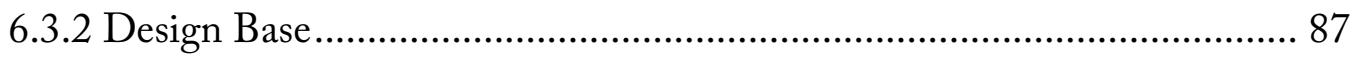

6.3.3 Design do Experimento ………………………………………….... 91

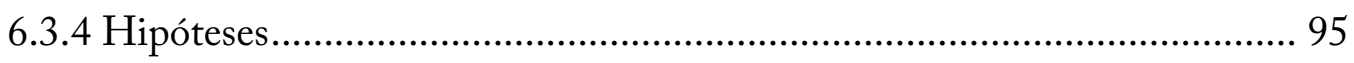

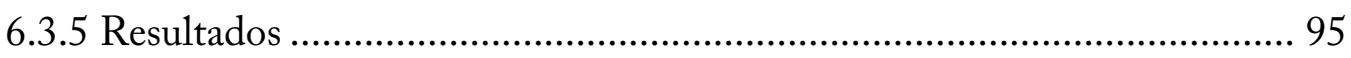

6.4 Experimento 3 - Comparando Tag Strings com Design Base, com Pandora..... 112

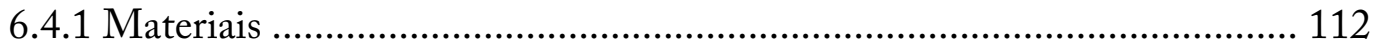




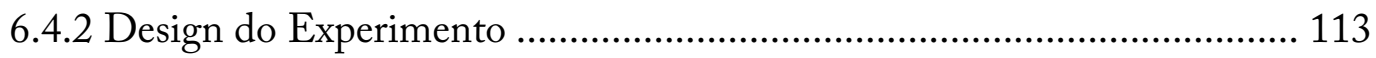

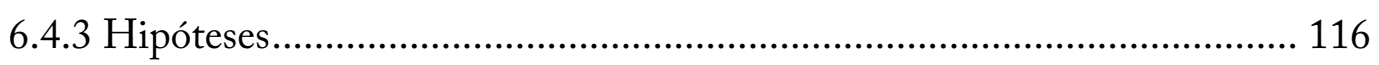

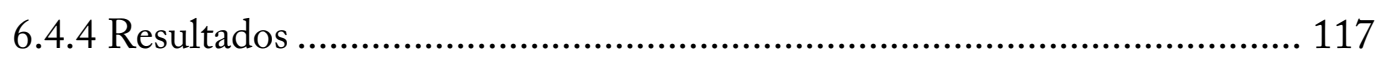

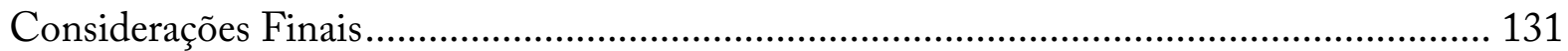

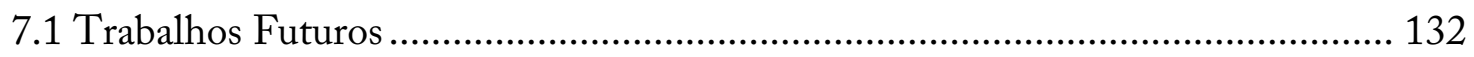

Referências Bibliográficas........................................................................................... 134

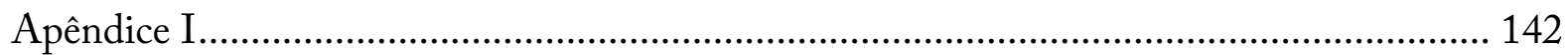

Questionário do Experimento 1 ......................................................................... 142

Questionário dos Experimentos 2 e 3 .................................................................... 148

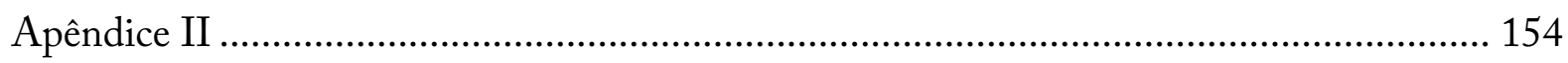

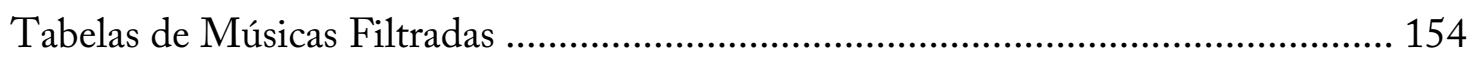

Lista de Recomendações para Experimento 2 …………………………………...... 167

Lista de Recomendações para Experimento 3 ....................................................... 170 


\section{Lista de Tabelas}

Tabela 5.1: Músicas como documentos, e tags como termos e suas frequências 60

Tabela 5.2: Músicas e usuário como documentos, e tags como termos ............................... 60

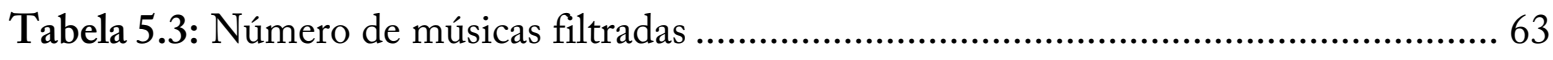

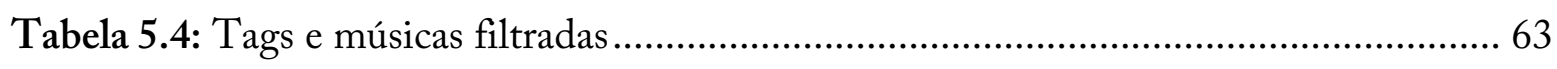

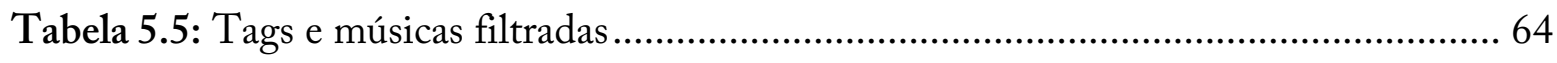

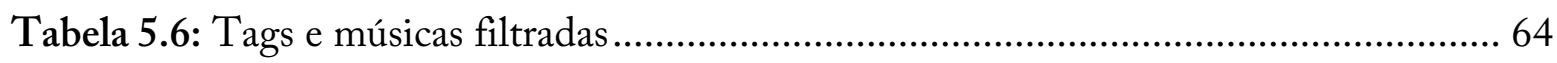

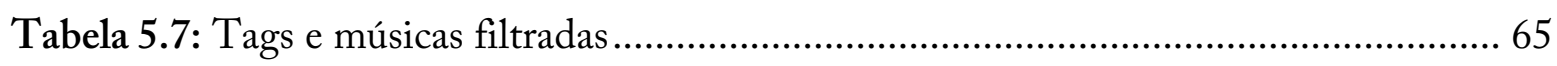

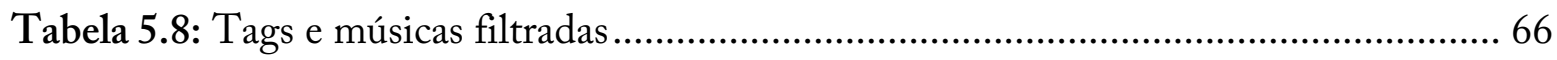

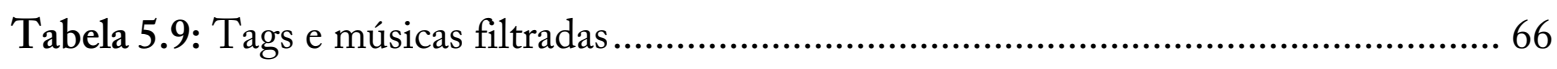

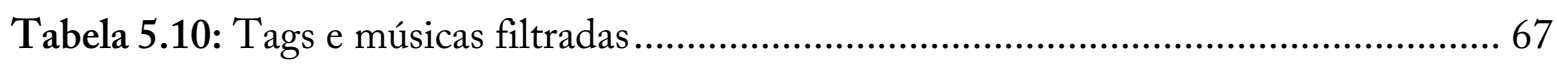

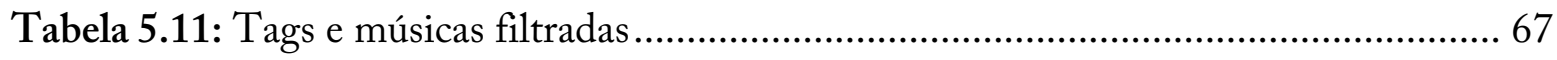

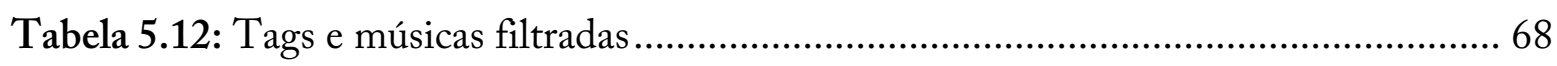

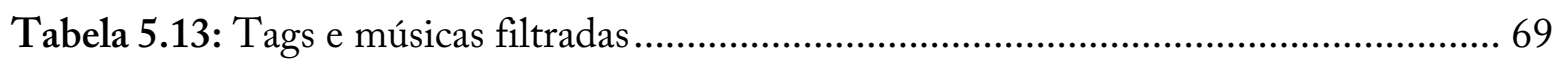

Tabela 6.1: Resultados do questionário aplicado aos participantes .................................. 81

Tabela 6.2: Tempo que usuários levaram para usar Designs A e B .................................. 83

Tabela 6.3:Resultados do questionário aplicado aos participantes .................................... 83

Tabela 6.4: Resultados do questionário aplicado aos participantes. .................................. 84

Tabela 6.5: Resultados do questionário aplicado aos participantes .................................. 85

Tabela 6.6 : Tempo para tarefas com tags "happy" e "piano" ............................................ 98

Tabela 6.7 : Média e desvio padrão do tempo para tarefas com tag "happy”...................... 98

Tabela 6.8 : Média e desvio padrão do tempo para tarefas com tag "piano"........................ 98

Tabela 6.9: Média e desvio padrão do tempo para tarefas para tags combinadas ................ 98

Tabela 6.11 : Número de acertos (respostas corretas) por tags......................................... 102

Tabela 6.12 : Média de acertos (respostas corretas) para tag "happy" ................................ 102 
Tabela 6.13: Média de acertos (respostas corretas) para tag "piano" ................................. 102

Tabela 6.14: Média de acertos (respostas corretas) para tags combinadas........................... 102

Tabela 6.23: Tempo para tarefas no Design A e B, com tags "female" e "piano"................ 118

Tabela 6.24 : Média e desvio padrão do tempo para tarefas com a tag "female" ................. 119

Tabela 6.25: Média e desvio padrão do tempo para tarefas com a tag "piano" ..................... 119

Tabela 6.26: Média e desvio padrão do tempo para tarefas com tags combinadas ............... 119

Tabela 6.28 : Número de acertos (respostas corretas) por tag ("happy”, "piano")............... 122

Tabela 6.29 : Média de acertos (respostas corretas) para tag "female" ............................... 122

Tabela 6.30 : Média de acertos (respostas corretas) para tag "piano" ................................. 123

Tabela 6.31 : Média de acertos (respostas corretas) para tags combinadas......................... 123 


\section{Lista de Figuras}

Figura 3.1: Tagsplanations, interface para recomendações de filme. [Vig et al., 2009]...... 24

Figura 3.2: Movie Tuner, uma interface para corrigir recomendações. [Vig et al. 2011] ... 25

Figura 3.3: Music Explaura [Green et al., 2009].......................................................... 26

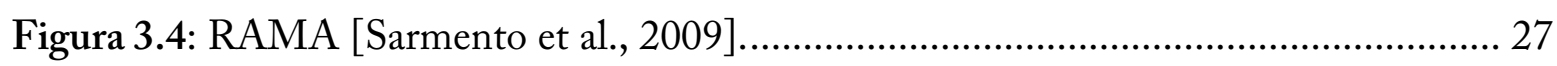

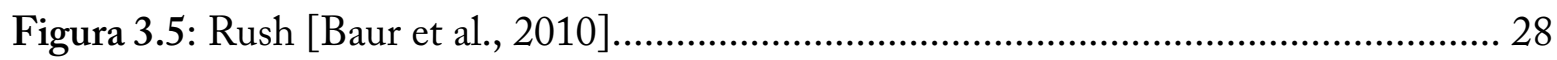

Figura 3.6: PeerChooser [O'Donovan et al., 2008]...................................................... 29

Figura 3.7 : Tag Clouds para explicar recomendações [Gedikli et al., 2011] ...................... 30

Figura 3.8 : TopicLens [Devendorf et al., 2012] ......................................................... 31

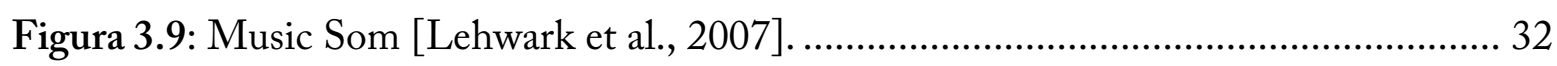

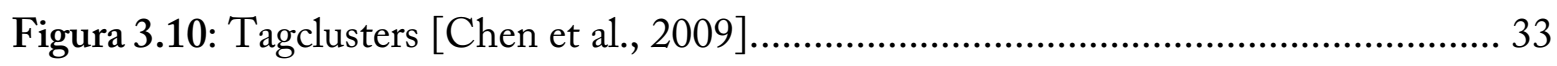

Figura 4.1: Telas do protótipo Tag Strings, na versão final. ........................................... 41

Figura 4.2: Telas do protótipo Tag Strings, na versão final, hover. ................................. 42

Figura 4.3: Telas do protótipo Tag Strings, em uma versão alternativa do protótipo......... 43

Figura 4.4: Telas do protótipo Tag Strings, teste com sombreamento, em hover............... 43

Figura 4.5: Telas do protótipo Tag Strings, na versão final, tag selecionada .................... 45

Figura 4.6 Design 1, uma nuvem Wordle, e Design 2, tags como botões em uma tela. ..... 46

Figura 4.7: Exemplo de uma Nuvem "Wordle" .......................................................... 47

Figura 4.8: Exemplos de conceitos explorados, design 3 e 4 ........................................ 48

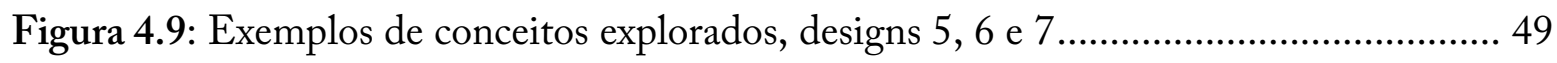

Figura 4.10: Exemplo de um Treemap. [Johnson e Shneiderman, 1991] ......................... 50

Figura 4.11 : Tela de Tag Strings utilizada no Experimento 1....................................... 51

Figura 4.12: Tela de Tag Strings, versão revisada e usada nos Experimentos 2 e 3. .......... 52

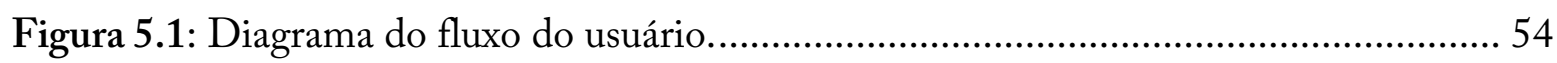

Figura 5.2: Diagrama da implementação de Tag Strings................................................ 55 
Figura 6.1: Tela do protótipo utilizado na avaliação.................................................... 72

Figura 6.2: Tela do serviço Clicky, com dados do comportamento do usuário................... 75

Figura 6.3: Tela do serviço Userfly, com gravação de atividades de um usuário. ................ 76

Figura 6.4 Tela do serviço Userfly combinada com a tela do protótipo, mostrando onde o usuário clicou.

Figura 6.5: Telas do protótipo utilizadas no Experimento 1, com os dois designs exibidos aos participantes 78

Figura 6.6: Telas do protótipo (Design B) mostrando hover e clique em uma tag ............ 81

Figura 6.7: Tela do player do serviço Last.fm............................................................. 88

Figura 6.8: Tela do player do serviço Pandora. ................................................................. 89

Figura 6.9: Tela do Design Base, design baseado nos serviços Pandora e Lastfm. ............ 90

Figura 6.10: Tela do Tag Strings, versão revisada e usada nos Experimentos 2 e 3.......... 91

Gráfico A1 : Média de tempo para tarefas ........................................................................ 99

Gráfico A2 : Média e mediana dos resultados na escala Likert ......................................... 100

Gráfico A3 : Média e mediana dos resultados na escala Likert........................................ 104

Gráfico A4 : Média e mediana dos resultados na escala Likert ........................................ 105

Gráfico A5 : Média e mediana dos resultados na escala Likert ....................................... 106

Gráfico A6 : Média e mediana dos resultados na escala Likert......................................... 107

Gráfico A7 : Média e mediana dos resultados na escala Likert....................................... 108

Gráfico A8 : Média e mediana dos resultados na escala Likert....................................... 109

Gráfico A9 : Média e mediana dos resultados na escala Likert ........................................ 110

Gráfico A10 : Média e mediana dos resultados na escala Likert ...................................... 111

Gráfico A11 : Média de tempo para tarefas ................................................................ 120

Gráfico A12 : Média e mediana dos resultados na escala Likert ...................................... 121

Gráfico A13 : Média e mediana dos resultados na escala Likert ...................................... 124

Gráfico A14 : Média e mediana dos resultados na escala Likert ...................................... 125

Gráfico A15 : Média e mediana dos resultados na escala Likert ...................................... 126 
Lista de Figuras

Gráfico A16 : Média e mediana dos resultados na escala Likert ..................................... 127

Gráfico A17 : Média e mediana dos resultados na escala Likert ....................................... 128

Gráfico A18 : Média e mediana dos resultados na escala Likert ..................................... 129

Gráfico A19 : Média e mediana dos resultados na escala Likert ....................................... 130 


\section{Capítulo 1}

\section{Introdução}

Coleções digitais de mídias, tanto pessoais como online, crescem rapidamente. Tornar essas coleções disponíveis é um desafio, principalmente para músicas, já que usuários tem dificuldade para descrever e classificar canções [Vignoli, 2004]. Em geral, usuários escutam músicas em grupos (listas de músicas, álbuns, programas de rádio), e buscar um número grande de músicas consome tempo. Outro desafio é a dificuldade de lembrar ou descrever metadados sobre uma música ou artista. [Cunningham et al., 2006].

Para que grandes quantidades de músicas sejam acessíveis à usuários, serviços populares como iTunes ${ }^{1}$, Last.fm ${ }^{2}$ e Pandora ${ }^{3}$ oferecem recomendações. Essa abordagem livra os usuários de lembrarem de músicas, e permite a descoberta de canções novas ou esquecidas. Mas recomendações apresentam problemas com usuários, como credibilidade e falta de controle [Herlocker et al., 2000].

Grande parte da pesquisa em sistemas de recomendação foca no aperfeiçoamento dos algoritmos, mas recentemente, a atenção à interface aumentou [McNee et al., 2006]. Swearingen e Sinha [2002] mostram que uma interface eficaz em um sistema de recomendação deve:

- Favorecer a percepção de credibilidade das recomendações;

- Transmitir ao usuário a lógica interna do sistema (transparência), e o motivo de uma recomendação;

- Indicar ao usuário itens novos (que o usuário ainda não conhece);

- Fornecer detalhes sobre itens recomendados;

- Fornecer formas de filtrar recomendações.

Segundo Tintarev e Masthoff [2007], sistemas de recomendação podem se beneficiar de explicações. Explicar recomendações melhora a credibilidade e satisfação do usuário, ao oferecer mais transparência [Swearingen e Sinha, 2002] e inspeção (scrutability: allow users to tell the system it is wrong).

\footnotetext{
${ }^{1} \mathrm{http}: / /$ www.apple.com/itunes

${ }^{2} \mathrm{http} / / /$ www.last.fm

${ }^{3}$ http://www.pandora.com
} 


\subsection{Motivação}

A motivação deste trabalho é melhorar a usabilidade de recomendações de música através do uso de explicações. Ao usar um sistema de recomendação, a satisfação e aceitação do usuário não depende só da eficácia do algoritmo, mas também de explicações. [Herlocker et al., 2000, Swearingen e Sinha, 2002].

\section{Definição de usabilidade}

A definição de usabilidade da "International Standards Organization" [ISO 9241-11, 1998] é: "Medida pela qual um produto pode ser usado por usuários específicos para alcançar metas específicas com eficácia, eficiência e satisfação em um contexto específico de uso.”

Nielsen e Loranger [2006] definem usabilidade como:

Usabilidade é um atributo de qualidade relacionado com o quanto algo é fácil de usar. Mais especificamente, se refere a rapidez em que usuários aprendem a usar algo, eficiência enquanto usam, se é fácil de lembrar, se é propenso a erros, e o quanto usuários gostam de usar algo. Se pessoas não conseguem ou não querem usar um recurso, é como se fosse inexistente.

\section{Definição de experiência do usuário}

A ISO 9241-210 [2010] define experiência do usuário como: as percepções e reações de um usuário, resultados do uso (ou uso antecipado) de um produto, sistema ou serviço. A experiência do usuário inclui as emoções, opiniões, preferencias, percepções, reações físicas e psicológicas, comportamento e realizações que ocorrem antes, durante e depois do uso.

Essas definições de usabilidade e experiência do usuário se refletem no modelo de classificação de Tintarev e Masthoff [2007]. O modelo mostra como explicações podem melhorar a usabilidade de sistemas de recomendação ao oferecer:

- Transparência (Explicar como o sistema funciona);

- Inspeção (Permitir que o usuário informe os erros do sistema );

- Credibilidade (Aumentar a confiança que o usuário tem no sistema);

- Eficácia (Ajudar o usuário a tomar boas decisões);

- Eficiência (Ajudar o usuário a tomar decisões mais rápido);

- Satisfação (Aumentar a facilidade de uso ou divertimento). 


\section{Explicando recomendações com visualizações de tags}

Entre as diferentes formas de explicação, tags tem se mostrado úteis ao explicar e revisar (critique) recomendações em filmes [Vig et al., 2009], [Vig et al., 2011]. Em sistemas de recomendação de músicas, Green et al. [2009] mostram como usar nuvens de tags para explicar recomendações de artistas.

Sistemas de recomendação de músicas (como o iTunes Genius) diferem de recomendações de artistas e filmes, por produzir uma longa lista de 20 a 100 itens. A complexidade de múltiplas recomendações e tags sugere o uso de uma visualização, que filtre e explique grandes coleções de itens.

\subsection{Objetivos}

O objetivo principal deste trabalho é desenvolver uma nova forma de visualização de tags, e testar sua viabilidade para explicar e filtrar recomendações de músicas. Mais precisamente, investigamos se essa visualização pode favorecer as metas de inspeção (scrutability), eficiência, eficácia e satisfação.

\subsection{Metodologia}

As atividades principais do trabalho são:

- Realizar um estudo bibliográfico de explicações para recomendação e visualização de tags.

- A partir do estudo bibliográfico, desenvolver visualizações de tags para atingir as metas das explicações.

- Desenvolver um espaço de testes (test bed) para avaliar as visualizações de tags em uma série de experimentos.

- A partir dos resultados dos experimentos, responder as questões de pesquisa.

\subsection{Contribuições Esperadas}

As contribuições esperadas para este trabalho são:

- Desenvolver uma nova forma de visualização de tags para filtrar e explicar recomendações.

E responder as questões de pesquisa: 
- A visualização desenvolvida ajuda usuários a filtrar recomendações de música (inspeção)?

- A visualização desenvolvida ajuda usuários a poupar tempo e esforço ao avaliar recomendações (eficiência)?

- A visualização desenvolvida ajuda usuários a tomar decisões melhores (eficácia)?

- A visualização desenvolvida ajuda o divertimento e facilidade de uso (satisfação)?

\subsection{Estrutura do Trabalho}

Este trabalho foi organizado em 7 capítulos, estruturados da seguinte maneira:

\section{Capítulo 2 - Explicando Recomendações}

Este capítulo apresenta pesquisas em sistemas de recomendação que focam em usabilidade e experiência do usuário, e explicações de recomendações. Apresentamos as características principais da classificação proposta por Tintarev e Masthoff [2007] para explicações de sistemas de recomendação, especificamente com as metas de melhorar a inspeção, eficiência, eficácia e satisfação. O capítulo também apresenta como essas metas contribuem com a usabilidade de sistemas de recomendações, e estabelece as métricas a serem utilizadas nos experimentos.

\section{Capítulo 3-Trabalhos Relacionados}

Apresentamos trabalhos relacionados a tags e coleções de música. Entre eles, trabalhos com tags como explicações, e visualizações combinadas com recomendações. Também são mostradas visualizações de música que utilizam tags.

\section{Capítulo 4 - Projetando e Desenvolvendo Visualizações de Tags}

Este capítulo detalha o processo de design da visualização de tags, através de estudos de usuário em busca e recomendação de músicas. Com base nesses estudos e trabalhos relacionados no capítulo anterior, mostramos temas e requisitos para a interface. Um novo tipo de visualização é projetado a partir das necessidades do usuário e requisitos.

\section{Capítulo 5 - Protótipo para o Espaço de Testes}

Este capítulo mostra o desenvolvimento da visualização de tags, a melhora da relevância de tags, e do espaço de testes.

\section{Capítulo 6 - Experimentos com Visualização de Tags}

Apresentamos quatro experimentos com visualização de tags, e a análise dos resultados a partir dos critérios definidos anteriormente. 
Introdução

\section{Capítulo 7 - Considerações Finais}

Considerações finais e trabalhos futuros. 


\section{Capítulo 2}

\section{Explicando Recomendações}

\subsection{Introdução}

Neste capítulo apresentamos pesquisas em sistemas de recomendação que focam em usabilidade e experiência do usuário, e mostramos a importância de explicações nas interfaces de recomendação. São apresentadas as características principais da classificação proposta por Tintarev e Masthoff [2007] para explicações de sistemas de recomendação, especificamente com as metas de melhorar a inspeção, eficiência, eficácia e satisfação. Esse capítulo também apresenta como essas metas contribuem com a usabilidade de sistemas de recomendações, e estabelece as métricas a serem utilizadas nos experimentos.

A oferta de música online cresce rapidamente, e serviços como iTunes, Spotify, Last.fm e Pandora oferecem coleções com milhões de músicas. Tornar essas coleções disponíveis é um desafio, e além de busca e navegação tradicional, esses serviços oferecem recomendações. Mas recomendações apresentam problemas com usuários, como credibilidade e falta de controle [Herlocker et al., 2000].

Em 2002, o jornal Wall Street Journal publicou um artigo intitulado "If TiVo Thinks You Are Gay, Here's How to Set It Straight”. O autor, Jeffrey Zaslow, mostra vários casos de usuários confusos com recomendações em serviços como $\mathrm{TiV}^{4}$, Amazon.com ${ }^{5}$ e Netflix ${ }^{6}$. O artigo descreve como usuários receberam recomendações que não correspondiam com seus interesses. Por não entenderem como o sistema de recomendação funciona, usuários não conseguiam corrigir recomendações [Zaslow, 2002].

Herlocker et al. [2000] mostram que muitos sistemas de recomendação funcionam como "caixaspretas”, e não transmitem informação adicional além do item recomendado. Swearingen e Sinha [2002] observam que explicações que tornam o sistema mais transparente (transmitindo sua lógica interna) aumentam a credibilidade e aprovação do usuário.

Historicamente, o foco do estudo em recomendações tem sido em algoritmos e precisão, baseado na suposição que recomendações mais precisas são mais úteis [Herlocker et al., 2004]. Mas pesquisas na área mostram que isso não é sempre o caso. Em estudo sobre recomendações, $\mathrm{McNee}$ et al. [2003] observam que uma interface de avaliação que oferece mais controle (apesar de exigir mais

\footnotetext{
${ }^{4}$ http://www.tivo.com

${ }^{5}$ http://www.amazon.com

${ }^{6}$ http://www.netflix.com
} 
esforço do usuário) aumenta o nível de retenção desses, mesmo sem melhora na qualidade das recomendações.

A medida que sistemas de recomendação tem se tornado mais populares (hoje presentes em sites de comércio eletrônico, notícia, e mídia), a importância das interfaces se reflete no aumento de pesquisas em recomendações, usabilidade e experiência do usuário [McNee et al., 2006].

\subsection{Metas de Usabilidade e Experiência do Usuário}

\section{Definição de Usabilidade}

Entre as várias definições de usabilidade citadas no capítulo 1, utilizamos a definição da "International Standards Organization" [ISO 9241-11, 1998].

\section{Definição de Experiência do Usuário}

Utilizamos a definição da “International Standards Organization” ISO 9241-210 [2010], citada no capítulo 1, como definição de Experiência do Usuário.

Tullis et al. [2008] descrevem como alguns pesquisadores distinguem a usabilidade e experiência do usuário. Para esses, usabilidade é considerada a habilidade que um usuário tem em completar uma tarefa com sucesso, enquanto que a experiência do usuário toma uma visão mais ampla, que inclui pensamentos, sentimentos, e percepções que são resultados da interação. Tullis et al. [2008] preferem a visão mais ampla de usabilidade, em que examinam a experiência do usuário como um todo.

\section{Metas de Usabilidade}

Segundo Rogers et al. [2011], metas de usabilidade são: assegurar que produtos interativos sejam fáceis de aprender, de uso eficaz, e agradáveis de usar. Mais especificamente, os pesquisadores dividem as metas de usabilidade em: eficiência, eficácia, segurança, utilidade, facilidade de lembrar e facilidade de lembrar como usar.

Metas de usabilidade, tradicionalmente, são vistas como relacionadas a critérios específicos de usabilidade. Metas de experiência de usuário, por sua vez, são relacionadas a aspectos de experiência do usuário, com por exemplo, um produto ser esteticamente agradável. Não há uma distinção clara entre os dois tipos de meta, já que usabilidade depende de experiência do usuário, e vice-versa.

\section{Metas de Experiência do Usuário vs. Metas de Usabilidade}

Rogers et al. [2011] mostram que a diversidade das metas de experiência do usuário são articuladas no design de interação, e cobrem um número grande de emoções e experiências. Muitas 
delas são qualidades subjetivas, e relacionadas apenas com os sentimentos de usuário em relação a um sistema. Elas diferem das metas de usabilidade, que são mais objetivas. As metas de experiência do usuário se concentram na experiência e perspectiva com um produto interativo, ao invés de avaliar sua produtividade ou utilidade. Muitas das metas de experiência do usuário são definidas em termos da contribuição para experiências agradáveis, divertidas, e estão relacionadas ao conceito de envolvimento emocional [Csikszentmihalyi, 1997].

Metas de usabilidade e metas de experiência do usuário relevantes para este projeto são eficiência, eficácia, satisfação, e diversão no contexto especifico de recomendações de música.

\subsection{Recomendações, Usabilidade e Experiência do Usuário}

Em um estudo sobre design de interação para sistemas de recomendação, Swearingen e Sinha [2002] investigaram as interfaces de diferentes sistemas de recomendação, com o objetivo de desenvolver diretrizes gerais de design. Esse estudo mostrou que, da perspectiva do usuário, um sistema de recomendação deve:

- Favorecer a percepção de credibilidade das recomendações;

- Transmitir ao usuário a lógica interna do sistema (transparência), e o motivo de uma recomendação;

- Indicar ao usuário itens novos (que o usuário ainda não conhece);

- Fornecer detalhes sobre itens recomendados;

- Fornecer formas de filtrar recomendações.

McNee [2006] aponta a necessidade de se repensar sistemas de recomendação a partir da perspectiva do design centrado em usuário, e propõe uma teoria de interação humanorecomendação. Ao invés de começar o processo com o algoritmo, são as necessidades do usuário que definem o design do sistema. [McNee, 2006].

Outro exemplo de pesquisa que mostra a relação entre necessidade do usuário e recomendações é a pesquisa de Torres e McNee [2004], que mostra como usuários com diferentes níveis de experiência avaliam recomendações de forma diferente. Por exemplo, um pesquisador profissional pode não ficar tão satisfeito com recomendações que satisfazem um estudante.

Em um estudo sobre diretrizes de design para sistemas de recomendação, Ozok et al. [2010] examina a relação entre design para interfaces de sistemas de recomendação e usabilidade. Os autores desenvolveram um modelo conceitual de critérios de usabilidade, focando em sistemas de recomendação para comércio eletrônico. Dois níveis de usabilidade de interface são identificados níveis micro e macro. O nível micro foca em informação específica ao produto recomendado, como 
o nome, preço, imagem, etc. O nível macro trata um conjunto de produtos recomendados como uma "entidade". Esse se refere a questões como quando e onde recomendações devem ser exibidas na interface.

Os critérios de usabilidade definidos por Ozok et al. [2010] são suficiência, transparência, flexibilidade e acessibilidade:

- Suficiência indica que o conteúdo da recomendação deve ser suficiente para que usuários se sintam confiantes ao tomarem decisões, e ao mesmo tempo, que economizem esforço e tempo.

- Transparência oferece informação que explica como um sistema de recomendação toma decisões.

- Flexibilidade se refere a como o sistema pode ser manipulado ou personalizado, de acordo com as necessidades e desejos do usuário.

- Acessibilidade se refere a facilidade de obter mais detalhes sobre um item recomendado.

Pu e Chen [2010] mostram como na comunidade de sistemas de recomendação, a pesquisa em experiência de usuário aumentou, e propõe um arcabouço para avaliação de sistemas de recomendação centrada no usuário.

Knijnenburg et al. [2012] examinam a relação entre experiência do usuário e sistemas de recomendação, e propõe um arcabouço com abordagem centrada em usuários para avaliar recomendações. O objetivo do arcabouço é descrever como aspectos objetivos do sistema, como algoritmos, são subjetivamente percebidos pelo usuário. E como essa percepção, combinada com contexto, influencia a experiência e interação do usuário com o sistema de recomendação.

\subsection{Explicando Recomendações}

Em "Recommender systems: from algorithms to user experience", Konstan e Ried1 [2012] examinam o crescimento da área de recomendação ligada a experiência do usuário. Entre os vários temas examinados, os autores destacam explicações de recomendação.

Herlocker et al. [2000] mostram que explicações tem um papel importante na aprovação de recomendações. Os autores descrevem como muitos sistemas de recomendação funcionam como “caixas-pretas", e não transmitem informação adicional além do item recomendado. Em artigo sobre diretrizes para interfaces de recomendações, Swearingen e Sinha [2002] aconselham que explicações devem ser usadas para aumentar a credibilidade e aprovação do usuário, pois tornam o sistema mais transparente. Vig et al. [2009] mostram que explicações são eficazes mesmo quando independentes 
do algoritmo. Os autores observam que explicar recomendações de filmes com tags melhora a credibilidade de usuários, mesmo quando as recomendações são geradas por avaliações (ratings).

Sinha e Swearingen [2002] conduziram um estudo de usuário com cinco sistemas de recomendação para música. Os resultados mostram que a satisfação e credibilidade de usuários aumenta com recomendações percebidas como transparentes. Mesmo quando um item recomendado era conhecida pelo usuário, esses mostraram interesse em entender o motivo. Em sistemas de recomendação, é importante que o usuário perceba a relação entre suas ações e os itens recomendados. A transparência é essencial não só para aumentar a confiança dos usuários, mas também porque ela pode ajuda-los a revisarem recomendações.

Lamere [2008] sugere a possibilidade do uso de tags para explicar recomendações de música. No caso de sistemas de recomendação que usam filtragem colaborativa, explicações com tags são mais informativas e úteis do que explicações típicas para esse tipo de sistema, como: "pessoas que escutaram XX também escutaram YY”.

Tintarev e Masthoff [2007] notam a importância do papel de explicações de recomendação na experiência do usuário e usabilidade. Para definir o que é uma boa explicação, as autoras fornecem uma classificação de explicações, baseada nos seguinte objetivos: transparência (explica como o sistema funciona); inspeção (permite que o usuário informe que o sistema está errado); credibilidade (aumenta a confiança que o usuário tem no sistema); eficácia (ajuda o usuário a tomar boas decisões); eficiência (ajuda o usuário a tomar decisões mais rápido); satisfação (aumenta a facilidade do uso ou divertimento).

\subsection{Transparência e Justificativa}

Apesar de explicações terem transparência como o objetivo principal, as vezes não há oportunidade ou interesse em transmitir o modelo conceitual do sistema. Uma alternativa a explicações transparentes é uma justificativa. A justificativa difere de explicações transparentes por não necessariamente revelar o mecanismo real do algoritmo de recomendação [Vig et al., 2009; Herlocker et al., 2000]. Uma diferença similar é descrita por Sørmo et al. [2005], em pesquisa de explicações em raciocínio baseado em casos. O objetivo é o mesmo da transparência em sistemas de recomendação - aumentar a confiança do usuário no sistema. Justificativas podem ser utilizadas para fornecer uma explicação simplificada, e até completamente não relacionada ao raciocínio real do sistema.

Neste trabalho, utilizamos tags como explicações. Portanto, nossas explicações são justificativas, já que as tags utilizadas não fazem parte do algoritmo de recomendação. Esse modelo de explicação oferece algumas vantagens, por ser aplicável a tipos diferentes de recomendação (baseada em conteúdo, filtragem colaborativa, modelos híbridos, etc.). Também é útil quando não existe interesse em revelar o funcionamento do sistema. Entretanto, esse tipo de explicação não visa metas como 
transparência e credibilidade. Seu objetivo é cumprir as metas de eficiência, eficácia, inspeção e satisfação.

\subsection{Metas de Explicação, Usabilidade e Experiência do Usuário}

Como detalhado na seção anterior, metas de usabilidade e metas de experiência do usuário relevantes para este projeto são: eficiência, eficácia, satisfação e diversão (no contexto específico de recomendações de música). Essas metas de usabilidade e experiência do usuário se refletem no modelo de classificação de Tintarev e Masthoff [2007]. Assim, nos concentramos em explicações que tem como metas inspeção, eficácia, eficiência e satisfação:

- Inspeção (permitir que o usuário informe os erros no sistema, afetando a eficácia e eficiência);

- Eficácia (ajudar o usuário a tomar boas decisões);

- Eficiência (ajudar o usuário a tomar decisões mais rápido);

- Satisfação (aumentar a facilidade de uso ou divertimento).

Sistemas de recomendação de música (como o iTunes Genius) diferem de recomendações de artistas e filmes, por produzir uma longa lista de 20 a 100 itens. A complexidade de múltiplas recomendações e tags sugere o uso de uma visualização como interface, que filtre e explique uma coleção grande de itens.

Entre as diferentes formas de explicação, tags tem se mostrado úteis ao explicar e revisar (critique) recomendações em filmes [Vig et al., 2009; Vig et al., 2011]. Em sistemas de recomendação de músicas, Green et al. [2009] mostram como usar nuvens de tags para explicar recomendações de artistas.

A partir das metas citadas acima, procuramos desenvolver uma nova forma de visualização de tags, e testar sua viabilidade para explicar e filtrar recomendações de músicas.

\subsection{Processo de Design de Interação}

A definição de Design de Interação de Rogers et al. [2011] é: "Design de produtos interativos que oferecem suporte em atividades cotidianas de pessoas, no lar ou no trabalho". O processo de design de interação se divide em:

- identificar necessidades de usuários e requisitos;

- desenvolver propostas de designs;

- construir protótipos dos designs; 
- avaliar protótipos.

Neste projeto, o foco do estudo de usuário e identificação de necessidades se concentra em recomendações para música, especificamente para as metas de inspeção (scrutability), eficiência, eficácia e satisfação.

Requisitos, desenvolvimento de propostas de design, construção de protótipo e avaliação são mostrados nos capítulos 4, 5 e 6 .

\subsubsection{Estudo e Necessidades do Usuário para Música e Recomendação}

Nesta seção apresentamos estudos de usuários em sistemas de recomendação e busca de músicas. Nosso objetivo é encontrar temas comuns, e partir desses, identificar as necessidades do usuário.

Tema: Usuários tem dificuldade em descrever e buscar músicas [Kim e Belkin, 2002], e consequentemente, preferem sistemas que oferecem recomendações baseadas em músicas ou artistas similares [Vignoli, 2004].

Vignoli [2004], em estudo sobre coleções pessoais, mostra que usuários tem dificuldade em descrever músicas, e favorecem sistemas com busca por música ou artista similar. Kim e Belkin [2002] e Chen et al. [2010] notam o mesmo problema com usuários sem conhecimento formal de música.

Chen et al. [2010] também observam que pessoas não usam tanta busca em coleções de mídia, e que procuram algo que satisfaz um critério vago, ao invés de um item especifico. Essa tipo de busca se reflete na preferência que usuários tem por sistemas de recomendação. Em pesquisa sobre organização de música digital, Cunningham et al., [2004] sugerem que a busca de músicas através de "mais itens como este" é útil (essencialmente, essa é uma forma de recomendações com músicas como semente). Em pesquisa sobre sistemas de recomendação de música, Lee [2011] observa que usuários tem curiosidade em saber por que músicas são recomendadas, justificando o uso de explicações. Vig et al. [2009] também mostram que usuários favorecem explicações de recomendações, mesmas que essas não sejam transparentes.

Lamere [2008] sugere que tags podem ser usadas para ajudar usuários a descreverem e buscarem músicas através de palavras. Em pesquisa sobre sistemas de recomendação para música, Åman e Liikkanen [2010] observam que usuários, ao escolher uma música como semente, não sabem especificar quais atributos são importantes para a recomendação. Por exemplo, um usuário pode escolher uma semente por querer recomendações com instrumentação similar, ou letras com o mesmo tema. Em pesquisa sobre recomendações interativas, Burke et al. [1997] observam que usuários tem mais facilidade em aperfeiçoar recomendações do que especificar e descrever o que querem. Bainbridge et al. [2003] notam que usuários tem dificuldade em descrever músicas, e recomenda buscas através de metadados "fuzzy". 
Necessidade do usuário: Apresentar recomendações e explicações.

Usuários preferem sistemas que oferecem recomendações baseadas em músicas ou artistas similares [Vignoli, 2004]. Música é difícil de descrever, por isso só busca não é suficiente [Kim e Belkin, 2002]. Usuários também favorecem recomendações com explicações.

Tema: Música é um produto de baixo envolvimento [Jones e $\mathrm{Pu}, 2007$ ], diferente de produtos como um pacote de férias ou um imóvel. Por esse motivo, usuários querem encontrar músicas rápido e com pouco esforço.

Jones e Pu [2007] mostram que ao comparar serviços como Pandora com Last.fm, usuários preferiram Pandora por receberem boas recomendações com o mínimo de esforço. O serviço Last.fm toma mais tempo e esforço do usuário, pois requer uma configuração inicial (criação de perfil) antes de oferecer recomendações. Os autores encontraram correlações que mostram que a satisfação do usuário aumentava a medida que o tempo configuração inicial diminuía.

Um dos problemas observados por usuários, tanto no serviço Last.fm e Pandora, era a limitação de tempo (ter tempo o suficiente) para escutar músicas. Por esse motivo, usuários preferiram usar Pandora, percebido por usuários como uma interface mais fácil e mais rápida de aprender, mesmo para um usuário novato [Jones e $\mathrm{Pu}, 2007$ ].

A satisfação de usuários com o sistema também depende da rapidez em que as ações do usuário afetam as recomendações [Jones e $\mathrm{Pu}, 2007$ ].

Barrington et al., [2009] observam como a presença de metadados ajudam usuários a avaliar recomendações mais rápido. Os pesquisadores efetuaram um experimento usando playlists com e sem a presença de metadados. Com metadados, usuários foram capazes de avaliar recomendações de playlists mais rápido. Sem metadados, usuários eram obrigados a escutar todos os trechos de música recomendadas, afetando consideravelmente o tempo de avaliação.

Necessidade do usuário: Encontrar músicas com mínimo de esforço e tempo (eficiência) Usuários querem encontrar músicas rápido e com menos esforço (eficiência), pois música é um produto de baixo envolvimento [Jones e $\mathrm{Pu}, 2007$ ] . Isto se reflete na oferta de recomendações, e na necessidade de explicações que permite que usuários avaliem e encontrem músicas mais rápido.

Tema: Usuários buscam tanto arquivos de música quanto atributos como metadados, contexto e conteúdo [Lee e Downie, 2004].

Metadados sobre as recomendações (estilo, nome, artista, etc.) são importantes. 
Em um estudo sobre recuperação de música, Lee e Downie [2004] observam a importância de metadados em interfaces de busca. A pesquisa mostra que usuários muitas vezes buscam ou navegam coleções usando metadados de contexto. Estes incluem metadados relacionais, como estilo musical, similaridade de som, etc., e metadados associativos, como referência a filmes, eventos, etc.

Barrington et al., [2009] e Lee [2011] mostram como a presença de metadados ajuda usuários a avaliar recomendações mais rápido. Entre os metadados importantes para avaliação de músicas recomendadas, usuários mencionaram tema (e.g., 4 de julho, trens), período (80s, 90s), instrumentação, letras, emoções, e estilo.

\section{Metadados que descrevem apenas estilos não são suficientes}

Apesar de estilos musicais serem um metadado relativamente comum em serviços de recomendação de música, Aucouturier e Pachet [2003] descrevem o problema da inconsistência e ambiguidades de estilos musicais. O mesmo é confirmado em Vignoli [2004] e Chen et al. [2010]. Usuários nem sempre concordam com os estilos atribuídos a certas músicas ou artistas. Segundo Kuhn et al. [2010], da perspectiva de um usuário só estilos não são suficientes para descrever músicas. Assim, é importante oferecer outras alternativas além de estilo musical. Em estudo sobre o uso de estilos para avaliar e identificar preferencias em música, Ferrer et al. [2012] descobriram que $29 \%$ da população pesquisada se mostrou insatisfeita com estilos para descrever músicas apreciadas por usuários.

\section{Metadados que descrevem contexto}

Como citado anteriormente, Lee e Downie [2004] apresentam diferentes tipos de metadados utilizados por usuários, como metadados associativos, que descrevem contexto (referências as filmes, eventos, etc.). O mesmo é observado por Kim e Belkin [2002], e Cunningham [2004], com usuários descrevendo certas músicas através de eventos (música para festa, etc.).

\section{Metadados que descrevem emoções}

Pesquisas indicam que muitos usuários descrevem músicas através de humor e emoções. Em estudo sobre os serviços Pandora e Last.fm, Jones e Pu [2007] revelam que usuários valorizam recomendações que levam em conta emoções e sentimentos. Tanto Vignoli [2004] quanto Kim e Belkin [2002] mostram que usuários descrevem e procuram músicas baseado em emoções.

Tintarev e Masthoff [2007] mostram que em recomendações de filmes, o humor de um usuário influencia seus gostos na escolha de gênero e outras características de um filme. Vig et al. [2009] também observam que usuários preferem recomendações com explicação porque essas oferecem mais informação e permitem que o usuário escolha um item mais apropriado para seu humor.

Lamere [2008] sugere que interfaces para música explorem o uso de tags para oferecer a usuários uma compreensão maior sobre qual a relação entre estilos e emoções em músicas recomendadas. 


\section{Metadados são importantes para educar usuários}

De acordo com Lee [2011], metadados são importantes para educar usuários sobre música. Usuários mostram interesse em aprender sobre estilos novos e descobrir novas músicas através de recomendações, principalmente no contexto de músicas já conhecidas. Por exemplo, um usuário tem maior interesse em um estilo desconhecido se esse inclui músicas que o usuário já conhece e aprecia.

Swearingen e Sinha [2001] confirmam que recomendações com explicações e metadados ajudam usuários a aprender mais sobre os produtos que estão explorando, e aprender mais sobre seus gostos.

\section{Necessidade do usuário: Metadados educam usuários, e auxiliam na avaliação de recomendações} (eficácia).

Usuários buscam tanto arquivos de música quanto atributos como metadados, contexto e conteúdo [Lee e Downie, 2004]. No caso de recomendações, esses atributos educam usuários, facilitam a avaliação de recomendações, e podem ser apresentados na forma de explicações [Barrington et al., 2009]. Neste projeto, utilizamos tags como explicações de recomendação.

Tema: Usuários descrevem músicas através de estilos musicais, emoções, ou contexto [Lee e Downie, 2004; Kim e Belkin, 2002]. Ao interagir com recomendações, usuários preferem sistemas que permitem a filtragem de recomendações (inspeção). Assim, usuários também preferem um sistema que oferece filtragem através destes atributos.

Em estudo sobre interfaces para recomendações, McNee et al. [2006] observaram que participantes preferiam ter controle sobre a interface, aumentando sua percepção que o "sistema entendia melhor seus gostos". Mesmo que mais controle signifique mais esforço por parte dos usuários, McNee [2003] mostrou que usuários preferem ter mais controle (mesmo quando suas ações não afetam o algoritmo de recomendação). $\mathrm{O}$ autor também mostrou que taxas de retenção eram maiores com sistemas que ofereciam mais controle na interface.

Ao definir os diferentes critérios de usabilidade, Ozok et al. [2010] indicam flexibilidade, que se refere a habilidade do sistema em se adaptar de acordo com a manipulação de um usuário. Em estudo sobre interfaces de recomendações para comércio eletrônico, os autores notam que 46.6\% dos participantes preferem um sistema que recomenda itens, e recebe feedback sobre as recomendações.

Donovan et al. [2009] observam que em interfaces visuais para recomendações, permitir controle de itens e preferências aumenta a satisfação de usuários.

Ao avaliar os serviços Pandora e Last.fm, Jones e $\mathrm{Pu}$ [2007] questionaram participantes sobre que fatores diminuíram sua satisfação com os serviços estudados. Para o Pandora, usuários indicaram como fator de insatisfação a falta de opções de feedback nas recomendações. 
Em artigo sobre inspeção e controle, Knijnenburg et al. [2012a] mostram que ambos tem efeitos positivos na experiência do usuário com recomendações, pois as tornam mais fáceis de entender. Os efeitos positivos de inspeção, controle e entendimento aumentam a percepção da qualidade das recomendações.

Swearingen e Sinha [2002] revelam que usuários ficam mais satisfeitos com explicações que permitem revisão ou filtragem de recomendações. Em artigo sobre diretrizes de design para recomendações, usuários se mostraram favoráveis ao sistema do serviço MovieCritic, para recomendações de filmes, pois esse permitia a filtragem através de estilos. Através dos filtros, usuários eram capazes de encontrar filmes que gostavam mais rápido. Assim, as autoras sugerem filtros nas interfaces de recomendação.

Devido a dificuldade que usuários tem em descrever o produto que buscam, Burke et al. [1997] observam que esses tem mais facilidade em revisar e filtrar alternativas de produtos, do que descrever o que querem.

Em avaliação de listas de recomendação, Lee [2011] observa que músicas muito similares aborrecem usuários, mas o critério do que é similar varia de usuário para o usuário, ou de músicas para músicas. Assim, é interessante oferecer opções para que usuários filtrem recomendações de acordo com seus critérios pessoais.

De acordo com Chen et al. [2010], usuários gostariam de filtrar músicas não só através de uma tag, mas através de múltiplas tags (e.g. "punk" e "indie electronic").

Necessidade do usuário: Filtragem ou revisão de recomendações (inspeção)

Ao interagir com recomendações, usuários preferem sistemas que permitem filtragem de recomendações (inspeção). Usuários descrevem músicas através de estilos musicais, emoções, ou contexto. [Lee e Downie, 2004; Kim e Belkin, 2002]. Assim, usuários preferem um sistema que oferece filtragem através destes atributos.

Tema: a maior parte dos usuários escuta música como entretenimento [Lee e Downie, 2004], ou durante outras atividades (estudando, ginástica, etc.) [Cunningham, 2006]. Assim, usuários preferem interfaces divertidas e fáceis de usar.

O sistema deve oferecer recomendações sem grande esforço de configuração. Jones e Pu [2007] observaram que tempo menor de configuração correlacionou com maior satisfação e diversão para usuários. O estudo também observou correlação entre a facilidade de uso do sistema e satisfação.

A habilidade de um sistema ao oferecer músicas adequadas as emoções de um usuário também se mostrou correlacionada com satisfação, e facilidade de uso [Jones e $\mathrm{Pu}$, 2007]. Essa correlação reflete a relação entre música e emoções, e no fato de usuários escutarem músicas como entretenimento. A diversão com o sistema está intimamente ligada a escutar recomendações adequadas. Rentfrow e 
Gosling [2003] mostram que ao escutar músicas, emoções e humor são importantes para usuários, e que muitos buscam certos tipos de estilo de música para regular seus estados emocionais internos.

A diversão de usuários com coleções de música é maior quando a experiência é enriquecida com metadados, informações adicionais e visuais [Cunningham et al., 2006]. Swearingen e Sinha [2001] também observam que sistemas que oferecem informações detalhadas sobre os itens recomendados são avaliados como mais úteis e fáceis de usar.

Knijnenburg et al. [2012a] mostram que inspeção e controle tem um efeito positivo na experiência do usuário, por aumentarem a satisfação de um usuário com um sistema de recomendação.

Necessidade do usuário: Diversão e facilidade de uso (satisfação)

Ao usar sistemas de recomendação de música, usuários preferem interfaces divertidas e fáceis de usar (satisfação).

\subsubsection{Perfil do Usuário}

Neste projeto, escolhemos focar em um usuário com o seguinte perfil: usuário casual, que escuta música por diversão, com pouco ou nenhum conhecimento formal de música, e que escuta música no computador ou tablet. É um usuário com experiência de sites de streaming de música(Grooveshark ${ }^{7}$, Spotify, Rdio ${ }^{8}$, Last.fm, Pandora), ou de software para música digital (iTunes, Winamp 9 , Windows Media Player ${ }^{10}$, etc.), e que usa Internet com frequência (todos os dias).

A plataforma alvo é: dispositivos de 8 polegadas ou mais, desktop, laptop ou tablet.

\subsection{Metas de Explicação: Eficiência, Eficácia, Inspeção e Satisfação}

Neste trabalho, usamos a classificação de Tintarev e Masthoff [2007] para explicações, com o objetivo de melhorar a usabilidade e experiência do usuário em sistemas de recomendação. Mais precisamente, nos concentramos em explicações que tem como meta a eficácia, eficiência, inspeção (scrutability) e satisfação. Neste seção, detalhamos cada uma das metas e suas métricas.

\section{Inspeção (Scrutability)}

\footnotetext{
${ }^{7} \mathrm{http} / / /$ grooveshark.com

${ }^{8}$ http://www.rdio.com

${ }^{9} \mathrm{http}: / /$ www.winamp.com

${ }^{10} \mathrm{http}: / /$ windows.microsoft.com/en-US/windows/download-windows-media-player
} 
Inspeção visa auxiliar o usuário a comunicar erros ao sistema. [Tintarev e Masthoff, 2007]. Czarkowski [2006] observa que explicações podem ajudar usuários a encontrarem suposições equivocadas em sistemas de recomendação. Em usabilidade, inspeção é relacionada ao princípio bem estabelecido de Controle do Usuário [Nielsen e Molich, 1990], pois aumenta a sensação de controle que usuários tem sobre o sistema.

Neste trabalho a definição de inspeção (scrutability) foi expandida para incluir filtragem como forma de inspeção, com o mesmo objetivo de aumentar o controle do usuário, e corrigir recomendações. Um estudo de usuário efetuado por Swearingen e Sinha [2002] descrevem os benefícios de oferecer a filtragem de recomendações. Neste, quase todos os usuários comentaram favoravelmente sobre a possibilidade de filtrar recomendações de filmes no site MovieCritic.

A inspeção está se tornando cada vez mais comum em sistemas de recomendação para música, e Åman e Liikkanen [2010] exemplificam formas de inspeção em serviços como Last.fm e Musicovery ${ }^{11}$. Last.fm oferece aos usuários os botões de "amo", "banir”, "parar", "pular”, que modificam o perfil do usuário e recomendações. Musicovery oferece uma forma de inspeção através de um filtro de tempo, que permite que o usuário limite recomendações de música a um certo período.

Pu e Chen [2010] desenvolveram uma plataforma de avaliação para sistemas de recomendação. Entre as diferentes qualidades avaliadas, estão: adequação de interação, controle/transparência, e facilidade de revisão de preferência. Todas essas qualidades lidam com o controle do usuário (modificação ou revisão de preferência, pedir uma nova lista de recomendações, etc). Algumas afirmações dos questionários dessa plataforma:

- Foi fácil fazer o sistema recomendar-me itens diferentes;

- Foi fácil treinar o sistema para atualizar minhas preferências;

- Foi fácil mudar os itens recomendados a partir das modificações que fiz nas minhas preferências;

- É fácil para eu comunicar ao sistema o que eu não gosto/gosto no sistema de recomendação;

- É fácil receber um novo conjunto de recomendações;

- Senti controle em pedir o que eu quero ao sistema de recomendação.

Neste trabalho, usamos um conjunto similar de declarações para avaliar as métricas de inspeção:

- A visualização de tags me ajudou a filtrar as músicas recomendadas (Experimento 1);

- A seleção de tags me ajudou a encontrar músicas que me interessam (Experimento 1);

- A seleção de tags me ajudou a encontrar músicas que eu não conhecia (Experimento 1);

- Ao selecionar uma tag, as músicas exibidas fizerem sentido para mim (Experimento 1);

\footnotetext{
${ }^{11} \mathrm{http}: / /$ musicovery.com
} 
- Design x aumentou o meu controle sobre as músicas recomendadas (Experimento 2 e 3).

\section{Eficácia}

A definição de eficácia da "International Standards Organization" [ISO 9241-11, 1998] é: precisão e plenitude em que usuários atingem objetivos específicos. Métricas de eficácia correspondem aos objetivos de um usuário, e com quanta precisão e plenitude estes objetivos são atingidos. Por exemplo, eficácia pode ser medida a partir do número de tarefas completadas corretamente [ISO 9241-11, 1998].

Tintarev e Masthoff [2007a] definem eficácia como uma explicação que ajuda usuários a tomarem boas decisões. Explicações eficazes também permitem que usuários encontrem itens úteis, e eliminem itens irrelevantes. Ao fornecer mais detalhes sobre recomendações, explicações eficazes. permitem que usuários julguem a qualidade de um item com mais precisão [Bilgic e Mooney, 2005].

Vig et al. [2009], ao avaliarem eficácia em recomendação para filmes, medem "eficácia aparente” ao pedir que usuários avaliem a frase: "A explicação me ajuda a determinar se eu vou gostar desse filme”. Já que o usuário não sabe se vai gostar mesmo de um filme até assistir, só se pode medir a eficácia aparente.

Uma maneira de avaliar explicações eficazes é medir a falta de diferença entre gostar de um item antes e depois do consumo [Bilgic e Mooney, 2005]. Como este trabalho é em música, a questão é mais fácil de resolver, já que usuários podem escutar trechos das músicas recomendadas durante o teste.

Explicações eficazes também ajudam usuários a obter conhecimento adicional sobre o produto que estão procurando, e aprender sobre a variedade de itens disponíveis [Felfernig e Gula, 2006].

Neste trabalho, avaliamos eficácia medindo o número de tarefas completadas corretamente, e com um questionário com as seguintes questões:

- As tags me ajudaram a determinar se eu ia gostar das músicas. (Experimento 1)

- As tags me ajudaram a decidir quais músicas eu deveria escutar. (Experimento 1)

- As tags me ajudaram a aprender algo sobre as músicas recomendadas. (Experimento 1)

- Design x me ajudou a encontrar músicas que eu procurava. (Experimentos 2 e 3 )

- Design x me ajudou a aprender algo sobre as músicas recomendadas. (Experimentos 2 e 3 )

\section{Eficiência}


Eficiência é um princípio de usabilidade bem estabelecido, que mostra quanto tempo uma tarefa pode levar para ser cumprida [Nielsen e Molich, 1990].

A definição de eficiência da "International Standards Organization" [ISO 9241-11, 1998], é: recursos consumidos com relação a precisão e plenitude em que usuários atingem objetivos. Medidas de eficiência relacionam o nível de eficiência atingido com o consumo de recursos. Recursos incluem esforço mental, físico, tempo, material ou custo financeiro. Por exemplo, eficiência humana pode ser medida como eficiência divida pelo esforço humano, eficiência temporal pode ser eficácia dividida por tempo gasto em tarefas, ou eficiência econômica em eficácia divida por custo [ISO 9241-11, 1998].

Explicações que visam eficiência podem ajudar usuários a decidir mais rapidamente quais são os melhores itens recomendados. Eficiência pode ser medida por tempo de realização ou número de interações necessárias para encontrar um produto satisfatório [Tintarev e Masthoff, 2007].

Pu e Chen [2010] medem eficácia como o tempo de realização de uma tarefa. A tarefa em questão é buscar, entre os itens recomendados, um produto satisfatório. Também medem o esforço subjetivo necessário para que o usuário complete a tarefa, através de um questionário.

Neste trabalho, avaliamos eficiência medindo o tempo das tarefas, e com um questionário com as seguintes questões:

- Qual opção (A ou B) foi mais rápida de usar? (Experimento 1)

- As tags me ajudaram a encontrar músicas interessantes mais rápido. (Experimento 1)

- Design x me ajudou a completar a tarefa mais rápido. (Experimentos 2 e 3 )

\section{Satisfação}

\section{Satisfação, usabilidade e experiência do usuário}

A definição de satisfação da "International Standards Organization" [ISO 9241-11, 1998] é: usuário livre de desconforto, e com atitudes positivas em relação ao uso de um produto. Satisfação mede o quanto usuários se livram de desconforto, e suas atitudes em relação a o uso de um produto. Satisfação pode ser especificada e medida através de avaliações subjetivas com escalas como desconforto experimentado, o quanto um usuário gosta de usar um produto, satisfação com o uso de um produto, etc. [ISO 9241-11, 1998].

Tintarev [2009] mostra que uma explicação que visa satisfação torna o uso do sistema mais fácil de usar e mais divertido. Já que muitos sistemas de recomendação são usados para recomendar itens de entretenimento (como música), interfaces divertidas tem uma função importante na experiência do usuário. 
Na definição de Tintarev [2009], a meta de satisfação (fácil de usar e divertido) inclui tanto características objetivas quanto subjetivas. Rogers et al. [2011] definem facilidade de uso como uma meta de usabilidade, e diversão como meta de experiência do usuário. Portanto, em sistemas de recomendação, explicações (que tem como meta a satisfação) afetam tanto a usabilidade quanto experiência do usuário.

Gedikli e Jannach [2011] comparam satisfação em três interfaces com explicações, e definem satisfação como o quão úteis são as explicações, e se a experiência é divertida. Para medir satisfação, os autores pedem que no fim do experimento usuários avaliem o sistema em escala de 0.5 (mais baixa) a 5 (mais alta).

Tanaka-Ishii e Frank [2000] medem satisfação perguntando diretamente ao usuário se o sistema é divertido e agradável. Em pesquisa sobre usabilidade de sites, Spool et al. [1999] notam que usuários favorecem sites com conteúdo divertido, e não recomendam avaliação dessa forma. Porém, os autores pedem que usuários comparem sites de conteúdos e objetivos diferentes (Travelocity ${ }^{12}$, site de turismo, com Fidelity ${ }^{13}$, site de finanças). Neste projeto, comparamos apenas interfaces com os mesmos conteúdos e objetivos. Assim, medir satisfação através de uma pergunta direta não apresenta os problemas encontrados por Spool.

Pu e Chen [2010] usam satisfação como outra qualidade a ser medida em um sistema de recomendação, pois determina, de uma forma muito direta, como o usuário se sente em relação ao sistema. Um exemplo de uma declaração que mede satisfação é:

- Em geral, estou satisfeita com as recomendações.

Em pesquisa sobre intenções e usos de computadores no trabalho, Davis et al. [1992] e Davis [1989] mostram que existe uma interação positiva entre utilidade, facilidade de uso, e diversão. $\mathrm{Na}$ avaliação de diversão e facilidade de uso, os autores utilizaram um questionário com perguntas (medidas na escala Likert de 7 pontos) como:

- Usar x é divertido.

- Eu me divirto usando x.

- É fácil aprender a usar x.

- Eu acho x fácil de usar.

\footnotetext{
12 http://www.travelocity.com

${ }^{13} \mathrm{https} / /$ www.fidelity.com
} 
Yi e Hwang [2003] conduziram uma pesquisa utilizando o sistema Blackboard ${ }^{14}$. Um questionário foi administrado com o objetivo de medir eficácia, divertimento, facilidade de aprender, facilidade de uso, etc. Perguntas utilizadas para avaliar o divertimento e facilidade do uso do sistema foram:

\section{Diversão}

- $\quad$ Eu me diverti usando...

- O sistema é divertido.

- Eu acho o sistema divertido.

\section{Facilidade de uso}

- O sistema é fácil para mim.

- O sistema é fácil de usar.

A partir dos questionários pesquisados, avaliamos satisfação com as questões e declarações a seguir:

- Qual design foi mais divertido de usar? (Experimento 1)

- Eu gostei de ver as tags. (Experimento 1)

- Usar as tags é divertido. (Experimento 1)

- O Design x foi divertido de usar. (Experimentos 2 e 3)

- O Design x foi fácil de usar. (Experimentos 2 e 3)

- Em geral, fiquei satisfeito usando o Design x. (Experimentos 2 e 3 )

Este capítulo apresentou pesquisas em sistemas de recomendação que focam em usabilidade e experiência do usuário. Mostramos a importância de explicações nas interfaces de recomendações, e as características principais da classificação proposta por Tintarev e Masthoff [2007] para explicações de sistemas de recomendação. Também foram apresentadas as metas que contribuem com a usabilidade de sistemas de recomendações, e as métricas a serem utilizadas nos experimentos.

\footnotetext{
${ }^{14} \mathrm{http}: / /$ www.blackboard.com
} 


\section{Capítulo 3}

\section{Trabalhos Relacionados}

Este capítulo tem como objetivo apresentar trabalhos relacionados a tags e coleções de música. Entre eles, são apresentados trabalhos com tags como explicações, visualizações combinadas com recomendações, e visualizações de música que utilizam tags.

\subsection{Explicações de Recomendação que Usam Tags}

\section{Tagsplanations}

Tagsplanations [Vig et al., 2009] é uma forma de explicação de recomendações criado pelo grupo de pesquisa GroupLens. Utilizando tags aplicadas a filmes pela comunidade do site MovieLens15, Tagsplanations usa tags para explicar recomendações.

Vig et al., [2009] observam que existe uma "entidade intermediária" que procura mostrar a relação entre usuário e item recomendado. Explicações de recomendações são um tipo de entidade intermediária, e podem ser baseadas em item, em usuário, ou em conteúdo.

Tagsplanations é um tipo de explicação baseado em conteúdo. A entidade intermediária entre o usuário e a recomendação são grupos de tags, apresentados através de escalas de relevância e escalas de preferência do usuário.

No estudo de usuário, Tagsplanations mostra-se viável como explicação de recomendações de filme, e favorece as metas de justificativa, eficácia e compatibilidade de humor. Tagsplanations não oferece nenhum tipo de inspeção ou revisão de recomendações.

15 http://www.movielens.org/ 


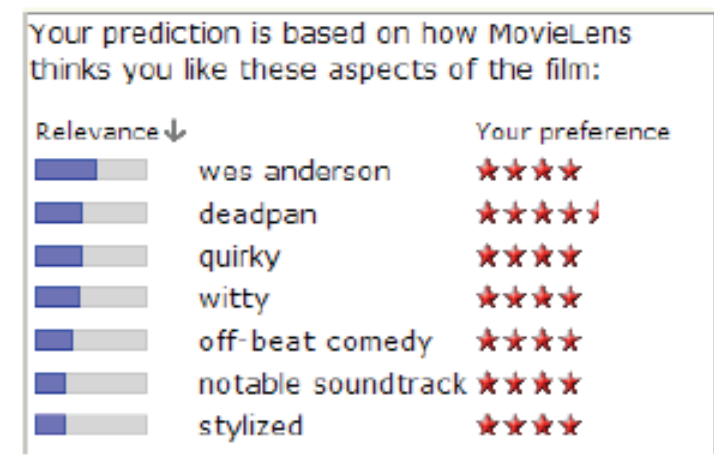

Figura 3.1: Tagsplanations, interface para recomendaçôes de filme. [Vig et al., 2009].

\section{Movie Tuner}

Movie Tuner [Vig et al. 2011] é um novo tipo de interface que permite que usuários do site MovieLens utilizem tags para revisar e explicar recomendações de filme. Por exemplo, um usuário que gosta do filme "Pulp Fiction" pode querer ver um filme parecido, mas menos violento. Movie Tuner é baseado em um novo tipo de estrutura de dados, o genoma de tags (tag genome). Essa estrutura codifica a relação entre um filme e o grupo de tags considerado mais relevante entre usuários do site MovieLens.

A interface de Movie Tuner permite que usuários escolham um filme que gostam como ponto de partida. As tags mais relevantes para o filme selecionado são apresentadas sobre uma lista de recomendações. Usuários podem então utilizar a escala de tags para revisar (critique) os filmes recomendados.

Os resultados do estudo de usuário do Movie Tuner mostram que os participantes ficaram satisfeitos com a oportunidade de corrigir recomendações de filmes. 


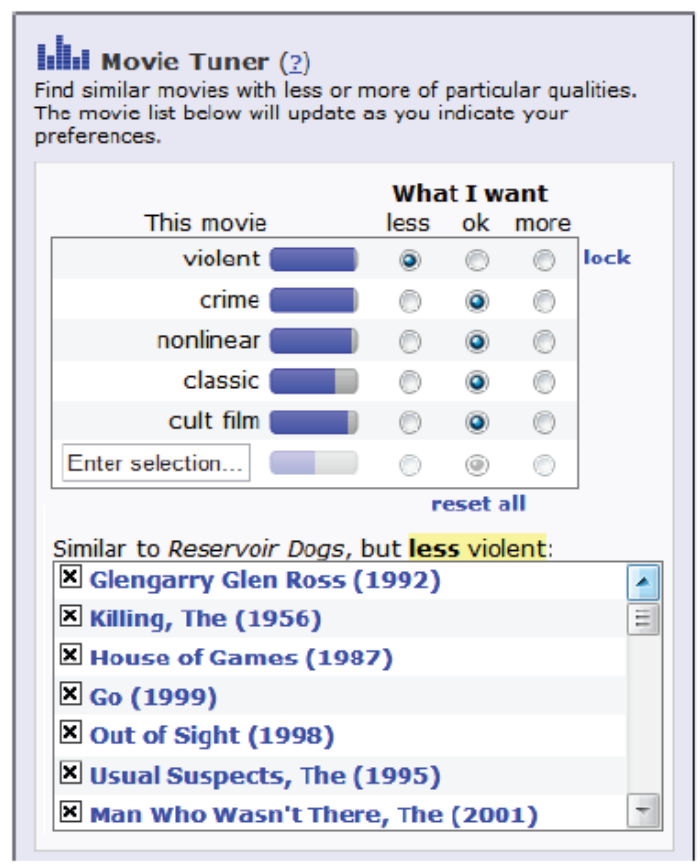

Figura 3.2: Movie Tuner, uma interface para corrigir recomendaçôes. [Vig et al. 2011].

Tagsplanations e Movie Tuner mostram que tags são viáveis para explicar e revisar recomendações de filme. Procuramos aplicar várias técnicas desses trabalhos ao usar tags para explicar recomendação de músicas. No entanto, existe uma diferença entre recomendação de filmes e recomendação de músicas: o número de itens que usuários consomem por sessão. Em geral, um usuário busca um filme para assistir, enquanto que para música, usuários buscam um conjunto maior de itens (10 a 50 itens). Assim, explicações para recomendação de música devem considerar um grupo muito maior de tags, por conta do número de itens recomendados. Para representar um grande número de tags, este projeto busca referências em visualizações de tags para coleções de música, e visualizações combinadas com recomendações.

\subsection{Visualização e Recomendação}

\section{Music Explaura}

Music Explaura [Green et al., 2009] é um novo tipo de interface criado em conjunto com o projeto AURA, do Sun Labs. AURA é um sistema que constrói auras de texto (textual auras), e as utiliza para recomendar itens similares. Além de servir como uma métrica de similaridade, a aura de texto também serve como um tipo de explicação, e forma de corrigir recomendações. 
No caso de Music Explaura, a aura é utilizada para recomendar artistas. Através de um artista "semente", o sistema recomenda uma lista similar de artistas. As recomendações são apresentadas com uma nuvem de tags, que pode ser usada para explicar e revisar recomendações. Ao serem selecionadas, as tags afetam diretamente o sistema de recomendação, tornando o sistema transparente e melhorando a experiência do usuário.

Entretanto, o estudo de usabilidade de Music Explaura mostra que a primeira vista, participantes acharam as nuvens de tags confusas. Usuários também tiveram dificuldade de revisar as recomendações, pois não esperavam que as tags pudessem ser manipuladas. Ao entenderem o que as nuvens de tags representavam, os participantes concordaram que as tags eram úteis como explicações, mas a reação geral com a visualização não foi positiva.

Apesar de Music Explaura mostrar melhoras em transparência e inspeção (scrutability) de recomendações, o estudo de usabilidade sugere que seria interessante tentar uma interface ou visualização diferente.

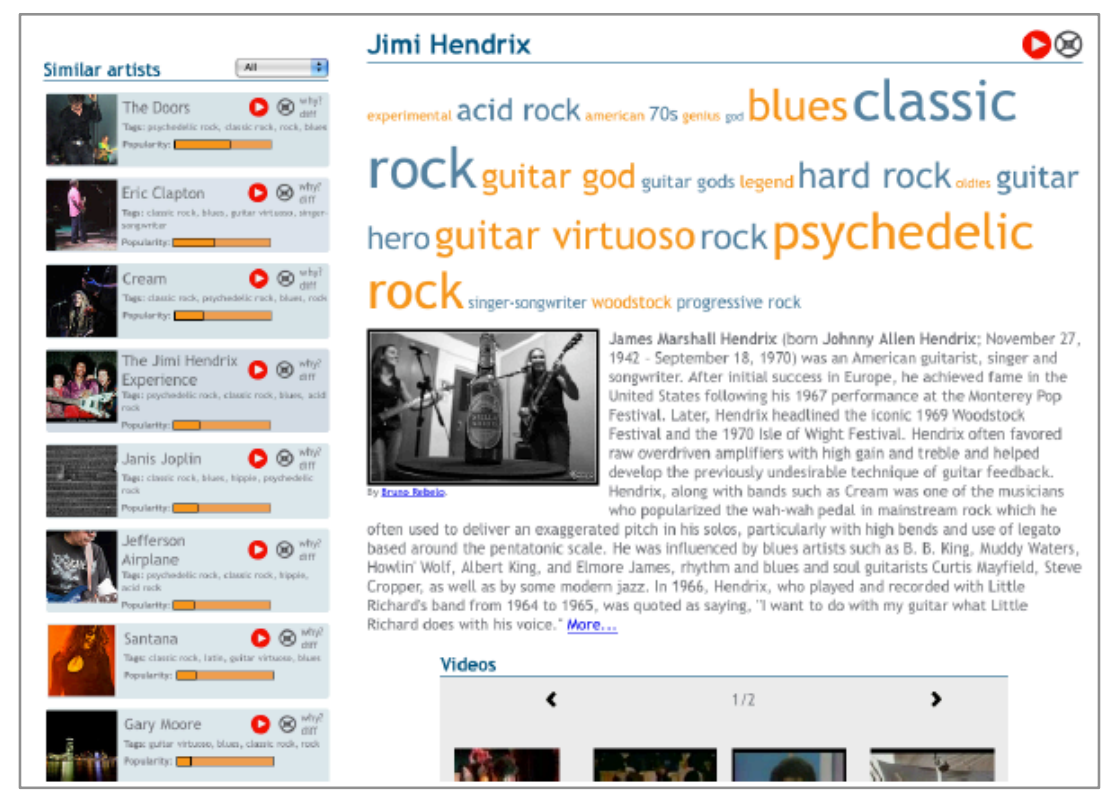

Figura 3.3: Music Explaura [Green et al., 2009].

\section{RAMA}

RAMA [Sarmento et al., 2009] é uma ferramenta de visualização que permite que o usuário explore redes de artistas do serviço Last.fm. RAMA usa informação sobre similaridade de artistas e 
tags para produzir um grafo, criando uma visualização de relações entre artistas. RAMA mostra não só as tags em comuns entre artistas, mas também tags específicas para cada artista.

Os pesquisadores do projeto reconhecem a importância de explicações em sistemas de recomendação, mas não abordam o problema dessa perspectiva.

"Albeit very useful, tag-based or similarity-based playlists are sometimes difficult for users to understand. The reason why a given artist or music was "selected" by the web radio is not always obvious and it can easily become confusing or frustrating for less experienced users that are unable to clearly express their músical preferences through queries."

"Apesar de úteis, playlists baseadas em tags ou similaridade são, as vezes, difíceis para usuários entenderem. A razão pela qual um artista ou música foi selecionada pela radio online não é sempre óbvia. Pode ser confuso ou frustrante para um usuário menos experiente, que não é capaz de articular com clareza sua preferencia musical através de palavras chaves."

Como outros projetos de visualização, RAMA apresenta uma interface complexa com bastante informação, mas que ocupa muito espaço na tela e necessita de "zoom" e "pan”. RAMA também mostra um pouco da relação entre tags e artistas recomendados.

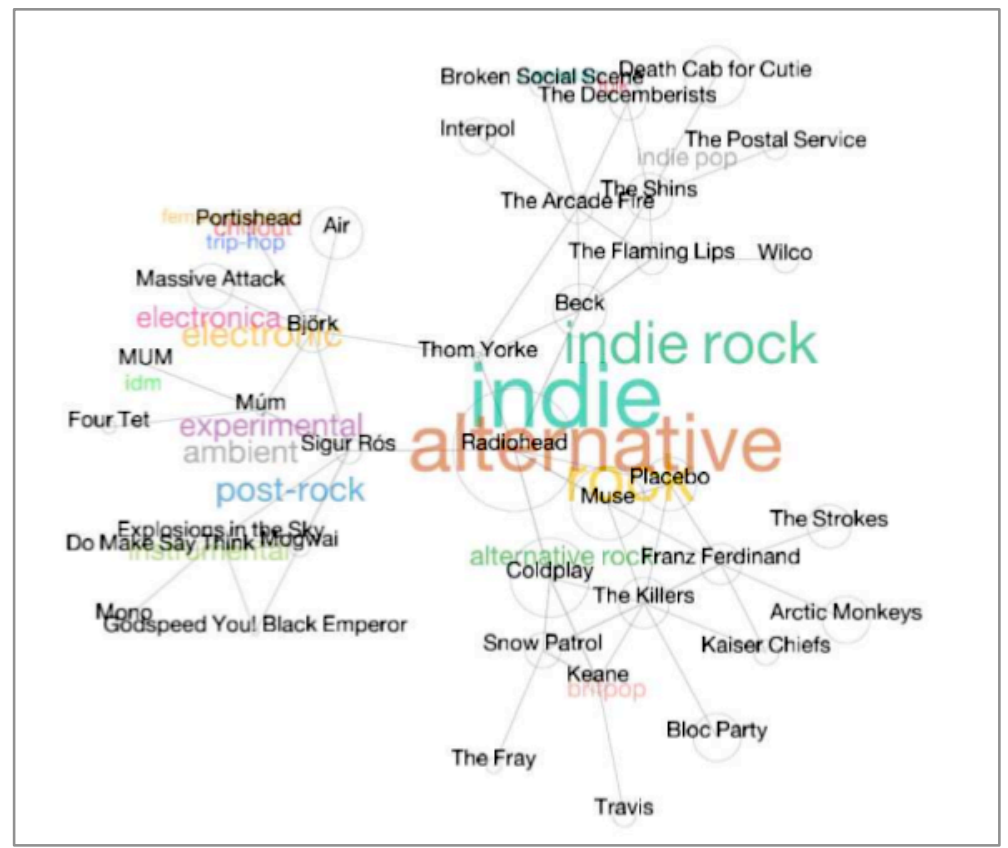

Figura 3.4: RAMA [Sarmento et al., 2009]. 


\section{Rush}

Rush [Baur et al., 2010] é uma técnica de interface e visualização baseada em recomendações. O objetivo de Rush é facilitar a seleção de itens em uma coleção grande de dados, no contexto de telas de toques para dispositivos móveis. A partir de uma "semente", o sistema de recomendação gera itens relacionados. Esses são dispostos próximo a semente, e usuários podem selecionar uma das sugestões, que por sua vez, geram mais recomendações. Esse processo é um tipo de revisão de uma recomendação.

Rush é um exemplo interessante da combinação de visualização e recomendação para criar playlists em um dispositivo móvel. Seu foco é ajudar usuários a revisar uma recomendação (inspeção), mas não considera aumentar transparência ou eficácia através de explicações.

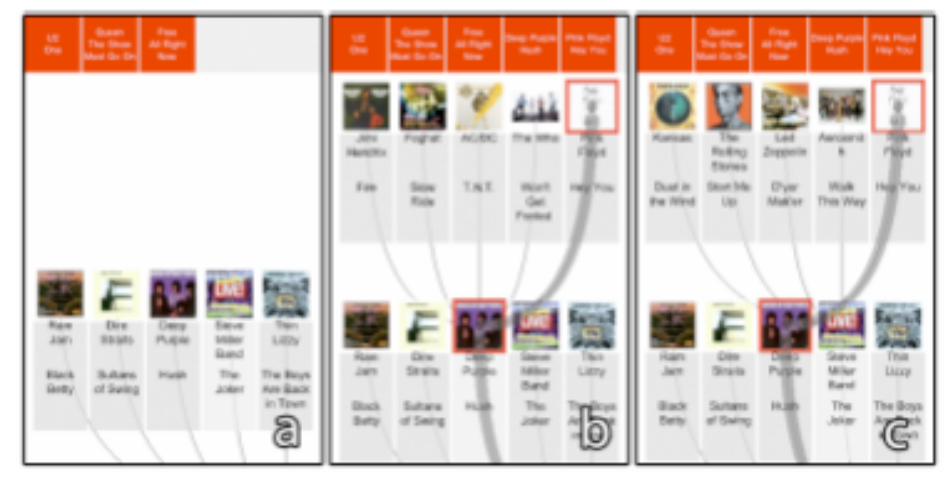

Figura 3.5: Rush [Baur et al., 2010].

\section{PeerChooser}

PeerChooser [O'Donovan et al., 2008] é um sistema de recomendação baseado em filtragem colaborativa. Através de uma visualização que mostra as correlações entre usuários, PeerChooser fornece uma explicação do processo de filtragem colaborativa, e também oferece a usuários a chance de revisar as recomendações.

Um estudo de usuário efetuado com PeerChooser mostrou que mais de $80 \%$ dos participantes da pesquisa encontraram benefícios ao interagir com o sistema para revisar recomendações. Apesar dos resultados positivos, a interface do PeerChooser ocupa bastante espaço na tela, e dedica pouco espaço aos itens recomendados. 


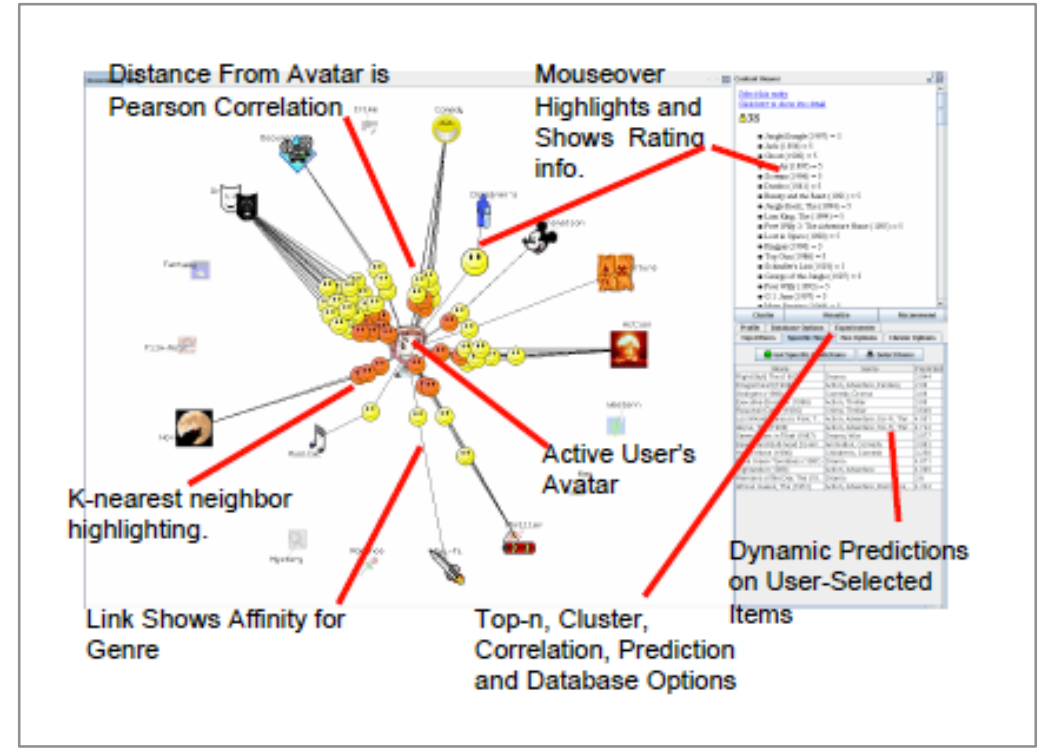

Figura 3.6. PeerChooser [O'Donovan et al., 2008].

\section{Tag Clouds como Explicações}

Gedikli e Jannach [2011] usam Tag Clouds para explicar recomendações de filmes, e em experimento comparam: Tag Clouds, listas de palavra-chave, e Tag Clouds personalizadas. Seguindo as metas definidas por Tintarev e Masthoff [2007], os autores pesquisam os efeitos de explicações (utilizando Tag Clouds) nas metas de eficiência e satisfação. Os autores mostram que Tag Clouds personalizadas tem melhor resultados em termos de eficiência, mas a diferença entre Tag Clouds e Tag Clouds personalizadas não é estatisticamente significativa. Na meta satisfação, usuários preferem Tag Clouds personalizadas, mas a diferença com Tag Clouds também não é estatisticamente significativa. As visualizações com Tag Clouds se mostram mais eficientes e satisfatórias que a lista de palavra-chave.

É interessante notar que nesse exemplo, as tags só servem como explicação para um filme recomendado de cada vez. Assim, a interface não permite a filtragem de recomendações. No caso de músicas, avaliar um item de cada vez não é eficiente, considerando que usuários buscam um certo número de músicas para escutar. Por exemplo, para um usuário que busca duas horas de entretenimento, um filme de duas horas corresponde a 30-40 canções. 


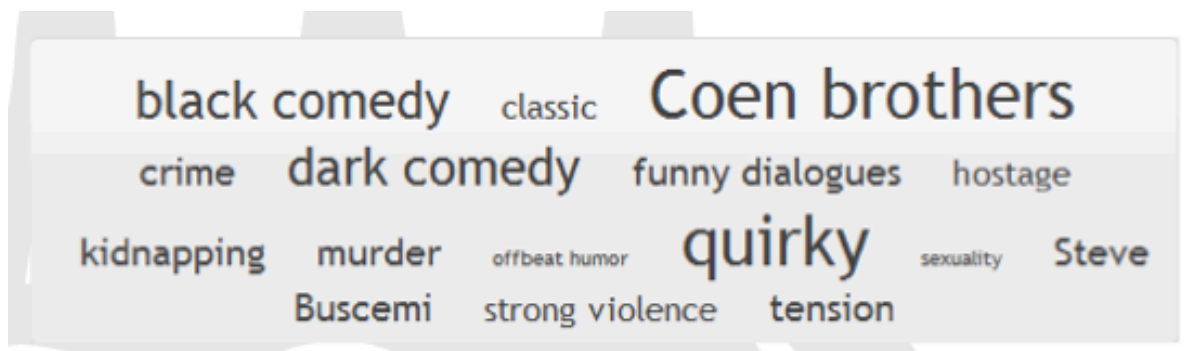

Fig. 2. Tag cloud (TC).

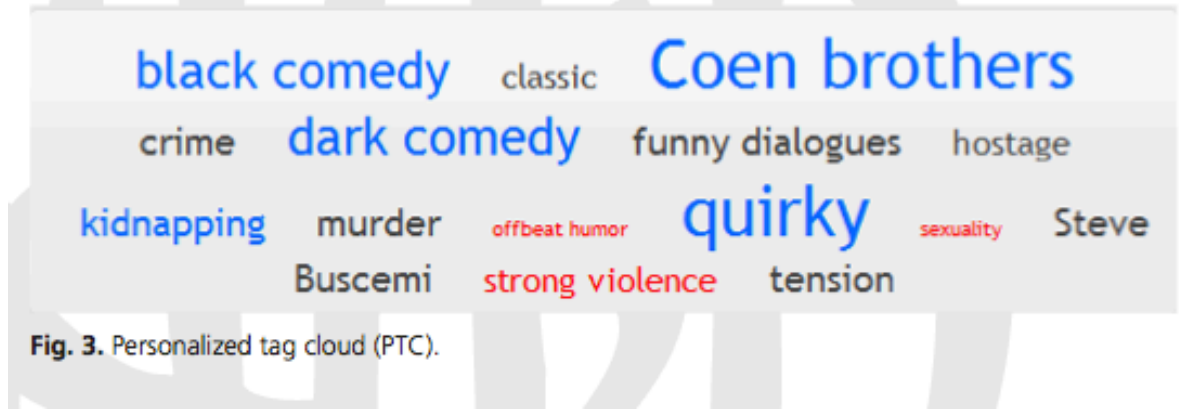

Figura 3.7: Tag. Clouds para explicar recomendaçôes [Gedikli et al., 2011]

\section{TopicLens}

TopicLens é uma ferramenta interativa projetada por Devendorf et al. [2012], que pode ser utilizada para explorar itens recomendados, baseados em metadados sociais e associações de tópicos. A abordagem permite que usuários observem a composição de tópicos relevantes, e sua relação com metadados de textos. Entre vários exemplos, TopicLens mostra a relação de recomendações de filme e sua popularidade com usuários da rede social Facebook ${ }^{16}$, ou uma rede de artigos do New York Times e sua relação com tópicos modelados.

O objetivo de TopicLens é facilitar a exploração de grandes conjuntos de dados baseados em um número de fatores. Usuários aprendem e exploram o sistema através da interação com a visualização, ao invés de ter uma visão geral estática da informação.

TopicLens mostra a relação entre itens recomendados e metadados sociais, com o objetivo de mostrar o impacto de certos itens na rede de contatos do usuário (por exemplo, se um filme é popular em seu círculo de amigos). Esse tipo de explicação atinge a meta de credibilidade, mas não se aplica a metas como inspeção (usuários não podem filtrar as recomendações).

\footnotetext{
${ }^{16} \mathrm{http}: / / \mathrm{www} \cdot$ facebook.com
} 


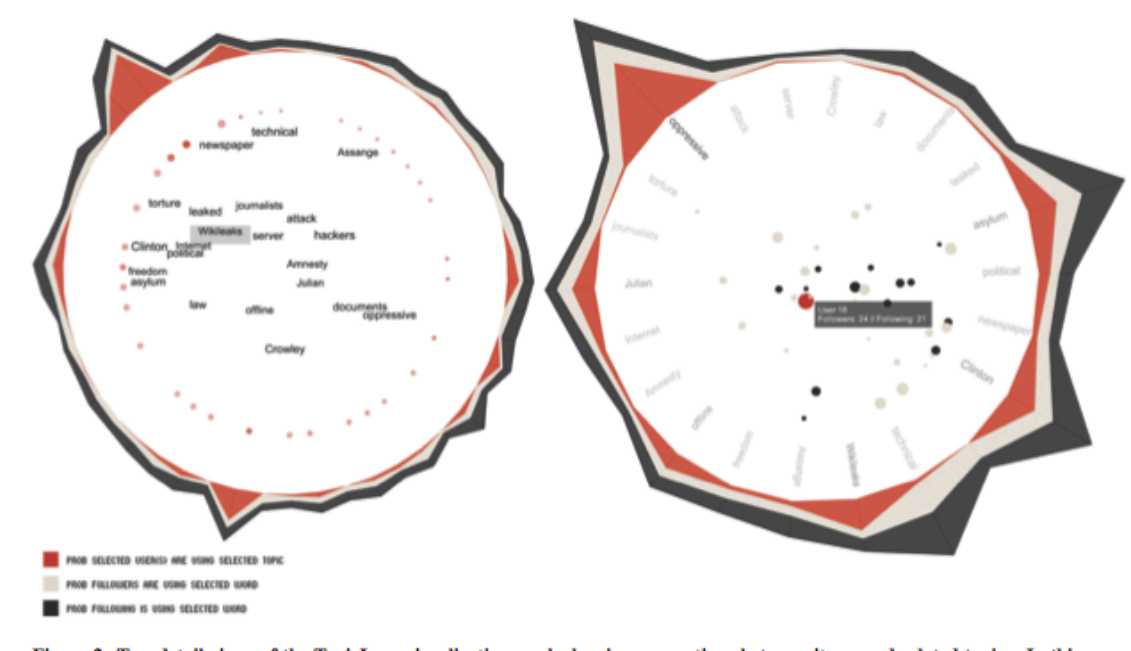

Figure 2: Two detail views of the TopicLens visualization, each showing connections between items and related topics. In this case the data is from the Twitter social network, so our generic "items" represent Twitter users. Fre

Figura 3.8: TopicLens [Devendorf et al., 2012]

\subsection{Visualizações de Tags para Coleções de Música}

Nesta seção apresentamos visualizações de tags utilizadas em coleções de músicas.

\section{Music Som}

Music Som [Lehwark et al., 2007] é um método de visualização que permite que usuários explorem coleções de dados de tags. Music Som analisa dados da comunidade no Last.fm. Usuários podem aplicar tags a artistas e músicas, e explorar conteúdo via tags. Como o número de artistas e músicas é enorme, uma interface intuitiva é necessária para que o usuário não perca a noção do todo. Music Som usa "Emergent-Self-Organizing-Map (ESOM)" para agrupar tags similares.

Music Som fornece uma interface interessante, mas que ocupa muito espaço na tela, e depende de controles como "zoom” e "pan”. A visualização também não mostra a relação entre tags e artistas. 


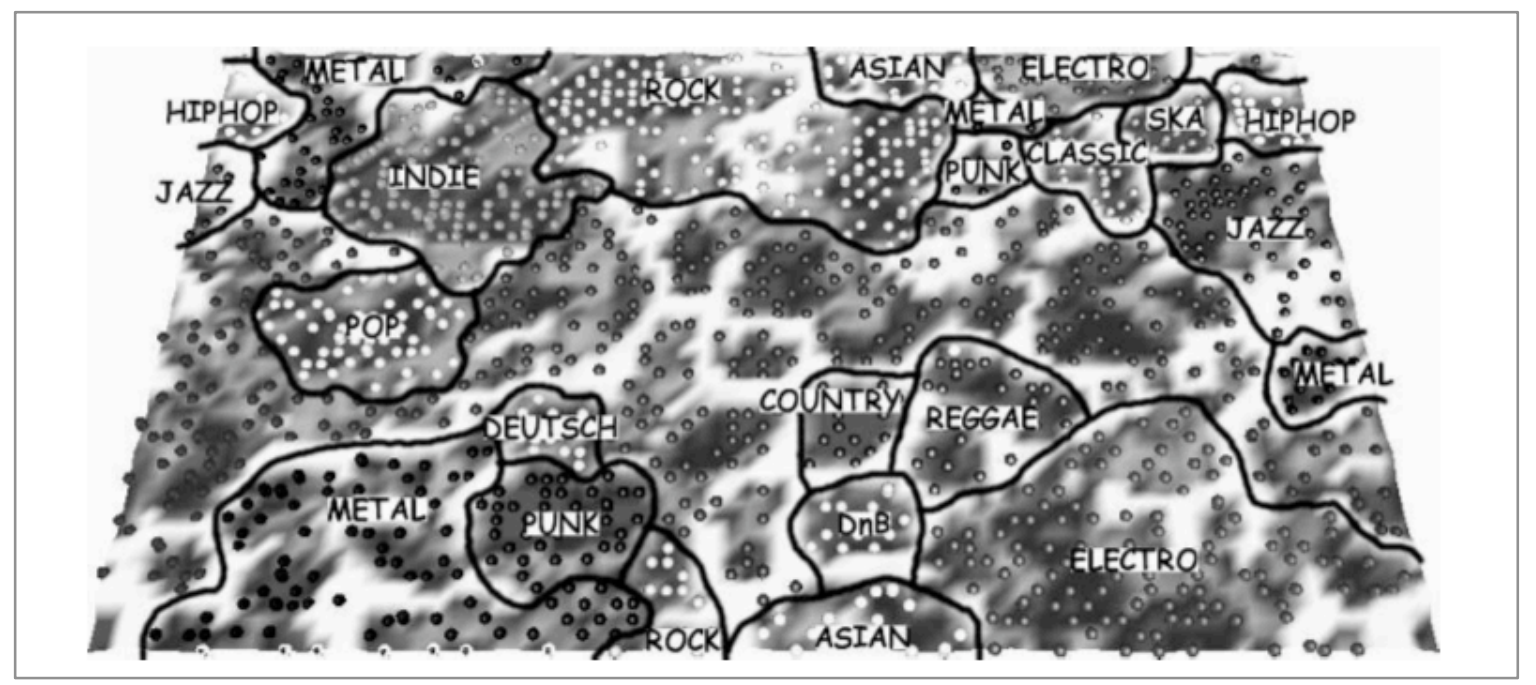

Figura 3.9: Music Som [Lehwark et al., 2007].

\section{Tagclusters}

Nuvens de tags são um exemplo de visualização que é bastante popular. Tagclusters [Chen et al., 2009] é uma visualização que busca melhorar nuvens de tags, permitindo sua compreensão semântica. Com base em análise semântica, tags são agrupadas em diferentes grupos, resolvendo problemas como redundância, e ambiguidade A distância visual depende da similaridade entre tags. Por exemplo, tags como "rock", "post rock" e "folk rock" são agrupadas e exibidas próximas uma das outras.

Tagclusters mostra como melhorar nuvens de tags, mas não oferece recomendações. Como outras visualizações de música, o usuário precisa navegar uma interface complexa para encontrar músicas e artistas da sua preferência. Tagclusters também utiliza muito espaço na tela e requer uso de "zoom" e "pan". 


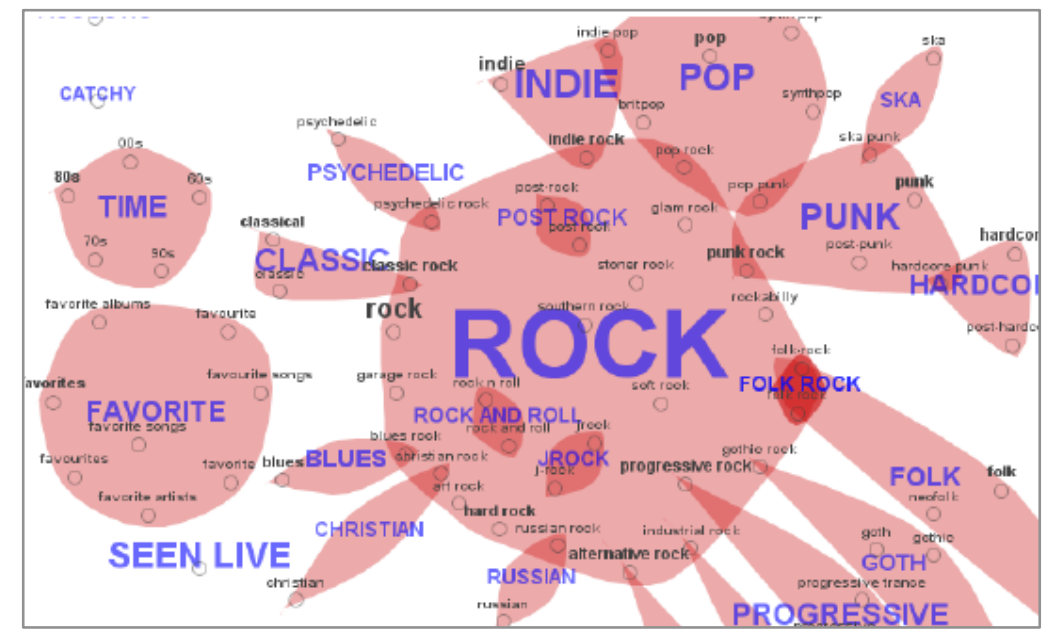

Figura 3.10: Tagclusters [Chen et al., 2009].

Apesar de enriquecerem a experiência do usuário mostrando diferentes relações entre tags ou itens, as visualizações citadas apresentam alguns problemas. A densidade de informação requer muito espaço na tela, e "zoom” ou "pan”, que com exceção de interfaces para mapas, não são controles comuns. Outro problema é a relação entre as visualizações e o conteúdo buscado pelo usuário. Muitas das visualizações de tags se concentram em mostrar relações entre as tags, mas não especificamente entre tags e músicas ou artistas.

Entre as visualizações apresentadas, alguns itens que podem ser melhorados:

- A visualização deve ser claramente manipulável (por exemplo, as tags devem parecer clicáveis);

- A interação com a visualização deve ser fácil de entender e aprender, já que música é um produto de baixo envolvimento, isto é, usuários não querem investir muito tempo buscando músicas (ao contrário de produtos como carros, pacotes de viagens, etc);

- A visualização deve mostrar uma relação clara entre as tags e os itens recomendados;

- A visualização deve ocupar menos espaço na tela, permitindo que usuários também vejam os itens recomendados. Apesar de importante, a explicação e filtragem de recomendações não pode ocupar mais espaço que os itens recomendados.

Este capítulo apresentou trabalhos relacionados a tags e coleções de música. Entre eles, foram apresentados trabalhos com tags como explicações, visualizações combinadas com recomendações, e visualizações de música que utilizam tags. 


\section{Capítulo 4}

\section{Projetando e Desenvolvendo Visualizações de Tags}

Este capítulo tem como objetivo detalhar o processo de design da visualização de tags. Com base na pesquisa, e trabalhos relacionados nos capítulos anteriores, consideramos que um novo tipo de visualização de tags pode ter um resultado melhor ao explicar e filtrar recomendações. Para tal, utilizamos parcialmente o seguinte processo de design de interação de Rogers et al. [2011], citado no capítulo 2 .

\subsection{Processo de Design de Interação}

A definição de Design de Interação de Rogers et al. [2011] é: "Design de produtos interativos que oferecem suporte a atividades cotidianas de pessoas, no lar ou no trabalho". O processo de design de interação se divide em:

- identificar necessidades do usuário e requisitos;

- desenvolver propostas de designs;

- construir protótipos dos designs;

- avaliar protótipos.

\subsubsection{Perfil do Usuário}

Neste projeto, escolhemos focar em um usuário com o seguinte perfil: usuário casual, que escuta música por diversão, com pouco ou nenhum conhecimento formal de música, e que escuta música no computador ou tablet. É um usuário com experiência de sites de streaming de música(Grooveshark, Spotify, Rdio, Last.fm, Pandora), ou de software para música digital (iTunes, Winamp, Windows Media Player, etc), e que usa internet com frequência (todos os dias). 
A plataforma alvo é para o usuário com dispositivos de 8 polegadas ou mais, desktop, laptop ou tablet.

\subsubsection{Cenários}

Usuários buscam e escutam músicas de múltiplas formas. Nesse projeto, procuramos contextos específicos de uso de um aplicativo de música. Para ilustrar estes contextos, apresentamos os seguinte cenários:

\section{Cenário 1}

Ana quer escutar música enquanto faz o dever de casa. Ela está enjoada da playlist que criou a alguns dias atrás, e quer criar outra playlist. Ana precisa de um jeito fácil de encontrar 20 a 50 músicas, sem ter que buscar uma por uma. Sua tarefa principal é estudar, não procurar por músicas, e não quer se distrair usando uma interface complexa ou difícil.

Ana gosta da banda Coldplay, e está com vontade de escutar uma música alegre. Como ela pode encontrar músicas parecidas com Coldplay, e que são alegres? O aplicativo que ela usa (iTunes) só permite que ela busque por nome de artista, título, etc, ou filtragem por estilo. Ela tenta filtrar pelo estilo do Coldplay (alternativo), mas quase todas as músicas em sua biblioteca são desse estilo. Além do estilo, Ana não sabe como descrever o tipo de música que ela gosta em detalhes.

Ana tenta usar o iTunes Genius, usando como referência a música "Viva la Vida" como semente, por ser uma música do Coldplay, e alegre. O aplicativo oferece uma lista de 50 músicas - Ana conhece algumas das músicas e sabe que são de artistas parecidos com Coldplay, mas algumas das músicas são tristes. Como Ana pode dizer para o iTunes Genius que ela quer músicas alegres?

Necessidades presentes no cenário 1: Apresentar recomendações, encontrar músicas com menos esforço e tempo (eficácia), descrever músicas, permitir filtragem de recomendações (inspeção), ser fácil de usar (diversão).

Encontrar músicas com mínimo de esforço e tempo (eficiência).

\section{Cenário 2}

Daniel procura novas músicas para escutar. Ele entra no servico Last.fm, e usa uma música do Pink Floyd como semente para recomendações. As duas primeiras músicas são boas, mas depois Last.fm recomenda uma música de uma banda dos anos 70 que ele detesta. Apesar de ter usado como semente uma música dos anos 70, isso não quer dizer que ele queira escutar músicas do ano 70. Como ele pode dizer para Last.fm que ele quer músicas de rock progressivo, e não anos 70?

Necessidades presentes no cenário 2: Apresentar recomendações, e permitir filtragem de recomendações (inspeção). 


\section{Cenário 3}

Mariana descobriu recentemente a banda Grizzly Bear, quer aprender mais sobre ela e encontrar bandas similares. Ela busca por Grizzly Bear no Wikipédia, aprendendo sobre seu estilo, e fazendo uma lista de artistas parecidos. Com a lista de artistas, ela faz buscas no Spotify. Dali, ela precisa escutar várias músicas para encontrar as que gosta, e adicionar a favoritos. Isso leva horas, por isso é difícil para Mariana encontrar músicas enquanto está trabalhando. Mariana geralmente escuta músicas enquanto trabalha, e tem que buscar música nas horas vagas.

Mariana quer um serviço que encontre músicas que ela goste, sem ter passar horas pesquisando, e quer aprender o que as músicas tem em comum. Por exemplo, se as músicas que ela gosta são descritas como "folk rock" e "lo-fi", então ela deve gostar de "folk rock" e "lo-fi".

Mariana também acha chato como muitas interfaces de música são simplesmente listas - ela gostaria de ver algo mais interessante, já que música é diversão, e não trabalho.

Necessidades presentes no cenário 3: Apresentar recomendações, encontrar músicas com menos esforço e tempo (eficiência), descrever músicas, ensinar algo sobre as recomendações (eficácia), permitir filtragem de recomendações (inspeção), ser uma interface atraente e divertida (satisfação).

\subsection{Necessidades do Usuário}

Neste projeto, o processo de identificação de necessidades do usuário e requisitos foi completada parcialmente, através da literatura em pesquisa de usuário para música e sistemas de recomendação.

Como definido no capítulo 2, a necessidade principal que buscamos atender é a busca de músicas relevantes (músicas que o usuário já conhece ou músicas novas) com o mínimo de esforço e tempo. Mais especificamente:

\section{Apresentar recomendações e explicações.}

Usuários preferem sistemas que oferecem recomendações baseadas em músicas ou artistas similares [Vignoli, 2004]. Música é difícil de descrever, por isso só busca não é o suficiente [Kim e Belkin, 2002]. Usuários também favorecem recomendações com explicações.

Encontrar músicas com mínimo de esforço e tempo (eficiência).

Usuários querem encontrar músicas rápido e com menos esforço (eficiência), pois música é um produto de baixo envolvimento [Jones e $\mathrm{Pu}, 2007$ ]. Isto se reflete na oferta de recomendações, e na necessidade de explicações que permitem que usuários avaliem e encontrem músicas mais rápido.

\section{Metadados educam usuários, e auxiliam na avaliação de recomendações (eficácia).}

Usuários buscam tanto arquivos de música quanto atributos como metadados, contexto e conteúdo [Lee e Downie, 2004]. No caso de recomendações, estes atributos educam usuários e facilitam a 
avaliação de recomendações. Estes metadados podem ser apresentados na forma de explicações [Barrington et al., 2009]. Neste projeto, utilizamos tags como explicações de recomendação.

Filtragem ou revisão de recomendações (inspeção).

Ao interagir com recomendações, usuários preferem sistemas que permitem filtragem de recomendações (inspeção). Usuários descrevem músicas através de estilos musicais, emoções, ou contexto. [Lee e Downie, 2004; Kim e Belkin, 2002]. Assim, usuários preferem um sistema que oferece filtragem através destes atributos.

Diversão e facilidade de uso (satisfação).

Ao usar sistemas de recomendação de música, usuários preferem interfaces divertidas e fáceis de usar (satisfação).

\subsection{Requisitos}

- A interface deve oferecer recomendações de música com pouco esforço inicial do usuário, sem que o usuário precise criar um perfil.

- A interface deve oferecer recomendações baseadas em um artista ou música. Para o protótipo usado nos experimentos, nos limitamos a recomendações baseadas em uma música.

- A interface deve oferecer explicações para recomendações, que permitam que usuários avaliem as músicas sem ter que ouvir todos os trechos de música. As explicações devem revelar atributos e características das músicas recomendadas. Os atributos devem corresponder ao modo em que usuários organizam e descrevem músicas, por exemplo, por estilo, emoção, período, etc.

- A interface deve exibir metadados como o nome do artista, nome da canção, álbum, ano, capa, etc.

- A interface deve permitir que usuários escutem as músicas ou trechos de músicas.

- A interface deve oferecer formas de filtragem das recomendações através de diferentes características, como estilo, emoção, etc.

- A interface deve ser divertida, fácil de usar e fácil de aprender.

\subsection{Design}

A partir das necessidades do usuário e requisitos, foram criados designs conceituais e wireframes. Após essa fase, duas opções foram selecionadas (com base nas necessidades dos usuários e requisitos). O design 3 (Tag Strings) foi escolhido para o protótipo e experimentos. 


\section{Necessidades do usuário:}

Apresentar recomendações e explicações.

Usuários preferem sistemas que oferecem recomendações baseadas em músicas ou artistas similares [Vignoli, 2004]. Música é difícil de descrever, por isso só busca não é suficiente [Kim e Belkin, 2002]. Usuários também favorecem recomendações com explicações.

Encontrar músicas com mínimo de esforço e tempo (eficiência)

Usuários querem encontrar músicas rápido e com menos esforço (eficiência), pois música é um produto de baixo envolvimento [Jones e $\mathrm{Pu}, 2007$ ]. Isso se reflete na oferta de recomendações, e na necessidade de explicações que permitem que usuários avaliem e encontrem músicas mais rápido.

\section{Solução:}

A interface deve exibir uma caixa de busca para que usuários busquem tanto o nome do artista, quanto o título de uma música. A partir dessa informação, um conjunto de recomendações é exibido, com 10-25 músicas. Usuários tem familiaridade com recomendações exibidas uma por vez (e.g., Last.fm e Pandora), ou com uma lista de 10 a 50 músicas (iTunes Genius, Mog). Na maior parte dos designs explorados, procuramos apresentar as recomendações em forma de lista. Já que a explicação das recomendações se refere a um conjunto de músicas, apresentar uma lista economiza espaço e permite que usuários vejam o conjunto como um todo. A lista é composta por título e artista. Quando usuários clicam no botão play para escutar uma música, a capa e metadados (álbum, ano de lançamento, etc.) são exibidos. Usuários usam metadados para avaliar recomendações.

\section{Necessidades do usuário:}

Metadados educam usuários, e auxiliam na avaliação de recomendações (eficácia).

Usuários buscam tanto arquivos de música quanto atributos como metadados, contexto e conteúdo [Lee e Downie, 2004]. No caso de recomendações, atributos educam usuários e facilitam a avaliação de recomendações. Metadados podem ser apresentados na forma de explicações [Barrington et al., 2009]. Neste projeto, utilizamos tags como explicações de recomendação.

\section{Solução:}

\section{Usando Tags como Explicação de Recomendações}

Tags oferecem um complemento interessante como metadados, já que podem ser utilizadas para explicar e filtrar recomendações musicais. Como fonte de dados usamos Last.fm, onde tags são aplicadas por usuários para organizar e contribuir com a comunidade que utiliza o serviço. 
Quanto a qualidade das tags de Last.fm, Geleijnse et al., [2007] observam que tags podem fornecer características valiosas sobre artistas e músicas. O estudo também mostra que as tags de Last.fm são descritivas e consistentes com as similaridades entre artistas.

Tags oferecem uma grande diversidade de metadados, que incluem estilos musicais, épocas, contextos e emoções. Exemplos de tags coletadas em Last.fm incluem: jazz, 80s, party, wedding, sad, mellow, etc.

Em um estudo sobre tags sociais e recuperação de informação musical, Lamere [2008] mostra a importância das tags encontradas no serviço Last.fm. Tags oferecem informação que é altamente relevante, como estilo musical, emoções, e instrumentos. Apesar de imperfeições e problemas, elas são uma fonte de conhecimento contextual sobre música.

Neste projeto, a interface oferece tags para explicar recomendações. Como detalhado no capítulo 2, explicações podem ser usadas como justificativas (não relacionadas ao algoritmo) ou transparentes (refletem como o algoritmo de recomendação funciona). Nesse caso, tags são justificativas, e não são transparentes, por serem independentes do algoritmo de recomendação. A vantagem do uso de tags é que essas podem ser usadas para explicar e filtrar qualquer tipo de recomendação de música, e.g., baseada em filtragem colaborativa, ou em conteúdo.

\section{Explicações com visualização de tags}

Como descrito no capítulo 3, os trabalhos Tagsplanations e Movie Tuner mostram que tags são viáveis para explicar e filtrar recomendações de filme. Procuramos aplicar várias técnicas desses trabalhos ao usar tags para explicar recomendação de músicas. No entanto, existe uma diferença entre recomendação de filmes e recomendação de músicas: o número de itens que usuários consomem por sessão. Em geral, um usuário busca um filme para assistir, enquanto que para música, usuários buscam um conjunto maior de itens (10 a 50 itens). Assim, explicações para recomendação de música devem considerar um grupo muito maior de tags, por conta do número de itens recomendados. Para representar um grande número de tags, este projeto busca referências em visualizações de tags para coleções de música, e visualizações combinadas com recomendações.

Card et al. [1999] definem visualização de informação como: "o uso de computadores para amplificar cognição, usando representações visuais interativas”.

Para manter a simplicidade da interface e satisfazer o requisito de criar uma interface que é fácil de usar e fácil de aprender, nos concentramos em visualizações casuais, como definido em Pousman et al.[2007]: visualização de informação casual é o uso de ferramentas computacionais para descrever informação pessoalmente relevante com formas visuais, que apoiam usuários em tarefas diárias e também em tarefas não relacionadas a trabalho.

Pousman et al.[2007] observam as diferenças principais entre visualização de informação tradicional e casual: 
- o público alvo de visualizações casuais não se limita a especialistas, e inclui um grupo amplo de usuários.

- A visualização casual não se limita ao uso no trabalho, e foca em outras usos.

- os dados são geralmente importantes no âmbito pessoal, e a relação entre o usuário e os dados é mais próxima.

- As visualizações casuais favorecem outras necessidades, que não são só de análise de informação.

- Visualizações casuais não requerem que usuários sejam analistas de informação, ou especialistas em gráficos de dados.

Um elemento importante em visualização casual é que o sistema tenha o objetivo de não ser só utilitário, mas também agradável de usar, relacionado à terminologia usada por Norman [2003] no conceito de apelo visceral, com foco emocional ou estético. Esse fator é importante para interfaces de música, já que busca por música é um processo visual [Cunningham, 2006], e usuários escutam música como entretenimento [Lee e Downie, 2004].

Kleedorfer et al. [2007] notam a dificuldade de usar técnicas típicas de visualização em aplicações comerciais de busca de música, e explora visualizações casuais para música como alternativa. A motivação é propor diferentes tipos de visualizações projetadas para serem intuitivas e fáceis de integrar em aplicações web.

Exploramos vários conceitos com visualizações casuais de tags diferentes - nuvens de tags, tag tree maps, tags como atributos em um gráfico de dispersão, etc. Após essa fase de exploração de conceitos e wireframes, duas opções foram selecionadas (com base nas necessidades dos usuários e requisitos). O designs 3 (Tag Strings), foi escolhido para o protótipo. Detalhamos o design de Tag Strings, usado no protótipo para a avaliação inicial e experimentos 1, 2 e 3. A avaliação de outras visualizações são mostrados no final da seção.

\section{O design de Tag Strings}

No capítulo 3 citamos o trabalho Music Explaura [Green et al., 2009], que usa nuvens de tags para explicar recomendações. Entretanto, o estudo de usabilidade de Music Explaura mostra que a primeira vista, participantes acharam as nuvens de tags confusas. Usuários também tiveram dificuldade de revisar as recomendações, pois não esperavam que as tags pudessem ser manipuladas. Ao entenderem o que as nuvens de tags representavam, participantes concordaram que as tags eram úteis como explicações, mas a reação geral com a visualização não foi positiva. Acreditamos que a dificuldade dos usuários estava em relacionar as tags com o conteúdo recomendado. Assim, entre todos os conceitos explorados, priorizamos o design Tag Strings, que mostra claramente a relação entre tags e conteúdo. 


\section{Relação entre tags e conteúdo}

Em Tag Strings, se uma tag é aplicada a uma música, essa é conectadas através de uma linha. O uso de linhas para conectar objetos relacionados é baseado no princípio Gestalt de continuidade [Palmer e Rock, 1994]. Ao conectar dois objetos com uma linha, expressa-se uma relação entre eles.

Quanto mais vezes uma tag é aplicada a uma música, maior é a opacidade da linha que as conecta. Para evitar a sobreposição de linhas sobre as tags, modificamos o layout do conteúdo. As tags e músicas são organizadas em duas listas, formando duas colunas. O layout de duas colunas conectadas é útil pois permite que o usuário leia a informação tanto separada (lista de tags e lista de músicas) quanto a informação integrada (linhas conectando as tags e músicas) [Tufte, 1983].

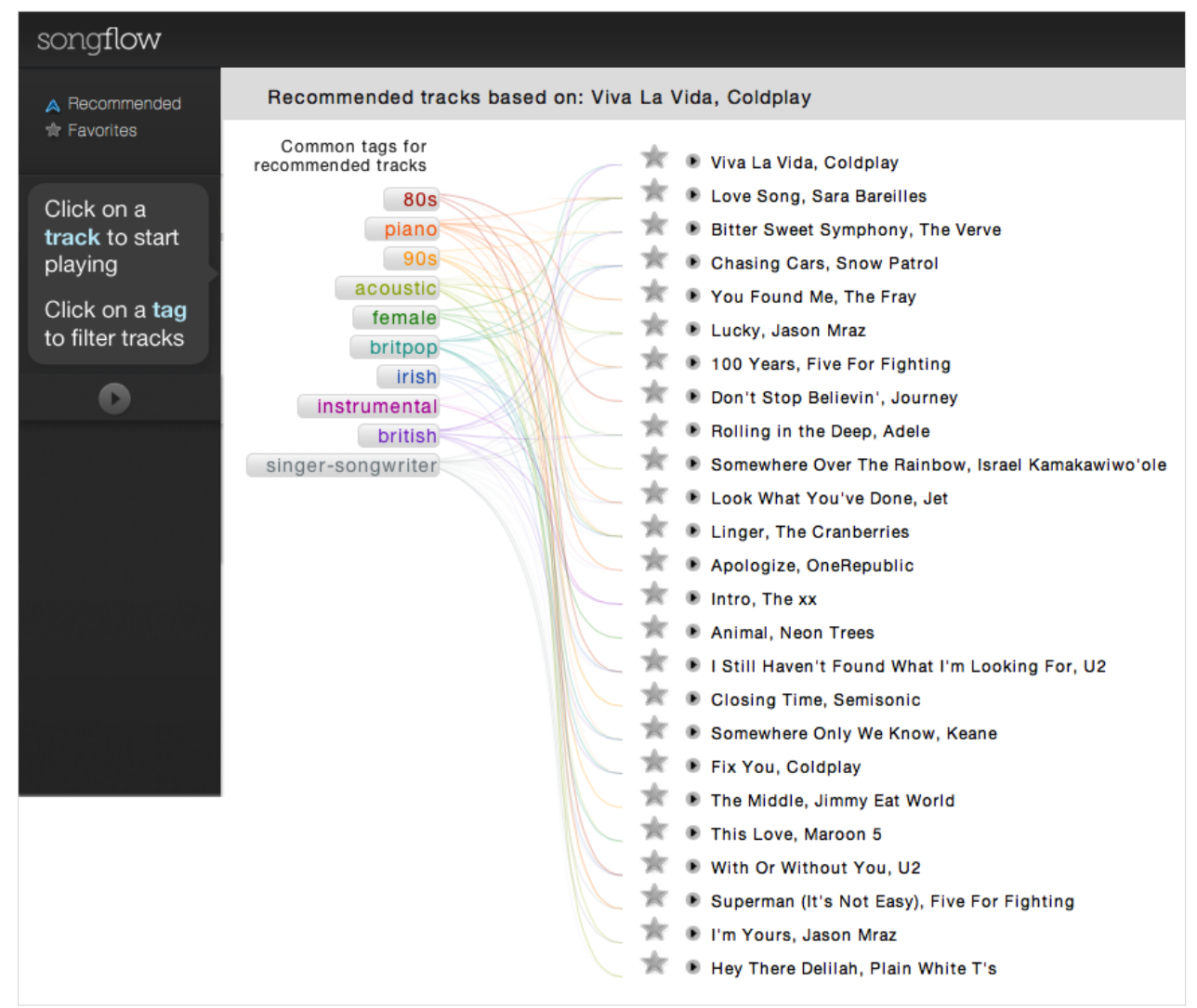

Figura 4.1: Telas do protótipo Tag Strings, na versão final.

As tags são dispostas em ordem de relevância. A coluna de tags é exibida à esquerda das músicas, seguindo uma forma comum de layout (navegação a esquerda, e conteúdo relacionado à direita), que é familiar para muitos usuários [Tidwell, 2010].

$\mathrm{Na}$ fase inicial do protótipo, experimentamos ligar as tags com as músicas através de uma linha reta. O resultado se tornou visualmente confuso, por conta dos ângulos formados entre as linhas, nos pontos entre uma tag e uma música. Experimentamos modificar as linhas para formar curvas. As 
curvas mostram a ligação entre tag e músicas com menos ruído visual, o que melhora a legibilidade da visualização. O princípio Gestalt de continuidade também se aplica neste caso. Ao utilizar linhas suaves e contínuas, e manter as mesmas cores, somos mais propensos a perceber tags, linhas e música como formas relacionadas [Ware, 2012].

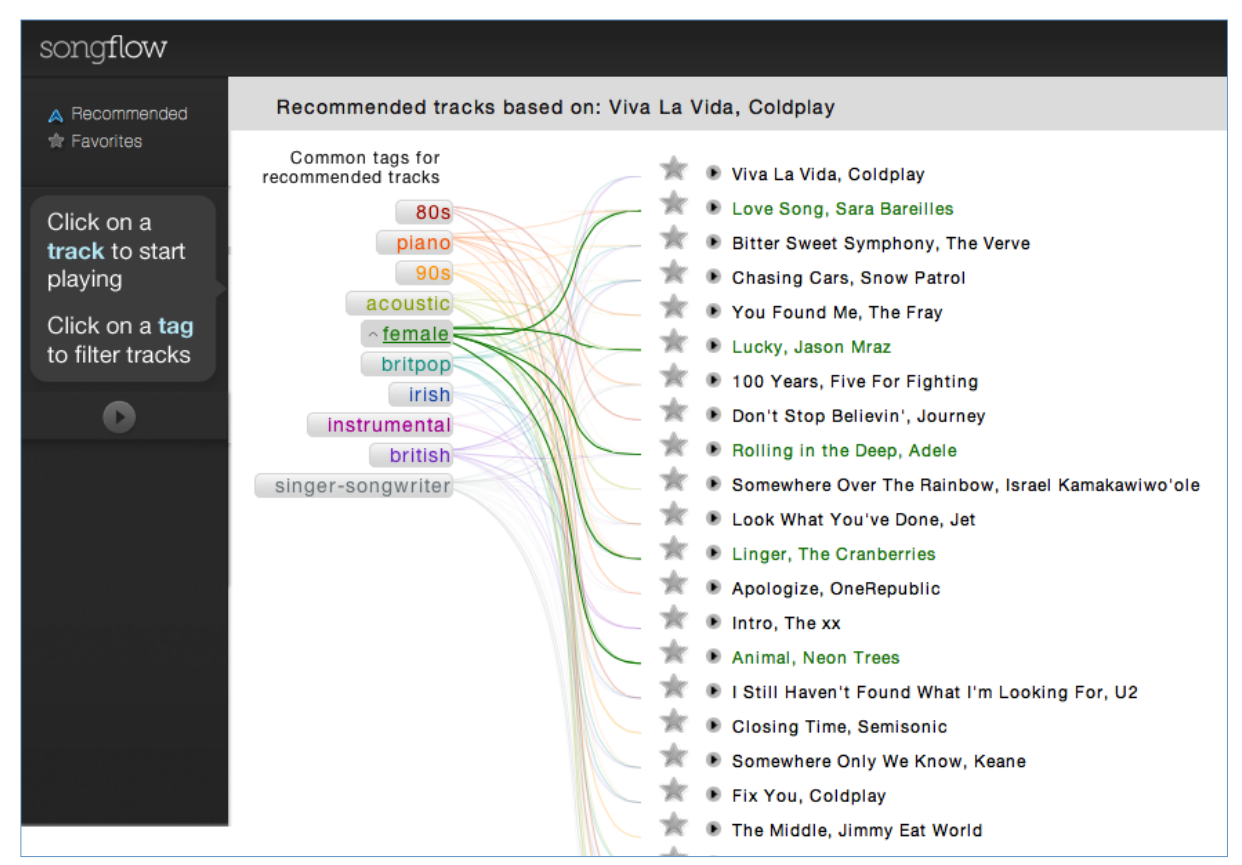

Figura 4.2: Telas do protótipo Tag Strings, na versão final, hover.

Também criamos um protótipo com uma versão alternativa, que não mostra linhas conectando músicas e tags. Somente em hover as tags e músicas são conectadas através de sombreamento. $\mathrm{O}$ design é mais discreto mas esconde muita informação. Por exemplo, se o usuário não pousa o cursor sobre uma tag, a relação entre tags e músicas não é exibida, como mostra a figura 4.3. E mesmo com a sombra em hover, essa versão não permite a comparação da popularidade de uma tag em relação a outras (por exemplo, se uma tag foi aplicada a 20 músicas ou a 1 música), como mostra a figura 4.4. Desse modo, preferimos usar a versão com linhas para os experimentos do capítulo 6. 
Projetando e Desenvolvendo Visualizações de Tags

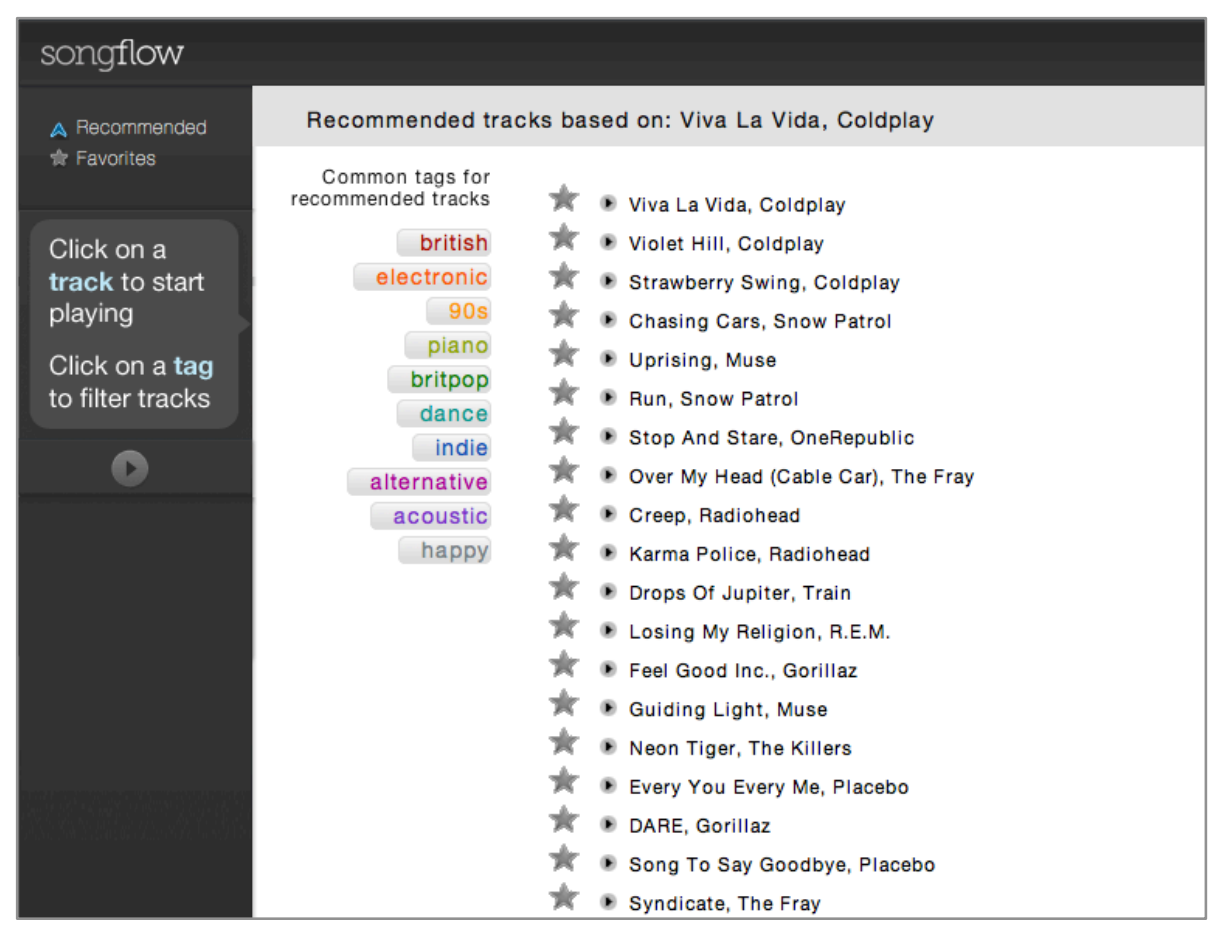

Figura 4.3: Telas do protótipo Tag Strings, em uma versão alternativa do protótipo.

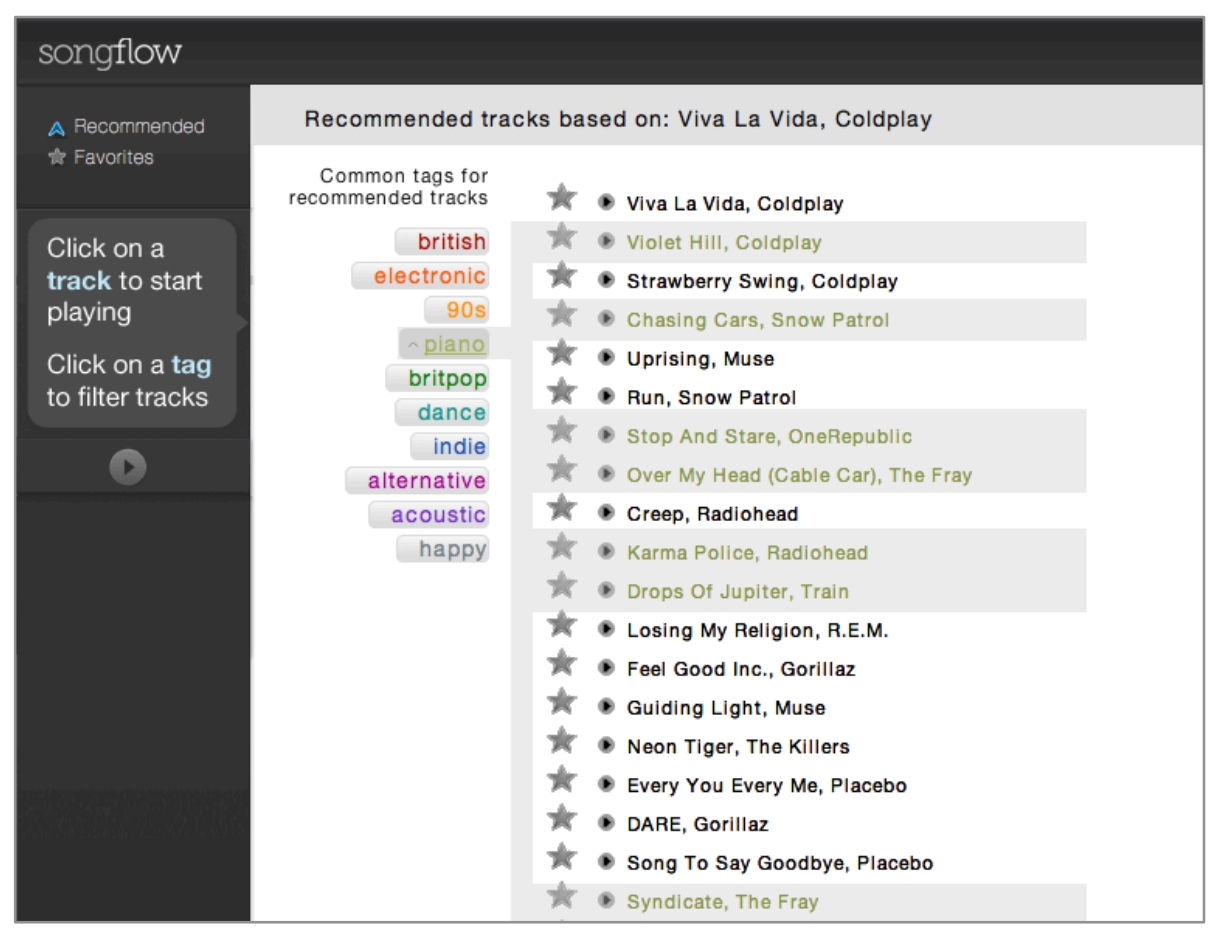

Figura 4.4: Telas do protótipo Tag Strings, teste com sombreamento, em hover. 


\section{Cores}

Para diferenciar as tags e linhas, utilizamos cores. Ware [2012] recomenda o uso de cores como código nominal já que a percepção de cores é pré-atenta, o que requer menos esforço do usuário. $\mathrm{O}$ uso de cores é arbitrário, e não apresenta nenhuma relação com conteúdo. Já que o significado simbólico de cores é diferente de cultura para cultura, preferimos utilizar cores apenas para diferenciar as tags e linhas, e no caso do hover e seleção, para diferenciar as músicas.

As 10 cores escolhidas são baseadas na recomendação de Ware [2012], que sugere um conjunto de 12 cores para diferenciar dados. Com exceção de preto, branco (usados no fundo e no texto), e marrom (usamos verde escuro), o conjunto sugerido é bastante similar ao conjunto utilizado no protótipo, com pequenas variações.

\section{Tipografia}

Escolhemos Helvetica Neue ou Arial, padrão em vários navegadores (Internet Explorer, Chrome, Firefox e Safari), tipo de boa legibilidade a 12 pixels (usuários podem aumentar o tamanho do texto usando os controles do navegador).

O número de tags exibidas é no máximo 10 tags. Esse número foi definido através de dois critérios:

- Número de tags (tamanho 12 pixels ou aumentado no navegador) que pode ser confortavelmente exibido numa tela de 800X600 pixels, considerado tamanho mínimo de desktops, laptops e tablets.

- Número de cores aplicadas para cada tag. Para diferencias as tags e linhas, o número de cores deve ser limitado, já que usuários tem dificuldade de diferenciar um número maior que 10 cores [Ware, 2012].

\section{Necessidades do usuário:}

Filtragem ou revisão de recomendações (inspeção)

Ao interagir com recomendações, usuários preferem sistemas que permitem filtragem de recomendações (inspeção). Usuários descrevem músicas através de estilos musicais, emoções, ou contexto. [Lee e Downie, 2004; Kim e Belkin, 2002] Assim, usuários preferem um sistema que oferece filtragem através desses atributos.

\section{Solução:}

A partir das tags, usuários podem filtrar recomendações. Tags devem ser clicáveis, e permitir multiseleção (selecionar mais de uma tag). Ao clicar em uma tag, a lista de recomendações deve ser filtrada para oferecer músicas que contém a tag no topo da lista. Se mais de uma tag é clicada, um 
cálculo de similaridade é efetuado entre cada música e tags, e a lista de recomendações é apresentada em ordem de maior para menor relevância. Explicamos o cálculo de similaridade no capítulo 5, sobre implementação.

Em Tag Strings, tags são apresentadas como botões, com um gradiente no fundo para enfatizar que as tags são clicáveis. Ao passar o cursor sobre uma tag, as linhas (que as ligam com músicas) ficam mais opacas, e as linhas restantes ficam mais transparentes. Desta forma, a tag que interessa ao usuário recebe destaque visual (cores mais vibrantes) e evidencia a relação de uma tag com músicas sem precisar clicá-las (figura 4.5). O mesmo ocorre quando um usuário passa o cursor sobre uma música: linhas são mostradas entre a música e tags relacionadas.

Quando uma tag é selecionada, ela move para o topo da lista, e as linhas e músicas relacionadas tomam a cor da tag selecionada, destacando o grupo visualmente.

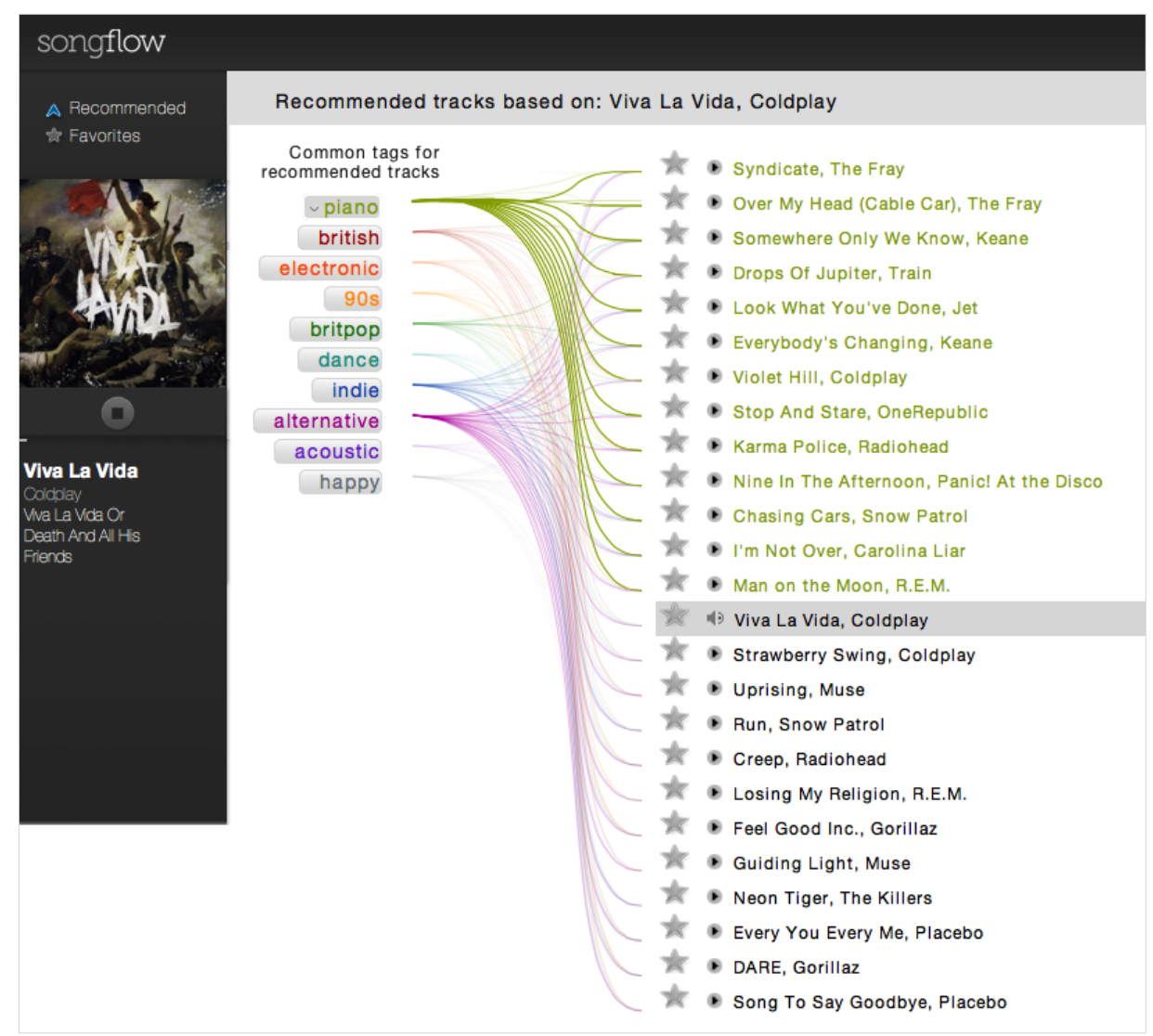

Figura 4.5: Telas do protótipo Tag Strings, na versão final, tag selecionada

\section{Necessidades do usuário:}




\section{Diversão e facilidade de uso (satisfação)}

Ao usar sistemas de recomendação de música, usuários preferem interfaces divertidas e fáceis de usar (satisfação).

\section{Solução:}

Tag Strings usa cores e linhas com curvas para criar uma interface atraente. Ao mesmo tempo que é visualmente diferente, a interface possui muitas características familiares ao usuário, como o uso de navegação à esquerda e a lista de músicas à direita [Tidwell, 2010]. A familiaridade ajuda a simplificar o uso e aprendizado da interface.

\subsection{Exemplos de Designs Conceituais e Critérios de Seleção}

Durante o processo de design, criamos vários conceitos e avaliamos qual era o mais promissor. A escolha final, detalhada nas seções anteriores, foi Tag Strings. Para ilustrar o processo de seleção, mostramos 6 conceitos criados durante o processo e as vantagens e desvantagens observados.

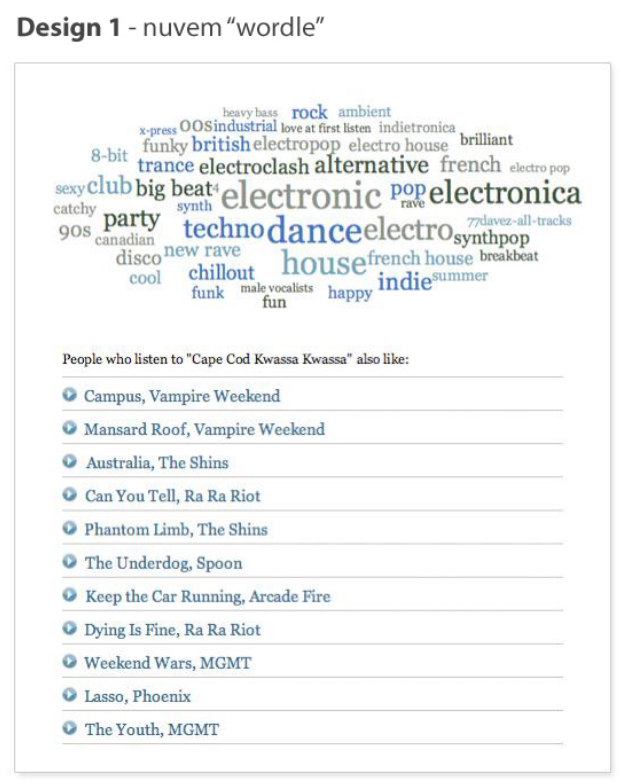

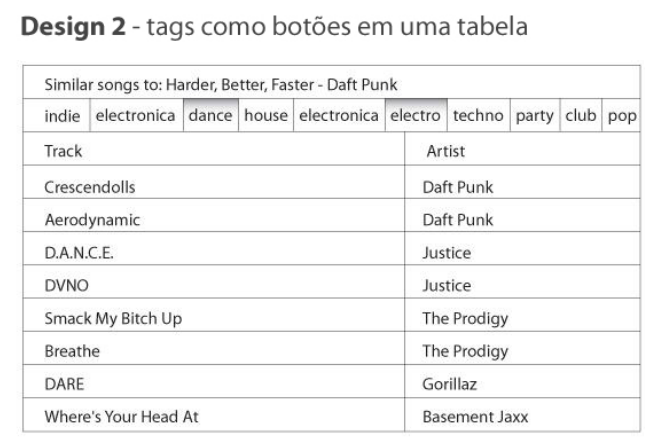

Figura 4.6 Design 1, uma nuvem Wordle, e Design 2, tags como botóes em uma tela.

\section{Design 1: Nuvem Wordle}

Wordle ${ }^{17}$ é uma ferramenta online que cria nuvens de palavras a partir de texto fornecido pelo usuário. O tamanho das letras na nuvem corresponde a frequência das palavras no texto.

\footnotetext{
${ }^{17}$ http://wordle.net, sep 2011
} 
Um exemplo de uma nuvem de palavras criadas com Wordle:

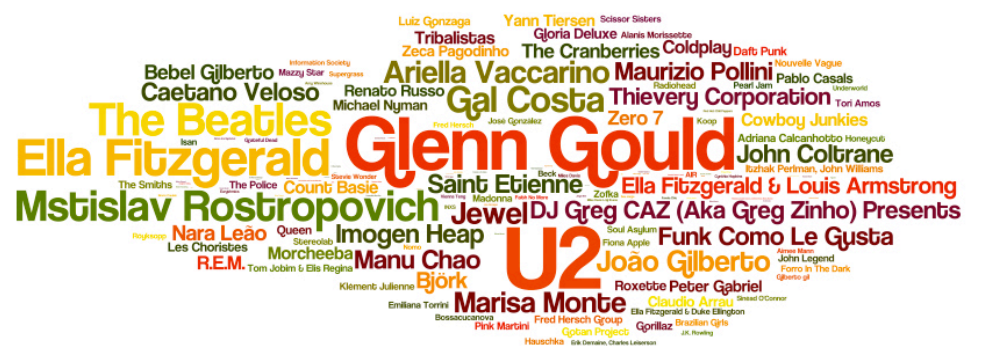

Figura 4.7: Exemplo de uma Nuvem "Wordle"

Prós

- Mostra claramente quais tags são mais relevantes para o conjunto de músicas recomendadas (tags maiores são mais relevantes)

Contras:

- Falta hierarquia de conteúdo, em que as tags tomam muito espaço e importância na tela, e o conteúdo principal (músicas) acaba escondido.

- Halvey e Keane [2007] mostram que listas de tags são lidas mais rápido do que nuvens de tags.

- Não mostra a relação entre as tags com cada música, apresentando um problema semelhante a Music Explaura, projeto citado no capítulo 3. Em Music Explaura [Green et al., 2009], usuários não conseguiam relacionar as tags com as músicas recomendadas, não cumprindo o objetivo de utilizar tags para explicar e filtrar recomendações.

\section{Design 2: Tags como botões em uma tabela}

Prós:

- Design compacto com hierarquia correta, em que tags ocupam menos espaço que as músicas, e ambas são exibidas na tela.

\section{Contras:}

- O sistema pressupõe que usuários podem fazer seleções múltiplas (por exemplo, selecionar as tags "happy" e "folk"). Raramente se usa botões para fazer múltiplas seleções, que é potencialmente confuso para usuários.

- número de tags que pode ser exibido é muito limitado, já que existe um limite espaço na largura de tela, e algumas tags são bastante longas.

- Não mostra a relação entre as tags com cada música, apresentando um problema 
semelhante a Music Explaura, projeto citado no capítulo 3. Em Music Explaura [Green et al., 2009], usuários não conseguiam relacionar as tags com as músicas recomendadas, não cumprindo o objetivo de utilizar tags para explicar e filtrar recomendações.

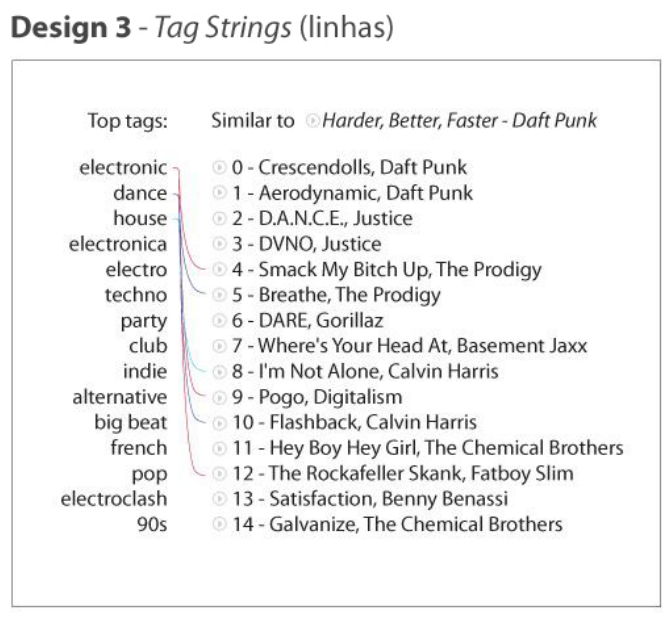

Design 4 - Checkboxes (caixas de seleção)

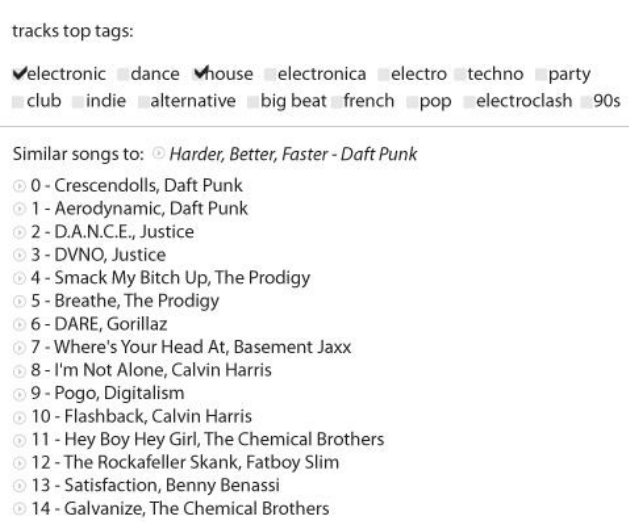

Figura 4.8: Exemplos de conceitos explorados, design 3 e 4

\section{Design 3: Tag Strings (linhas)}

Prós:

- Mostra relação entre as tags com cada música, e vice-versa.

- Halvey e Keane [2007] mostram que listas de tags são lidas mais rápido do que nuvens de tags.

Contras:

- Comparado com outros designs, não mostra tão claramente quais tags são mais populares;

\section{Design 4: Checkboxes (caixas de seleção)}

Prós:

- Design compacto com hierarquia correta, em que tags ocupam menos espaço que as músicas, e ambas são exibidas na tela.

- Usuários tem familiaridade com caixas de seleção e seleção múltipla; 


\section{Contras:}

- Não mostra a relação entre as tags com cada música, apresentando um problema semelhante a Music Explaura, projeto citado no capítulo 3. Em Music Explaura [Green et al., 2009], usuários não conseguiam relacionar as tags com as músicas recomendadas, não cumprindo o objetivo de utilizar tags para explicar e filtrar recomendações.
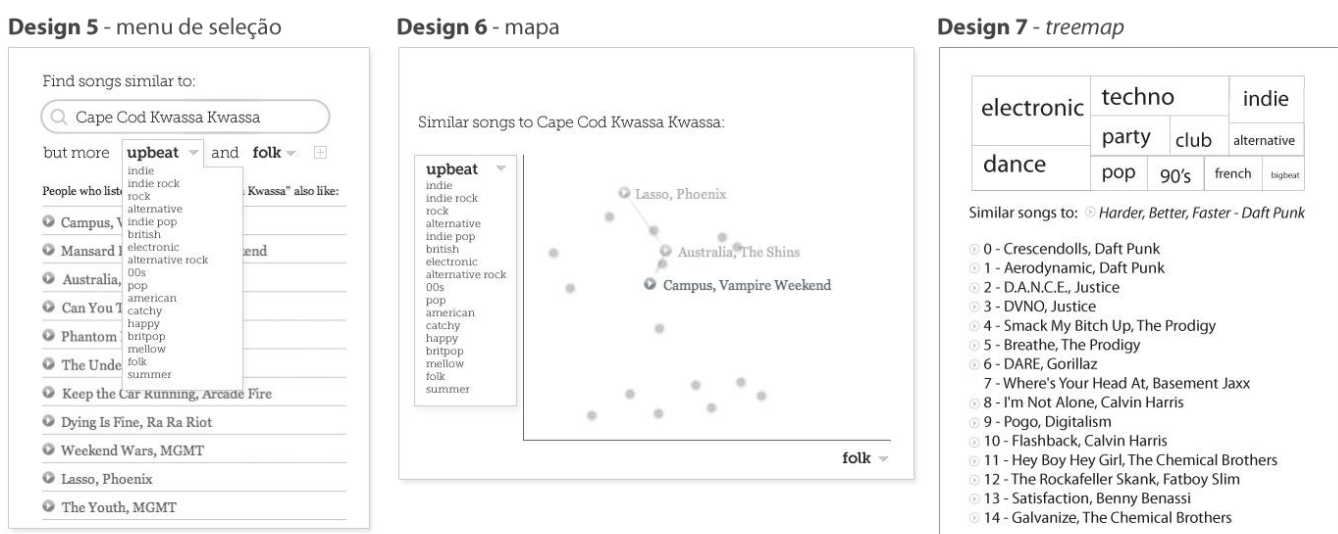

Figura 4.9: Exemplos de conceitos explorados, designs 5, 6 e 7

\section{Design 5, menu de seleção}

Prós:

- Design compacto com hierarquia correta, em que tags ocupam menos espaço que as músicas, e ambas são exibidas na tela.

- O convite para revisar a recomendação é mais direto.

\section{Contras:}

- Esconde a maioria das tags; usuários precisam selecionar o menu de seleção para ver outras tags disponíveis.

- Não mostra a relação entre as tags com cada música, apresentando um problema semelhante a Music Explaura, projeto citado no capítulo 3. Em Music Explaura [Green et al., 2009], usuários não conseguiam relacionar as tags com as músicas recomendadas, não cumprindo o objetivo de utilizar tags para explicar e filtrar recomendações .

\section{Design 6: Mapa}

Prós:

- Mostra relações de similaridade entre todas as recomendações. 


\section{Contras:}

- Esconde a maioria das tags e as músicas.

- Só permite duas combinações de tags em cada vez;

- Para ler o título e artista de uma música, o usuário precisa pousar o cursor sobre um ponto (bover).

- Não mostra a relação entre as tags com cada música, apresentando um problema semelhante a Music Explaura, projeto citado no capítulo 3. Em Music Explaura [Green et al., 2009], usuários não conseguiam relacionar as tags com as músicas recomendadas, não cumprindo o objetivo de utilizar tags para explicar e filtrar recomendações .

\section{Design 7: Treemap}

Treemaps são uma técnica de visualização adotada por Johnson e Shneiderman (1991), para representar árvores em duas dimensões. Nesta exemplo, uma árvore de diretórios é representada por subdivisões do retângulo na tela.

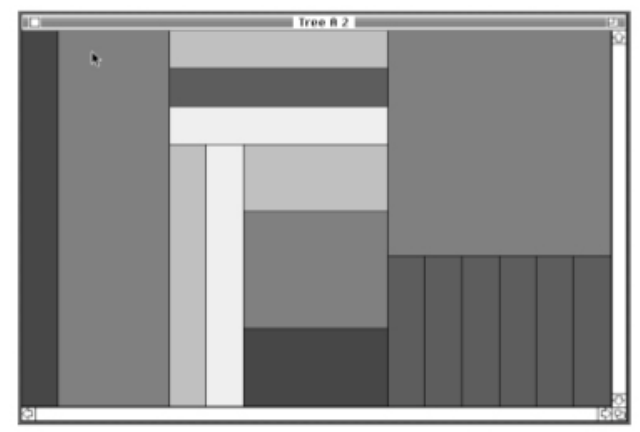

Figura 4.10: Exemplo de um Treemap. [Johnson e Shneiderman, 1991].

Prós:

- Mostra claramente quais tags são mais relevantes para o conjunto de músicas recomendadas (tags maiores são mais relevantes)

\section{Contras:}

- Falta hierarquia de conteúdo, em que as tags tomam muito espaço e importância na tela, e o conteúdo principal (músicas) acaba escondido.

- Não mostra a relação entre as tags com cada música, apresentando um problema semelhante a Music Explaura, projeto citado no capítulo 3. Em Music Explaura [Green et al., 2009], usuários não conseguiam relacionar as tags com as músicas recomendadas, não cumprindo o objetivo de utilizar tags para explicar e filtrar recomendações. 


\section{Iterações em Tag Strings para os Experimentos 2 e 3}

Ao escolher Tag Strings, o design passou por iterações e a versão final é descrita na seção 4.4. Algumas observações sobre as iterações seguem abaixo:

- No design utilizado para os avaliação inicial e experimento 1, utilizamos Tag Strings com o fundo cinza escuro. Durante os testes, o fundo escuro não agradou alguns usuários, que acharam que o fundo escuro afetava a legibilidade. Assim, utilizamos um fundo claro no design para os Experimentos 2 e 3.

- Inicialmente, a interface apresentou 25 tags, mas para simplificar a interface, o número diminuiu para 10 tags.

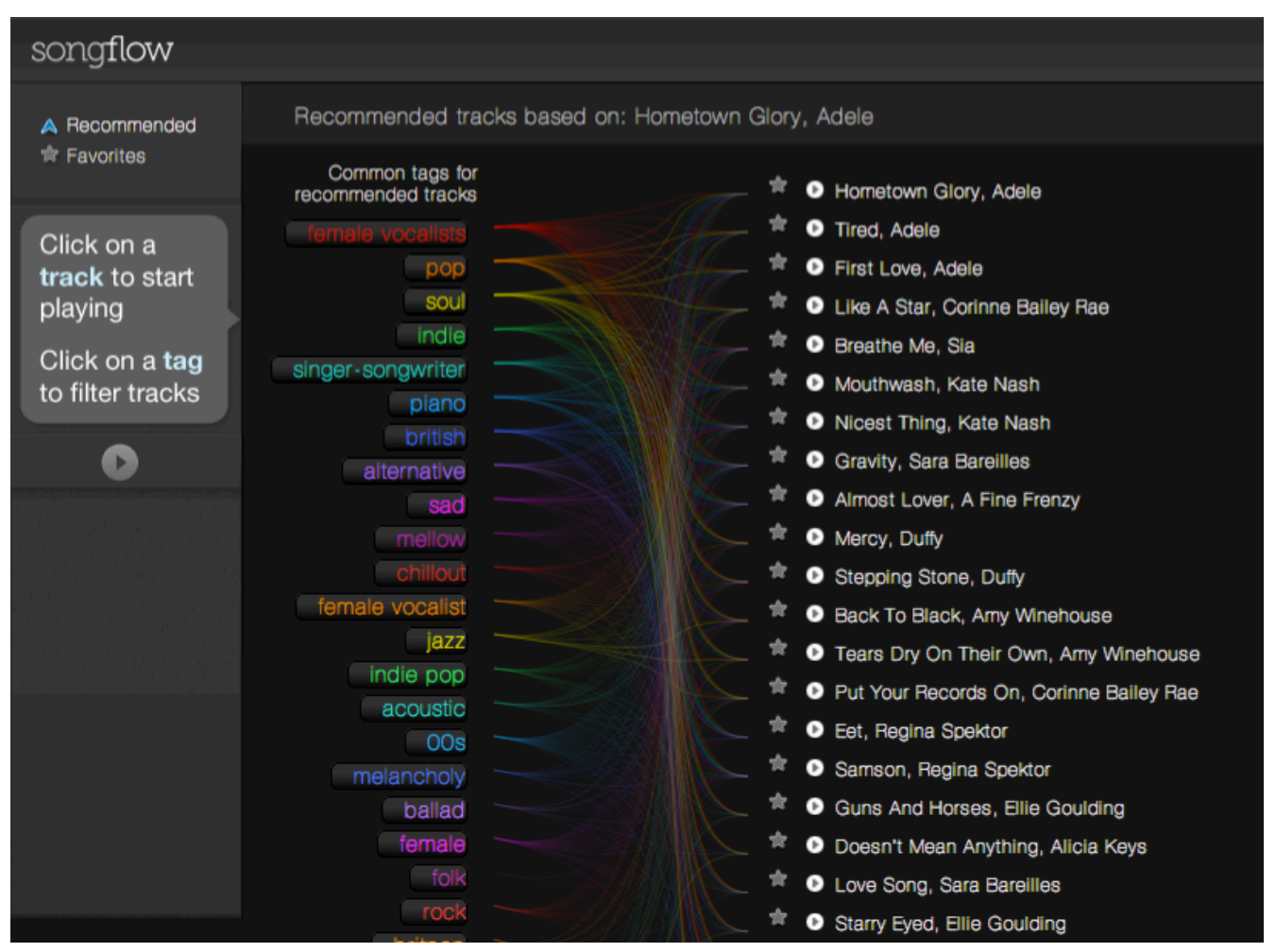

Figura 4.11: Tela de Tag Strings utilizada no Experimento 1. 
Projetando e Desenvolvendo Visualizações de Tags

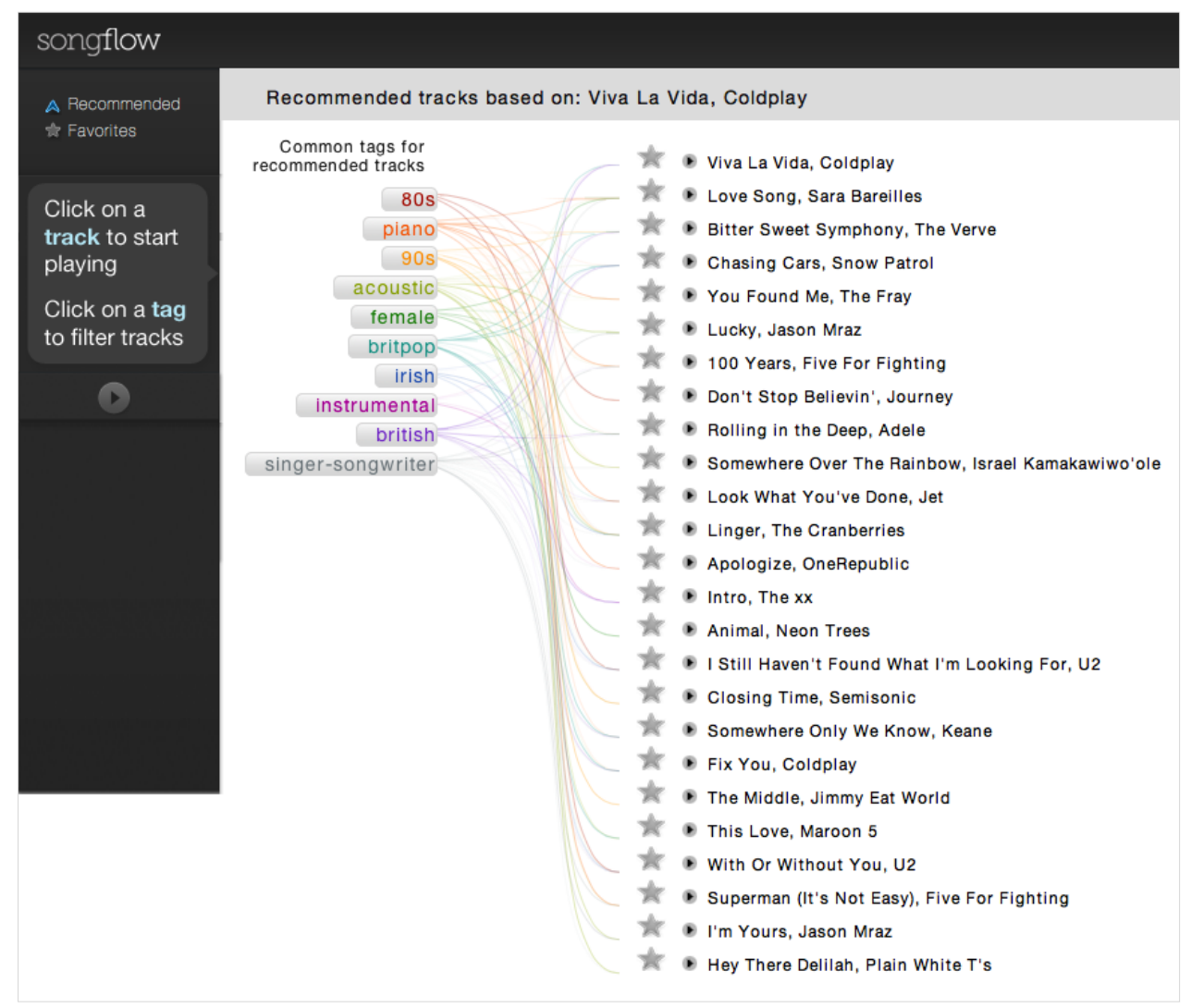

Figura 4.12: Tela de Tag Strings, versão revisada e usada nos Experimentos 2 e 3.

Nesse capítulo apresentamos o perfil do usuário, suas necessidades e requisitos do sistema. Mostramos como o uso de tags nos levou a explorar visualizações de tags como solução para a interface. Detalhamos e justificamos o design Tag Strings, escolhido para o protótipo. Também apresentamos outros conceitos de designs criados durante a fase exploratória, e sua avaliação. 


\section{Capítulo 5}

\section{Protótipo para o Espaço de Testes}

O espaço de testes foi implementado para gerar explicações com tags, usando Java para o processamento da tags, HTML5 e Javascript para a interface.

Escolhemos a interface (api) do serviço Last.fm por oferecer tanto recomendações para músicas, quanto tags para cada música. Com base na explicação oferecida pelo serviço Last.fm ("People who listen to this also like:" - "Usuários que escutam essa música também escutam:"), supomos que o sistema de recomendação de Last.fm seja baseado em filtragem colaborativa.

\subsection{Fluxo do Usuário}

- Usuário escolhe uma música como "semente" para buscar recomendações;

- Uma lista de 50 recomendações é recuperada do sistema. Apenas as 20 primeiras músicas da lista de recomendação são exibidas ao usuário;

- Tags são recuperadas para cada música, e combinadas para criar uma visualização de tags. Essa visualização pode ser usada para explicar e filtrar as recomendações;

- Usuários podem selecionar tags para filtrar as recomendações, e revelar músicas recomendadas que não foram exibidas entre as 20 primeiras músicas. 

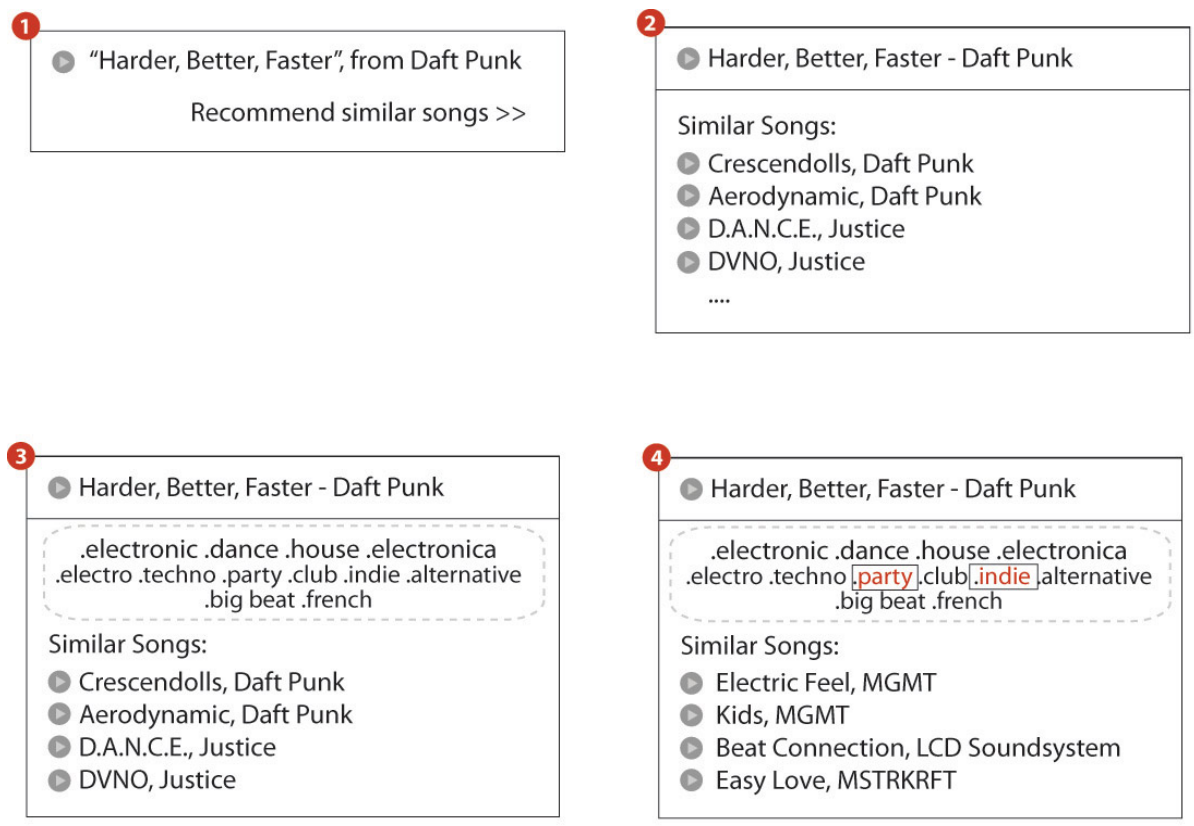

Figura 5.1: Diagrama do fluxo do usuário.

\subsection{Implementação de Tag Strings}

Tag Strings usa Java para o recuperar e pré-processar as recomendações e tags. A interface e visualização são construídas usando HTML5 e Javascript. A tabela de similaridade e o vetor de tags do usuário são calculados usando Javascript.

Usuários podem ouvir trechos de músicas (30 segundos) através da interface (api) Rdio ${ }^{18}$, com Adobe Flash. Rdio.com é um serviço de música por assinatura que durante os experimentos, não estava disponível no Brasil. Desse modo, os experimentos foram efetuados com usuários nos Estados Unidos. Metadados adicionais, como capas de álbuns, também são fornecidos pela interface (api) Rdio.

O processo funciona da seguinte forma:

O sistema de recomendação (1) gera a lista de recomendações(2). Para este protótipo, utilizamos Last.fm, mas outros serviços podem ser utilizados;

Para cada recomendação, tags são recuperadas através de um serviço (3) que oferece tags para músicas(4). Para este protótipo, utilizamos Last.fm;

Os dados de tags são processados(5) para calcular a relevância das tags (e a ordem em que são apresentadas);

\footnotetext{
${ }^{18} \mathrm{http} / /$ www.rdio.com
} 
A visualização de tags é exibida para explicar e filtrar as recomendações(6).

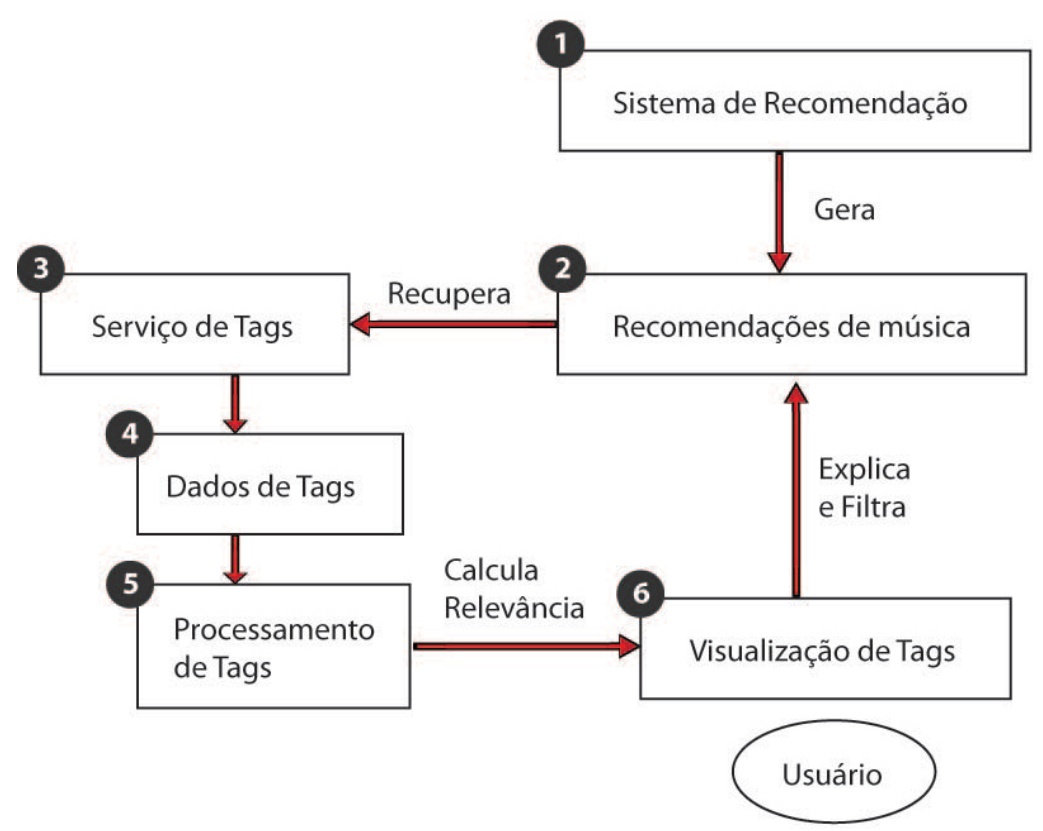

Figura 5.2: Diagrama da implementação de Tag Strings.

\subsection{Processamento de Tags}

Após a coleta dos dados de tags, a relevância é calculada para que somente as $n$ tags mais relevantes sejam exibidas para filtrar as recomendações.

Inicialmente, as tags são convertidas em letras minúsculas, e as palavras irrelevantes (stopwords) são removidas. Exemplos de palavras irrelevantes usadas neste caso são "great", "favorite", que são tags pessoais.

Em pesquisa sobre o uso de tags, Sen et al. [2006] mostram que usuários preferem tags factuais e não gostam de tags pessoais, com 67\% destes preferindo não ver tags pessoais. Resultado semelhante foi encontrado em estudo sobre o uso do serviço Last.fm. Chen et al., [2010] descrevem como participantes da pesquisa criticaram tags que não descrevem músicas (por exemplo, como "great" ou "favorite"), por serem genéricas demais, e portanto, inúteis para outros usuários.

Também removemos nomes de artistas ou músicas presentes na lista de recomendação. Por exemplo, para uma música como "Help" dos “The Beatles", é comum que usuários apliquem tags como “belp”, "beatles", que não são úteis, pois duplicam metadados do sistema.

Calculamos então tag_share. uma medida de frequência de tags usada para calcular seus pesos. Usamos a definição de tag_share de Vig et al.[2009]: 
"A tag_share de uma tag $t$ aplicada a um item $i$ é o número de vezes que $t$ foi aplicada a $i$, divido pelo número de vezes que qualquer tag tenha sido aplicada a $i$. Indicamos esse valor como tag_share $(\mathrm{t}, \mathrm{i}) . "$

Apesar de usarmos o valor de tag_share como parte do cálculo de relevância, nossa abordagem difere de Vig. Em filmes, faz sentido exibir apenas a tag_share da semente, pois é comum que usuários busquem apenas um filme para assistir. Com música, usuários buscam um conjunto de itens, já que geralmente, usuários escutam listas de músicas. Nosso objetivo é encontrar tags relevantes à um grupo de itens recomendados, e não relevantes apenas à semente. Assim, para estimar a relevância das tags, calculamos tag_list_relevance.

A tag_list_relevance é uma medida de relevância de tags em relação a uma lista de músicas recomendadas. Seja $\mathrm{R}$ um conjunto de itens $i$ numa lista de recomendações, e $\mathrm{T}$ o conjunto de todas as tags aplicadas a cada item $i$ em R. Para cada tag t, tag_list_relevance é a soma de tag_share de todas as tags $t$ em R. Tags no conjunto T são então reordenadas por tag_list_relevance, e as $n$ tags mais relevantes são utilizadas na visualização.

Para a avaliação e Experimentos 1, utilizamos tag_share e tag_list_relevance para calcular a relevância de tags, e exibimos 25 tags para cada conjunto de recomendações.

\subsection{Melhorando a Relevância de Tags}

Em estudo sobre tags utilizadas no serviço MovieLens, Sen et al. [2006], classificam tags em 3 categorias:

- Tags factuais - definidas como tags que a maioria das pessoas concordariam que se aplica de fato a um filme. Tags factuais ajudam a descrever um filme e encontrar filmes relacionados.

- Tags subjetivas - definidas como tags que expressam as opiniões de um usuário sobre um filme, e podem ser utilizadas para avaliar recomendações.

- Tags pessoais - que tem como público o usuário que aplicou a tag (alguns usuários, por exemplo, usam seu login como tag). Utilizadas muitas vezes para organizar os filmes de um usuário, tags pessoais nem sempre são úteis para outros usuário.

Dos três tipos de tags, Sen et al. [2006] mostram que usuários preferem tags factuais e subjetivas, e não gostam de tags pessoais.

Em estudo sobre o comportamento de usuários e tags no serviço Last.fm, Chen et al. [2010] observam que os 3 tipos de tags mais utilizadas descrevem estilos musicais, emoções, ou estão relacionadas a biografia do artista. Usuários entrevistados na pesquisa buscavam filtrar músicas e 
artistas com mais de uma tag, e todos os participantes acharam que tags muito genéricas ou comuns podem confundir usuários com muitos resultados, não sendo nem específicos ou relevantes.

Para melhorar a interface de Tag Strings procuramos reduzir o número de tags exibidas, para não sobrecarregar usuários com muita informação. Durante a avaliação inicial e Experimento 1, a interface exibia 25 tags. Para os Experimentos 2 e 3, o objetivo foi reduzir o número de tags para 10.

Para melhorar a relevância do conjunto de tags, eliminamos tags pessoais com a lista de stopwords, e consideramos dois critérios: popularidade de uma tag, e o número de itens filtrados por uma tag.

Se uma tag foi aplicada muitas vezes a uma música (tag count), provavelmente é uma tag popular. Vig et al. (2009) utilizam uma medida semelhante, selecionando tags que foram aplicadas por pelo menos um certo número de usuários. Infelizmente, Last.fm não nos dá acesso a essa informação, mas pode-se assumir que usuários não aplicam a mesma tag repetidamente a uma mesma música, e se isso ocorre, é muito incomum.

Se uma tag foi aplicada a muitas músicas diferentes (dentre o conjunto de músicas recomendadas), provavelmente é popular dentre esse conjunto. Mas se a tag foi aplicada a todas as músicas nesse conjunto de recomendações, a tag não é útil para filtrar as músicas, já que tags genéricas ou comuns não são úteis para usuários [Chen et al., 2010, e Lamere, 2008].

Um dos motivos mais importantes para usar tags nesta pesquisa é permitir que usuários filtrem as músicas e melhoram a meta de inspeção. Assim, procuramos equilibrar esses fatores quando calculamos a relevância de tags.

\subsection{Frequência Inversa de Documentos Aplicada a Relevância de Tags}

Usamos a frequência inversa de documentos para melhorar a relevância de tags em uma lista de recomendações. O objetivo é aumentar não só a relevância de tags populares, mas também de tags que são mais úteis na filtragem de músicas recomendadas.

Aplicamos a técnica de Green et al. [2009], que usa frequência inversa do documento para calcular relevância de tags. Em recuperação de informação, a frequência inversa de documentos é utilizada para resolver o seguinte problema: certos termos tem pouco poder de discriminar resultados, por estarem presentes em muitos documentos [Manning et al., 2008].

Green e Lamere descrevem como certas tags, como "rock" e "alternative" são aplicadas a muitos artistas, e por isso não são muito descritivas ou discriminantes [Green et al., 2009, Lamere, 2008]. Lamere também descreve como certas tags que são aplicadas com muita frequência, como "rock", tendem a dominar certas técnicas de similaridade. Tanto Green e Lamere recomendam a 
combinação de frequência de termos com a frequência inversa de documentos para a melhora de relevância de tags. Assim, além do cálculo de tag_share e tag_list_relevance, utilizamos a frequência inversa de documentos para calcular o relevância de tags.

Após testar diferentes variações de combinações, usamos tag_list_relevance e frequência inversa de documentos [Manning et al., 2008]. Para tal, calculamos tag_share. Como definido anteriormente, tag_share é uma medida de frequência de tags usada para calcular seus pesos. Usamos a definição de tag_share de Vig et al. [2009]:

“A tag_share de uma tag $t$ aplicada a um item $i$ é o número de vezes que $t$ foi aplicada a $i$, divido pelo número de vezes que qualquer tag tenha sido aplicada a $i$. Indicamos esse valor como tag_share(t,i)."

A partir de tag_share, calculamos tag_list_relevance. A tag_list_relevance é uma medida de relevância de tags em relação a uma lista de músicas recomendadas. Seja $\mathrm{R}$ um conjunto de itens $i$ numa lista de recomendações, e $\mathrm{T}$ o conjunto de todas as tags aplicadas a cada item $i$ em $\mathrm{R}$. Para cada tag t, tag_list_relevance é a soma de tag_share de todas as tags t em R.

Tag_list_relevance é então combinada com a frequência inversa do documento da seguinte forma:

Seja $\mathrm{R}$ um conjunto de itens $i$ em uma lista de recomendações. Para cada tag $t$, a relevância tag_relevance é:

$$
\text { tag_relevance }=\text { tag_list_relevance }{ }^{*} \log (\mathrm{D} / f t)
$$

onde $\mathrm{D}$ é o número total de itens no conjunto $\mathrm{R}$, e $f t$ é o número de itens em que a tag $t$ está presente.

Tags no conjunto T são então reordenadas por tag_relevance, e as $n$ tags mais relevantes são utilizadas na visualização.

Uma das dificuldades de usar frequência inversa de documentos é aumentar a relevância de tags muito incomuns (por exemplo, "soundtrack of my life"). Para evitar esse problema, calculamos o número total de tags, e removemos todas as tags que foram aplicadas a menos que $0.5 \%$ do número total de tags. O objetivo é remover um número proporcional de tags, já que algumas música são extremamente populares e tem um número muito grande de tags. Músicas que são menos populares tem o número muito menor de tags, mesmo para as mais populares.

\subsubsection{Agrupando Tags Semelhantes}

Consideramos usar radicalizadores (stemmers) para agrupar tags semelhantes, mas existem várias dificuldades com esse tipo de abordagem. Por exemplo, estilos musicais como "electro" e "electronic" tem as mesmas raízes, mas são muito diferentes. Como descrito por Levy e Sandler [2009], tags sociais são em grande parte substantivos, em que radicalizadores não são muito úteis. 
Também decidimos não criar um thesaurus, já que tags não se aplicam só a estilos musicais, e são muito difíceis de combinar, por não serem consistentes [Lamere, 2008]. Como alternativa, usamos a técnica utilizada por Levy e Sandler [2009] para transformar as tags em "tokens". Desse modo, tags como "female vocalist", "jazz female singer", etc., podem ser combinadas com a tag "female".

\subsubsection{Filtrando Recomendações Através de Tags}

A visualização é construída com as $n$ tags mais relevantes. No Experimento 1, a relevância é baseadas em tag_list_relevance. Para os Experimentos 2 e 3, a relevância é calculada através de tag_relevance.

- Usuários podem selecionar múltiplas tags;

- A seleção de tags cria um vetor user_tag_vector,

- O vetor user_tag_vector é então utilizado para calcular a similaridade com as músicas recomendadas;

- Para ordenar as músicas, utilizamos a similaridade de cosseno;

- Músicas são reordenadas e exibidas com base na similaridade das músicas e o vetor user_tag_vector.

\subsubsection{Cálculo da Similaridade entre Músicas e o Vetor de Tags:}

Usamos a abordagem de Green et al.[2009] para calcular a similaridade entre recomendações e tags selecionadas pelo usuário.

Green et al.[2009] empregam uma variação da representação do espaço vetorial utilizado em sistemas de recuperação de informação. Uma música é representada por um vetor de comprimento $\mathrm{N}$, onde $\mathrm{N}$ é o número de termos únicos. Cada componente do vetor é o peso de um termo que mede a importância deste para cada documento. Na abordagem de Green, os termos sobre cada item são gerados através de texto recolhido da web. A vantagem dessa abordagem é que se pode utilizar técnicas bem conhecidas de recuperação de informação para lidar com os termos.

Neste projeto, os itens são as músicas na lista de recomendação, e os termos sobre cada item são tags recolhidas através do serviço Last.fm.

No modelo de espaço vetorial um documento é representado como vetores de termos. O peso para cada termo é determinado pela frequência do termo em um documento. [Manning et al., 2008]. Neste trabalho, cada música corresponde a um documento, e as tags correspondem aos termos. O número de vezes que uma tag é aplicada a uma música corresponde ao peso do termo no documento. 
Por exemplo, na tabela abaixo, a música $x$ recebeu as 3 tags "rock", 2 tags "progressive”, 1 tag "guitar", 2 tags "sad". A música y recebeu uma tag "rock", e uma tag "sad".

\begin{tabular}{|l|l|l|l|l|}
\hline Documento & rock & progressive & guitar & sad \\
\hline Música $x$ & 3 & 2 & 1 & 2 \\
\hline Música $y$ & 1 & 0 & 0 & 1 \\
\hline
\end{tabular}

Tabela 5.1: Músicas como documentos, e tags como termos e suas frequências

Para calcular a similaridade entre as músicas $x$ e $y$, usamos a medida de similaridade do cosseno (cosine similarity) Tan et al., [2006]. A medida de similaridade do coseno pode ser calculada com:

$$
\operatorname{Cos}(\mathrm{x}, \mathrm{y})=\mathrm{x} \cdot \mathrm{y} /\|\mathrm{x}|||| \mathrm{y}\|
$$

Um usuário pode ser modelado como um documento, onde os termos são as tags (tags selecionadas pelo usuário). Isso permite o cálculo da similaridade entre usuário e as músicas recomendadas (Tabela 5.2).

\begin{tabular}{|l|l|l|l|l|}
\hline Documento & rock & progressive & guitar & sad \\
\hline Música $x$ & 3 & 2 & 1 & 2 \\
\hline Música $y$ & 1 & 0 & 0 & 1 \\
\hline $\begin{array}{l}\text { Tags selecionadas } \\
\text { pelo usuário }\end{array}$ & 0 & 1 & 0 & 1 \\
\hline
\end{tabular}

Tabela 5.2: Músicas e usuário como documentos, e tags como termos

Por exemplo, um usuário seleciona as tags: "sad", "progressive rock". Isso corresponde a um vetor user_tag_vector $\{0,1,0,1\}$. Calculamos a similaridade desse vetor com cada música na lista de recomendação, e a partir da similaridade, a lista é reordenada e exibida ao usuário [Green et al., 2009].

\subsection{Experimento com Relevância de Tags}




\section{Conjunto de dados selecionados para experimento:}

Escolhemos um conjunto de 29 músicas de 14 estilos (a lista de estilos escolhida é a mesma do trabalho de Knees, Pampalk e Widmer [Knees et al., 2004]. Os estilos são: blues, classical, country, electronic, folk, hip-hop, indie, jazz, metal, punk, pop, rEbb, rock, reggae.

Cada música foi selecionada do serviço Last.fm, buscando pelas músicas ou artistas mais populares em cada um dos estilos. Esta informação foi recuperada em 11 de abril de 2012, com o objetivo de selecionar músicas de diferentes estilos e épocas. A lista completa consta no anexo.

\subsubsection{Métricas para Avaliação}

O experimento tinha como objetivo aumentar o número de músicas filtradas através da escolha de tags mais discriminantes. Portanto, usamos o número de músicas filtradas como métrica de avaliação. Para comparar os diferentes cálculos de relevância, comparamos tags coletadas para o conjunto de dados, sem frequência inversa de documentos, e com frequência inversa de documentos.

O teste foi efetuado em um conjunto de 29 músicas. Calculamos então o número de músicas filtradas em cada versão, e usamos esse número para avaliar qual versão seleciona as tags mais discriminantes.

\subsubsection{Resultados e Análise}

A tabela mostra o número total de músicas filtradas através das 10 tags mais relevantes. Em todos os exemplos escolhidos, o cálculo de relevância com fid (frequência inversa de documentos) filtra um número maior de músicas do que o cálculo sem frequência inversa de documentos.

\begin{tabular}{|l|l|l|l|}
\hline Música, artista, e estilo & Sem fid & Com fid & \% filtrada \\
\hline The Thrill Is Gone, B.B. King (blues) & 231 & 271 & 17.32 \\
\hline These Days, The Black Keys (blues) & 234 & 323 & 38.03 \\
\hline Für Elise, Ludwig van Beethoven (classical) & 247 & 277 & 12.15 \\
\hline Clair de lune, Claude Debussy (classical) & 324 & 350 & 8.02 \\
\hline
\end{tabular}




\begin{tabular}{|c|c|c|c|}
\hline I Walk The Line, Johnny Cash (country) & 205 & 309 & 50.73 \\
\hline Ours, Taylor Swift (country) & 292 & 365 & 25.00 \\
\hline Where the Boats Go, M83 (electronic) & 259 & 359 & 38.61 \\
\hline $\begin{array}{l}\text { Harder, Better, Faster, Stronger, Daft Punk } \\
\text { (electronic) }\end{array}$ & 148 & 282 & 90.54 \\
\hline Like a Rolling Stone, Bob Dylan (folk) & 130 & 236 & 81.54 \\
\hline Skinny Love, Bon Iver (folk) & 167 & 187 & 11.98 \\
\hline All of the Lights, Kanye West (hip hop) & 276 & 280 & 1.45 \\
\hline Can I Kick It?, A Tribe Called Quest (hip hop) & 94 & 185 & 96.81 \\
\hline Somebody That I Used To Know, Gotye (indie) & 216 & 303 & 40.28 \\
\hline $\begin{array}{l}\text { I Will Follow You Into The Dark, Death Cab for } \\
\text { Cutie (indie) }\end{array}$ & 151 & 247 & 63.58 \\
\hline So What, Miles Davis (jazz) & 236 & 297 & 25.85 \\
\hline Strange Fruit, Billie Holiday (jazz) & 229 & 321 & 40.17 \\
\hline Chop Suey!, System of a Down (metal) & 133 & 294 & 121.05 \\
\hline Run To The Hills, Iron Maiden (metal) & 204 & 340 & 66.67 \\
\hline London Calling, The Clash (punk) & 262 & 365 & 39.31 \\
\hline Boulevard Of Broken Dreams, Green Day (punk) & 148 & 239 & 61.49 \\
\hline Billie Jean, Michael Jackson (pop) & 154 & 263 & 70.78 \\
\hline Alejandro, Lady Gaga (pop) & 100 & 290 & 190.00 \\
\hline Love on Top, Beyoncé (r\&b) & 194 & 274 & 41.24 \\
\hline We Found Love, Rihanna (r\&b) & 311 & 320 & 2.89 \\
\hline Come Together, The Beatles (rock) & 123 & 237 & 92.68 \\
\hline Californication, Red Hot Chili Peppers (rock) & 137 & 261 & 90.51 \\
\hline Viva La Vida, Coldplay (rock) & 160 & 245 & 53.13 \\
\hline
\end{tabular}


Protótipo para o Espaço de Testes

\begin{tabular}{|l|l|l|l|}
\hline Bongo Bong, Manu Chao (reggae) & 316 & 341 & 7.91 \\
\hline Three Little Birds, Bob Marley (reggae) & 253 & 292 & 15.42 \\
\hline
\end{tabular}

Tabela 5.3: Número de músicas filtradas

Alguns exemplos das diferenças entre as 10 tags mais relevantes para cada tipo de cálculo (a lista completa se encontra no Apêndice II.

\section{The Thrill Is Gone, B.B. King (blues)}

Neste exemplo, a tag "rock" é substituídas por "psychedelic".

\begin{tabular}{|l|l|}
\hline Sem fid & Músicas filtradas \\
\hline rock & 1 \\
\hline guitar & 9 \\
\hline classic & 7 \\
\hline soul & 30 \\
\hline electric & 18 \\
\hline jazz & 27 \\
\hline 60 s & 28 \\
\hline $50 s$ & 38 \\
\hline delta & 39 \\
\hline rhythm & 34 \\
\hline & \\
\hline Total & 231 \\
\hline
\end{tabular}

\begin{tabular}{|l|l|}
\hline Com fid & Músicas filtradas \\
\hline soul & 30 \\
\hline delta & 39 \\
\hline guitar & 9 \\
\hline 50 s & 38 \\
\hline jazz & 27 \\
\hline 60 s & 28 \\
\hline rhythm & 34 \\
\hline psychedelic & 41 \\
\hline classic & 7 \\
\hline electric & 18 \\
\hline & \\
\hline Total & 271 \\
\hline
\end{tabular}

Tabela 5.4: Tags e músicas filtradas

\section{Harder, Better, Faster, Stronger, Daft Punk (electronic)}

Neste exemplo, as tags "electronica” , "dance”, "electro" e "alternative” são substituídas por "british”, "trip-hop", "synthpop” e "progressive”.

\section{Sem fid}

Músicas filtradas
Com fid

Músicas filtradas 


\begin{tabular}{|l|l|}
\hline electronic & 2 \\
\hline dance & 2 \\
\hline electronica & 3 \\
\hline electro & 2 \\
\hline techno & 14 \\
\hline indie & 26 \\
\hline club & 11 \\
\hline french & 38 \\
\hline alternative & 16 \\
\hline $90 s$ & 34 \\
\hline & \\
\hline Total & 148 \\
\hline
\end{tabular}

\begin{tabular}{|l|l|} 
french & 38 \\
\hline indie & 26 \\
\hline 90s & 34 \\
\hline techno & 14 \\
\hline british & 33 \\
\hline trip-hop & 40 \\
\hline synthpop & 38 \\
\hline electronic & 2 \\
\hline progressive & 33 \\
\hline trance & 24 \\
\hline & \\
\hline Total & 282 \\
\hline
\end{tabular}

Tabela 5.5: Tags e músicas filtradas

\section{Für Elise, Ludwig van Beethoven (classical)}

Neste exemplo, a tag “klassik” é substituídas por “french”.

\begin{tabular}{|l|l|}
\hline Sem fid & Músicas filtradas \\
\hline classical & 4 \\
\hline romantic & 9 \\
\hline instrumental & 15 \\
\hline classic & 17 \\
\hline klassik & 12 \\
\hline baroque & 40 \\
\hline relaxing & 29 \\
\hline russian & 45 \\
\hline german & 33 \\
\hline impressionist & 43 \\
\hline & \\
\hline Total & 247 \\
\hline
\end{tabular}

\begin{tabular}{|l|l|}
\hline Com fid & Músicas filtradas \\
\hline classical & 4 \\
\hline baroque & 40 \\
\hline russian & 45 \\
\hline instrumental & 15 \\
\hline impressionist & 43 \\
\hline romantic & 9 \\
\hline french & 42 \\
\hline classic & 17 \\
\hline german & 33 \\
\hline relaxing & 29 \\
\hline & \\
\hline Total & 277 \\
\hline
\end{tabular}

Tabela 5.6: Tags e músicas filtradas 


\section{Like a Rolling Stone, Bob Dylan (folk)}

Neste exemplo, as tags "classic" , "70s" e "pop” são substituídas por "glam”, "proto-punk" e "acoustic".

\begin{tabular}{|l|l|}
\hline Sem fid & Músicas filtradas \\
\hline rock & 2 \\
\hline classic & 2 \\
\hline $60 s$ & 3 \\
\hline psychedelic & 16 \\
\hline 70 s & 4 \\
\hline folk & 26 \\
\hline british & 28 \\
\hline singer-songwriter & 23 \\
\hline blues & 20 \\
\hline pop & 6 \\
\hline & \\
\hline Total & 130 \\
\hline
\end{tabular}

\begin{tabular}{|l|l|}
\hline Com fid & Músicas filtradas \\
\hline folk & 26 \\
\hline british & 28 \\
\hline singer-songwriter & 23 \\
\hline psychedelic & 16 \\
\hline blues & 20 \\
\hline glam & 47 \\
\hline rock & 2 \\
\hline proto-punk & 41 \\
\hline 60 s & 3 \\
\hline acoustic & 30 \\
\hline & \\
\hline Total & 236 \\
\hline
\end{tabular}

Tabela 5.7: Tags e músicas filtradas

\section{All of the Lights, Kanye West (hip hop)}

Neste exemplo, a tag "2010s” é substituída por “epic”.

\begin{tabular}{|l|l|}
\hline Sem fid & Músicas filtradas \\
\hline hip-hop & 13 \\
\hline rap & 15 \\
\hline hip & 18 \\
\hline hop & 18 \\
\hline pop & 32 \\
\hline rnb & 27 \\
\hline 2011 & 37 \\
\hline $10 s$ & 38 \\
\hline 2010 & 40 \\
\hline
\end{tabular}

\begin{tabular}{|l|l|}
\hline Com fid & Músicas filtradas \\
\hline hip-hop & 13 \\
\hline rap & 15 \\
\hline pop & 32 \\
\hline hip & 18 \\
\hline hop & 18 \\
\hline 2011 & 37 \\
\hline rnb & 27 \\
\hline 2010 & 40 \\
\hline epic & 42 \\
\hline
\end{tabular}




\begin{tabular}{|l|l|}
\hline $2010 s$ & 38 \\
\hline & \\
\hline Total & 276 \\
\hline
\end{tabular}

\begin{tabular}{|l|l|}
\hline $10 \mathrm{~s}$ & 38 \\
\hline & \\
\hline Total & 280 \\
\hline
\end{tabular}

Tabela 5.8: Tags e músicas filtradas

\section{Can I Kick It?, A Tribe Called Quest (hip hop)}

Neste exemplo, as tags "classic” , "biphop”, “coast” e "east" são substituídas por "jazz”, "funk”, "gangsta" e "york".

\begin{tabular}{|l|l|}
\hline Sem fid & Músicas filtradas \\
\hline hip-hop & 2 \\
\hline rap & 2 \\
\hline 90s & 8 \\
\hline classic & 5 \\
\hline hiphop & 4 \\
\hline school & 15 \\
\hline underground & 18 \\
\hline coast & 9 \\
\hline chill & 20 \\
\hline east & 16 \\
\hline & \\
\hline Total & 94 \\
\hline
\end{tabular}

\begin{tabular}{|l|l|}
\hline Com fid & Músicas filtradas \\
\hline hip-hop & 2 \\
\hline 90s & 8 \\
\hline underground & 18 \\
\hline jazz & 33 \\
\hline funk & 31 \\
\hline gangsta & 33 \\
\hline school & 15 \\
\hline chill & 20 \\
\hline rap & 2 \\
\hline york & 23 \\
\hline & \\
\hline Total & 185 \\
\hline
\end{tabular}

Tabela 5.9: Tags e músicas filtradas

\section{Will Follow You Into The Dark, Death Cab for Cutie (indie)}

Neste exemplo, as tags “mellow" , "pop” e "emo" são substituídas por "british”, "canadian” e "electronic".

\begin{tabular}{|l|l|}
\hline Sem fid & Músicas filtradas \\
\hline indie & 5 \\
\hline rock & 7 \\
\hline
\end{tabular}

\begin{tabular}{|l|l|}
\hline Com fid & Músicas filtradas \\
\hline acoustic & 22 \\
\hline folk & 27 \\
\hline
\end{tabular}




\begin{tabular}{|l|l|} 
alternative & 7 \\
\hline acoustic & 22 \\
\hline folk & 27 \\
\hline mellow & 9 \\
\hline singer-songwriter & 26 \\
\hline pop & 9 \\
\hline emo & 22 \\
\hline sad & 17 \\
\hline & \\
\hline Total & 151 \\
\hline
\end{tabular}

\begin{tabular}{|l|l|} 
indie & 5 \\
\hline british & 43 \\
\hline singer-songwriter & 26 \\
\hline rock & 7 \\
\hline canadian & 46 \\
\hline electronic & 42 \\
\hline emo & 22 \\
\hline alternative & 7 \\
\hline & \\
\hline Total & 247 \\
\hline
\end{tabular}

Tabela 5.10. Tags e músicas filtradas

\section{So What, Miles Davis (jazz)}

Neste exemplo, as tags “instrumental” e“bop” são substituídas por “funk” e “bardbop”.

\begin{tabular}{|l|l|}
\hline Sem fid & Músicas filtradas \\
\hline piano & 13 \\
\hline saxophone & 21 \\
\hline instrumental & 4 \\
\hline trumpet & 27 \\
\hline bebop & 16 \\
\hline fusion & 34 \\
\hline swing & 32 \\
\hline bass & 39 \\
\hline bop & 22 \\
\hline sax & 28 \\
\hline & \\
\hline Total & 236 \\
\hline
\end{tabular}

\begin{tabular}{|l|l|}
\hline Com fid & Músicas filtradas \\
\hline trumpet & 27 \\
\hline saxophone & 21 \\
\hline bass & 39 \\
\hline bebop & 16 \\
\hline piano & 13 \\
\hline fusion & 34 \\
\hline swing & 32 \\
\hline funk & 44 \\
\hline hardbop & 43 \\
\hline sax & 28 \\
\hline & \\
\hline Total & 297 \\
\hline
\end{tabular}

Tabela 5.11: Tags e músicas filtradas 


\section{Billie Jean, Michael Jackson (pop)}

Neste exemplo, as tags "pop", "vocalists", "classic" e "party” são substituídas por "british”, "motown”, "ballad" e "70s".

\begin{tabular}{|l|l|}
\hline Sem fid & Músicas filtradas \\
\hline 80 s & 2 \\
\hline pop & 0 \\
\hline soul & 14 \\
\hline disco & 14 \\
\hline female & 29 \\
\hline funk & 27 \\
\hline classic & 8 \\
\hline rnb & 25 \\
\hline party & 11 \\
\hline $90 s$ & 24 \\
\hline & \\
\hline Total & 154 \\
\hline
\end{tabular}

\begin{tabular}{|l|l|}
\hline Com fid & Músicas filtradas \\
\hline female & 29 \\
\hline funk & 27 \\
\hline soul & 14 \\
\hline british & 38 \\
\hline motown & 41 \\
\hline disco & 14 \\
\hline rnb & 25 \\
\hline 80 s & 2 \\
\hline ballad & 38 \\
\hline 70s & 35 \\
\hline & \\
\hline Total & 263 \\
\hline
\end{tabular}

Tabela 5.12: Tags e músicas filtradas

\section{Viva La Vida, Coldplay (rock)}

Neste exemplo, as tags “rock", "pop” e "OOs" são substituídas por "piano", "dance" e "acoustic”.

\begin{tabular}{|l|l|}
\hline Sem fid & Músicas filtradas \\
\hline rock & 0 \\
\hline alternative & 2 \\
\hline indie & 4 \\
\hline pop & 5 \\
\hline british & 23 \\
\hline britpop & 18 \\
\hline electronic & 35 \\
\hline
\end{tabular}

\begin{tabular}{|l|l|}
\hline Com fid & Músicas filtradas \\
\hline british & 23 \\
\hline electronic & 35 \\
\hline 90 s & 36 \\
\hline piano & 37 \\
\hline britpop & 18 \\
\hline dance & 31 \\
\hline indie & 4 \\
\hline
\end{tabular}




\begin{tabular}{|l|l|}
\hline 00s & 12 \\
\hline 90s & 36 \\
\hline happy & 25 \\
\hline & \\
\hline Total & 160 \\
\hline
\end{tabular}

\begin{tabular}{|l|l|} 
alternative & 2 \\
\hline acoustic & 34 \\
\hline happy & 25 \\
\hline & \\
\hline Total & 245 \\
\hline
\end{tabular}

\section{Tabela 5.13: Tags e músicas filtradas}

Entre os exemplos, nota-se que as algumas das tags comuns eliminadas são: “rock”, "pop”, "alternative", "classic", "instrumental", “oldies" e "old”. É interessante observar que essas tags se referem a tipos de música bastante diferentes, dependendo do contexto das recomendações. Por exemplo, músicas "pop” entre as recomendações para "Billie Jean”, de Michael Jackson são muito diferentes de músicas "pop” em recomendações para "I Will Follow You Into The Dark", de Death Cab for Cutie.

Nota-se também que para a música “All of the Lights”, de Kanye West, a diferença entre as músicas filtradas nos dois casos é muito pequena. Nesse caso, existe maior redundância nas tags, e em geral, a variedade de vocabulário é menor. Percebe-se que o número de músicas filtradas nos dois casos é relativamente alta, se comparada com os outros exemplos. Comparada com outra música do estilo hip hop, “Can I Kick It?”, de A Tribe Called Quest, pode-se notar diferenças na variedade de vocabulário das tags.

A diferença entre os dois exemplos pode estar relacionada ao que Lamere [2008] descreve como "tagger bias". O usuário que aplica tags a músicas tem um certo perfil, e seu gosto não corresponde necessariamente com os interesses musicais do público como um todo. Isso pode criar um "tagging bias", em que alguns tipos de músicas recebem mais tags que outros. No caso dos exemplos acima, é possível que "All of the Lights", de Kanye West seja popular entre um público mais jovem. "Can I Kick It?", de A Tribe Called Quest é um clássico do hip hop, e provavelmente mais popular entre um público mais velho. A idade e experiência dos diferentes grupos pode afetar a variedade de vocabulário e quantidade das tags aplicadas a cada música.

$\mathrm{O}$ uso da frequência inversa de documentos mostrou bons resultados ao aumentar a relevância de tags, atingindo o objetivo de filtrar um número maior de músicas. Assim, utilizamos essa técnica para diminuir o número de tags exibidas nos Experimentos 2 e 3 . O processo de filtragem e cálculo de similaridade com as músicas recomendadas e tags selecionadas pelo usuário continua o mesmo, com a única diferença no número de tags exibidas (10 ao invés de 25 tags).

Nesse capítulo apresentamos a implementação da visualização Tag Strings e dos espaços de testes, e mostramos estudos sobre tags, e quais tipos são considerados mais úteis para usuários. Em 
Protótipo para o Espaço de Testes

seguida, foi detalhada a comparação entre duas técnicas para o cálculo de relevância, com o objetivo de selecionar tags mais discriminantes. 


\section{Capítulo 6}

\section{Experimentos com Visualização de Tags}

Neste capítulo apresentamos experimentos com visualização de tags, e a análise dos resultados a partir de critérios definidos no capítulo 2. A metodologia para o design dos experimentos foi baseada em Rubin et al. [1994] e Tullis et al.[2008].

Uma avaliação inicial foi conduzida com a interface da visualização Tag Strings, proposta no capítulo 4. O objetivo da avaliação era testar tarefas básicas como tocar músicas, selecionar tags, etc. A visualização Tag Strings cumpriu os objetivos, e deste modo, foi utilizada também no Experimento 1.

A avaliação inicial foi conduzida para investigar se a visualização Tag Strings podia ser usada para explicar e filtrar músicas.

Mais precisamente, o objetivo era responder as seguintes questões:

- A visualização Tag Strings ajuda usuários a filtrar recomendações de música (inspeção)?

- A visualização Tag Strings ajuda usuários a poupar tempo e esforço ao avaliar recomendações (eficiência)?

- A visualização Tag Strings ajuda usuários a tomarem decisões melhores (eficácia)?

- A visualização Tag Strings aumenta o divertimento do usuário (satisfação)?

\subsection{Avaliando a Interface da Visualização}

Conduzimos uma avaliação por usabilidade com desconto [Nielsen, 1994], para validar a interface de Tag Strings Entre outras visualizações propostas, escolhemos Tag Strings como a melhor alternativa para o experimento. Se participantes não fossem capazes de cumprir todas as tarefas usando Tag Strings, outra visualização seria testada.

O objetivo da avaliação era minimizar os problemas do design da interface antes do Experimento 1, onde é avaliado o impacto de se utilizar tags como explicação e filtros. Essa avaliação também testou a usabilidade do protótipo a ser usado no espaço de testes, para questões básicas como tocar musicas, filtrar clicando em tags, etc. 
Mais especificamente, a avaliação pretendia responder as seguintes perguntas:

- Usuários estão cientes de quais áreas da interface são clicáveis?

- Usuários conseguem tocar um trecho de música?

- Usuários entendem a relação entre tags e músicas recomendadas?

- Usuários percebem que é possível filtrar as recomendações?

\subsubsection{Materiais}

O protótipo para o espaço de testes foi construído em Java, HTML5 e Javascript. Solicitamos aos participantes algumas músicas favoritas, para serem usadas como sementes. Para cada música, uma lista de 50 recomendações foi recuperada da interface (api) do serviço Last.fm. Através do mesmo serviço, tags foram coletadas para cada semente e para cada música recomendada.

Para que os participantes pudessem escutar as músicas recomendadas durante o teste, utilizamos a interface (api) do serviço Rdio.

\subsubsection{Design}

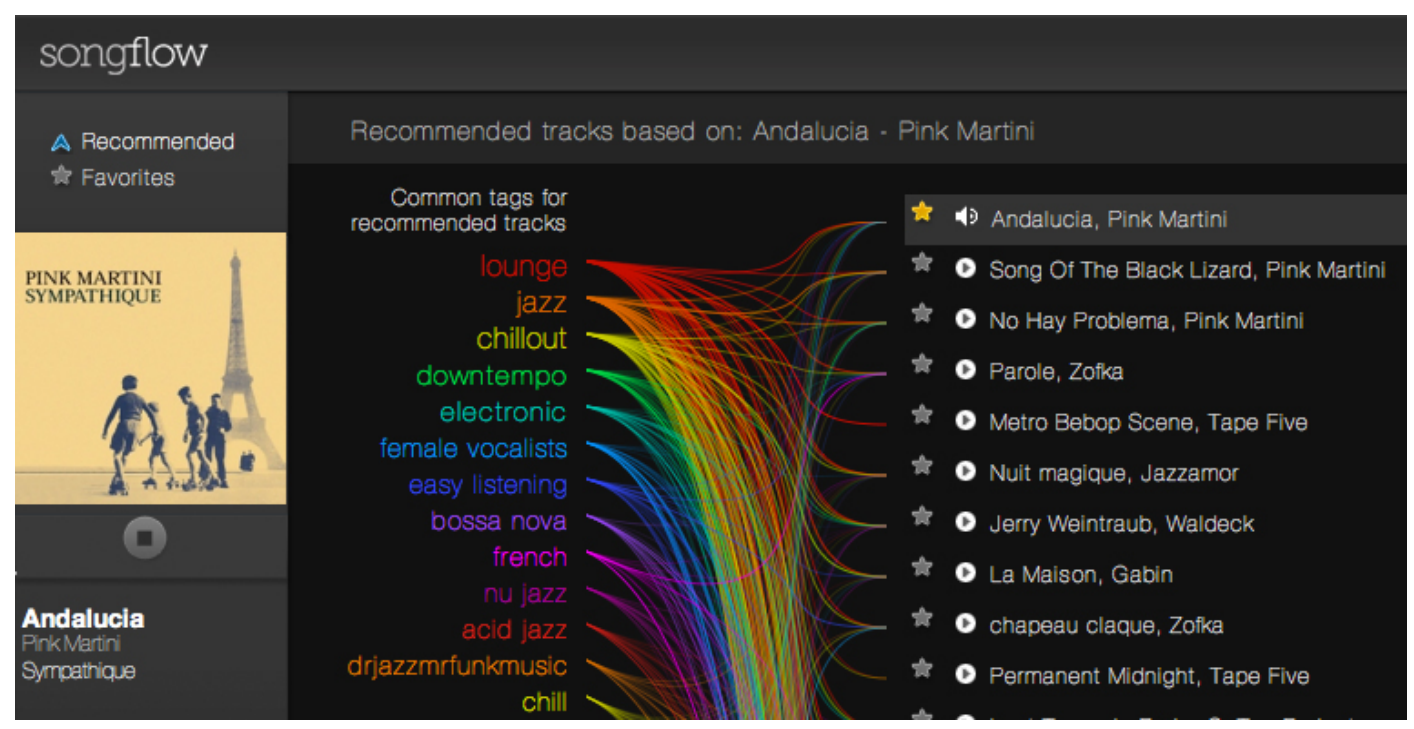

Figura 6.1: Tela do protótipo utilizado na avaliaçấo.

Participantes foram instruídos a imaginar que estavam usando um novo tipo de player, onde buscariam recomendações baseadas em uma semente (música favorita). A tela do protótipo era então apresentada com as recomendações de músicas. 
Experimentos com Visualização de Tags

Os participantes executaram as seguinte tarefas:

- Procurar uma música que você gosta entre as músicas recomendadas;

- Marcar a música como "favorita".

As duas tarefas deveriam cobrir todas as atividades a ser testadas:

- Tocar uma música;

- Parar uma música;

- Adicionar uma música a favoritos;

- Manter o cursor sobre tags (hover) para ver as linhas conectando tags e músicas;

- Clicar em tags para filtrar recomendações.

\section{Metodologia}

Usamos o protocolo "pensar em voz alta" (think aloud protocol).

\section{Participantes}

A interface foi avaliada por 5 participantes., sendo 2 homens e 3 mulheres na faixa de 26 a 42 anos de idade.

\subsubsection{Resultados}

- 5 de 5 usuários perceberam que as músicas e botões de play e stop eram clicáveis;

- 5 de 5 usuários pousaram o cursor sobre uma tag e viram as linhas;

- 4 de 5 usuários clicaram em uma tag para filtrar as músicas;

- 5 de 5 usuários tocaram e pararam um trecho de música;

- 4 de 5 usuários adicionaram músicas a lista de favoritos; 
- 4 de 5 participantes perceberam que as recomendações podiam ser filtradas. Depois de clicar em uma tag, eles viram a diferença nas linhas e nas recomendações;

- 3 de 4 participantes levaram um tempo razoável antes de clicarem em uma tag. As tags não pareciam clicáveis a primeira vista. $\mathrm{O}$ problema foi resolvido para o Experimento 1;

- 2 de 5 participantes acharam a lista de recomendações muito longa. O problema foi resolvido para o Experimento 1.

A maior parte dos usuários foram capazes de completar todas as tarefas testadas. Como Tag Strings cumpriu os objetivos da avaliação, a design foi revisado e utilizado no Experimento 1.

Esta seção detalhou a avaliação da visualização Tag Strings, e a partir de seu resultado, utilizamos esse design no Experimento 1, mostrado na seção seguinte.

\subsection{Experimento 1 - Avaliando Visualizações de Tags como Explicações}

No Experimento 1, conduzimos testes para descobrir se Tag Strings poderia ser usada para explicar e filtrar recomendações.

Mais especificamente, procuramos responder as seguinte questões:

- A visualização Tag Strings ajuda usuários a filtrar recomendações de música (inspeção)?

- A visualização Tag Strings ajuda usuários a poupar tempo e esforço ao avaliar recomendações (eficiência)?

- A visualização Tag Strings ajuda usuários a tomarem decisões melhores (eficácia)?

- A visualização Tag Strings aumenta o divertimento do usuário (satisfação)?

\subsubsection{Materiais}

Para o Experimento 1 usamos o protótipo da avaliação inicial, com revisões baseadas nos resultados dos testes. A avaliação foi feita remotamente, no computador do participante. Foi pedido que participantes utilizassem os navegadores Safari ou Firefox, com plugin para Adobe Flash, e suporte para HTML5. 
Experimentos com Visualização de Tags

Os testes foram avaliados através dos serviços $\mathrm{Clicky}^{19}$, uma ferramenta de análise em tempo real, e Userfly ${ }^{20}$, um serviço que grava os cliques e movimentos do mouse.

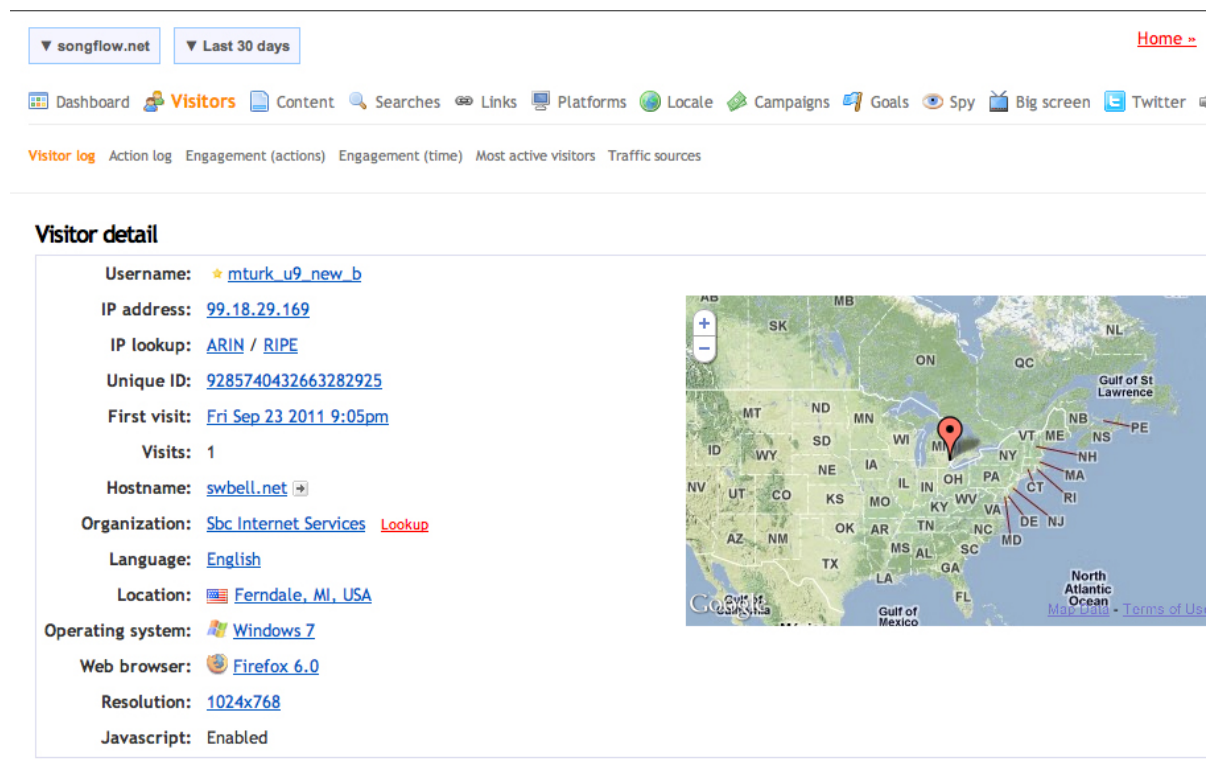

Actions from this session, oldest to newest:

\begin{tabular}{|c|c|c|c|}
\hline Time & User & Action & Referrer \\
\hline $\begin{array}{l}\text { Sep } 232011 \\
\text { 9:05:18 pm }\end{array}$ & 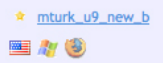 & $/ \mathrm{v1} 10 \mathrm{t} / \mathrm{t} / \mathrm{u} 0 \mathrm{~g} / \mathrm{s} 24 / \mathrm{b} /$ & \\
\hline Sep 232011 & \# mturk_u9_new_b & /tr/Wake+Up+Call & \\
\hline 9:05:48 pm & 즐 슨 중 & http://songflow.net/110t/t/u12/s24/a/ & \\
\hline
\end{tabular}

Figura 6.2: Tela do serviço Clicky, com dados do comportamento do usuário.

\footnotetext{
${ }^{19} \mathrm{http}: / /$ getclicky.com

${ }^{20} \mathrm{http}: / /$ userfly.com
} 
Experimentos com Visualização de Tags

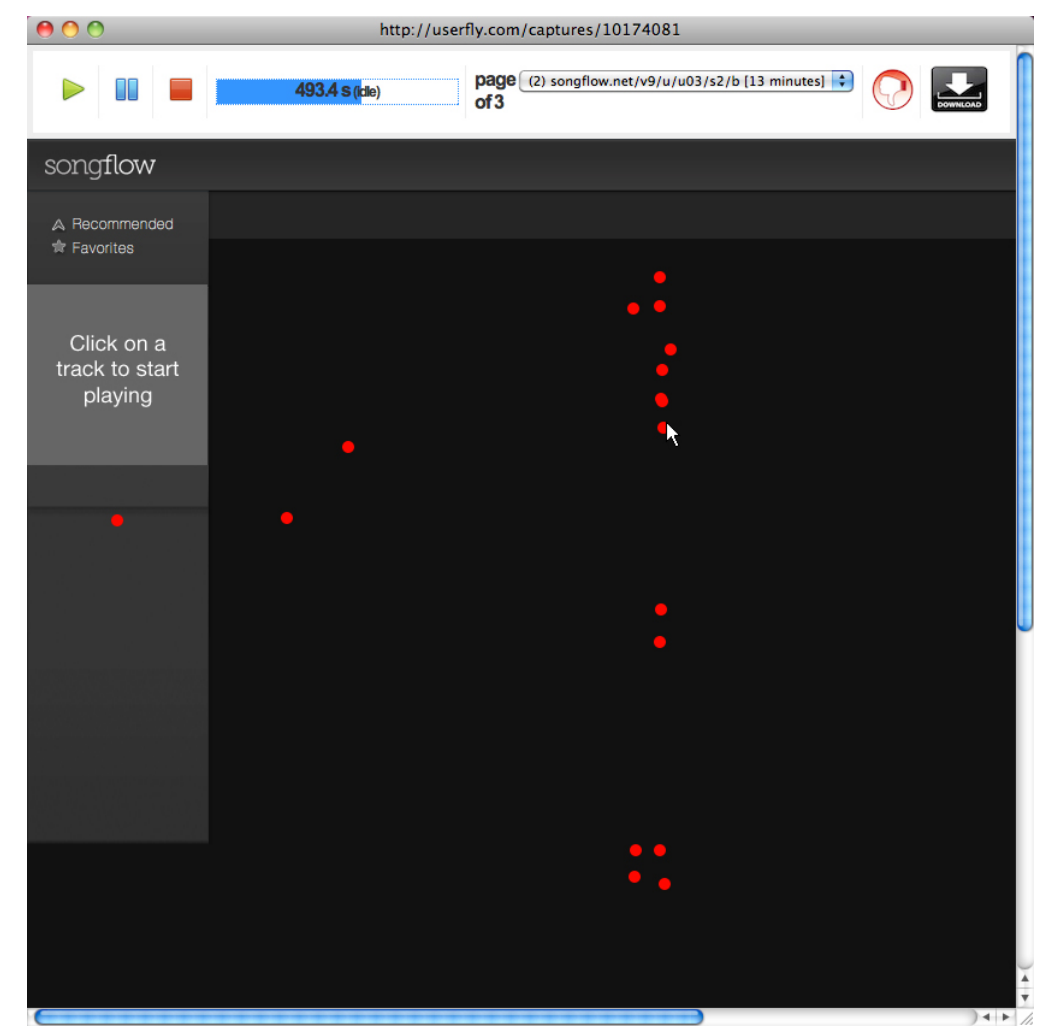

Figura 6.3: Tela do serviço Userfly, com gravação de atividades de um usuário. ${ }^{21}$

${ }^{21}$ Userfly não mostra javascript durante o "playback", por isso a gravação não mostra todos os elementos que o usuário viu. (http://userfly.com, set 2011) . 


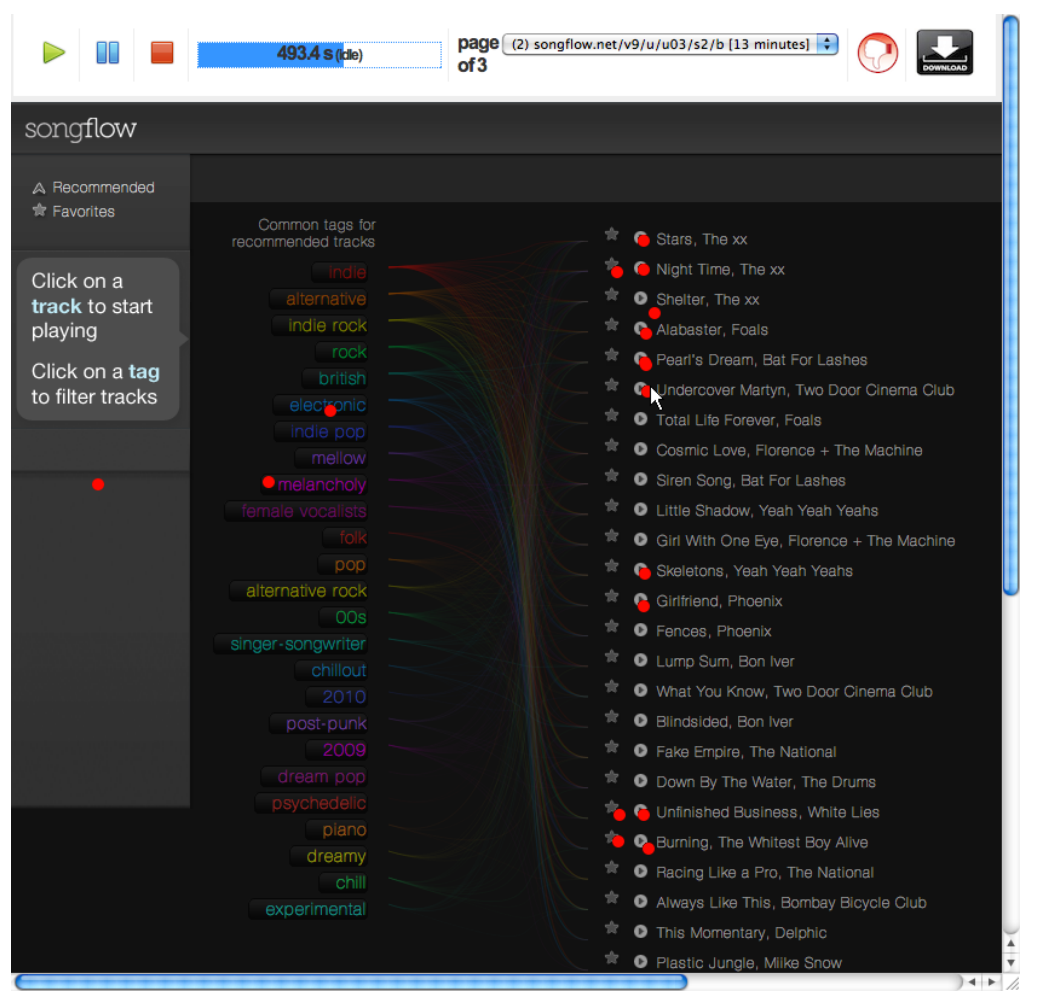

Figura 6.4 Tela do serviço Userfly combinada com a tela do protótipo, mostrando onde o usuário clicou.

Um conjunto de 26 músicas foram selecionadas como sementes. As músicas foram escolhidas por:

- Usuários (6 dos 18 participantes), que, algumas semanas antes do teste, enviaram músicas preferidas por email;

- Listas de músicas mais populares na iTunes Store.

Para cada semente, recuperamos uma lista de 50 recomendações usando a interface $(a p i)$ do serviço Last.fm. Os dados foram coletados da mesma forma que na avaliação inicial.

As diferenças entre as interfaces da avaliação inicial e Experimento 1 foram:

- Baseado nos resultados da avaliação, exibimos apenas as primeiras 20 músicas, para minimizar a rolagem da página;

- Ao pousar o cursor sobre uma música, linhas são desenhadas ligando a música as tags;

- As tags receberam textura para parecerem mais clicáveis.

\subsubsection{Design do Experimento}


1. Participantes tinham como tarefa escolher duas músicas (de preferência músicas que o usuário gostasse) em uma lista de 26 músicas. O objetivo era reproduzir uma experiência real de busca, onde usuários buscam músicas favoritas, e recomendações são exibidas.

2. Para cada música, foram apresentadas 20 recomendações.

3. Mostramos dois tipos diferentes de interfaces com recomendações, baseadas na semente. Para metade dos participantes mostramos primeiro o Design A, depois o Design B. Para a outra metade, mostramos primeiro o Design B, e depois o Design A.

\section{Design A}

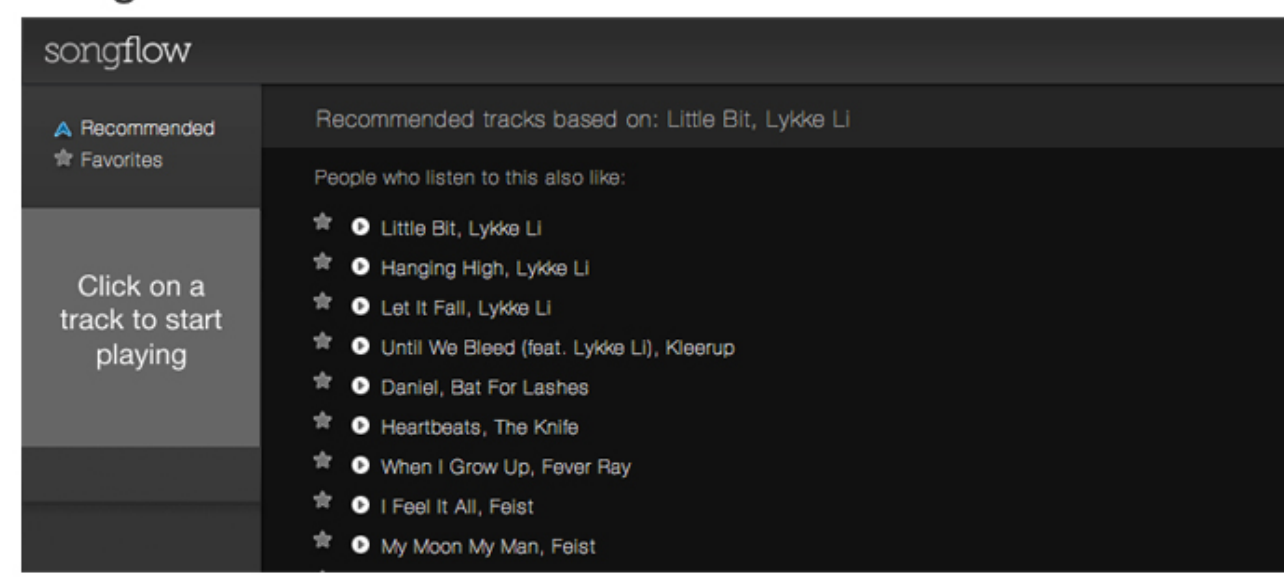

\section{Design B}

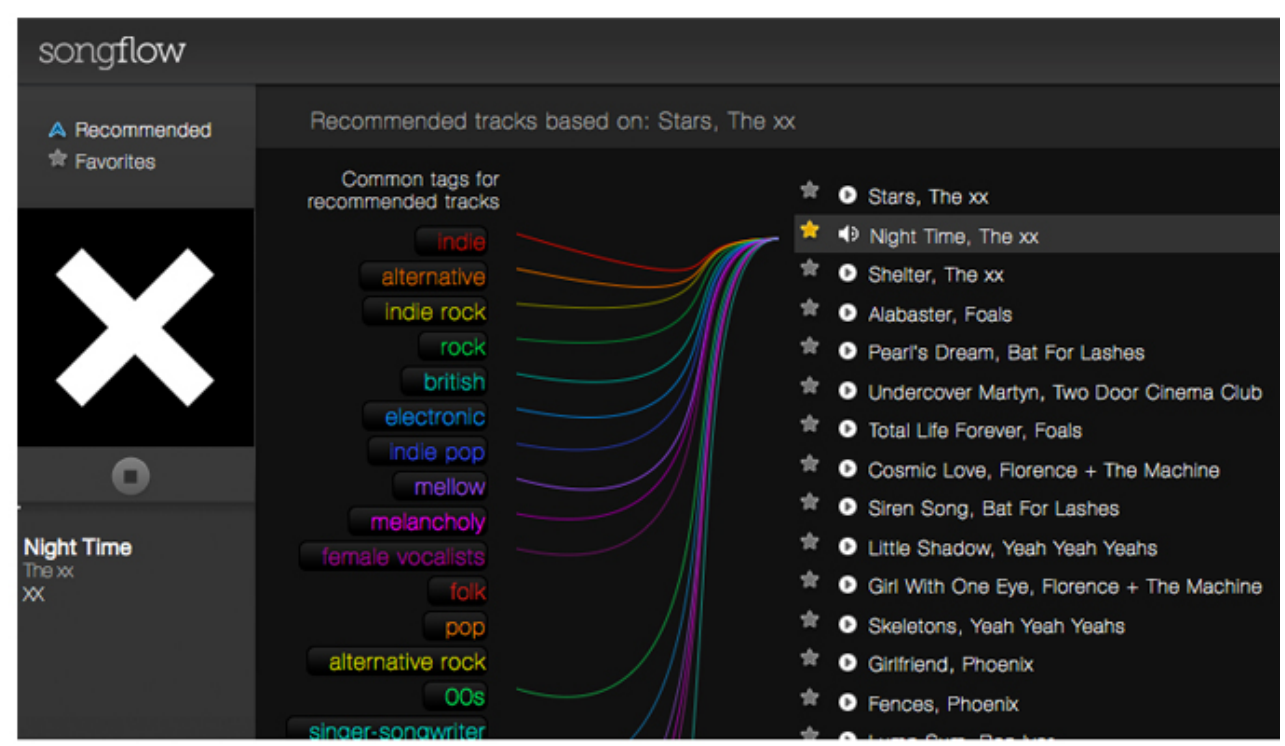

Figura 6.5: Telas do protótipo utilizadas no Experimento 1, com os dois designs exibidos aos participantes 
Design A mostra as 20 recomendações mais relevantes em forma de uma lista. A explicação das recomendações é a mesma do Last.fm, serviço que fornece as recomendações: "People who listen to this also like:" ( "Pessoas que escutam isso também escutam:" ).

Design B mostra as 20 recomendações mais relevantes em forma de lista. Uma lista de tags também é apresentada, com linhas conectando tags e músicas. As tags são descritas com a frase: "Common tags for recommended tracks" ("Tags comuns entre as músicas recomendadas"). O Design B não mostrou a explicação "People who listen to this also like".

4 - Pedimos que participantes procurassem pelo menos uma música que gostassem. Alguns participantes pararam ao terminar a tarefa, mas a maior parte passou mais tempo explorando as músicas.

5 - Ao final da tarefa, participantes preencheram um questionário. Usuários listaram quais músicas escolheram avaliar, compararam Design A com Design B, e responderam questões relacionadas as tags. A pesquisa completa pode ser encontrada no Apêndice I.

\subsubsection{Hipóteses}

Nossas hipóteses são:

H1 - A visualização Tag Strings ajuda usuários a filtrar recomendações de música (inspeção);

H2 - A visualização Tag Strings ajuda usuários a poupar tempo e esforço ao avaliar recomendações (eficiência);

H3 - A visualização Tag Strings ajuda usuários a tomarem decisões melhores (eficácia);

H4 - A visualização Tag Strings aumenta o divertimento do usuário (satisfação);

H5 - Entre Design A e B, usuários preferem as explicações do Design B;

Apesar do Design A oferecer explicações transparentes (mostrando como o sistema de recomendação realmente funciona), Design B (com tags) vai ser percebido como tendo uma explicação melhor. (Design B não favorece transparência, mas favorece os metas de inspeção, eficiência e eficácia).

H6 - Em geral, usuários vão preferir o Design B.

Inspeção, eficiência, eficácia e satisfação podem melhorar a experiência do usuário. Se o Design B favorece esses metas, usuários vão preferir Design B ao Design A.

\section{Limitações do experimento}


Num cenário ideal, usuários seriam capazes de buscar uma música que gostam, e receber recomendações. Infelizmente, isso não é possível por causa de limitações da interface (api) do serviço Last.fm. A alternativa foi fazer uma lista de músicas que são populares.

\subsubsection{Resultados e Análise}

\section{Participantes}

A interface foi avaliada por 18 participantes. Seis participantes foram recrutados por email, e doze foram recrutados usando o Mechanical Turk ${ }^{22}$. Dentre os participantes, 10 eram mulheres, 8 homens, com idades de 21 a 58 anos.

Depois de executar os experimentos, analisamos os resultados para confirmar ou reprovar as hipóteses formuladas anteriormente. Para o cálculo das médias e desvio padrão, seguimos a recomendação de Sauro e Lewis [2012], com a escala Likert convertida em escala de 1 a 5 (Discordo firmemente: 1, Discordo: 2, Neutro:3, Concordo:4, Concordo firmemente:5).

\section{H1 - A visualização Tag Strings ajuda usuários a filtrar recomendações de música (inspeção)}

Os dados coletados mostram que 38\% dos participantes clicaram nas tags. Este número não foi surpreendente, já que corrigir recomendações não é uma prática tão comum entre usuários [Czarkowski, 2006]. Dos 38\% dos participantes que clicaram nas tags, 57\% concordaram (28.5\% concordaram, e $28.5 \%$ concordaram firmemente) que Design B ajudou a corrigir as recomendações, e $43 \%$ foram neutros. A relação entre tags e músicas é mostrada ao colocar o cursor sobre uma tag (bover), e ao clicar em uma tag. É possível que alguns usuários considerem o bover como um tipo de filtragem.

Hover sobre tag

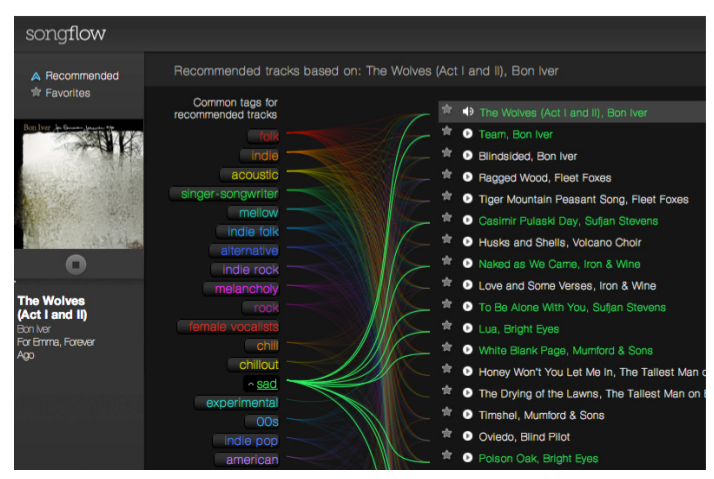

Clique em tag

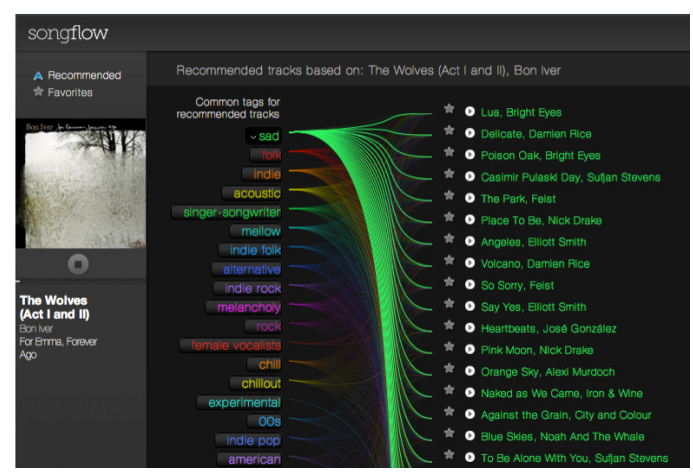

22 Foram criadas 37 tarefas (HITs) no Mechanical Turk, um serviço da Amazon. 35 participantes completaram as tarefas, mas somente 22 fizeram as tarefas corretamente. Destes 22 participantes, 17 eram mulheres e 5 eram homens. Selecionamos 5 homens e 8 mulheres a partir do tempo total de uso (a suposição é que participantes que levaram mais tempo para executar a tarefa estavam mais interessados na tarefa, e assim, eram participantes mais confiáveis). 
Figura 6.6: Telas do protótipo (Design B) mostrando bover e clique em uma tag.

Assim, ao perguntar aos usuários se as tags selecionadas resultaram em uma filtragem coerente, consideramos hover como um tipo de seleção.

\begin{tabular}{|l|l|l|l|l|l|}
\hline & $\begin{array}{l}\text { Discordo } \\
\text { firmemente }\end{array}$ & Discordo & Neutro & Concordo & $\begin{array}{l}\text { Concordo } \\
\text { firmemente }\end{array}$ \\
\hline $\begin{array}{l}\text { Design B me ajudou a corrigir uma } \\
\text { recomendação (dos 38\% dos usuários } \\
\text { que clicaram em uma tag). }\end{array}$ & $0.00 \%$ & $0.00 \%$ & $43 \%$ & $28.5 \%$ & $28.5 \%$ \\
\hline $\begin{array}{l}\text { Média: 3.85, desvio padrão: 0.89 } \\
\text { Design B me ajudou a filtrar as músicas } \\
\text { recomendadas. }\end{array}$ & $0.00 \%$ & $0.00 \%$ & $5.5 \%$ & $55.50 \%$ & $39.00 \%$ \\
\hline $\begin{array}{l}\text { Média: 4.3, desvio padrão: 0.59 } \\
\text { Após selecionar uma tag, as músicas } \\
\text { exibidas eram coerentes com a seleção. }\end{array}$ & $0.00 \%$ & $0.00 \%$ & $28.00 \%$ & $61.00 \%$ & $11.00 \%$ \\
\hline \begin{tabular}{l} 
Média: 4.27, desvio padrão:0.67 \\
\hline
\end{tabular}
\end{tabular}

Tabela 6.1: Resultados do questionário aplicado aos participantes

Em geral, os resultados na Tabela 6.1 mostram que o Design B ajudou usuários a filtrarem recomendações, confirmando $\mathrm{H} 1$.

Alguns comentários de usuários sobre tags para corrigir e filtrar recomendações:

"Love the tags but not so much because seeing them is cool, it's like a missing aspect of Pandora, if I can just click something that says "sad" within my recommendations I can refine. Really cool."

(“Adoro as tags mas não tanto porque vê-las é legal, mas também é um aspecto que falta no Pandora, se eu simplesmente clicar em algo que diz "triste" dentre as recomendações eu posso filtrar. Muito legal").

"I didn't realize at first that the recommendations changed when you clicked on a tag. That was cool because with both lists, I felt limited by the tracks that were listed first."

("No início não percebi que as recomendações mudavam quando uma tag é clicada. Isso foi legal porque nas duas listas, eu me senti limitado pelas músicas que foram listadas primeiro”). 
H2 - A visualização Tag Strings ajuda usuários a poupar tempo e esforço ao avaliar recomendações (eficiência)

Eficiência foi medida de formas objetiva (em termos de tempo), e subjetiva (esforço percebido pelo usuário). Com base nos dados da ferramenta Clicky, medimos o tempo que os participantes levaram para usar Design A e Design B.

\begin{tabular}{|l|l|l|}
\hline Participante & Design A (minutos) & Design B (minutos) \\
\hline 1 & 3 & 0.9 \\
\hline 2 & 3.2 & 3.1 \\
\hline 3 & 3.1 & 4 \\
\hline 4 & 3.2 & 3.9 \\
\hline 5 & 2.1 & 5.5 \\
\hline 6 & 4 & 4.1 \\
\hline 7 & 4.3 & 4.5 \\
\hline 8 & 3.9 & 4.9 \\
\hline 9 & 5.1 & 3.7 \\
\hline 10 & 4.5 & 4.5 \\
\hline 11 & 4.2 & 5.2 \\
\hline 12 & 6.5 & 3.1 \\
\hline 13 & 4.5 & 6.7 \\
\hline 14 & 7.1 & 6 \\
\hline 15 & 5.3 & 8.5 \\
\hline 16 & 7.5 & 8 \\
\hline 17 & 6.8 & 9 \\
\hline & & \\
\hline & 3.5 & \\
\hline
\end{tabular}




\begin{tabular}{|l|l|l|}
\hline $18 *$ & 7.8 & 28 \\
\hline média & 4.783 & 6.311 \\
\hline desvio padrão & 1.707 & 5.784 \\
\hline
\end{tabular}

Tabela 6.2: Tempo que usuários levaram para usar Designs $A$ e $B$

Em geral, a média para o Design A foi 4.78 minutos, e para o design B, 6.3 minutos. O valor do participante 18 no Design $B$ foi mais que 3 desvios padrão do que a média, por isso foi removido do t-test. Comparando o tempo levado no Design A e Design B, a diferença não foi estatisticamente significativa ( $\mathrm{p}>0.05$, t-test).

No questionário, ao perguntar qual design é mais rápido de usar, os resultados foram: Design A (22\%), Neutro (61\%), Design B (16.5\%). Notamos o número alto de respostas neutras, que sugere que para os participantes, a diferença não era clara entre o Design B e A. Entretanto, 89\% dos usuários concordaram que as tags foram úteis para encontrar músicas interessantes mais rápido.

\begin{tabular}{|l|l|l|l|l|l|}
\hline & $\begin{array}{l}\text { Discordo } \\
\text { firmemente }\end{array}$ & Discordo & Neutro & Concordo & $\begin{array}{l}\text { Concordo } \\
\text { firmemente }\end{array}$ \\
\hline $\begin{array}{l}\text { As tags me ajudaram a encontrar } \\
\text { músicas que eu gosto mais rápido. }\end{array}$ & $0.00 \%$ & $5.50 \%$ & $5.50 \%$ & $72.00 \%$ & $17.00 \%$ \\
\hline Média: 4, desvio padrão: 0.68 & & & & & \\
\hline
\end{tabular}

Tabela 6.3:Resultados do questionário aplicado aos participantes

Como a média de tempo no Design B foi maior que no Design A (mesmo não sendo estatisticamente significante), e o questionário apresentou muitas respostas neutras, pode-se assumir que o Design B não é mais rápido que o Design A, e possivelmente, que o Design A é mais rápido. Mas especificamente sobre o uso de tags, usuários responderam que as tags tornaram a tarefa mais rápida (tabela 5.3).

O que podemos inferir é que as tags aumentam eficiência, mas não é o caso da visualização de tags. Como o Design B mostra mais informação, usuários podem levar mais tempo para compreender a interface à primeira vista, comparado como Design A.

\section{H3 - A visualização Tag Strings ajuda usuários a tomarem decisões melhores (eficácia)}

Como detalhado no capítulo 2, explicações eficazes afetam decisões de usuários de várias maneiras diferentes: 
Explicações eficazes ajudam usuários a encontrar itens novos. A tabela 6.4 mostra que $72 \%$ (61\% concordo, $11 \%$ concordo firmemente) dos participantes concordaram com: "Selecionar tags me ajudou a encontrar músicas que eu não conhecia”.

Explicações eficazes ajudam usuários a encontrar itens úteis e eliminar os inúteis. A tabela 6.4 mostra que $78 \%$ (33.5\% concordo, $44.5 \%$ concordo firmemente) dos participantes concordaram com: "Selecionar tags me ajudou a encontrar músicas que me interessam" e "As tags me ajudaram a decidir quais músicas eu deveria escutar”.

Explicações eficazes ensinam usuários algo sobre as recomendações. A tabela 6.4 mostra que 89\% (67\% concordo, $22 \%$ concordo firmemente) dos participantes concordaram com: "As tags me ajudaram a aprender algo sobre as músicas recomendadas".

\begin{tabular}{|c|c|c|c|c|c|}
\hline & $\begin{array}{l}\text { Discordo } \\
\text { firmemente }\end{array}$ & Discordo & Neutro & Concordo & $\begin{array}{l}\text { Concordo } \\
\text { firmemente }\end{array}$ \\
\hline $\begin{array}{l}\text { Selecionar tags me ajudou a encontrar } \\
\text { músicas que eu não conhecia. } \\
\text { Média: } 3.8 \text {, desvio padrão: } 0.6\end{array}$ & $0.00 \%$ & $0.00 \%$ & $28.00 \%$ & $61.00 \%$ & $11.00 \%$ \\
\hline $\begin{array}{l}\text { Selecionar tags me ajudou a encontrar } \\
\text { músicas que me interessam. } \\
\text { Média: 4.2, desvio padrão: } 0.8\end{array}$ & $0.00 \%$ & $0.00 \%$ & $22.00 \%$ & $33.50 \%$ & $44.50 \%$ \\
\hline $\begin{array}{l}\text { As tags me ajudaram a determinar o } \\
\text { quanto eu vou gostar das músicas. } \\
\text { Média: } 3.4 \text {, desvio padrão: } 0.85\end{array}$ & $0.00 \%$ & $16.5 \%$ & $28.00 \%$ & $50.00 \%$ & $5.50 \%$ \\
\hline $\begin{array}{l}\text { As tags me ajudaram a aprender algo } \\
\text { sobre as músicas recomendadas. } \\
\text { Média: 4.1, desvio padrão: } 0.58\end{array}$ & $0.00 \%$ & $0.00 \%$ & $11.00 \%$ & $67.00 \%$ & $22.00 \%$ \\
\hline $\begin{array}{l}\text { As tags me ajudaram a decidir quais } \\
\text { músicas eu deveria escutar. } \\
\text { Média: } 4.2 \text {, desvio padrão: } 0.86\end{array}$ & $0.00 \%$ & $5.50 \%$ & $11.00 \%$ & $44.50 \%$ & $39.00 \%$ \\
\hline
\end{tabular}

Tabela 6.4: Resultados do questionário aplicado aos participantes. 
Em geral, os resultados mostram que as tags ajudam usuários a tomarem decisões melhores, o que confirma a hipótese H3.

Alguns participantes notaram que algumas tags eram incorretas, repetitivas, confusas ou irrelevantes. Por exemplo:

"Some of the tags are mistaken." ("Algumas das tags estão erradas")

"I wasn't sure what some of the tags meant" ("Eu não tinha certeza do que algumas tags significavam.")

\section{H4 - A visualização Tag Strings aumenta o divertimento do usuário (satisfação)}

Em geral, participantes concordaram que o Design B é mais divertido que o Design A, e parecem ser favoráveis ao usar e ver as tags (tabela 6.5), o que favorece a hipótese H4.

Participantes avaliaram o Design B como mais divertido que o Design A (Design B (100\%)).

\begin{tabular}{|c|c|c|c|c|c|}
\hline & $\begin{array}{l}\text { Discordo } \\
\text { firmemente }\end{array}$ & Discordo & Neutro & Concordo & $\begin{array}{l}\text { Concordo } \\
\text { firmemente }\end{array}$ \\
\hline $\begin{array}{l}\text { Eu gosto de ver as tags. } \\
\text { Média: 4.4, desvio padrão: } 0.61\end{array}$ & $0.00 \%$ & $0.00 \%$ & $5.50 \%$ & $44.50 \%$ & $50.00 \%$ \\
\hline $\begin{array}{l}\text { É divertido usar tags. } \\
\text { Média: } 4.27 \text {, desvio padrão: } 0.75\end{array}$ & $0.00 \%$ & $0.00 \%$ & $39.00 \%$ & $39.00 \%$ & $44.50 \%$ \\
\hline
\end{tabular}

Tabela 6.5: Resultados do questionário aplicado aos participantes

Alguns comentários dos usuários:

"Not only was the tagging useful, it was colorful, bright and fun to use. I found myself using it out of curiosity, to see which songs would fall under which tag."

("Usar as tags não era somente útil, era colorido, vivo e divertido de usar. Eu usei as tags por curiosidade, para ver quais músicas se relacionavam com quais tags.")

\section{H5 - Entre Design A e B, usuários vão preferir as explicações do Design B}

$\mathrm{Na}$ hipótese 5, apesar do Design A oferecer explicações transparentes (mostrando como o sistema de recomendação realmente funciona), Design B (com tags) será percebido como tendo uma 
explicação melhor. (Design B não favorece transparência, mas favorece as metas de inspeção, eficiência e eficácia).

Ao responder qual design apresentava a melhor explicação, participantes preferiram Design B (89\%), (Neutro (11\%)) apesar do Design A apresentar a explicação "Pessoas que gostam desta música também gostam de:". Este resultado confirma a hipótese H5.

\section{H6 - Em geral, usuários vão preferir o Design B ao Design A}

Inspeção, eficiência, eficácia e satisfação podem melhorar a experiência do usuário. Se o Design B favorece essas metas, usuários vão preferir o Design B ao Design A.

Em geral, os usuários preferiram Design B ao Design A por uma margem considerável: Design B(94.5\%) e Design A(5.5\%), o que confirma H6.

Essa seção detalhou o Experimento 1, e estabeleceu seis hipóteses que buscaram responder questões da pesquisa. A construção desses experimentos permitiu avaliar empiricamente a visualização Tag Strings para explicar e filtrar recomendações de música. Na seção seguinte, detalhamos o Experimento 2.

\subsection{Experimento 2 - Comparando Tag Strings com Design Base}

\section{Objetivo}

O objetivo do Experimento 2 é comparar Tag Strings com serviços semelhantes, usando como referência Last.fm e Pandora. Para facilitar a observação das atividades do usuário durante o experimento, criamos um design baseado nas referências (Design Base).

No Experimento 2, conduzimos testes para descobrir se Tag Strings pode ser usada para atingir as metas de inspeção, eficiência, eficácia e satisfação.

Mais especificamente, procuramos responder as seguinte questões:

- A visualização Tag Strings ajuda usuários a filtrar recomendações de música (inspeção)?

- A visualização Tag Strings ajuda usuários a poupar tempo e esforço ao avaliar recomendações (eficiência)?

- A visualização Tag Strings ajuda usuários a tomar decisões melhores (eficácia)?

- A visualização Tag Strings ajuda o divertimento do usuário (satisfação)? 


\subsubsection{Materiais}

Para o Experimento 2 usamos dois protótipos: Tag Strings (com alguns ajustes) e Design Base (baseado nos serviços Last.fm e Pandora).

\subsubsection{Design Base}

Para os Experimentos 2 e 3 foi criado um design de comparação, que chamamos de Design Base. Utilizar um design de comparação oferece as vantagens de permitir o rastreamento (tracking) exato das atividades do usuário, além do controle sobre as músicas recomendadas e sua ordem. É importante notar que, ao utilizar um design de comparação ao invés de um serviço real, existe a possibilidade de introduzir ruídos no experimento.

O design de comparação usou como referência os serviços Last.fm e Pandora. Escolhemos estes entre outros serviços de recomendação de músicas por serem muito populares, e ambos são gratuitos nos Estados Unidos. Também escolhemos estes serviços por serem usados como referência em pesquisa na área de sistemas recomendação e interfaces (Lamere [2008], Green et al. [2009], Åman e Liikkanen [2010], Jones e $\mathrm{Pu}$ [2007], Chen et al. [2010]).

Analisamos as características básicas da interface dos dois serviços, e a partir destas, a interface foi projetada. A análise dos serviços Last.fm e Pandora segue abaixo, indicando os controles principais: 
Experimentos com Visualização de Tags

\section{Last.fm}

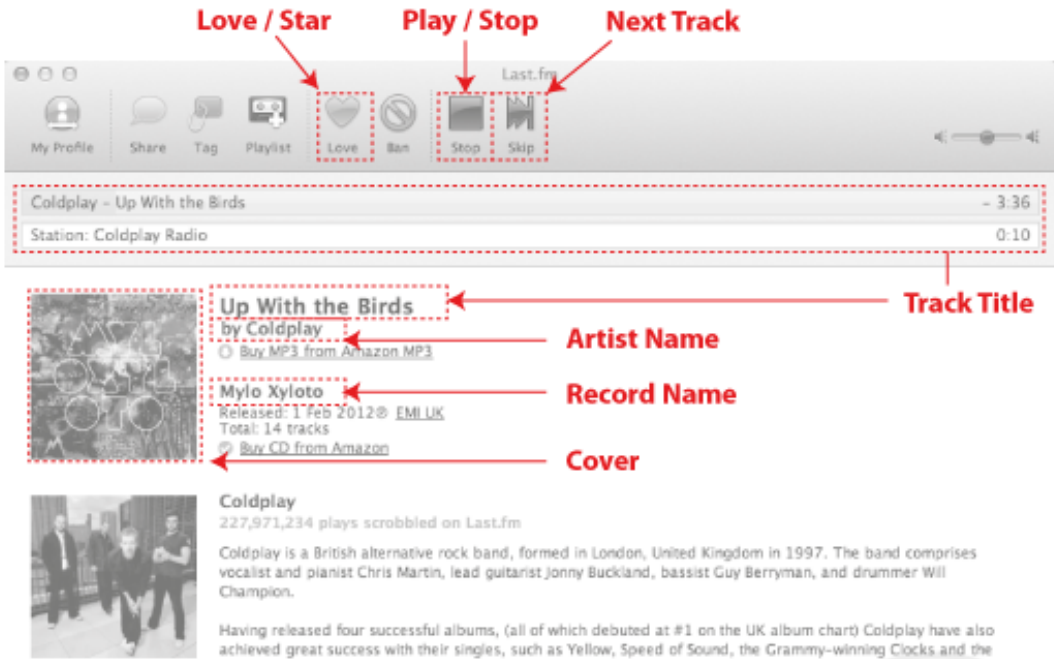

achieved great success with their singes, such as Yellow, Speed of Sound, the Grameny-Winning Cocks and the Us and UK of single vira La vica.

Froneman Chris Martin credits 1980 . Nerweglan pop band a-ha for inspiring him to form wis own band

Read more.m.

Tags: rock, albernative, britpap, alternative rock, indid

Similar artists: Snow Patrol, Keane, The fray, The Killers, OneRepublic

Top listeners on Last.fm: c0ax, Elizabbeth, PlikOura, supermarsu, vinnie_ver

Figura 6.7: Tela do player do serviço Last.fm. 
Experimentos com Visualização de Tags

\section{Pandora}

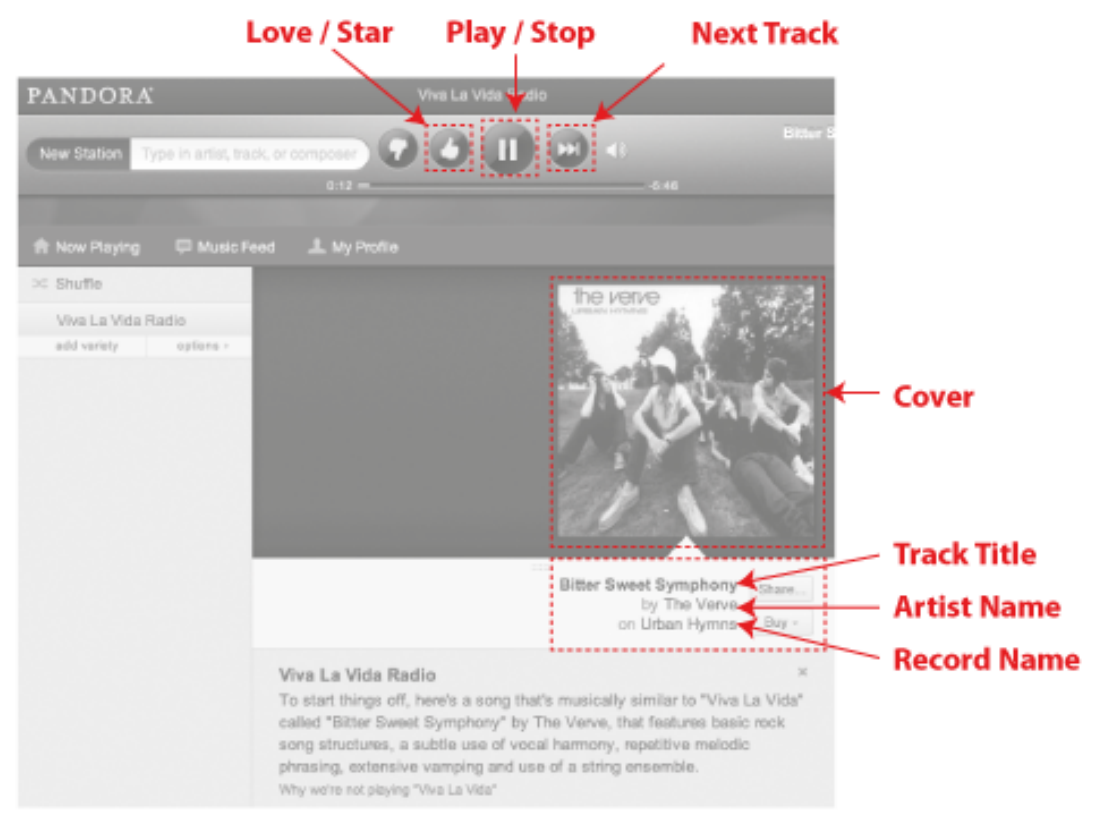

Figura 6.8: Tela do player do serviço Pandora. 
Experimentos com Visualização de Tags

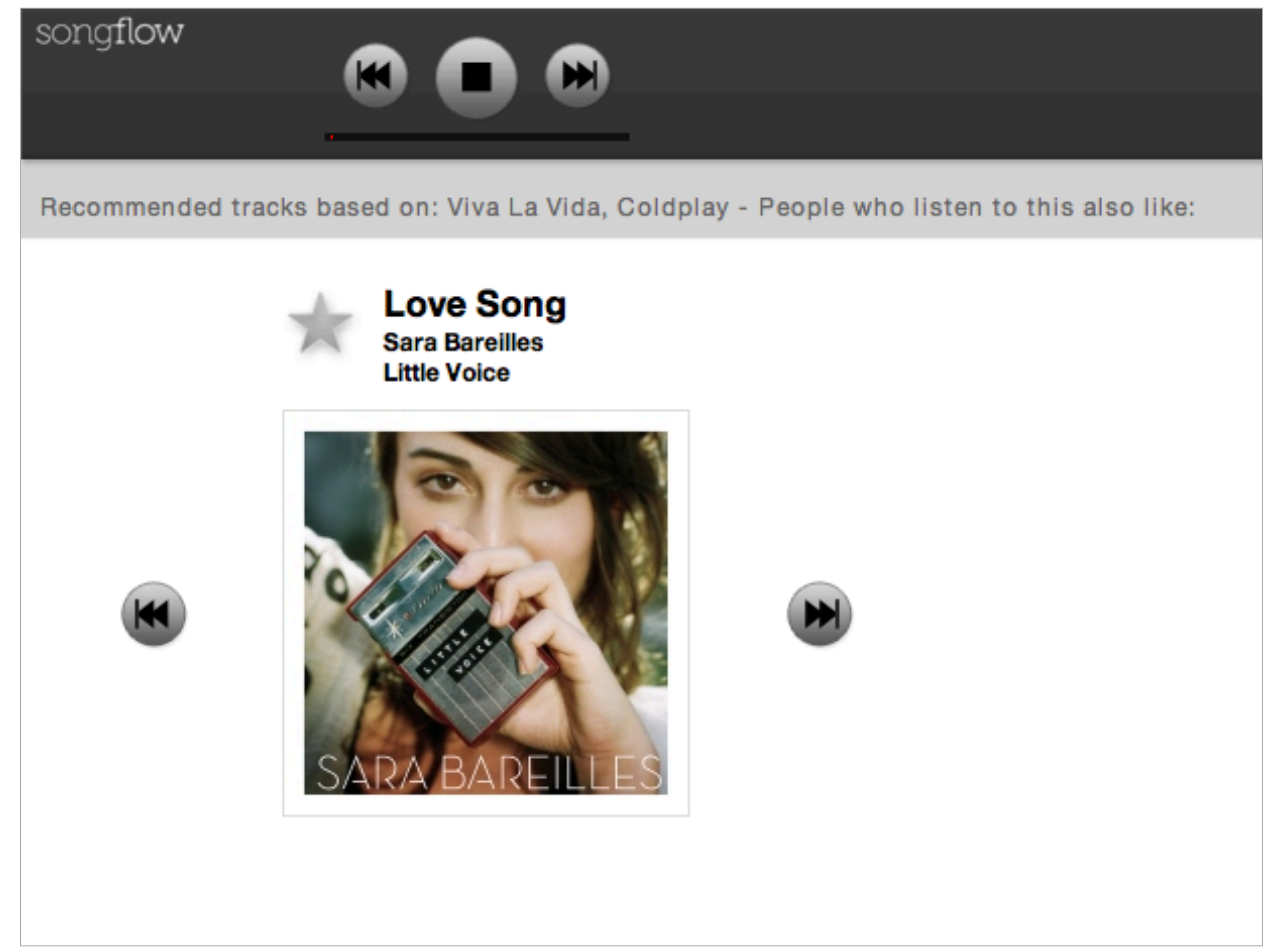

Figura 6.9: Tela do Design Base, design baseado nos serviços Pandora e Lastfm. 


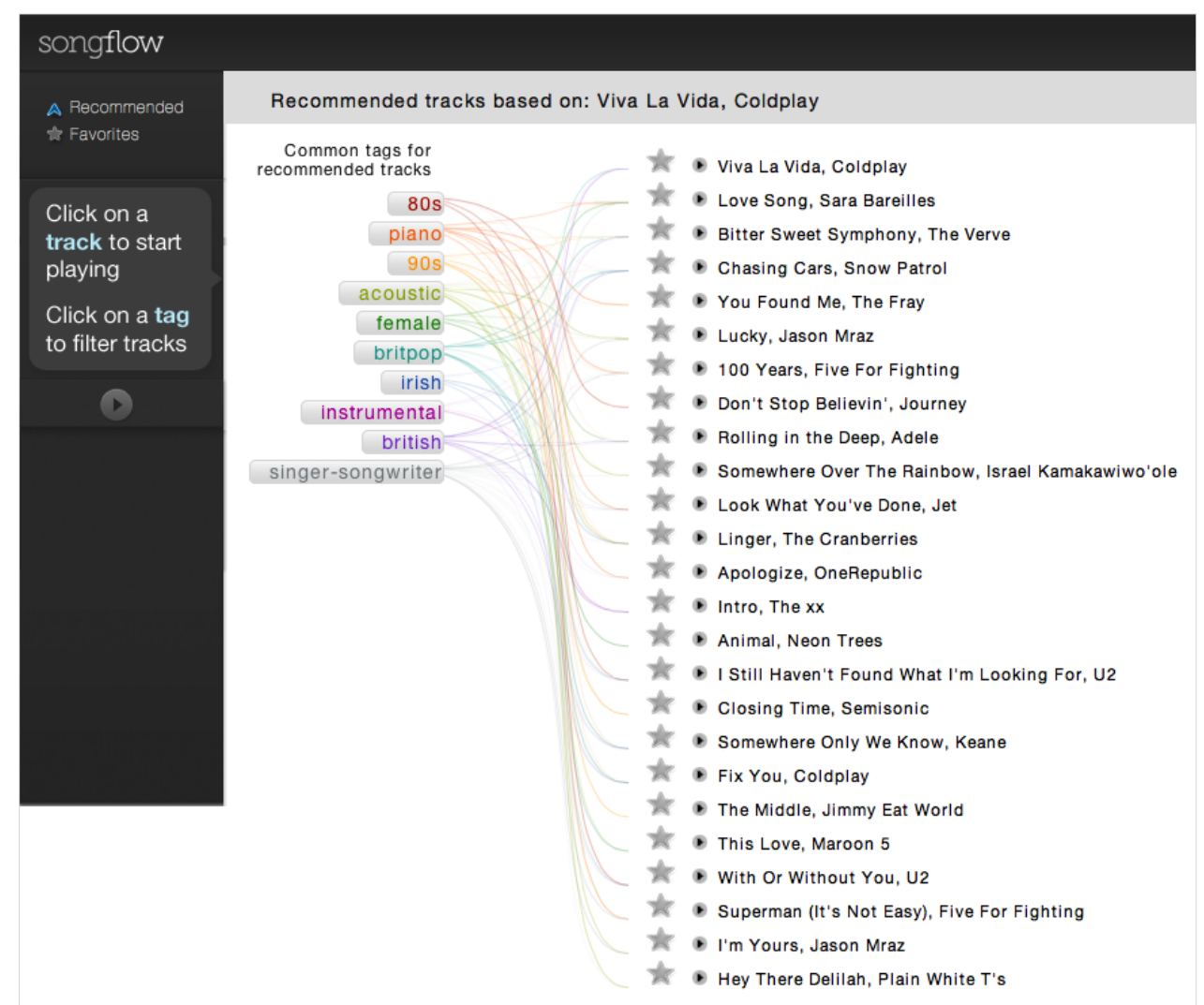

Figura 6.10: Tela do Tag Strings, versão revisada e usada nos Experimentos 2 e 3.

O experimento foi feita remotamente, no computador do participante. Foi pedido que participantes utilizassem os navegadores Safari ou Firefox, com plugin para Adobe Flash, suporte para HTML5.

Os testes foram avaliados através dos serviços Clicky, uma ferramenta de análise em tempo real, e Mouseflow ${ }^{23}$, um serviço que grava os cliques e movimentos do mouse.

\subsubsection{Design do Experimento}

Usuários vão testar duas interfaces: Tag Strings ou Design Base.

\section{Participantes}

\footnotetext{
${ }^{23} \mathrm{http}: / /$ mouseflow.com
} 
Efetuamos um teste intra-sujeitos (within subjects), com participantes usando as duas interfaces:

A tarefa usa duas tags: tag1: "happy", tag2: "piano".

As tarefas foram contrabalançadas para evitar efeito residual (carryover effect), deste modo:

- 17 usuários testaram tag1 com Design Base, e tag2 com Tag Strings

- 17 usuários testaram tag2 com Design Base, e tag1 com Tag Strings

- 17 usuários testaram tag1 com Tag Strings, e tag2 com Design Base

- 17 usuários testaram tag2 com Tag Strings, e tag1 com Design Base

Ao completar as duas tarefas, os participantes completaram um questionário.

Total de participantes: 68 .

Ao aceitar a tarefa no Mechanical Turk, os participantes concordaram com um termo de consentimento.

\section{Questionário de avaliação}

Ao final da tarefa, participantes preencheram um questionário. O objetivo do questionário era obter a opinião dos participantes sobre eficiência, eficácia, inspeção e satisfação, e comparar as opiniões entre o Design Base e Tag Strings.

Para a comparação de cada design, frases são apresentadas ao usuário, e esse deve indicar seu grau de concordância em uma escala Likert de 1-7. As frases são idênticas para cada design (Design Base e Tag Strings), permitindo sua comparação.

Para não influenciar os usuários com os nomes dos designs (Design Base e Tag Strings), durante o teste os designs foram chamados de: Design A (para o Design Base) e Design B (tags) (para Tag Strings).

Como a escala Likert é ordinal, mostramos a média e mediana dos resultados. A comparação dos resultados é feita através de um Teste de Wilcoxon emparelhado (Two Paired Sample Wilcoxon Signed Rank Test).

O questionário completo está no Apêndice I. 


\section{Questionário pré-teste}

O questionário pré-teste perguntou aos participantes sobre sua experiência com sites de streaming de música e serviços como o iTunes.

Sexo:

Idade:

Você utiliza algum desses programas ou sites?

iTunes, Windows Media Player, Pandora.com, Last.fm, Grooveshark, Rdio, Rhapsody, Spotify?

( ) Nunca

( ) Às vezes

( ) Sempre

Com que frequência você acessa a Internet?

( ) Uma vez por mês ou menos

( ) Uma vez por semana

( ) Todo dia

( ) Várias vezes ao dia

\section{Resultados do questionário pré-teste}

68 participantes foram selecionados a partir do questionário pré-teste.

O questionário pré-teste também foi usado para coletar informações relativas a experiência dos usuários com a Internet e sites de música.

O perfil procurado nos participantes era: usuários que utilizam a Internet com frequência, pelo menos todos os dias, e que usam programas ou sites de música. 


\section{Perfil dos 68 participantes:}

\section{Uso de Internet}

- $10 \%$ dos usuários usam a Internet todos os dias.

- $90 \%$ dos usuários usam a Internet muitas vezes ao dia.

\section{Uso de programas ou serviços de música digital}

- $100 \%$ usa pelo menos um software de música ou site de música digital.

- $\quad$ 98\% usa pelo menos um destes softwares ou serviços: iTunes, Windows Media Player or Winamp; Pandora, Last.fm; Spotify, Mog, Rdio, Grooveshark.

- $68 \%$ usa pelo menos um destes serviços: Pandora or Last.fm.

- $25 \%$ usa pelo menos um destes serviços: Spotify, Mog, Rdio, Grooveshark.

\section{Dados demográficos}

A média de idade dos participantes é 32.7 anos (o Mechanical Turk não permite trabalhadores com menos de 18 anos, por isso a idade dos participantes é no mínimo 18 anos).

- $41 \%$ dos participantes eram mulheres, $53 \%$ homens, e $6 \%$ não responderam.

\section{Tarefas}

Usuários vão efetuar as seguinte tarefas, utilizando uma das duas interfaces:

- Dentre as músicas recomendadas, marque com a estrela 3 músicas "bappy"

- Dentre as músicas recomendadas, marque com a estrela 3 músicas que usam "piano"

- Em termos de funcionalidade, as tarefas são as mesmas, só o conteúdo (tags) é diferente.

\section{Definição de respostas corretas}


Para definir quais as respostas corretas, usamos as tags aplicadas no serviço Last.fm, para cada música. No serviço Last.fm, as tags são aplicadas por usuários do serviço. Se uma música teve a tag "happy" aplicada por mais que 3 usuários, ela é considerada uma música "bappy".

Se uma música teve a tag "piano" ou "piano rock" aplicada por mais que 3 usuários, ela é considerada como usando "piano" como instrumento.

Para efetuar a checagem das respostas, a lista de tags para cada música foi baixada do serviço Last.fm, e para cada música, contamos o número de vezes que uma tag "bappy" ou "piano" foi aplicada.

\section{Limitações do experimento}

Para a definição das tarefas neste experimento, procuramos focar no cenário em que usuários procuram características específicas em uma lista de recomendações de música. Esse cenário pressupõe a necessidade de filtrar ou corrigir recomendações. Czarkowski [2006] mostra que corrigir recomendações não é uma prática comum. Portanto, esse cenário pode não ser o mais comum para usuários, mas é o cenário que procuramos otimizar neste projeto.

\subsubsection{Hipóteses}

H1 - Tag Strings vai superar Design Base em tempo para completar tarefa (eficiência)

H2 - Tag Strings vai superar Design Base em precisão (respostas corretas) (eficácia)

H3 - Tag Strings vai superar Design Base no suporte de decisões (eficácia)

H4 - Tag Strings vai superar Design Base em controle do usuário, por permitir filtragem das músicas (inspeção).

H5 - Tag Strings vai superar Design Base em diversão (satisfação)

H6 - Tag Strings vai superar Design Base em facilidade de utilização (satisfação)

\subsubsection{Resultados}

\section{H1 - Tag Strings vai superar o Design Base em tempo para completar tarefa (eficiência)}

Para testar a hipótese $\mathrm{H} 1$, analisamos o tempo utilizado pelos usuários para completar a tarefa com as duas tags. O tempo foi coletado automaticamente durante o experimento remoto, através da ferramenta Clicky. 
Conduzimos um teste $t$ para duas amostras independentes (two sample t test (unpaired)), para cada tag (como a ordem de interfaces e tags foi contrabalançada, o teste para cada tag é inter-sujeitos). Para o teste combinado (duas tags combinadas para cada interface testada), efetuamos um teste $\mathrm{t}$ emparelhado.

\begin{tabular}{|c|c|c|}
\hline \multicolumn{3}{|c|}{ Tag 1 - "bappy" } \\
\hline Participante & Design A (minutos) & Design B (minutos) \\
\hline 1 & 1.449 & 0.866 \\
\hline 2 & 1.15 & 1.766 \\
\hline 3 & 1.733 & 4.183 \\
\hline 4 & 1.233 & 0.366 \\
\hline 5 & 7.983 & 1.083 \\
\hline 6 & 0.583 & 1.983 \\
\hline 7 & 1.15 & 1.4 \\
\hline 8 & 2.716 & 1.283 \\
\hline 9 & 1.016 & 2.766 \\
\hline 10 & 1.483 & 0.283 \\
\hline 11 & 2.833 & 1.299 \\
\hline 12 & 2.683 & 1.233 \\
\hline 13 & 2.1 & 1.499 \\
\hline 14 & 1.233 & 1.716 \\
\hline 15 & 1.366 & 0.983 \\
\hline 16 & 3.999 & 1.183 \\
\hline 17 & 3.35 & 1.583 \\
\hline 18 & 2.15 & 0.883 \\
\hline 19 & 2.75 & 4.199 \\
\hline 20 & 1.466 & 2.633 \\
\hline 21 & 3.666 & 1.316 \\
\hline 22 & 4.933 & 1.549 \\
\hline 23 & 2.649 & 0.949 \\
\hline 24 & 2.033 & 4.516 \\
\hline 25 & 3.566 & 6.749 \\
\hline 26 & 5.2 & 0.666 \\
\hline 27 & 3.766 & 2.316 \\
\hline 28 & 6.4 & 1.183 \\
\hline
\end{tabular}


Experimentos com Visualização de Tags

\begin{tabular}{|l|l|l|}
\hline 29 & 1.216 & 0.999 \\
\hline 30 & 2.216 & 2.533 \\
\hline 31 & 1.933 & 6.133 \\
\hline 32 & 5.849 & 3.2 \\
\hline 33 & 2.283 & 0.883 \\
\hline 34 & 1.316 & 3.016 \\
\hline & & \\
\hline
\end{tabular}

Tag 2 - "piano"

\begin{tabular}{|c|c|c|}
\hline Participante & Design A (minutos) & Design B (minutos) \\
\hline 35 & 2.85 & 1.6 \\
\hline 36 & 3.666 & 1.066 \\
\hline 37 & 4.533 & 1.199 \\
\hline 38 & 1.5 & 1.566 \\
\hline 39 & 1.399 & 3.45 \\
\hline 40 & 12.833 & 4.116 \\
\hline 41 & 4.716 & 1.533 \\
\hline 42 & 4.45 & 2.616 \\
\hline 43 & 4.366 & 5.033 \\
\hline 44 & 1.05 & 1.55 \\
\hline 45 & 2.666 & 0.983 \\
\hline 46 & 3.283 & 0.466 \\
\hline 47 & 1.749 & 0.999 \\
\hline 48 & 2.833 & 0.449 \\
\hline 49 & 2.816 & 4.316 \\
\hline 50 & 3.266 & 1.349 \\
\hline 51 & 1.033 & 1.016 \\
\hline 52 & 1.483 & 2.299 \\
\hline 53 & 2.633 & 2.116 \\
\hline 54 & 4.616 & 0.899 \\
\hline 55 & 7.65 & 1.383 \\
\hline 56 & 1.433 & 3.383 \\
\hline 57 & 1.1 & 0.633 \\
\hline 58 & 6.133 & 2.033 \\
\hline 59 & 10.833 & 2.35 \\
\hline 60 & 0.583 & 0.766 \\
\hline
\end{tabular}




\begin{tabular}{|l|l|l|}
\hline 61 & 2.083 & 2.383 \\
\hline 62 & 2.066 & 1.399 \\
\hline 63 & 3.266 & 1.366 \\
\hline 64 & 2.35 & 0.366 \\
\hline 65 & 3.183 & 3.516 \\
\hline 66 & 2.216 & 1.116 \\
\hline 67 & 0.949 & 3.949 \\
\hline 68 & 3.999 & 0.133 \\
\hline
\end{tabular}

Tabela 6.6. Tempo para tarefas com tags "bappy" e "piano"

Tag 1: Dentre as músicas recomendadas, marque com a estrela 3 músicas " $h a p p y$ "

\begin{tabular}{|l|l|l|}
\hline & Design Base (minutos) & Tag Strings (minutos) \\
\hline Média & 2.69 & 2.036 \\
\hline Desvio padrão & 1.72 & 1.55 \\
\hline
\end{tabular}

Tabela 6.7: Média e desvio padrão do tempo para tarefas com tag "bappy"

Para tag 1 (“happy”) o valor bilateral p é 0.1039 , para alpha 0.05 , e não é estatisticamente significativo.

Tag 2: Dentre as músicas recomendadas, marque com a estrela 3 músicas que usam "piano"

\begin{tabular}{|l|l|l|}
\hline & Design Base (minutos) & Tag Strings (minutos) \\
\hline Média & 3.4 & 1.87 \\
\hline Desvio padrão & 2.66 & 1.26 \\
\hline
\end{tabular}

Tabela 6.8: Média e desvio padrão do tempo para tarefas com tag "piano"

Para tag 2 ("piano") o valor bilateral p é 0.0034, para alpha 0.05, e é estatisticamente significativo.

Tempo total da tarefa (combinando as duas tags)

\begin{tabular}{|l|l|l|}
\hline & Design Base (minutos) & Tag Strings (minutos) \\
\hline Média & 3.05 & 1.95 \\
\hline Desvio padrão & 2.25 & 1.4 \\
\hline
\end{tabular}

Tabela 6.9: Média e desvio padrão do tempo para tarefas para tags combinadas 
Para as tags combinadas, o valor bilateral p é 0.0009 , para alpha 0.05 , e é estatisticamente significativo.

Para a tag1 ("bappy"), não encontramos nenhuma diferença significativa entre o Design Base e Tag Strings, mas em geral, o tempo utilizado em Tag Strings $(M=2.036, \mathrm{DP}=1.55)$ foi menor que no Design Base $(\mathrm{M}=2.69, \mathrm{DP}=1.72)$.

Para a tag2 ("piano") encontramos diferença significativa no tempo utilizado entre o Design Base e Tag Strings, com $\mathrm{p}<0.003$ (bilateral), para alpha $=0.05$.

Para a tarefa com as duas tags combinadas, encontramos diferença significativa no tempo utilizado entre o Design Base e Tag Strings, com $\mathrm{p}<0.001$ (bilateral), para alpha $=0.05$.

\section{Tempo porTarefa}

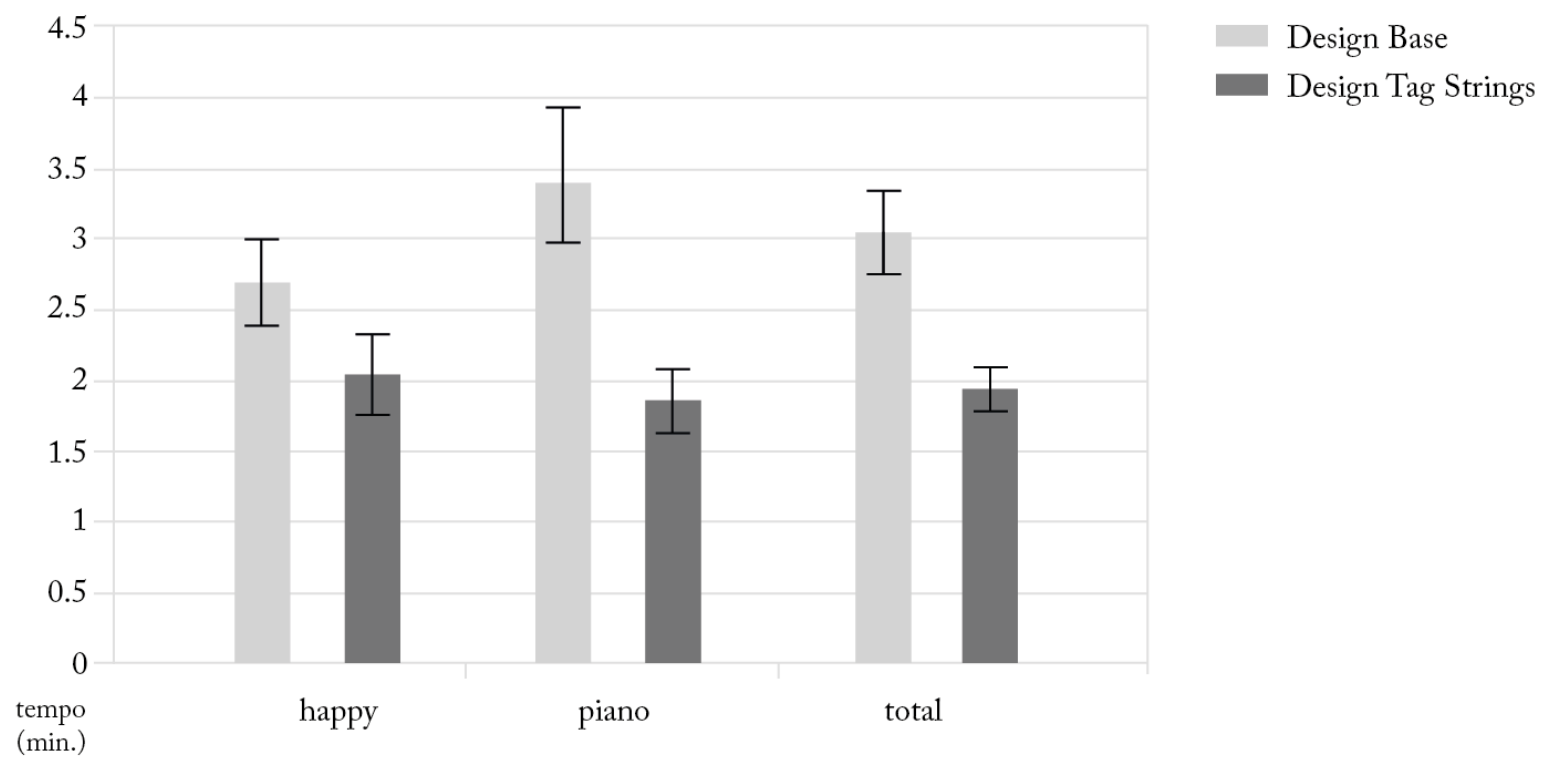

Gráfico A1: Média de tempo para tarefas

No questionário, ao perguntar como os design ajudam os usuários a completarem a tarefa mais rápido, os resultados foram (escala Likert de 1-7, onde 1: discordo firmemente, 7: concordo firmemente).

O Design A me ajudou a completar a tarefa mais rápido. 
Mediana: 1

Média: 2.26

O Design B (tags) me ajudou a completar a tarefa mais rápido.

Mediana: 7

Média: 6.38

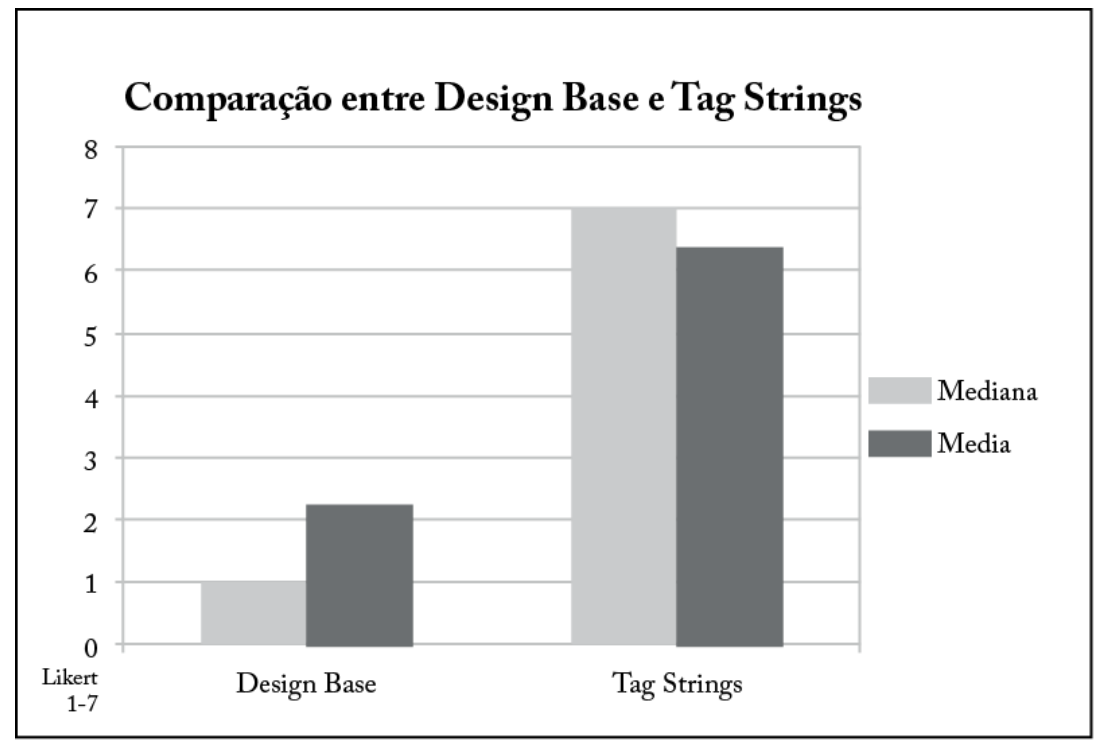

Gráfico A2: Média e mediana dos resultados na escala Likert

Comparando as duas frases na escala Likert, os resultados foram estatisticamente significativos, com $\mathrm{p}<0.001$ (bilateral).

Em geral, os resultados mostram que usuários completaram a tarefa mais rápido com Tag Strings, o que confirma a hipótese H1.

\section{H2 - Tag Strings vai superar Design Base em precisão (número de acertos) (eficácia)}

Para testar a hipótese $\mathrm{H} 2$, analisamos o número de acertos (respostas corretas) durante a tarefa. Para cada tag, o número mínimo de respostas corretas é 0 , e o máximo é 3. Conduzimos um teste da soma dos postos de Wilcoxon independentes (Two Independent Sample Wilcoxon Rank Sum Test) para cada uma das tags. 


\begin{tabular}{|c|c|c|}
\hline \multicolumn{3}{|c|}{ Tag 1 - "bappy” } \\
\hline Participantes & Design Base & Tag Strings \\
\hline 1 & 3 & 3 \\
\hline 2 & 3 & 1 \\
\hline 3 & 3 & 3 \\
\hline 4 & 2 & 3 \\
\hline 5 & 1 & 3 \\
\hline 6 & 0 & 3 \\
\hline 7 & 3 & 3 \\
\hline 8 & 3 & 3 \\
\hline 9 & 3 & 3 \\
\hline 10 & 3 & 3 \\
\hline 11 & 3 & 3 \\
\hline 12 & 3 & 2 \\
\hline 13 & 0 & 3 \\
\hline 14 & 3 & 3 \\
\hline 15 & 3 & 3 \\
\hline 16 & 2 & 3 \\
\hline 17 & 2 & 3 \\
\hline 18 & 3 & 3 \\
\hline 19 & 2 & 3 \\
\hline 20 & 3 & 3 \\
\hline 21 & 3 & 3 \\
\hline 22 & 3 & 2 \\
\hline 23 & 3 & 3 \\
\hline 24 & 3 & 2 \\
\hline 25 & 2 & 3 \\
\hline 26 & 2 & 3 \\
\hline 27 & 3 & 3 \\
\hline 28 & 3 & 3 \\
\hline 29 & 2 & 2 \\
\hline 30 & 3 & 3 \\
\hline 31 & 2 & 1 \\
\hline 32 & 3 & 3 \\
\hline
\end{tabular}

\begin{tabular}{|c|c|c|}
\hline \multicolumn{3}{|c|}{ Tag 2 - "piano" } \\
\hline Participantes & Design Base & Tag Strings \\
\hline 1 & 1 & 3 \\
\hline 2 & 2 & 2 \\
\hline 3 & 2 & 3 \\
\hline 4 & 3 & 3 \\
\hline 5 & 2 & 3 \\
\hline 6 & 3 & 3 \\
\hline 7 & 2 & 3 \\
\hline 8 & 3 & 3 \\
\hline 9 & 3 & 3 \\
\hline 10 & 3 & 2 \\
\hline 11 & 2 & 3 \\
\hline 12 & 3 & 3 \\
\hline 13 & 3 & 3 \\
\hline 14 & 2 & 3 \\
\hline 15 & 2 & 3 \\
\hline 16 & 2 & 3 \\
\hline 17 & 1 & 1 \\
\hline 18 & 2 & 3 \\
\hline 19 & 2 & 3 \\
\hline 20 & 3 & 3 \\
\hline 21 & 3 & 3 \\
\hline 22 & 2 & 3 \\
\hline 23 & 2 & 3 \\
\hline 24 & 3 & 3 \\
\hline 25 & 3 & 3 \\
\hline 26 & 2 & 3 \\
\hline 27 & 2 & 3 \\
\hline 28 & 3 & 3 \\
\hline 29 & 2 & 2 \\
\hline 30 & 3 & 3 \\
\hline 31 & 2 & 3 \\
\hline 32 & 2 & 3 \\
\hline
\end{tabular}




\begin{tabular}{|l|l|l|l|l|l|}
33 & 3 & 3 & 33 & 3 & 3 \\
\hline 34 & 1 & 3 & 0 & 3 \\
\hline 34 & Tabela & $6.11:$ Nimero de acertos (respostas corretas) por tags
\end{tabular}

Tag 1: Dentre as músicas recomendadas, marque com a estrela 3 músicas que usam "happy"

\begin{tabular}{|l|l|l|}
\hline & Design Base (acertos) & Tag Strings (acertos) \\
\hline Média & 2.29 & 2.85 \\
\hline
\end{tabular}

Tabela 6.12: Média de acertos (respostas corretas) para tag "bappy"

Para a tag "happy", ao comparar o número de acertos nos dois designs, os resultados foram estatisticamente significativos, com $\mathrm{p}<0.001$ (bilateral), e z-score $=3.293$.

Tag 2: Dentre as músicas recomendadas, marque com a estrela 3 músicas "piano"

\begin{tabular}{|l|l|l|}
\hline & Design Base (acertos) & Tag Strings (acertos) \\
\hline Média & 2.47 & 2.77 \\
\hline
\end{tabular}

Tabela 6.13: Média de acertos (respostas corretas) para tag "piano"

Para a tag "piano", ao comparar o número de acertos nos dois designs, os resultados não foram estatisticamente significativos, com $\mathrm{p}<0.202$ (bilateral), e z-score $=1.276$.

Em geral, a média de acertos em Tag Strings (2.77) foi maior que a média de acertos do Design Base (2.47).

\section{Tags Combinadas}

\begin{tabular}{|l|l|l|}
\hline & Design Base (acertos) & Tag Strings (acertos) \\
\hline Média & 2.38 & 2.81 \\
\hline
\end{tabular}

Tabela 6.14: Média de acertos (respostas corretas) para tags combinadas

Para as tags combinadas, ao comparar o número de acertos nos dois designs, os resultados foram estatisticamente significativos, com $\mathrm{p}<0.001$ (bilateral), e z-score $=3.293$.

Em geral, os resultados mostram mais acertos com Tag Strings, o que confirma a hipótese H2. 
Ao comparar o design Tag Strings e Design Base, observamos que para a tag "happy”, a diferença do tempo foi menor, mas a diferença de acertos foi estatisticamente significativa. Com a tag "piano", a diferença do tempo foi estatisticamente significativa, mas no número de acertos, não.

Uma possibilidade é que a tag "bappy" é mais subjetiva que "piano", e por isso, usuários se esforçaram menos para encontrar respostas corretas, e levaram menos tempo para completar a tarefa (em ambos designs). A tag "piano", mais objetiva, requer mais esforço dos usuários e leva mais tempo, mas o número de respostas corretas foi maior.

As respostas do questionário a seguir mostram a opinião dos usuários com relação a qual design ajuda usuários a tomarem decisões melhores (eficácia).

\section{H3 - Tag Strings vai superar Design Base no suporte de decisões (eficácia)}

Como detalhado no capítulo 2, explicações eficazes afetam decisões de usuários de várias maneiras diferentes:

- Explicações eficazes ajudam usuários a encontrar itens úteis e eliminar os inúteis.

- Explicações eficazes ensinam usuários algo sobre as recomendações.

\section{O Design A me ajudou a encontrar músicas que eu procurava}

Mediana: 1

Média: 2

O Design B (tags) me ajudou a encontrar músicas que eu procurava

Mediana: 7

Média: 6.41 


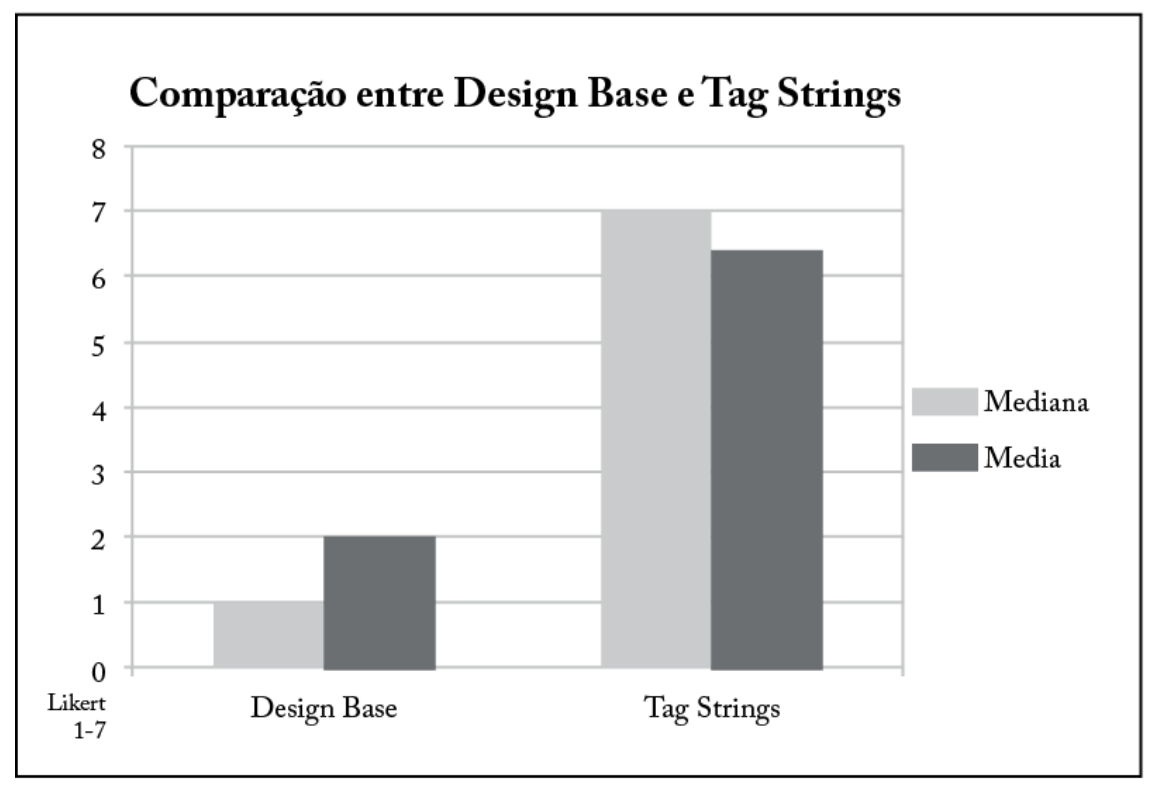

Gráfico A3: Média e mediana dos resultados na escala Likert

Comparando as duas frases na escala Likert, os resultados foram estatisticamente significativos, com $\mathrm{p}<0.001$ (bilateral).

Design A me ajudou a aprender algo sobre as músicas recomendadas

Mediana: 2

Média: 2.25

Design B (tags) me ajudou a aprender algo sobre as músicas recomendadas.

Mediana: 6

Média: 5.96 


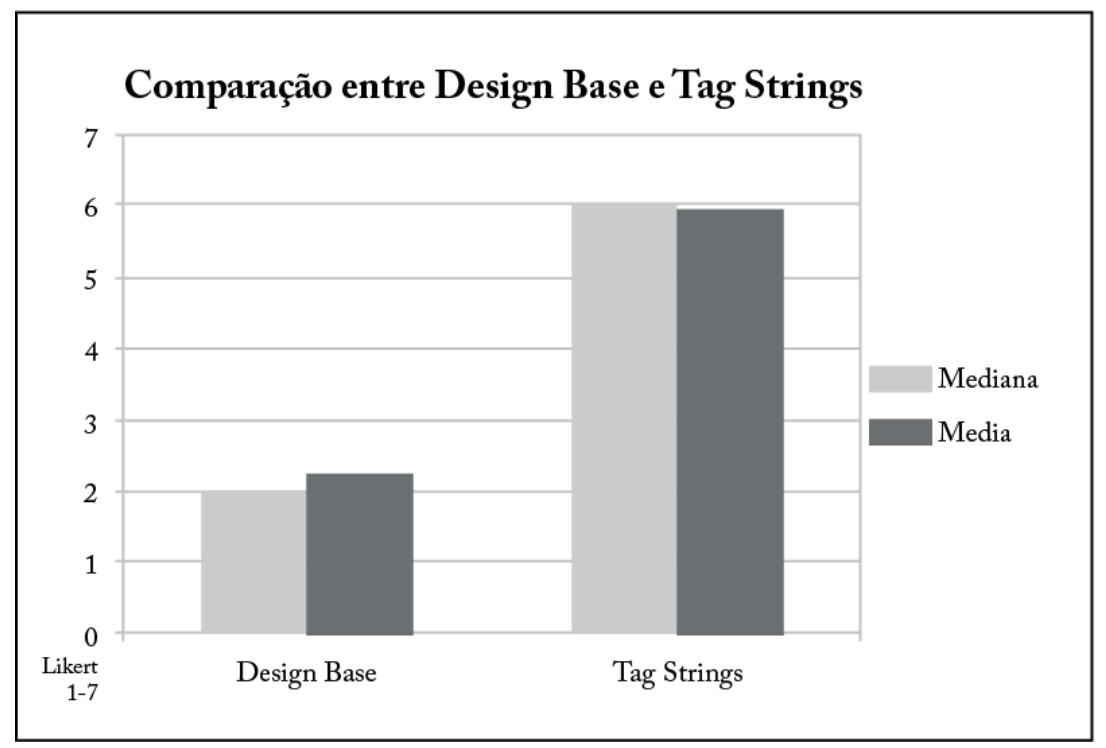

Gráfico A4: Média e mediana dos resultados na escala Likert

Comparando as duas frases na escala Likert, os resultados foram estatisticamente significativos, com $\mathrm{p}<0.001$ (bilateral).

Em geral, os resultados mostram que Tag Strings supera o Design Base no suporte de decisões (ajuda usuários a encontrar músicas procuradas, e ajuda usuários a aprender algo sobre as músicas recomendadas), o que confirma a hipótese $\mathrm{H} 3$.

\section{H4 - Tag Strings vai superar Design Base em controle do usuário, por permitir filtragem das músicas (inspeção).}

Os dados coletados mostram que 53\% dos participantes clicaram nas tags. Esse número não foi surpreendente, já que corrigir recomendações não é uma prática tão comum entre usuários [Czarkowski, 2006]. A relação entre tags e músicas também é mostrada ao colocar o cursor sobre uma tag (hover). Assim, é difícil medir a influência das tags apenas em cliques, mas sabemos que pelo menos $53 \%$ dos usuários clicaram nas tags para filtrar recomendações.

O resultado do questionário segue abaixo:

Design A me ajudou a filtrar as músicas recomendadas

Mediana: 1

Média: 1.74 
Experimentos com Visualização de Tags

Design B (tags) me ajudou a filtrar as músicas recomendadas

Mediana: 7

Média: 6.57

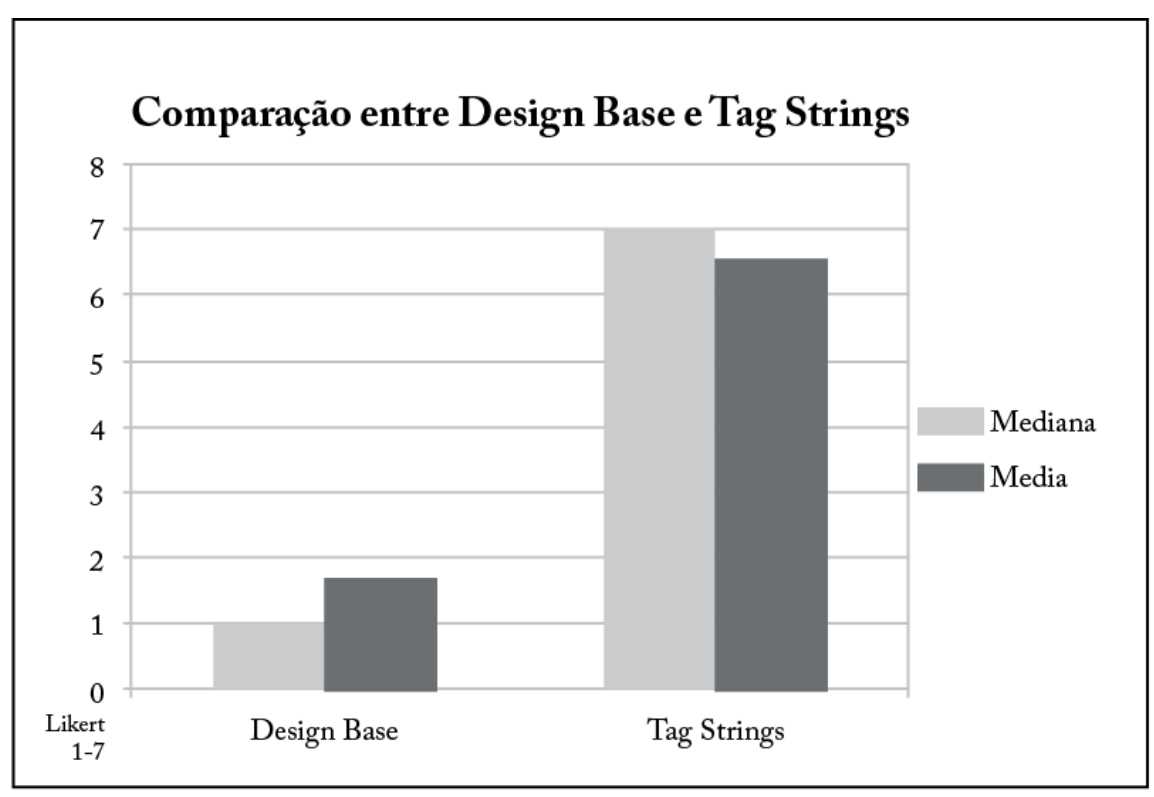

Gráfico A5: Média e mediana dos resultados na escala Likert

Comparando as duas frases na escala Likert, os resultados foram estatisticamente significativos, com $\mathrm{p}<0.001$ (bilateral).

Design A aumentou meu controle sobre as músicas recomendadas

Mediana: 1

Média: 1.88

Design B (tags) aumentou meu controle sobre as músicas recomendadas

Mediana: 7

Média: 6.46 


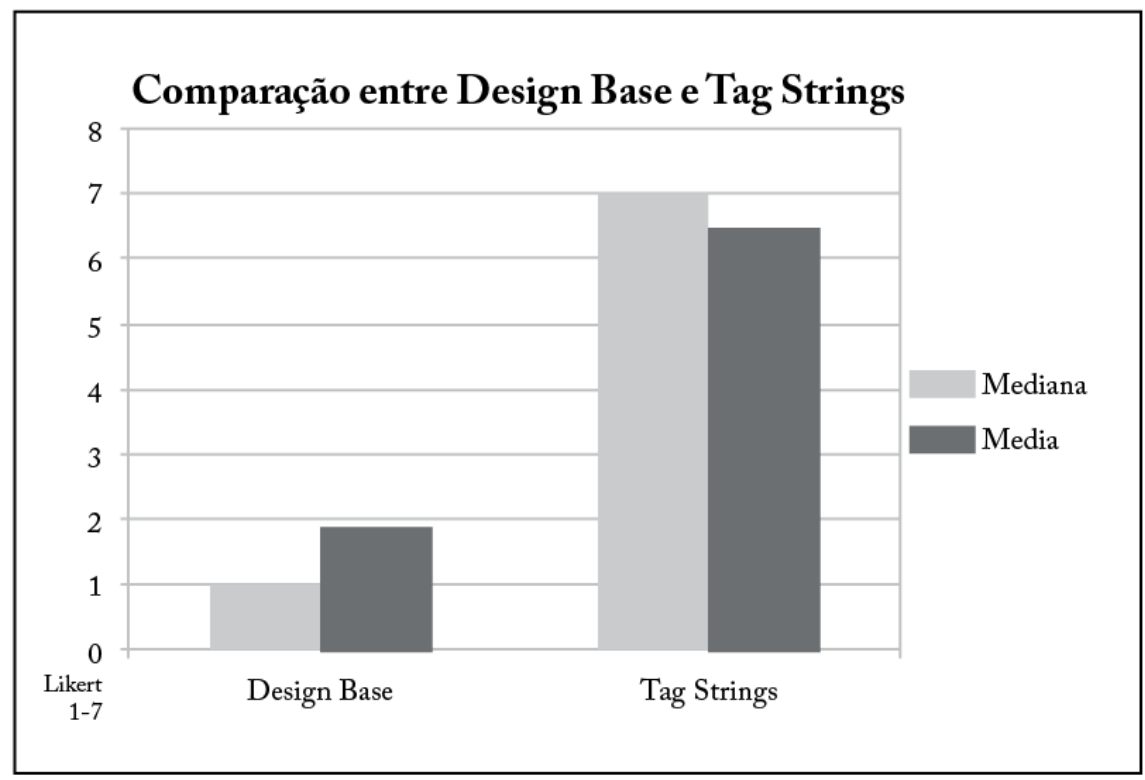

Gráfico A6: Média e mediana dos resultados na escala Likert

Comparando as duas frases na escala Likert, os resultados foram estatisticamente significativos, com $\mathrm{p}<0.001$ (bilateral).

Em geral, os resultados mostram que ao comparar o Design Base e Tag Strings, Tag Strings supera Design Base nas avaliações dos participantes em filtragem e aumento do controle sobre as recomendações, o que confirma a hipótese H4.

\section{Alguns comentários dos usuários:}

"I didn't know how to filter on Design A-but I just listened to all the songs to see if I could hear the piano. But I loved Design $B$ - it was just like a flow chart and very easy to use."

(“Eu não sabia como filtrar no Design A - eu simplesmente escutei todas as músicas para ver se eu podia escutar o piano. Mas eu adorei o Design B - era como um gráfico de fluxos e muito fácil de usar.")

"I strongly liked design B over design A. I liked the way you could sort the songs much better."

("Eu gostei muito mais do Design B do que do A. Eu gostei muito mais da maneira em que se pode ordenar as músicas")

"I really liked design B. I liked the tags!!!"

(“Eu realmente gostei do design B. Eu gostei das tags!!!”)

"Design $A$ is not really user friendly. It does not allow the user to chose their music quickly and sort through it. Design B is much more user friendly." 
(“Design A não é muito amigável. Ele não permite que o usuário escolha músicas rapidamente, e ordene entre essas. Design B é muito mais amigável.”)

\section{H5 - Tag Strings vai superar Design Base em diversão (satisfação)}

Design A foi divertido de usar

Mediana: 2

Média: 2.66

Design B (tags) foi divertido de usar

Mediana: 7

Média: 6.24

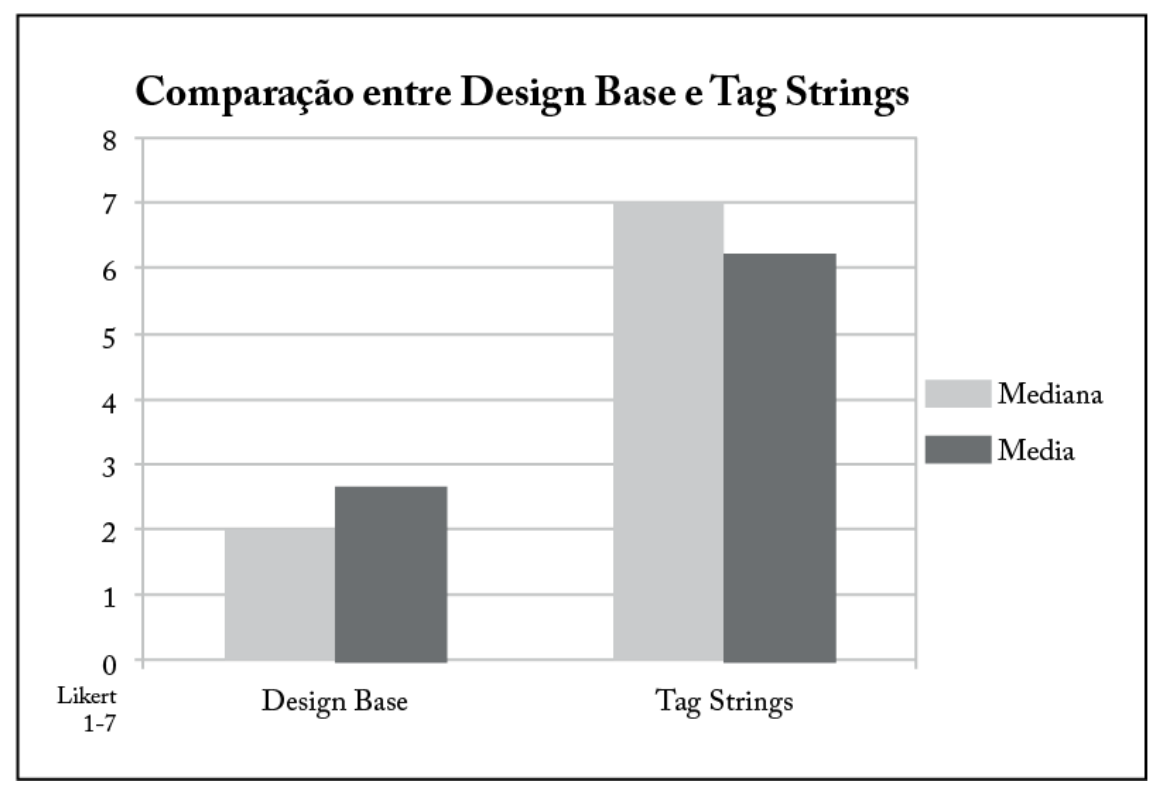

Gráfico A7: Média e mediana dos resultados na escala Likert

Comparando as duas frases na escala Likert, os resultados foram estatisticamente significativos, com $\mathrm{p}<0.001$ (bilateral).

Em geral, eu fiquei satisfeito usando o Design A

Mediana: 3

Média: 2.87 
Em geral, eu fiquei satisfeito usando o Design B (tags)

Mediana: 7

Média: 6.338

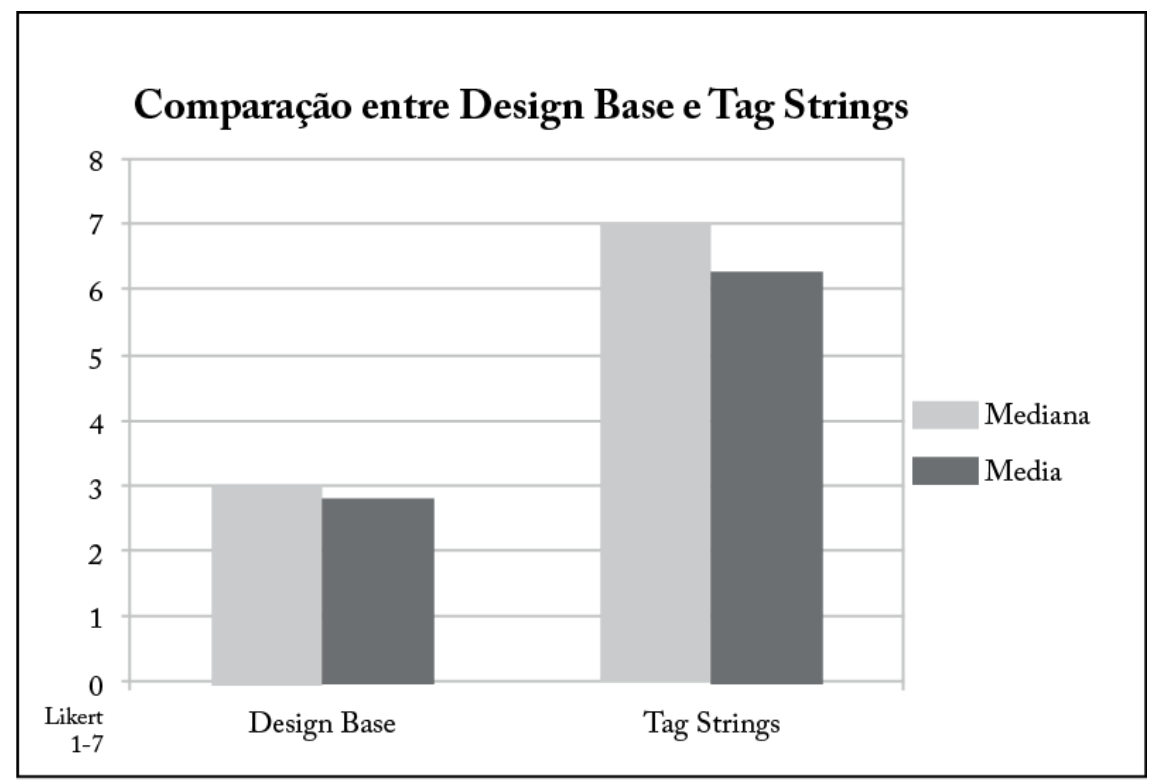

Gráfico A8: Média e mediana dos resultados na escala Likert

Comparando as duas frases na escala Likert, os resultados foram estatisticamente significativos, com $\mathrm{p}<0.001$ (bilateral).

Em geral, os resultados mostram que ao comparar o Design Base e Tag Strings, Tag Strings supera Design Base nas avaliações dos participantes em diversão e satisfação, o que favorece a hipótese H5.

Alguns comentários dos usuários:

"b is fun to use"

("b é divertido de usar")

\section{H6 - Tag Strings vai superar Design Base em facilidade de utilização (satisfação)}

Design A foi fácil de usar

Mediana: 5

Média: 4.25 
Experimentos com Visualização de Tags

\section{Design B foi fácil de usar}

Mediana: 6

Média: 6.25

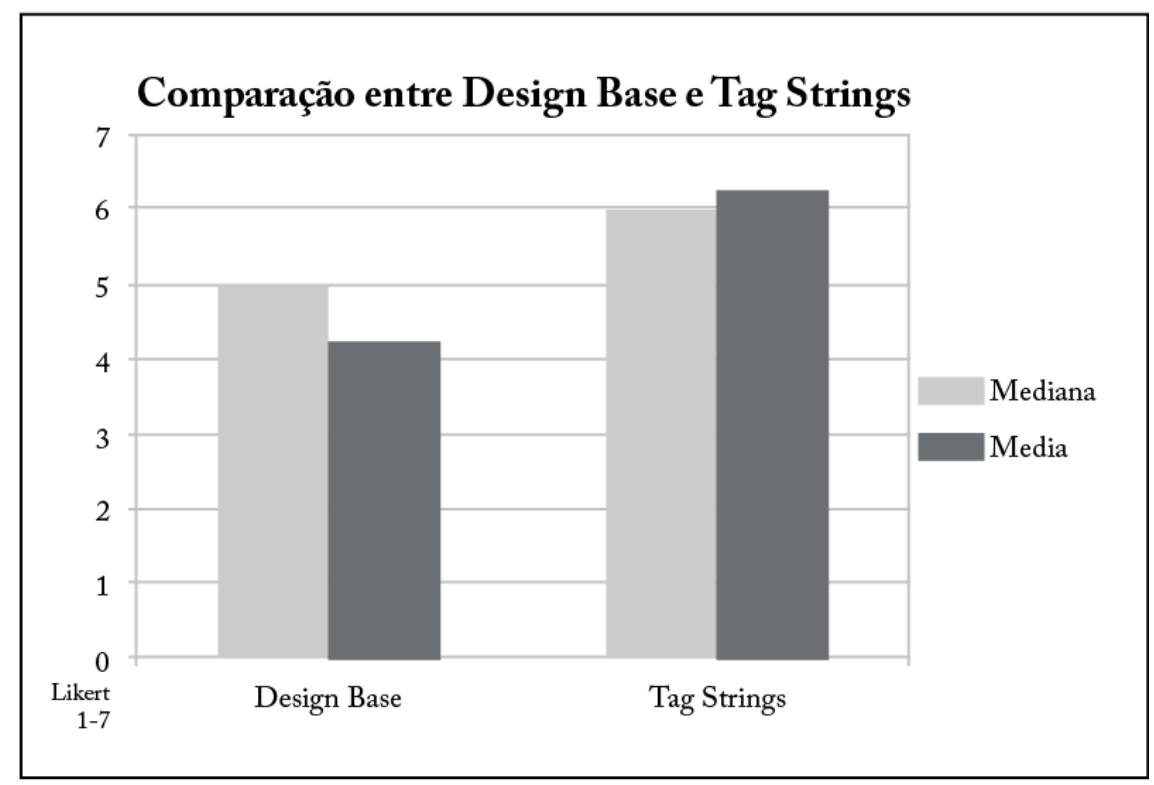

Gráfico A9: Média e mediana dos resultados na escala Likert

Comparando as duas frases na escala Likert, os resultados foram estatisticamente significativos, com $\mathrm{p}<0.001$ (bilateral).

A explicação das recomendações no Design A (“Pessoas que escutam isto também gostam de:") é útil.

Mediana: 4

Média: 3.47

A explicação das recomendações do Design B (a lista de tags) é útil.

Mediana: 6

Média: 6.19 


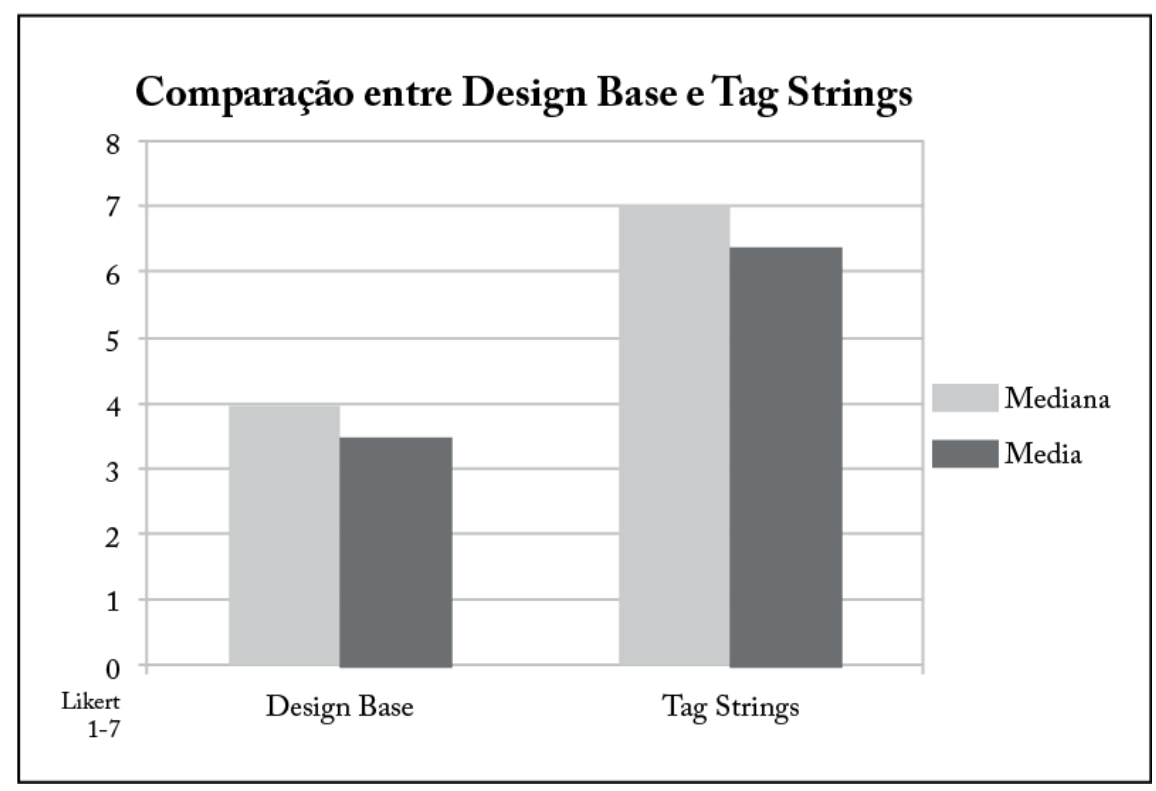

Gráfico A10: Média e mediana dos resultados na escala Likert

Comparando as duas frases na escala Likert, os resultados foram estatisticamente significativos, com $\mathrm{p}<0.001$ (bilateral).

Em geral, os resultados mostram que ao comparar o Design Base e Tag Strings, Tag Strings supera Design Base nas avaliações dos participantes em diversão, facilidade de uso e utilidade das explicações, o que apóia a hipótese 6.

\section{Alguns comentários dos usuários:}

" $B$ is much, much easier to use"

("B é muito, muito mais fácil de usar")

"I think that design A needs to give the user more choice over what songs they are listening to. This design seemed very unintuitive and was difficult to figure out at first. I thought Design $B$ was excellent, easy to understand, and very useful."

(“Acho que o design A precisa oferecer aos usuários mais escolhas de quais músicas escutar. Esse design era muito pouco intuitivo e a primeira vista, difícil de entender. Eu achei o Design B excelente, fácil de entender, e muito útil.”)

Essa seção detalhou o Experimento 2, e estabeleceu hipóteses que buscaram responder as questões da pesquisa. A construção desse experimento permitiu avaliar empiricamente a visualização Tag Strings comparada com o Design Base. Na seção seguinte, detalhamos o Experimento 3. 


\subsection{Experimento 3 - Comparando Tag Strings com Design Base, com Pandora}

\section{Objetivo}

Comparar Tag Strings com serviços semelhantes, usando como referência o Design Base, baseado nos serviços Last.fm e Pandora. Mas ao invés de utilizar recomendações do serviço Last.fm, como no Experimento 2, utilizamos recomendações do serviço Pandora.

O sistema de recomendação do serviço Pandora é baseado em conteúdo, e avaliação do conteúdo é feita por uma equipe de musicólogos [Pandora, 2012]:

"Nossa equipe de analistas musicólogos tem escutado músicas, uma canção de cada vez, estudando e coletando literalmente centenas de detalhes - melodia, harmonia, instrumentação, ritmo, vocais, letras... e mais! (...) Cada música no Projeto Genoma é analisada usando até 450 características distintas por um analista treinado na área. Esses atributos capturam não só a identidade musical de uma canção, mas também muitas qualidades significantes que são relevantes para o entendimento de preferências de ouvintes. (...) Acreditamos que cada individuo tem uma relação única com música - nenhum gosto é exatamente igual. Assim, entregar uma grande experiência de rádio para cada ouvinte requer um entendimento amplo e profundo de música. (...) Pandora não usa analisa músicas através de computadores, ou outras formas automáticas de extração de dados."

O Experimento 2 utilizou recomendações do serviço Last.fm, que é baseado em filtragem colaborativa. Com o Experimento 3, procuramos mostrar que o processo de coleta de tags e interface Tag Strings também pode ser utilizado com um serviço de recomendação diferente. Assim, no Experimento 3, conduzimos testes para descobrir se a interface Tag Strings pode ser usada para atingir as metas de eficiência e eficácia.

Mais especificamente, procuramos responder as seguinte questões, aplicadas a um serviço de recomendação baseado em conteúdo:

- A visualização Tag Strings ajuda usuários a filtrar recomendações de música (inspeção)?

- A visualização Tag Strings ajuda usuários a poupar tempo e esforço ao avaliar recomendações (eficiência)?

- A visualização Tag Strings ajuda usuários a tomar decisões melhores (eficácia)?

- A visualização Tag Strings ajuda no divertimento do usuário (satisfação)?

\subsubsection{Materiais}


Para o Experimento 3 usamos dois protótipos: Tag Strings (com alguns ajustes) e Design Base (baseado em serviços populares como Last.fm e Pandora). Detalhamos o Design Base na seção anterior.

A avaliação foi feita remotamente, no computador do participante. Foi pedido que participantes utilizassem os navegadores Safari ou Firefox, com plugin para Adobe Flash, e suporte para HTML5.

Os testes foram avaliados através dos serviços Clicky, uma ferramenta de análise em tempo real, e Mouseflow, um serviço que grava os cliques e movimentos do mouse.

\subsubsection{Design do Experimento}

Usuários vão testar duas interfaces; Tag Strings ou Design Base.

\section{Participantes}

Efetuamos um teste intra-sujeitos, com participantes usando as duas interfaces. A tarefa usa duas tags: tag1: female e tag2: piano.

As tarefas foram contrabalançadas para evitar efeito residual (carryover effect), deste modo:

- 13 usuários testaram tag1 com Design Base, e tag2 com Tag Strings

- 13 usuários testaram tag2 com Design Base, e tag1 com Tag Strings

- 13 usuários testaram tag1 com Tag Strings, e tag2 com Design Base

- 13usuarios testaram tag2 com Tag Strings, e tag1 com Design Base

Ao completar as duas tarefas, os participantes completaram um questionário.

Total de participantes: 52 .

Ao aceitar a tarefa no Mechanical Turk, os participantes concordaram com um termo de consentimento.

\section{Questionário de avaliação}

Ao final da tarefa, participantes preencheram um questionário. O objetivo do questionário era obter a opinião dos participantes sobre eficiência, eficácia, inspeção e satisfação, e comparar as opiniões entre o Design Base e Tag Strings. 
Para a comparação de cada design, frases são apresentadas ao usuário, e esse deve indicar seu grau de concordância em uma escala Likert de 1-7. As frases são idênticas para cada design (Design Base e Tag Strings), permitindo sua comparação.

Para não influenciar os usuários com os nomes dos designs (Design Base e Tag Strings), durante o teste os designs foram chamados de: Design A (para o Design Base) e Design B (tags) (para Tag Strings).

Como a escala Likert é ordinal, mostramos a média e mediana dos resultados. A comparação dos resultados é feita através de um Teste de Wilcoxon emparelhado (Two Paired Sample Wilcoxon Signed Rank Test).

O questionário completo está no Apêndice I.

\section{Questionário pré-teste}

O questionário pré-teste perguntou aos participantes sobre sua experiência com sites de streaming de música e serviços como o iTunes.

Sexo:

Idade:

Você utiliza algum destes programas ou sites?

iTunes, Windows Media Player, Pandora.com, Last.fm, Grooveshark, Rdio, Rhapsody, Spotify?

( ) Nunca

( ) As vezes

( ) Sempre

Com que frequência você acessa a Internet?

( ) Uma vez por mês ou menos

( ) Uma vez por semana

( ) Todo dia

( ) Várias vezes ao dia 


\section{Resultados do questionário pré-teste}

52 participantes foram selecionados a partir do questionário pré-teste. O questionário pré-teste também foi usado para coletar informações relativas a experiência dos usuários com a Internet e sites de música. O perfil procurado nos participantes era: usuários que utilizam a Internet com frequência, e que utilizam programas ou sites de música.

\section{Perfil dos 52 participantes:}

\section{Uso de Internet}

- $2 \%$ dos usuários usam a Internet uma vez por semana

- $11.5 \%$ dos usuários usam a Internet todos os dias

- $\quad 86.5 \%$ dos usuários usam a Internet muitas vezes ao dia

\section{Uso de programas ou serviços de música digital}

- 100\% usa pelo menos um software de música ou site de música digital, e usa pelo menos um desses softwares ou serviços: iTunes, Windows Media Player ou Winamp; Pandora, Last.fm; Spotify, Mog, Rdio, Grooveshark

- $65 \%$ usa pelo menos um destes serviços: Pandora ou Last.fm

- $\quad 25 \%$ usa pelo menos um desses serviços: Spotify, Mog, Rdio, Grooveshark

\section{Dados demográficos}

A média de idade dos participantes é 30.5 anos (o Mechanical Turk não permite trabalhadores com menos de 18 anos, por isso a idade dos participantes é no mínimo 18 anos).

- $34.5 \%$ dos usuários eram mulheres, 59.5\% homens, e 6\% não responderam.

\section{Tarefas}

Usuários vão efetuar as seguinte tarefas, utilizando uma das duas interfaces: 
- Dentre as músicas recomendadas, marque com a estrela 3 músicas que tem pelo menos uma "female singer"

- Dentre as músicas recomendadas, marque com a estrela 3 músicas que usam "piano"

Em termos de funcionalidade, as tarefas são as mesmas, só o conteúdo (tags) é diferente.

\section{Definição de respostas corretas}

Para definir quais as respostas corretas, usamos as tags aplicadas no serviço Last.fm, para cada música. No serviço Last.fm, as tags são aplicadas por usuários do serviço.

Para efetuar a checagem das respostas, a lista de tags para cada música foi baixada do serviço Last.fm, e para cada música, contamos o número de vezes que uma tag "female" ou "piano" foi aplicada.

\section{Limitações do experimento}

Para a definição das tarefas neste experimento, procuramos focar no cenário em que usuários procuram características específicas em uma lista de recomendações de música. Esse cenário pressupõe a necessidade de filtrar ou corrigir recomendações. Czarkowski [2006] mostra que corrigir recomendações não é uma prática comum. Portanto, esse cenário pode não ser o mais comum para usuários, mas é o cenário que procuramos otimizar neste projeto.

\subsubsection{Hipóteses}

H1 - Tag Strings vai superar Design Base em tempo para completar tarefa (eficiência)

H2 - Tag Strings vai superar Design Base em precisão (com mais respostas corretas) (eficácia)

H3 - Tag Strings vai superar Design Base no suporte de decisões (eficácia)

H4 - Tag Strings vai superar Design Base em controle do usuário, por permitir filtragem das músicas (inspeção).

H5 - Tag Strings vai superar Design Base em diversão (satisfação)

H6 - Tag Strings vai superar Design Base em facilidade de utilização (satisfação) 


\subsubsection{Resultados}

\section{H1 - Tag Strings vai superar o Design Base em tempo para completar tarefa (eficiência)}

Para testar a hipótese H1, analisamos o tempo utilizado pelos usuários para completar a tarefa com as duas tags. O tempo foi coletado automaticamente durante o experimento remoto, através da ferramenta Clicky.

Conduzimos um teste $t$ para duas amostras independentes (two sample t test (unpaired)), para cada tag (como a ordem de interfaces e tags foi contrabalançada, o teste para cada tag é inter-sujeitos). Para o teste combinado (duas tags combinadas para cada interface testada), efetuamos um teste $t$ emparelhado.

\begin{tabular}{|c|c|c|}
\hline \multicolumn{3}{|c|}{ Tag 1 - "female" } \\
\hline Participante & Design Base (minutos) & Tag Strings (minutos) \\
\hline 1 & 1.866 & 0.766 \\
\hline 2 & 1.083 & 0.183 \\
\hline 3 & 0.999 & 1.166 \\
\hline 4 & 3.016 & 1.183 \\
\hline 5 & 1.15 & 1.799 \\
\hline 6 & 5.366 & 0.683 \\
\hline 7 & 2.133 & 3.016 \\
\hline 8 & 8.2 & 1.383 \\
\hline 9 & 1.499 & 1.966 \\
\hline 10 & 4.733 & 0.75 \\
\hline 11 & 2.15 & 0.633 \\
\hline 12 & 3.35 & 0.699 \\
\hline 13 & 0.866 & 0.566 \\
\hline 14 & 0.883 & 0.566 \\
\hline 15 & 1.849 & 1.466 \\
\hline 16 & 1.649 & 0.516 \\
\hline 17 & 2.083 & 0.216 \\
\hline 18 & 0.566 & 1.2 \\
\hline 19 & 0.649 & 2.583 \\
\hline 20 & 9.933 & 3.4 \\
\hline 21 & 4.233 & 0.766 \\
\hline
\end{tabular}




\begin{tabular}{|l|l|l|}
\hline 22 & 0.583 & 4.616 \\
\hline 23 & 1.383 & 0.35 \\
\hline 24 & 6.033 & 0.466 \\
\hline 25 & 0.733 & 0.3 \\
\hline 26 & 0.549 & 1.216 \\
\hline & & \\
\hline
\end{tabular}

Tag 2 - "piano"

\begin{tabular}{|c|c|c|}
\hline Participante & Design Base (minutos) & Tag Strings (minutos) \\
\hline 1 & 0.716 & 0.066 \\
\hline 2 & 0.649 & 2.216 \\
\hline 3 & 1.05 & 1.616 \\
\hline 4 & 1.983 & 1.016 \\
\hline 5 & 4.433 & 1.05 \\
\hline 6 & 2.333 & 0.916 \\
\hline 7 & 2.4 & 0.233 \\
\hline 8 & 2.983 & 2.766 \\
\hline 9 & 1.666 & 0.599 \\
\hline 10 & 2.366 & 1.3 \\
\hline 11 & 1.649 & 0.416 \\
\hline 12 & 3.266 & 2.583 \\
\hline 13 & 1.2 & 0.4 \\
\hline 14 & 2.016 & 2.333 \\
\hline 15 & 5.433 & 1.4 \\
\hline 16 & 3.966 & 1.883 \\
\hline 17 & 1.233 & 0.683 \\
\hline 18 & 1.2 & 0.766 \\
\hline 19 & 1.899 & 0.716 \\
\hline 20 & 1.933 & 3.666 \\
\hline 21 & 1.299 & 6.35 \\
\hline 22 & 1.3 & 0.35 \\
\hline 23 & 0.583 & 1.483 \\
\hline 24 & 0.949 & 2.1 \\
\hline 25 & 0.799 & 0.233 \\
\hline 26 & 2.166 & 0.483 \\
\hline
\end{tabular}

Tabela 6.23: Tempo para tarefas no Design A e B, com tags "female" e "piano" 
Tag 1: Dentre as músicas recomendadas, marque com a estrela 3 músicas com pelo menos uma "female singer"

\begin{tabular}{|l|l|l|}
\hline & Design Base (minutos) & Tag Strings (minutos) \\
\hline Média & 2.59 & 1.25 \\
\hline Desvio padrão & 2.45 & 1.08 \\
\hline
\end{tabular}

Tabela 6.24 : Média e desvio padrão do tempo para tarefas com a tag "female"

Para tag 1 (“female") o valor bilateral p é 0.0134, para alpha 0.05, e é estatisticamente significativo.

Tag 2: Dentre as músicas recomendadas, marque com a estrela 3 músicas que usam "piano"

\begin{tabular}{|l|l|l|}
\hline & Design Base (minutos) & Tag Strings (minutos) \\
\hline Média & 1.98 & 1.45 \\
\hline Desvio padrão & 1.21 & 1.36 \\
\hline
\end{tabular}

Tabela 6.25: Média e desvio padrão do tempo para tarefas com a tag "piano"

Para tag 2 (“piano") o valor bilateral p é 0.14 , para alpha 0.05 , e não é estatisticamente significativo.

Tempo total da tarefa (combinando as duas tags)

\begin{tabular}{|l|l|l|}
\hline & Design Base (minutos) & Tag Strings (minutos) \\
\hline Média & 2.28 & 1.34 \\
\hline Desvio padrão & 2.25 & 1.4 \\
\hline
\end{tabular}

Tabela 6.26: Média e desvio padrão do tempo para tarefas com tags combinadas

Para as tags combinadas, o valor bilateral p é 0.0009., para alpha 0.05, e é estatisticamente significativo.

Para a tag1 ("female") encontramos diferença significativa no tempo utilizado entre o Design Base e Tag Strings, com $\mathrm{p}<0.0134$ (bilateral), para alpha $=0.05$.

Para a tag2 (“piano"), não encontramos nenhuma diferença significativa entre o Design Base e Tag Strings, mas em geral, o tempo utilizado em Tag Strings $(M=1.45, \mathrm{DP}=1.36)$ foi menor que no Design Base (M=1.98, DP=1.21).

Para a tarefa com as duas tags combinadas, encontramos diferença significativa no tempo utilizado entre o Design Base e Tag Strings, com p<0.001 (bilateral), para alpha $=0.05$. 


\section{Tempo por'Tarefa}

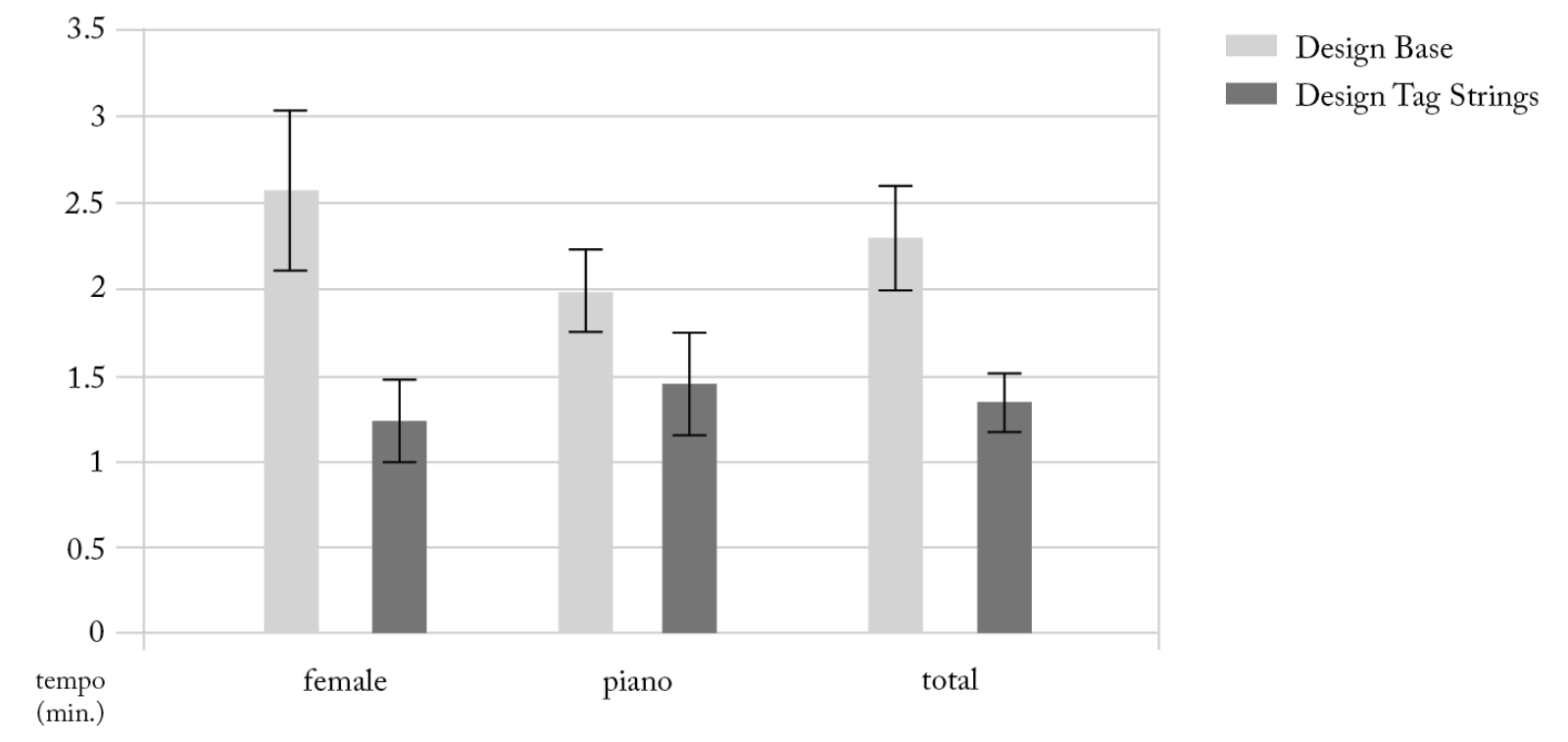

Gráfico A11: Média de tempo para tarefas

No questionário, ao perguntar como os design ajudam os usuários a completarem a tarefa mais rápido, os resultados foram (escala Likert de 1-7, onde 1: discordo firmemente, 7: concordo firmemente).

O Design A me ajudou a completar a tarefa mais rápido.

Mediana: 2

Média: 2.82

O Design B (tags) me ajudou a completar a tarefa mais rápido.

Mediana: 7

Média: 6.31 


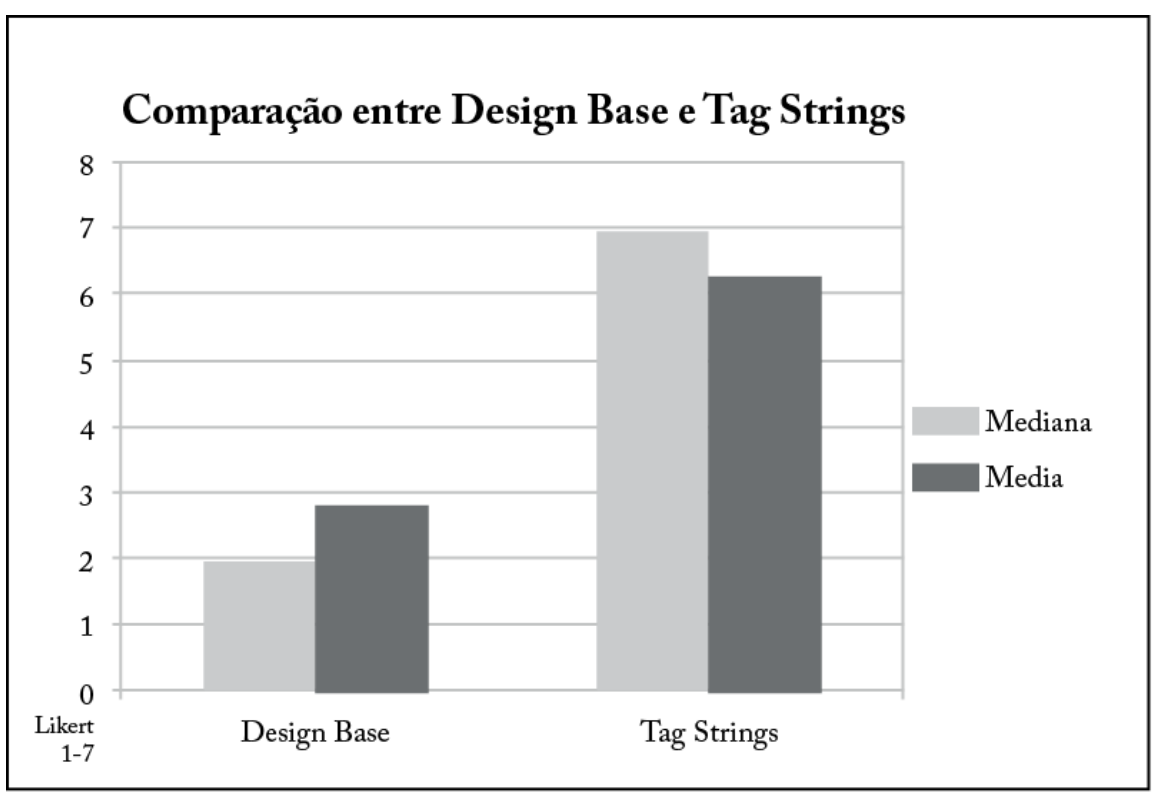

Gráfico A12: Média e mediana dos resultados na escala Likert

Comparando as duas frases na escala Likert, os resultados foram estatisticamente significativos, com $\mathrm{p}<0.001$ (bilateral).

Em geral, os resultados mostram que usuários completaram a tarefa mais rápido com Tag Strings, o que confirma a hipótese H1.

\section{H2 - Tag Strings vai superar Design Base em precisão (número de acertos) (eficácia)}

Para testar a hipótese 2, analisamos o número de acertos (respostas corretas) durante a tarefa. Para cada tag, o número mínimo de respostas corretas é 0, e o máximo 3. Conduzimos um teste da soma dos postos de Wilcoxon independentes (Two Independent Sample Wilcoxon Rank Sum Test) para cada uma das tags.

\begin{tabular}{|l|l|l|}
\hline \multicolumn{2}{|l|}{ Tag 1 - "female" } \\
\hline Participante & Design Base & Tag Strings \\
\hline 1 & 2 & 3 \\
\hline 2 & 1 & 3 \\
\hline 3 & 3 & 3 \\
\hline 4 & 3 & 3 \\
\hline 5 & 3 & 3 \\
\hline 6 & 2 & 3 \\
\hline 7 & 2 & 3 \\
\hline
\end{tabular}

\begin{tabular}{|l|l|l|}
\hline Tag 2 - "piano" & \\
\hline Participante & Design Base & Tag Strings \\
\hline 1 & 3 & 3 \\
\hline 2 & 3 & 3 \\
\hline 3 & 2 & 3 \\
\hline 4 & 2 & 3 \\
\hline 5 & 3 & 3 \\
\hline 6 & 2 & 3 \\
\hline 7 & 3 & 3 \\
\hline
\end{tabular}




\begin{tabular}{|c|c|c|c|c|c|}
\hline 8 & 3 & 3 & 8 & 3 & 3 \\
\hline 9 & 1 & 3 & 9 & 3 & 3 \\
\hline 10 & 3 & 3 & 10 & 3 & 3 \\
\hline 11 & 3 & 3 & 11 & 3 & 3 \\
\hline 12 & 3 & 2 & 12 & 3 & 3 \\
\hline 13 & 3 & 3 & 13 & 3 & 3 \\
\hline 14 & 2 & 3 & 14 & 2 & 3 \\
\hline 15 & 3 & 3 & 15 & 2 & 3 \\
\hline 16 & 3 & 3 & 16 & 3 & 3 \\
\hline 17 & 1 & 3 & 17 & 3 & 3 \\
\hline 18 & 3 & 3 & 18 & 3 & 3 \\
\hline 19 & 2 & 3 & 19 & 3 & 3 \\
\hline 20 & 3 & 3 & 20 & 3 & 3 \\
\hline 21 & 2 & 3 & 21 & 3 & 3 \\
\hline 22 & 3 & 2 & 22 & 1 & 3 \\
\hline 23 & 2 & 3 & 23 & 3 & 3 \\
\hline 24 & 3 & 3 & 24 & 3 & 3 \\
\hline 25 & 3 & 3 & 25 & 3 & 3 \\
\hline 26 & 3 & 3 & 26 & 3 & 3 \\
\hline
\end{tabular}

Tabela 6.28: Número de acertos (respostas corretas) por tag ("Bappy", "piano")

Tag 1: Dentre as músicas recomendadas, marque com a estrela 3 músicas que usam "female"

\begin{tabular}{|l|l|l|}
\hline & Design Base (acertos) & Tag Strings (acertos) \\
\hline Média & 2.71 & 3 \\
\hline
\end{tabular}

Tabela 6.29: Média de acertos (respostas corretas) para tag "female"

Para a tag "female", ao comparar o número de acertos nos dois designs, os resultados não foram estatisticamente significativos, com $\mathrm{p}<0.153$ (bilateral), e $\mathrm{z}$-score $=1.427$.

Em geral, a média de acertos no Design Tag Strings (3) superou a média de acertos do Design Base (2.71).

Tag 2: Dentre as músicas recomendadas, marque com a estrela 3 músicas "piano"

\begin{tabular}{|l|l|l|}
\hline & Design Base (acertos) & Tag Strings (acertos) \\
\hline Média & 2.5 & 2.92 \\
\hline
\end{tabular}


Tabela 6.30: Média de acertos (respostas corretas) para tag "piano"

Para a tag "piano", ao comparar o número de acertos nos dois designs, os resultados foram estatisticamente significativos, com p $<0.05$ (bilateral), e $z$-score $=1.958$.

Tags Combinadas

\begin{tabular}{|l|l|l|}
\hline & Design Base (acertos) & Tag Strings (acertos) \\
\hline Média & 2.62 & 2.96 \\
\hline
\end{tabular}

Tabela 6.31: Média de acertos (respostas corretas) para tags combinadas

Para as tags combinadas, ao comparar o número de acertos nos dois designs, os resultados foram estatisticamente significativos, com $\mathrm{p}<0.001$ (bilateral), e $\mathrm{z}$-score $=-3.266$.

Em geral, os resultados mostram mais acertos com Tag Strings, o que confirma a hipótese H2.

As respostas do questionário mostram a opinião dos usuários com relação a qual design ajuda usuários a tomarem decisões melhores (eficácia).

\section{H3 - Tag Strings vai superar Design Base no suporte de decisões (eficácia)}

Como detalhado no capítulo 2, explicações eficazes afetam decisões de usuários de várias maneiras diferentes:

- Explicações eficazes ajudam usuários a encontrar itens úteis e eliminar os inúteis.

- Explicações eficazes ensinam usuários algo sobre as recomendações.

O Design A me ajudou a encontrar músicas que eu procurava

Mediana: 1

Média: 2.04

O Design B (tags) me ajudou a encontrar músicas que eu procurava

Mediana: 7

Média: 6.35 


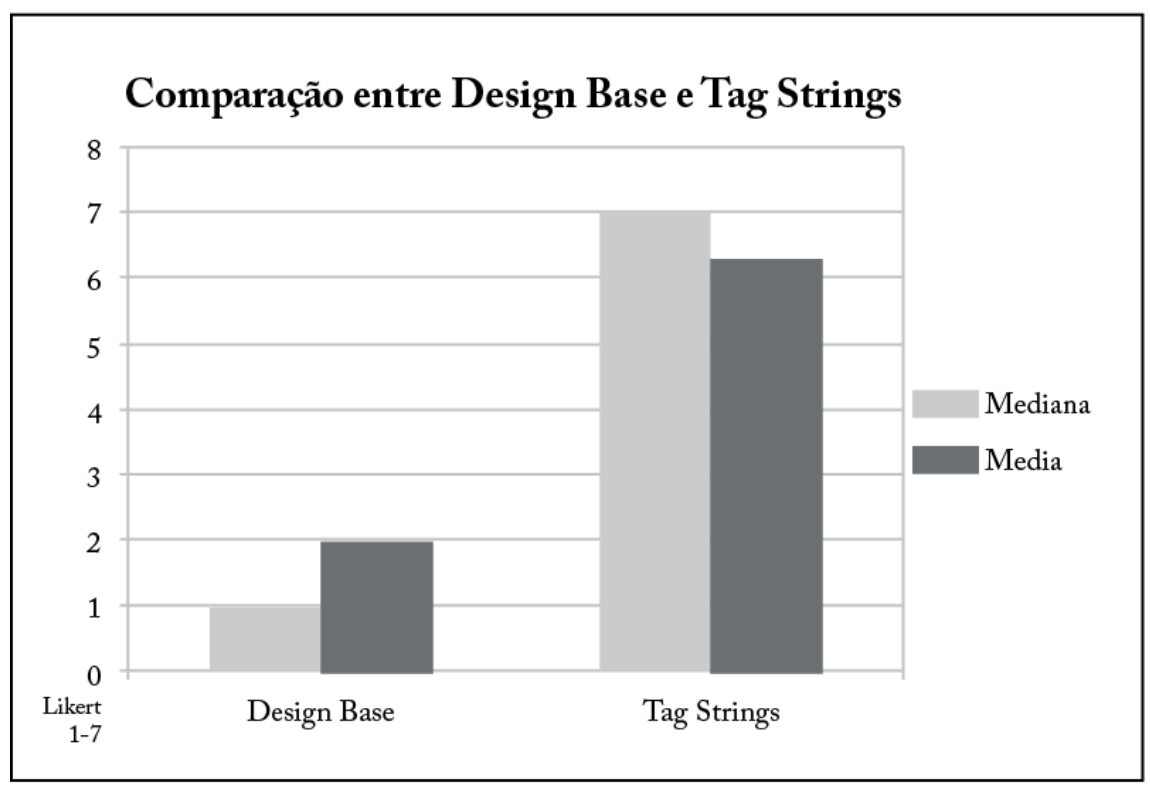

Gráfico A13: Média e mediana dos resultados na escala Likert

Comparando as duas frases na escala Likert, os resultados foram estatisticamente significativos, com $\mathrm{p}<0.001$ (bilateral).

Design A me ajudou a aprender algo sobre as músicas recomendadas

Mediana: 2

Média: 2.83

Design B (tags) me ajudou a aprender algo sobre as músicas recomendadas.

Mediana: 7

Média: 5.83 


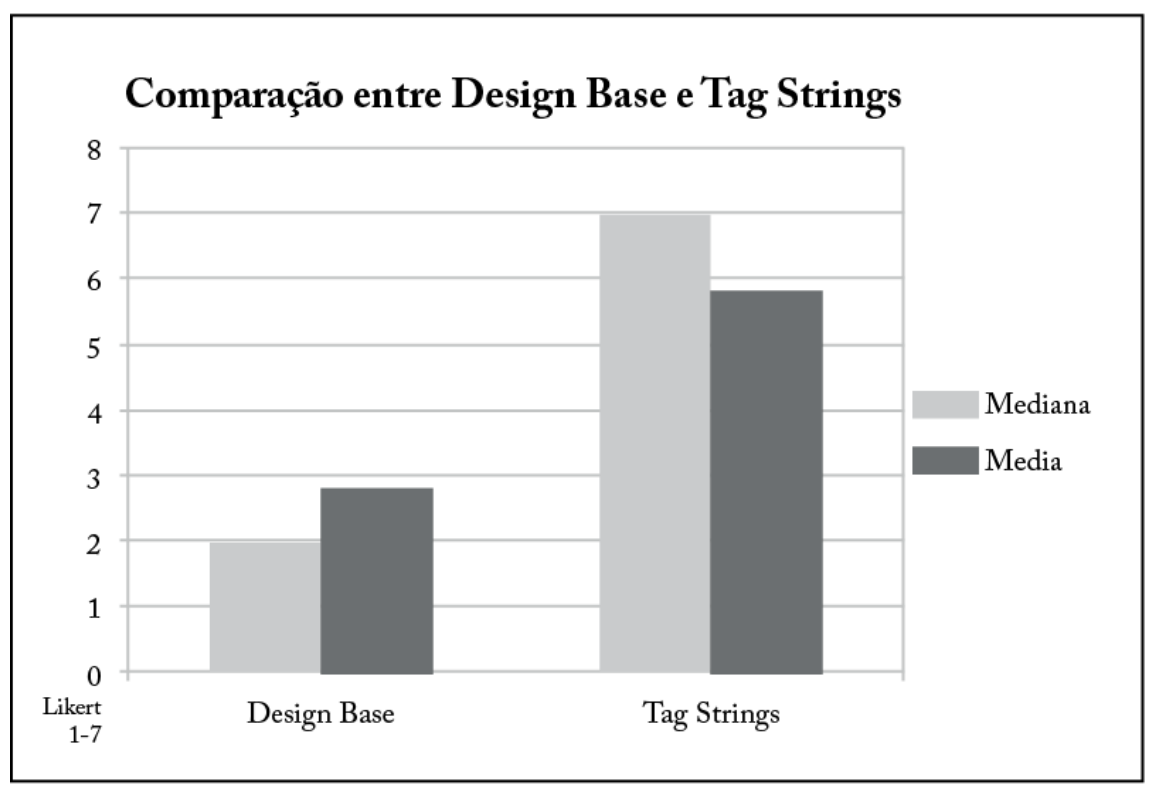

Gráfico A14: Média e mediana dos resultados na escala Likert

Comparando as duas frases na escala Likert, os resultados foram estatisticamente significativos, com $\mathrm{p}<0.001$ (bilateral).

\section{Comentários dos usuários}

"I definitely liked the second design better; the first was far too sparse. In general, more information is better. I like players that are easily navigated and tailored to my tastes."

("Eu definitivamente gostei mais do segundo design. O primeiro era muito disperso. Em geral, mais informação é melhor. Eu gosto de players que são fáceis de navegar e adaptados ao meu gosto.")

"Design A needs the attributes on the side (Piano, Female Singer, etc.) where you can click on it to hear more like that attribute."

("Design A precisa ter os atributos ao lado (Piano, Female Singer, etc.) onde você pode clicar nestes e escutar mais músicas com aquele atributo.”)

Em geral, os resultados mostram que usuários que Tag Strings supera o Design Base no suporte de decisões (ajuda usuários a encontrar músicas procuradas, e ajuda usuários a aprender algo sobre as músicas recomendadas), o que confirma a hipótese H3.

\section{H4 - Tag Strings vai superar Design Base em controle do usuário, por permitir filtragem das músicas (inspeção).}


Os dados coletados mostram que 54\% dos participantes clicaram nas tags. Esse número não foi surpreendente, já que corrigir recomendações não é uma prática tão comum entre usuários (Czarkowski, 2006). A relação entre tags e músicas é também é mostrada ao colocar o cursor sobre uma tag (hover). Assim, é difícil medir a influência das tags apenas em cliques, mas sabemos que pelo menos 54\% dos usuários utilizaram as tags para filtrar recomendações.

\section{Resultado dos questionários}

Design A me ajudou a filtrar as músicas recomendadas

Mediana: 1

Média: 1.79

Design B (tags) me ajudou a filtrar as músicas recomendadas

Mediana: 7

Média: 6.48

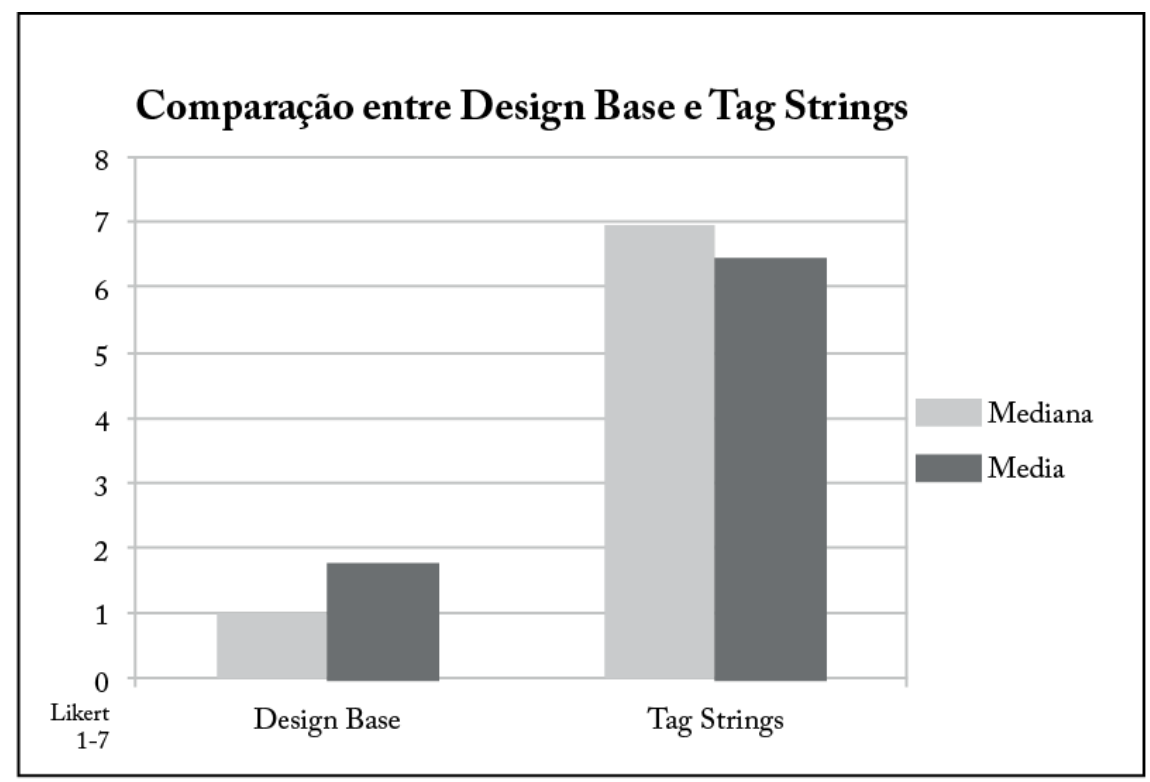

Gráfico A15: Média e mediana dos resultados na escala Likert

Comparando as duas frases na escala Likert, os resultados foram estatisticamente significativos, com $\mathrm{p}<0.001$ (bilateral).

Design A aumentou meu controle sobre as músicas recomendadas

Mediana: 1.5 
Média: 2.18

Design B (tags) aumentou meu controle sobre as músicas recomendadas

Mediana: 7

Média: 6

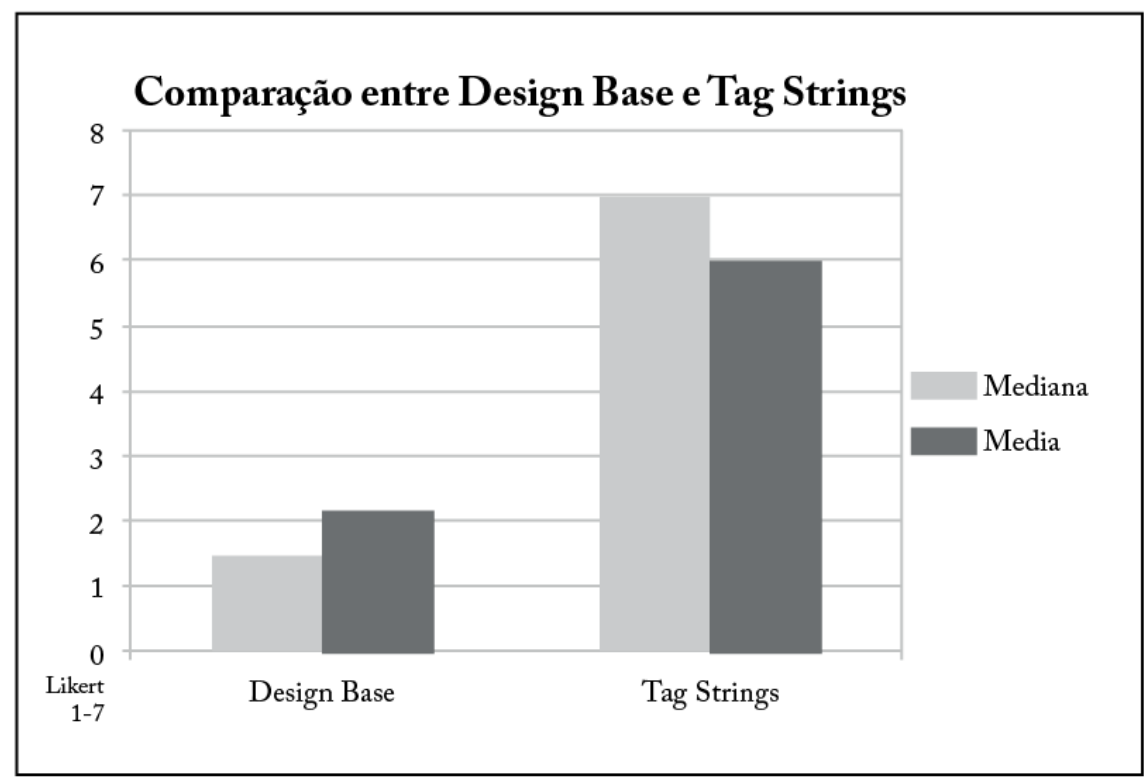

Gráfico A16: Média e mediana dos resultados na escala Likert

Comparando as duas frases na escala Likert, os resultados foram estatisticamente significativos, com $\mathrm{p}<0.001$ (bilateral).

Em geral, os resultados mostram que ao comparar o Design Base e Tag Strings, Tag Strings supera Design Base nas avaliações dos participantes em filtragem e aumento de controle sobre as recomendações, o que apóia a hipótese 4.

Alguns comentários dos usuários:

"A was terrible, it gave me no control at all."

(“A foi terrível, não me ofereceu controle nenhum.”)

\section{H5 - Tag Strings vai superar Design Base em diversão (satisfação)}

Design A foi divertido de usar 
Experimentos com Visualização de Tags

Mediana: 3

Média: 3.19

Design B (tags) foi divertido de usar

Mediana: 6.5

Média: 6

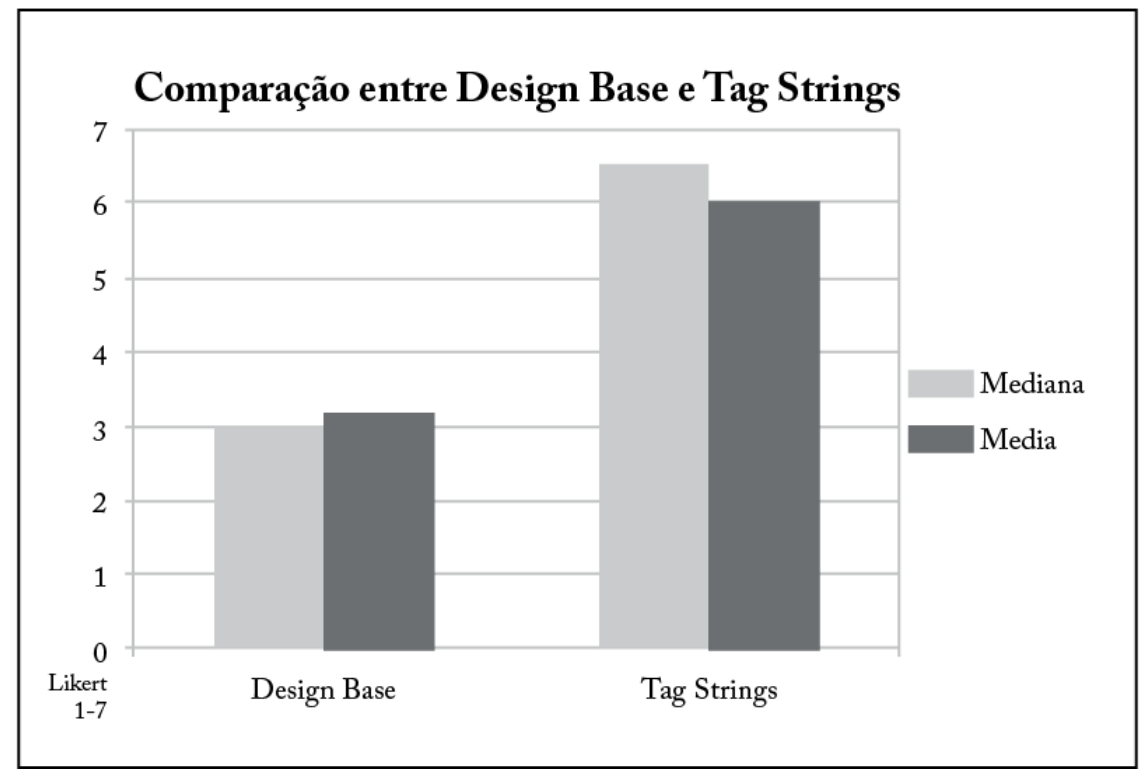

Gráfico A17: Média e mediana dos resultados na escala Likert

Comparando as duas frases na escala Likert, os resultados foram estatisticamente significativos, com $\mathrm{p}<0.001$ (bilateral).

Em geral, eu fiquei satisfeito usando o Design A

Mediana: 3

Média: 3.45

Em geral, eu fiquei satisfeito usando o Design B (tags)

Mediana: 7

Média: 6.1 


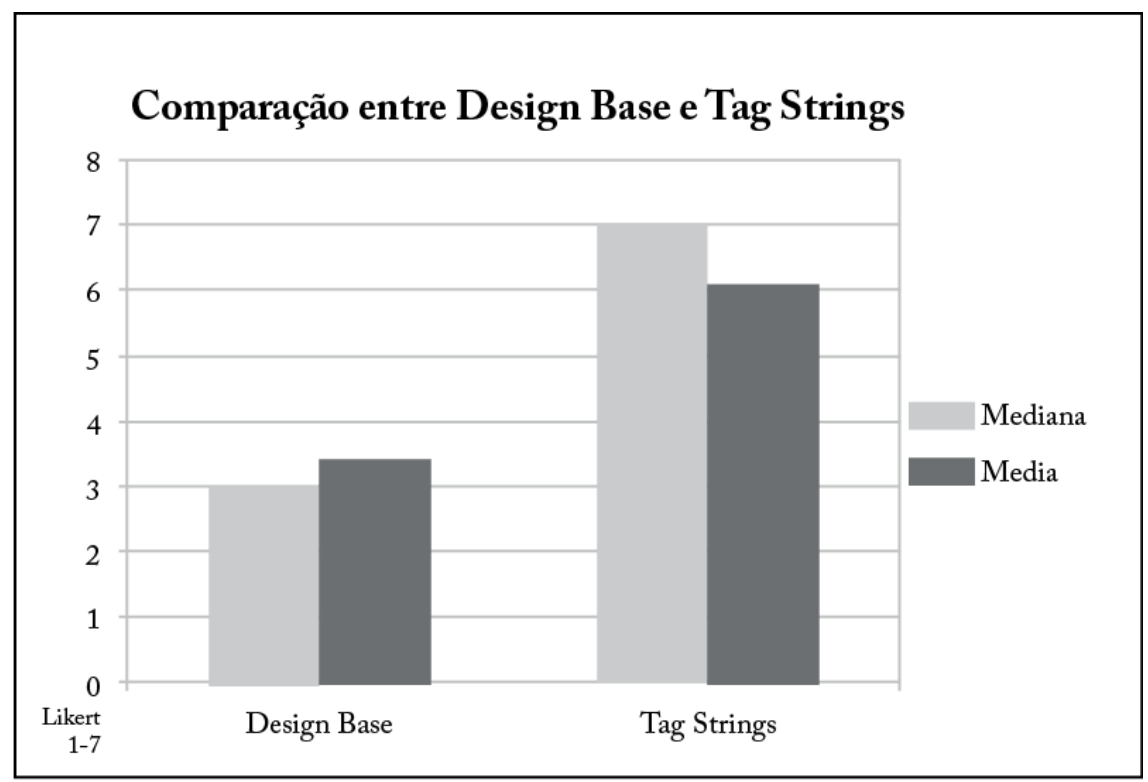

Gráfico A18: Média e mediana dos resultados na escala Likert

Comparando as duas frases na escala Likert, os resultados foram estatisticamente significativos, com $\mathrm{p}<0.001$ (bilateral).

Em geral, os resultados mostram que ao comparar o Design Base e Tag Strings, Tag Strings supera Design Base nas avaliações dos participantes em diversão e satisfação, o que apóia a Hipótese 5.

Alguns comentários dos usuários:

"Overall I would definitely say that Design B is more interesting and innovative compared to Design A."

("Em geral eu posso dizer, definitivamente, que o Design B é mais interessante e mais inovador comparado ao Design A.”)

\section{H6 - Tag Strings vai superar Design Base em facilidade de utilização (satisfação)}

Design A foi fácil de usar

Mediana: 5

Média: 4.79

Design B foi fácil de usar

Mediana: 6.5 
Média: 5.95

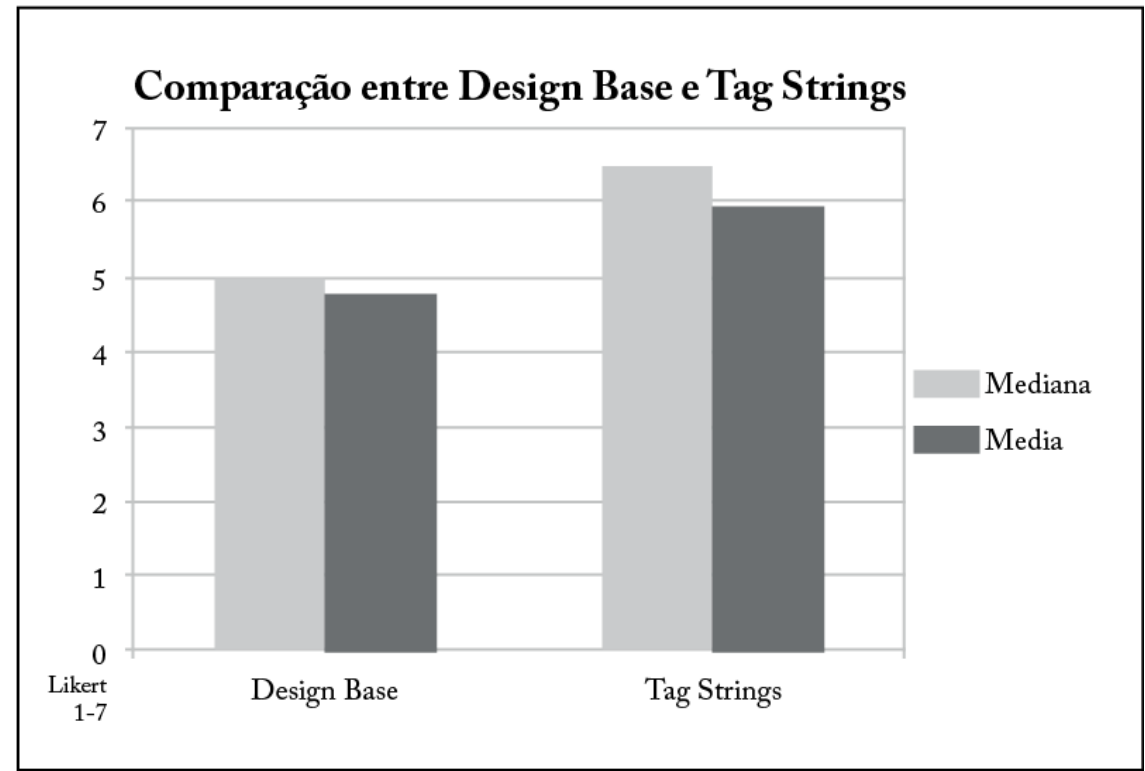

Gráfico A19: Média e mediana dos resultados na escala Likert

Comparando as duas frases na escala Likert, os resultados foram estatisticamente significativos, com $\mathrm{p}<0.004$ (bilateral).

Em geral, os resultados mostram que ao comparar o Design Base e Tag Strings, Tag Strings supera Design Base nas avaliações dos participantes em facilidade de uso e diversão, o que apóia a hipótese 6.

\section{Alguns comentários dos usuários:}

"Really like design B a lot. Very easy to navigate."

(“Realmente gostei muito do design B. Muito fácil de navegar.”)

Esse capítulo detalhou a avaliação inicial e experimentos 1, 2 e 3, e estabeleceu hipóteses que buscaram responder questões da pesquisa. A construção dos diferentes experimentos permitiu avaliar empiricamente a visualização Tag Strings quando comparada com interfaces de referência. 


\section{Capítulo 7}

\section{Considerações Finais}

Com o crescimento da oferta de músicas online, serviços como iTunes, Last.fm, Pandora, Spotify, Rdio e Mog contém catálogos com milhões de músicas. Para facilitar o acesso a catálogos tão extensos, muitos desses serviços oferecem recomendações. O crescimento de conteúdo em várias áreas se reflete na variedade de sistemas de recomendação em sites de mídia, notícia, e comércio eletrônico. A medida que a popularidade de sistemas de recomendação aumenta, também aumenta a importância de suas interfaces.

A motivação deste trabalho foi melhorar a usabilidade e experiência do usuário com recomendações através do uso de explicações. Ao usar um sistema de recomendação, a satisfação e aceitação do usuário não depende só da eficácia do algoritmo, mas também de explicações. A pesquisa na área de recomendação mostra que explicações podem beneficiar a usabilidade e experiência do usuário. Explicar recomendações aumenta a credibilidade e satisfação do usuário, e neste projeto, nos concentramos em explicações que favorecem as metas de inspeção, eficiência, eficácia e satisfação.

Entre as diferentes formas de explicação, tags tem se mostrado úteis ao explicar e revisar (critique) recomendações em filmes. Sistemas de recomendação de músicas (como o iTunes Genius) diferem de recomendações de artistas e filmes, por produzir uma longa lista de 20 a 100 itens. A complexidade de múltiplas recomendações e tags sugere o uso de uma visualização como interface, que filtre e explique uma coleção grande de itens.

Inicialmente foi pesquisada a usabilidade e experiência do usuário em recomendações. Observamos a importância de explicações, e através de estudos de usuários focados em música e recomendação, definimos as necessidades de usuários e requisitos.

Escolhemos tags como o tipo de metadado que melhor cumprem os requisitos e necessidades dos usuários. Trabalhos relacionados a visualização e recomendação foram pesquisados, e projetamos diferentes designs para visualização de tags. A partir da lista de requisitos, selecionamos o design Tag Strings, que satisfazia melhor os requisitos e necessidades do usuário.

Para a implementação de Tag Strings, foi desenvolvido um processo para coletar tags associadas aos itens recomendados. Dentre essas, foi criado um processo para encontrar as tags mais relevantes para exibir na visualização. 
A viabilidade da visualização Tag Strings foi avaliada através de duas versões desse design: uma versão inicial, utilizada no Experimentos 1, e uma versão final, nos Experimentos 2 e 3. Os Experimentos 1 e 2 usaram músicas recomendadas pelo serviço Last.fm, geradas a partir de filtragem colaborativa. O Experimento 3 usou recomendações do serviço Pandora, geradas a partir do conteúdo das músicas. Esses experimentos permitiram avaliar empiricamente se Tag Strings favorecia as metas de inspeção (scrutability), eficiência, eficácia e satisfação.

Como resultado da validação das hipóteses, pode-se concluir que Tag Strings favoreceu as metas de inspeção (scrutability), eficiência, eficácia e satisfação:

Tag Strings ajudou usuários a filtrar recomendações de música (inspeção).

Tag Strings ajudou usuários a poupar tempo e esforço ao avaliar recomendações (eficiência).

Tag Strings ajudou usuários a tomar decisões melhores (eficácia).

Tag Strings ajudou usuários em divertimento e facilidade de uso (satisfação).

Os resultados dos experimentos indicam que a visualização Tag Strings pode ser usadas para melhorar a usabilidade e experiência do usuário com recomendações de música, tanto para filtragem colaborativa, quanto para recomendações baseadas em conteúdo.

\subsection{Trabalhos Futuros}

É grande a competição de serviços de música online como iTunes, Last.fm, Pandora, Spotify, Mog, etc. Todos esses serviços oferecem catálogos similares, e com milhões de músicas. Nesse cenário, o diferencial pode ser definido pelas melhores interfaces e recomendações. Uma interface que permite a filtragem de recomendações não só melhora a experiência do usuário, como também oferece informações sobre quais tags são importantes para cada usuário. A longo prazo, perfis de recomendação complexos podem ser criados, sem que usuários tenham que gastar tempo com a configuração inicial do sistema.

Entre trabalhos futuros, seria interessante executar um experimento com uma interface mais similar a Tag Strings, como uma Tag Cloud e uma lista de músicas. Esta comparação permitiria uma avaliação mais precisa, como por exemplo, quão efetivas são as linhas em Tag Strings.

Também gostaríamos de modificar os questionários aplicados para produzir resultados mais amplos e imparciais, usando frases como "O Design B foi difícil de usar", ao invés de "O Design B foi fácil de usar".

Para este projeto, Tag Strings foi desenvolvida com o objetivo de servir dispositivos com mais de 8 polegadas, mas o design da visualização pode ser facilmente reduzido para acomodar uma tela de 
um smartphone. Ao facilitar a filtragem de recomendações com tags, Tag Strings pode ser utilizado em uma versão com tags preferidas para usuários, reduzindo seu número ao longo do tempo de uso, e economizando espaço na interface.

Além do uso de tags, Tag Strings também poderia acomodar nomes de usuários, que podem ser úteis em casos de recomendações dentre as redes sociais. Serviços de streaming de músicas como Spotify, que recomendam músicas a partir de amigos na rede social Facebook, pode integrar não só os nomes de amigos, mas também outras tags mais descritivas. Tag Strings poderia permitir que usuários filtrassem recomendações de músicas por amigos, ou grupos de amigos.

Apesar do foco deste trabalho ser em sistemas de recomendação de música, acreditamos que o processo e visualização desenvolvidos podem ser usados para outros tipos de recomendação, como filmes, notícias, interfaces de comércio eletrônico, imóveis, etc. Para produtos de alto envolvimento, como pacotes de ferias e imóveis, Tag Strings poderia acomodar uma interface mais complexa, já que usuários podem investir mais tempo e esforço na seleção dos melhores itens. 


\section{Referências Bibliográficas}

Åman e Liikkanen (2010) Åman, Pirkka, and Lassi A. Liikkanen. A survey of music recommendation aids. Proceedings of Workshop on Music Recommendation And Discovery (WOMRAD), at ACM RecSys conference. Citado na pág. 18, 87,

Aucouturier e Pachet (2003) Aucouturier, Jean-Julien, and Francois Pachet. Representing musical genre: A state of the art. Journal of Nerw Music Research, Vol. 32, No. 1, páginas 83-93. Citado na pág. 14

Bainbridge et al. (2003) Bainbridge, David, Sally Jo Cunningham, and J. Stephen Downie. How people describe their music information needs: A grounded theory analysis of music queries. Proceedings of the International Symposium on Music Information Retrieval, páginas 221-222. Citado na pág. 12

Barrington et al. (2009) Barrington, Luke, Reid Oda, and Gert Lanckriet. Smarter than genius? Human evaluation of music recommender systems. 10th International Society for Music Information Retrieval Conference (ISMIR'09). Citado na pág. 13- 15, 37, 38

Baur et al. (2010) Baur, Dominikus, Sebastian Boring, and Andreas Butz. Rush: repeated recommendations on mobile devices. Proceeding of the 14th international conference on Intelligent user interfaces, páginas 91-100, 2010. Citado na pág. 28

Bilgic e Mooney (2005) Bilgic, Mustafa, and Raymond J. Mooney. Explaining recommendations: Satisfaction vs. promotion. In Beyond Personalization Workshop, IUI, vol. 5. 2005. Citado na pág. 19

Burke et al. (1997) Burke, Robin D., Kristian J. Hammond, and B. C. Yound. The FindMe approach to assisted browsing. IEEE Expert 12, no. 4 (1997): páginas 32-40. Citado na pág. 12, 16

Card et al. (1999) Card, Stuart K., Jock D. Mackinlay, and Ben Shneiderman. Readings in information visualization: using vision to think. Morgan Kaufmann, 1999. Citado na pág. 39

Chen et al. (2009) Chen, Ya-Xi, Rodrigo Santamaría, Andreas Butz, and Roberto Therón. Tagclusters: Semantic aggregation of collaborative tags beyond tagclouds. Smart Graphics, páginas 56-67. Citado na pág. 32, 33

Chen et al. (2010) Chen, Ya-Xi, Sebastian Boring, and Andreas Butz. How Last. fm Illustrates the Musical World: User Behavior and Relevant User-Generated Content. Proceedings of the international workshop on Visual Interfaces to the Social and Semantic Web. (Hong Kong, China) 2010. Citado na pág. 9, 12, 14, 16, 55- 57, 87 
Csikszentmihalyi (1997) Csikszentmihalyi, Mihaly. Creativity: Flow and the psychology of discovery and invention. Harper perennial, quarta edição, 1997. Citado na pág. 8

Cunningham et al. (2004) Cunningham, Sally Jo, Matt Jones, and Steve Jones. Organizing digital music for use: an examination of personal music collections. Proceedings of the 5th International Symposium on Music Information Retrieval, 2004. Citado na pág. 12, 14

Cunningham et al. (2006) Cunningham, Sally Jo, David Bainbridge, and Annette Falconer. A. More of an art than a science: Supporting the creation of playlists and mixes. Proceedings of the 7 th International Conference on Music Information Retrieval, páginas 240-245. Citado na pág. 1, 16, 17, 40

Czarkowski et al. (2006) Czarkowski, Marek, and Judy Kay. A scrutable adaptive hypertext. Adaptive Hypermedia and Adaptive Web-Based Systems, 384-387. Springer Berlin/Heidelberg, 2006. Citado na pág. 18, 80, 95, 105, 116, 126

Davis (1989) Davis, Fred D. Perceived Usefulness, Perceived Ease of Use, and User Acceptance of Information Technology .MIS Quarterly, 1989, páginas 21. Citado na pág. 21

Davis et al. (1992) Davis, Fred D., Richard P. Bagozzi, and Paul R. Warshaw. Extrinsic and Intrinsic Motivation to Use Computers in the Workplace. Journal of Applied Social Psychology, Blackwell Publishing Ltd, 1992, páginas 22, 1111-1132. Citado na pág. 21

Devendorf et al. (2012) Devendorf, Laura, John O’Donovan, and Tobias Höllerer. TopicLens: An Interactive Recommender System based on Topical and Social Connections. First International Workshop on Recommendation Technologies for Lifestyle Change (LIFESTYLE 2012), 2012, páginas 41. Citado na pág. 30, 31

Felfernig e Gula (2006) Felfernig, Alexander, and Bartosz Gula. An empirical study on consumer behavior in the interaction with knowledge-based recommender applications. In E-Commerce Technology, 2006. The 8th IEEE International Conference on and Enterprise Computing, E-Commerce, and E-Services, The 3rd IEEE International Conference on, páginas 37-37. IEEE, 2006. Citado na pág. 19

Ferrer et al. (2012) Ferrer, Rafael, Tuomas Eerola, and Jonna K. Vuoskoski. Enhancing genrebased measures of music preference by user-defined liking and social tags. Psychology of Music, SAGE Publications, 2012. Citado na pág. 14

Gedikli e Jannach (2011) Gedikli, Fatih, Mouzhi Ge, and Dietmar Jannach. Explaining Online Recommendations Using Personalized Tag Clouds. i-com, Oldenbourg Wissenschaftsverlag GmbH St. Augustin, Germany, 2011, páginas 10, 3-10. Citado na pág. 21, 29, 30

Geleijnse et al. (2007) Geleijnse, Gijs, Markus Schedl, and Peter Knees. The quest for ground truth in musical artist tagging in the social web era. Proceedings of the Eighth International Conference on Music Information Retrieval, páginas 525-530. Citado na pág. 39 
Green et al. (2009) Green, Stephen J., Paul Lamere, Jeffrey Alexander, François Maillet, Susanna Kirk, Jessica Holt, Jackie Bourque, and Xiao-Wen Mak. Generating transparent, steerable recommendations from textual descriptions of items. Proceedings of the third ACM conference on Recommender systems, $A C M$, páginas 281-284. Citado na pág. 3, 11, 25, 40, 47-50, 51, 57, 59, 60, 87.

Halvey e Keane (2007) Halvey, Martin J., and Mark T. Keane. An assessment of tag presentation techniques. Proceedings of the 16th international conference on World Wide Web, 2007, páginas 13131314, ACM, 2007. Citado na pág. 47, 48

Herlocker et al. (2000) Herlocker, Jonathan L., Joseph A. Konstan, and John Riedl. Explaining collaborative filtering recommendations. Proceedings of the 2000 ACM conference on Computer supported cooperative work, páginas 241-250. ACM, 2000. Citado na pág. 1, 2, 6, 9, 10

Herlocker et al. (2004) Herlocker, Jonathan L., Joseph A. Konstan, Loren G. Terveen, and John T. Riedl. Evaluating collaborative filtering recommender systems. ACM Transactions on Information Systems (TOIS), ACM, 2004, páginas 22, 5-53. Citado na pág. 6

ISO 9241-11 (1998). Ergonomic requirements for office work with visual display terminals (VDTs) - Part 11: Guidance on usability. The international organization for standardization (1998). Citado na pág. 2, 7, 19-20

ISO 9241-210 (2010) Ergonomics of human system interaction-Part 210: Human-centred design for interactive systems (formerly known as 13407). International Organization for Standardization (ISO). Switzerland, 2010. Citado na pág. 2, 7

Jones e Pu (2007) Jones, Nicholas, and Pearl Pu. User technology adoption issues in recommender systems. Proceedings of NAEC, ATSMA (2007): páginas 379-39. Citado na pág. 13-16, 37, 38, 87

Kim e Belkin (2002) Kim, Ja-Young, and Nicholas J. Belkin. Categories of music description and search terms and phrases used by non-music experts. Proceedings of the 3rd International Conference on Music Information Retrieval, páginas 13-17. 2002. Citado na pág. 12-16, 36-38, 44

Kleedorfer et al. (2007) Kleedorfer, Florian, Ulf Harr, and Brigitte Krenn. Making large music collections accessible using enhanced metadata and lightweight visualizations. Automated Production of Cross Media Content for Multi-Channel Distribution, 2007. AXMEDIS'07. Third International Conference on, 2007, páginas 138-144. IEEE, 2007. Citado na pág. 40

Knees et al. (2004) Knees, Peter, Elias Pampalk, and Gerhard Widmer. Artist Classification with Web-based Data. Proceedings of the 5th International Conference on Music Information Retrieval (ISMIR '04), 2004, páginas 517-524. Citado na pág. 61

Knijnenburg et al. (2012) Knijnenburg, Bart P., Martijn C. Willemsen, Zeno Gantner, Hakan Soncu, and Chris Newell. Explaining the user experience of recommender systems. User Modeling and User-Adapted Interaction, Springer, 2012, páginas 1-64. Citado na pág. 9, 16, 17 
Knijnenburg et al. (2012a) Knijnenburg, Bart P., John O’Donovan, Svetlin Bostandjiev, and Alfred Kobsa. Inspectability and control in social recommenders. 6th ACM Conference on Recommender Systems, Dublin, Ireland, September 9 to 13th, 2012. Citado na pág. 16, 17

Konstan e Riedl (2012) Konstan, Joseph A., and John Riedl. Recommender systems: from algorithms to user experience. User Modeling and User-Adapted Interaction, Springer, 2012, páginas 1-23. Citado na pág. 9

Kuhn et al. (2010) Kuhn, Michael, Roger Wattenhofer, and Samuel Welten. Social audio features for advanced music retrieval interfaces. Proceedings of the international conference on Multimedia, 2010, ACM, páginas 411-420. Citado na pág. 14

Lamere (2008) Lamere, Paul. Social tagging and music information retrieval. Journal of Nerw Music Research, Routledge, part of the Taylor \& Francis Group, Volume 37, páginas 101-114. Citado na pág. 10, 12, 14, 39, 57, 59, 69, 87

Lee e Downie (2004) Lee, Jin Ha, and J. Stephen Downie. Survey of music information needs, uses, and seeking behaviours: preliminary findings. Proceedings of the International Conference on Music Information Retrieval, páginas 441-446. 2004. Citado na pág. 13-16, 37, 38, 40, 44

Lee (2011) Lee, Jin Ha. How similar is too similar?: Exploring users' perceptions of similarity in playlist evaluation. Proceedings of the 12th International Society for Music Information Retrieval Conference (ISMIR 2011) páginas 109-114. 2011. Citado na pág. 12-16

Lehwark et al. (2007) Lehwark, Pascal, Sebastian Risi, and Alfred Ultsch. Visualization and Clustering of Tagged Music Data. Proceedings 31st Annual Conference of the German Classification Society (GfKl 2007). Citado na pág. 31, 32

Levy e Sandler (2009) Levy, Mark, and Mark Sandler. Music information retrieval using social tags and audio. Multimedia, IEEE Transactions on 11, no. 3 (2009): páginas 383-395. Citado na pág. 58, 59

Manning et al. (2008) Manning, Christopher D., Prabhakar Raghavan, and Hinrich Schütze. Introduction to information retrieval Cambridge University Press, 2008. Citado na pág. 57-59

McNee et al. (2003) McNee, Sean, Shyong Lam, Joseph Konstan, and John Riedl. Interfaces for eliciting new user preferences in recommender systems. User Modeling 2003, Springer, 2003, páginas 148-148. Citado na pág. 6, 15

McNee et al. (2006) McNee, Sean M., John Riedl, and Joseph A. Konstan. Making recommendations better: an analytic model for human-recommender interaction. CHI'O6 extended abstracts on Human factors in computing systems, páginas 1103-1108 ACM, 2006. Citado na pág. 1, 7, 8, 15 
Nielsen e Loranger (2006) Nielsen, Jakob, and Hoa Loranger. Prioritizing Web Usability New Riders, 2006. Citado na pág. 2

Nielsen e Molich (1990) Nielsen, Jakob, and Rolf Molich. Heuristic evaluation of user interfaces. Proceedings of the SIGCHI conference on Human factors in computing systems: Empowering people, páginas 249-25. ACM, 1990. Citado na pág. 18, 20

Nielsen (1994). Guerilla HCI: Using discount usability engineering to penetrate the intimidation barrier. Avaliable on-line at: http://useit.com Último acesso em 04/10/2013. Citado na pág. 101

Norman (2003) Norman, Donald A. Emotional design: Why we love (or hate) everyday things Basic books, 2003. Citado na pág. 40

O'Donovan et al. (2008) O'Donovan, John, Barry Smyth, Brynjar Gretarsson, Svetlin Bostandjiev, and Tobias Höllerer. Peerchooser: visual interactive recommendation. Proceeding of the twenty-sixth annual SIGCHI conference on Human factors in computing systems, páginas 1085-1088. ACM, 2008. Citado na pág. 28, 29

Ozok et al. (2010) Ozok, A. Ant, Quyin Fan, and A. Norcio. Design guidelines for effective recommender system interfaces based on a usability criteria conceptual model: results from a college student population. Behaviour E Information Technology, Taylor E Francis, 2010, páginas 29, 57-83. Citado na pág. $8,9,15$

Palmer e Rock (1994) I. Palmer, Stephen, and Irvin Rock. Rethinking perceptual organization: The role of uniform connectedness. Psychonomic Bulletin E Review, Springer, 1994, páginas 1, 29-55. Citado na pág. 41

Pandora (2012) Pandora.com. About Pandora. Available on-line at: http://www.pandora.com/about. Último acesso em 08/22/2012. Citado na pág. 112

Pousman et al. (2007) Pousman, Zachary, John T. Stasko, and Michael Mateas. Casual information visualization: Depictions of data in everyday life. Visualization and Computer Graphics, IEEE Transactions on, IEEE, 2007, páginas 13, 1145-1152. Citado na pág. 39, 40

Pu e Chen (2010) Pu, Pearl, Li Chen. A User-Centric Evaluation Framework of Recommender Systems. Proceedings of the fifth ACM conference on Recommender systems, páginas 157-164. ACM, 2011. Citado na pág. 9, 18, 20, 21

Rentfrow e Gosling (2003 Rentfrow, Peter J., and Samuel D. Gosling. The do re mi's of everyday life: the structure and personality correlates of music preferences. Journal of personality and social psychology, American Psychological Association, 2003, páginas 84, 1236. Citado na pág. 17

Rogers et al. (2007) Rogers, Yvonne, Helen Sharp, and Jenny Preece. Interaction Design: Beyond Human Computer Interaction. Wiley, 2007. Citado na pág. 7, 11, 21, 34 
Rubin et al. (2008) Rubin, Jeffrey, and Dana Chisnell. (Ed.) Handbook of Usability Testing: How to Plan, Design, and Conduct Effective Tests, John Wiley \& Sons, Inc. Citado na pág. 71

Sarmento et al. (2009) Sarmento, Luís, and Eugénio C. Oliveira. Visualizing Networks of Music Artists with RAMA. International Conference on Web Information Systems and Technologies. Citado na pág. 26, 27

Sauro e Lewis (2012) Sauro, Jeff, and James R. Lewis. Quantifying the user experience: Practical statistics for user research Morgan Kaufmann, 2012. Citado na pág. 80

Sen et al. (2006) Sen, Shilad, Shyong K. Lam, Al Mamunur Rashid, Dan Cosley, Dan Frankowski, Jeremy Osterhouse, F. Maxwell Harper, and John Riedl. Tagging, communities, vocabulary, evolution. Proceedings of the 2006 20th anniversary conference on Computer supported cooperative work, 2006, páginas 181-190 ACM, 2006. Citado na pág. 55, 56

Sinha e Swearingen (2002) Sinha, Rashmi, and Kirsten Swearingen. The role of transparency in recommender systems. CHI'O2 extended abstracts on Human factors in computing systems, 2002, páginas 830-831. ACM, 2002. Citado na pág. 10

Spool (1999) Spool, Jared M. Web site usability: a designer's guide. Morgan Kaufmann, 1999. Citado na pág. 21

Swearingen e Sinha (2001) Swearingen, Kirsten, and Rashmi Sinha. Beyond algorithms: An HCI perspective on recommender systems. ACM SIGIR 2001 Workshop on Recommender Systems, página 11. 2001. Citado na pág. $15-17$

Swearingen e Sinha (2002) Swearingen, Kirsten, and Rashmi Sinha. Interaction design for recommender systems. Designing Interactive Systems, vol. 6, no. 12, páginas 312-334. 2002. Citado na pág. $1,2,6,8,9,16,18$

Sørmo et al. (2005) Sørmo, Frode, Jörg Cassens, and Agnar Aamodt. Explanation in case-based reasoning--perspectives and goals. Artificial Intelligence Revierw, Springer, páginas 24, 109-143. Citado na pág. 10

Tan et al. (2006) Tan, Pang-Ning, Michael Steinbach, and Vipin Kumar. Introduction to Data Mining. Addison-Wesley, 2006. Citado na pág. 60

Tanaka-Ishii e Frank, (2000) Tanaka-Ishii, Kumiko, and Ian Frank. Multi-agent explanation strategies in real-time domains. Proceedings of the 38th Annual Meeting on Association for Computational Linguistics, páginas 158-165. Association for Computational Linguistics, 2000. Citado na pág. 21

Tidwell (2010) Tidwell, Jenifer. Designing interfaces O'Reilly Media, Incorporated, 2010. Citado na pág. 42,46 
Tintarev e Masthoff (2007) Tintarev, Nava, and Judith Masthoff. A Survey of Explanations in Recommender Systems. Proceedings of the 2007 IEEE 23rd International Conference on Data Engineering Workshop, IEEE Computer Society, páginas 801-810. Citado na pág. 1, 2, 4, 6, 10, 11, 14, $17,18,20,22,29$

Tintarev e Masthoff(2007a) Tintarev, Nava, and Judith Masthoff. Effective explanations of recommendations: user-centered design. Proceedings of the 2007 ACM conference on Recommender systems, páginas 153-156, ACM, 2007. Citado na pág. 19

Tintarev(2009) Tintarev, Nava, Explaining Recommendations. Tese de Doutorado, Department of Computing Science, University of Aberdeen, Reino Unido. Citado na pág. 21

Torres et al. (2004) Torres, Roberto, Sean M. McNee, Mara Abel, Joseph A. Konstan, and John Riedl. Enhancing digital libraries with TechLens+. Proceedings of the 4th ACM/IEEE-CS joint conference on Digital libraries, páginas 228-236. ACM, 2004. Citado na pág. 8

Tufte e Graves-Morris (1983) Tufte, Edward R., and P. R. Graves-Morris. The visual display of quantitative information. Graphics press Cheshire, CT, 1983, página 31. Citado na pág. 41

Tullis e Albert (2008) Tullis, Thomas, and William Albert. Measuring the user experience: collecting, analyzing, and presenting usability metrics. Morgan Kaufmann. Citado na pág. 7, 71

Vig et al. (2009) Vig, Jesse, Shilad Sen, and John Riedl. Tagsplanations: explaining recommendations using tags. IUI '09: Proceedings of the 13th international conference on Intelligent user interfaces, $A C M$, páginas 47-56. Citado na pág. 3, 9, 10-12, 14, 19, 23, 24, 25, 55, 57, 58

Vig et al. (2011) Vig, Jesse, Shilad Sen, and John Riedl. Navigating the tag genome. Proceedings of the 15th international conference on Intelligent user interfaces páginas 93-102. ACM, 2011. Citado na pág. $3,11,24,25$

Vignoli (2004) Vignoli, Fabio. Digital Music Interaction concepts: a user study. International Symposium of Music Information Retrieval (ISMIR04). Citado na pág. 1, 12-14, 36, 38

Ware (2012) Ware, Colin. Information visualization: perception for design Morgan Kaufmann, 2012. Citado na pág. 44

Yi e Hwang (2003) Yi, Mun Y., and Yujong Hwang. Predicting the use of web-based information systems: self-efficacy, enjoyment, learning goal orientation, and the technology acceptance model. International Journal of Human-Computer Studies, Elsevier, 2003, páginas 59, 431-449. Citado na pág. 22

Zaslow (2002) Zaslow, Jeffrey. If TiVo Thinks You Are Gay, Here's How To Set It Straight -Amazon.com Knows You, Too, Based on What You Buy; Why All the Cartoons? The Wall Street Journal, sect. A, p. 1, November 26, 2002. Citado na pág. 6 
Referências Bibliográficas 


\section{Apêndice I}

Apresentamos neste apêndice os questionários usado no experimento 1, descritos no capítulo 6.

\section{Questionário do Experimento 1}

1. Please enter:

- Age:

- Gender:

2. Please write the name of Track 1 (the first track you evaluated)

3. Please describe the track using at least 3 tags

4. Please rate how strongly you agree or disagree with each of the following statements: (Recommendations were provided by Lastfm)

- I like Track 1

- Recommendations for Track 1 were useful

- Recommendations for Track 1 were new to me

5. Please write the name of Track 2 (the second track you evaluated)

6. Please describe the track using at least 3 tags

7. Please rate how strongly you agree or disagree with each of the following statements: (Recommendations were provided by Lastfm) 
Apêndice I

- I like Track 2

- Recommendations for Track 2 were useful

- Recommendations for Track 2 were new to me

\section{Next questions are about Design A and Design B}

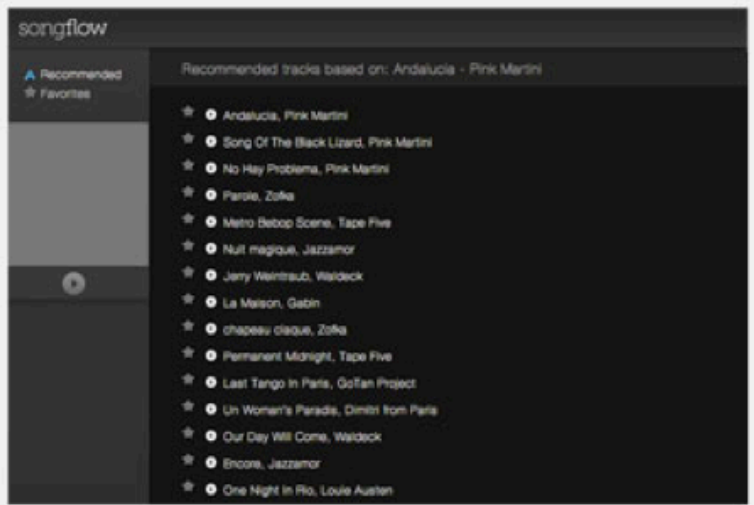

Design A

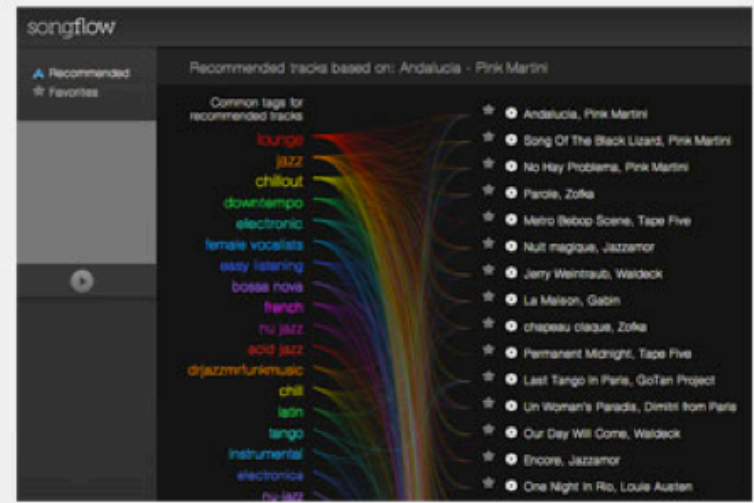

Design B

8. Overall, which design would you prefer to use?

- Prefer Design A

- Neutral

- Prefer Design B

9. Which design was easier to use?

- Prefer Design A

- Neutral

- Prefer Design B 
Apêndice I

10. Which design was faster to use?

- Prefer Design A

- Neutral

- Prefer Design B

11. Which design was more fun to use?

- Prefer Design A

- Neutral

- Prefer Design B

12. Which design helped explain why a track was recommended?

- Prefer Design A

- Neutral

- $\quad$ Prefer Design B

\section{Questions about Design B (with tags)}

13. Please rate how strongly you agree or disagree with each of the following statements: (Strongly disagree, Disagree, Neutral, Agree, Strongly agree)

- Design B helps me correct a recommendation

- Design B helps me filter the recommended tracks

- After selecting a tag, the tracks displayed made sense to me

- Selecting tags helped me find tracks I did not know

- Selecting tags helped me find tracks I was interested in 
Apêndice I

14. Please rate how strongly you agree or disagree with each of the following statements: (Strongly disagree, Disagree, Neutral, Agree, Strongly agree)

- The tags helped me find songs I like faster

- The tags helped me determine how well I will like the tracks

- The tags helped me learn something about the recommended tracks

- I like seeing the tags

- Using the tags is fun

- The tags helped me decide which tracks I should try

- Overall the tags are a good explanation of the track recommendations

15. Do you have any comments or suggestions of how to improve the design?

(Questão enviada apenas para participantes do Mechanical Turk.)

16. Make up a 5 digit completion code. Enter the code below. You'll enter the same code to complete this HIT:

\section{Questionário do Experimento 1 (tradução)}

1. Favor preencher:

- Idade:

- Sexo:

2. Favor escrever o nome da Música 1 (a primeira música que você avaliou) 
Apêndice I

3. Favor descrever a música usando pelo menos 3 tags

4. Favor avaliar o quanto você concorda ou discorda com as seguinte declarações:

- Eu gosto da Música 1

- As recomendações para a música 1 foram úteis

- As recomendações para música 1 foram novas para mim

5. Favor escrever o nome da Música 2 (a segunda música que você avaliou)

6. Favor descrever a música usando pelo menos 3 tags

7. Favor avaliar o quanto você concorda ou discorda com as seguinte declarações: (As recomendações foram fornecidas pelo site Last.fm)

- Eu gosto da Música 2

- As recomendações para a música 2 foram úteis

- As recomendações para música 2 foram novas para mim

\section{As próximas questões são sobre o Design A e o Design B}

Imagem do Design A e Design B

8. Em geral, qual design você prefere usar?

- Prefiro Design A

- Neutro

- Prefiro Design B 
Apêndice I

9. Em geral, qual design é mais fácil de usar?

- Prefiro Design A

- Neutro

- Prefiro Design B

10. Em geral, qual design é mais rápido de usar?

- Prefiro Design A

- Neutro

- Prefiro Design B

11. Em geral, qual design é mais divertido de usar?

- Prefiro Design A

- Neutro

- Prefiro Design B

12. Em geral, qual design ajudou a explicar por que uma música foi recomendada?

- Prefiro Design A

- Neutro

- Prefiro Design B

\section{Questões sobre o Design B (com tags)}

13. Favor avaliar o quanto você concorda ou discorda com as seguinte declarações:(discordo fortemente, discordo, neutro, concordo, concordo fortemente) 
- Design B me ajuda a corrigir uma recomendação

- Design B me ajuda a filtrar uma recomendação de músicas

- Depois de selecionar uma tag, as músicas mostradas fizerem sentido para mim.

- Selecionar tags me ajudou a achar músicas que eu não conhecia

- Selecionar tags me ajudou a achar músicas que me interessam

14. Favor avaliar o quanto você concorda ou discorda com as seguinte declarações:(discordo fortemente, discordo, neutro, concordo, concordo fortemente)

- As tags me ajudaram a encontrar músicas que eu gosto mais rápido

- As tags me ajudaram a determinar quanto eu vou gostar das músicas

- As tags me ajudaram a aprender algo novo sobre as músicas recomendadas

- Eu gostei de ver as tags

- Usar as tags é divertido

- As tags me ajudaram a decidir quais músicas eu devo escutar

- Em geral, as tags explicam bem as músicas recomendadas

15. Você tem algum comentário ou sugestão de como melhorar o design?

(Questão enviada apenas para participantes do Mechanical Turk.)

16. Invente um código de finalização com 5 dígitos. Digite o código abaixo. Você deve digitar o mesmo código de finalização quando completar esse HIT:

\section{Questionário dos Experimentos 2 e 3}

1. Please enter: 
- Age:

- Gender:

2. How often do you use the internet? Once a month or less

- Once a week

- Every day

- Many times a day

3. Do you use any of these music sites or players? (select all that apply)

- iTunes, Windows Media Player or Winamp

- Pandora, Last.fm

- Spotify, Mog, Rdio, Grooveshark

- Other

- None

Next questions are about Design A and Design B (tags), shown below:

Design A

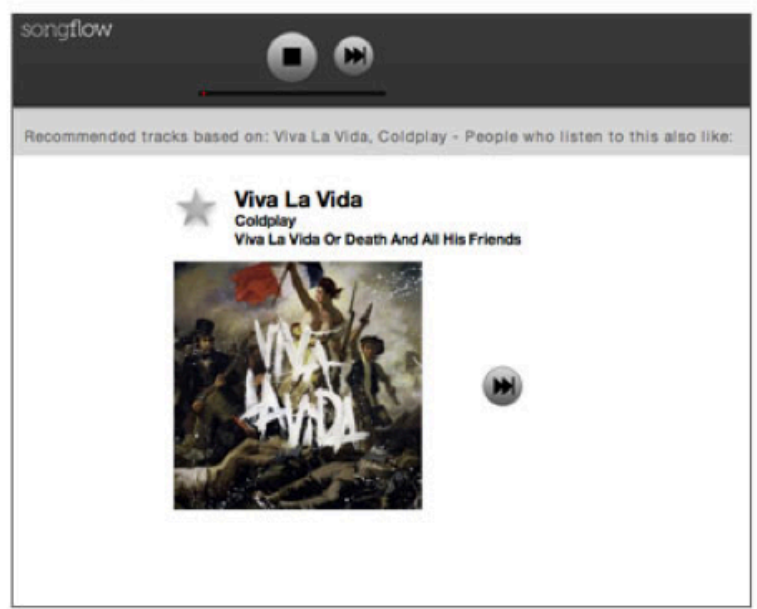

Design B (tags)

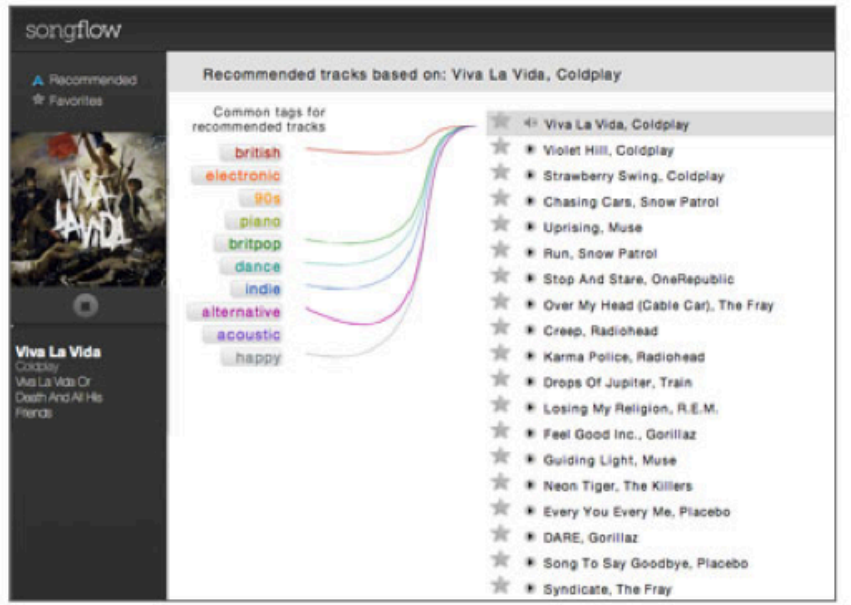


4. Please rate each of the following statements (1-strongly disagree, 7- strongly agree).

- "Design A" helped me filter the recommended songs

- "Design B (tags)" helped me filter the recommended songs

- $\quad$ "Design A" gave me more control over the recommended songs

- "Design B (tags)" gave me more control over the recommended songs

- "Design A" helped me find songs I was looking for

- "Design B (tags)" helped me find songs I was looking for

- $\quad$ "Design A" helped me learn something about the recommended songs

- "Design B (tags)" helped me learn something about the recommended songs

- "Design A" was fun to use

- "Design B (tags)" was fun to use

- "Design A" was easy to use

- "Design B (tags)" was easy to use

- Overall, I was satisfied using "Design A"

- Overall, I was satisfied using "Design B (tags)"

- $\quad$ "Design A" helped me complete the task quickly

- "Design B (tags)" helped me complete the task quickly

- The explanation for "Design A" recommendations ("People who listen to this also like") is helpful

- The explanation for "Design B" recommendations (list of tags) is helpful

5. Do you have any comments or suggestions of how to improve the player design? 
6. Make up a 5 digit completion code. Enter the code below. You'll enter the same code to complete this HIT:

\section{Questionário dos Experimentos 2 e 3 (tradução)}

1. Favor preencher:

- Idade:

- Sexo:

2. Com que frequência você usa a Internet?

- Uma vez por semana

- Todo dia

- Muitas vezes ao dia

3. Você usa algum desses sites ou players de música? (selecione todos que se aplicam)

- iTunes, Windows Media Player or Winamp

- Pandora, Last.fm

- Spotify, Mog, Rdio, Grooveshark

- Outro

- Nenhum

As próximas questões são sobre o Design A e o Design B (tags), mostrados abaixo: 


\section{Design A}

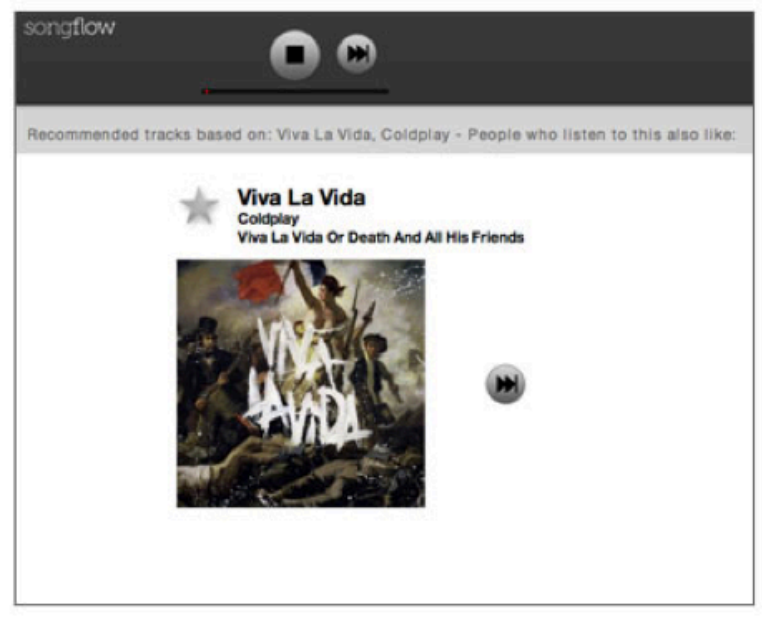

Design B (tags)

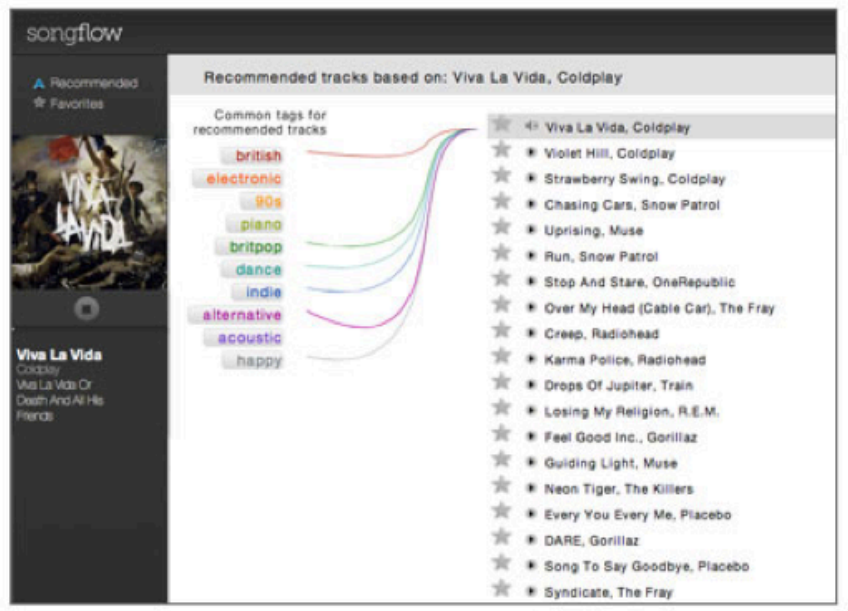

4. Favor avaliar o quanto você concorda ou discorda com as seguinte declarações:(1 - discordo fortemente, 7 - concordo fortemente)

- "Design A" me ajudou a filtrar as músicas recomendadas

- “Design B” (tags) me ajudou a filtrar as músicas recomendadas

- “Design A” me deu mais controle sobre as músicas recomendadas

- "Design B" me deu mais controle sobre as músicas recomendadas

- “Design A" me ajudou a encontrar músicas que eu procurava

- “Design B” me ajudou a encontrar músicas que eu procurava

- "Design A" me ajudou a aprender algo novo sobre as músicas recomendadas

- "Design B" me ajudou a aprender algo novo sobre as músicas recomendadas

- "Design A" foi divertido de usar

- “Design B” foi divertido de usar

- "Design A" foi fácil de usar

- "Design B" foi fácil de usar

- Em geral, fiquei satisfeito usando o "Design A"

- "Design A" me ajudou a completar a tarefa rapidamente 
- "Design B" me ajudou a completar a tarefa rapidamente

- A explicação para as recomendações do "Design A" (Pessoas que escutam isso também escutam) é útil

- A explicação para as recomendações do "Design B" (lista de tags) é útil

5. Você tem algum comentário ou sugestões de como melhorar o design do player?

6. Invente um código de finalização com 5 dígitos. Digite o código abaixo. Você deve digitar o mesmo código de finalização quando completar esse HIT: 


\section{Apêndice II}

\section{Tabelas de Músicas Filtradas}

Tabelas que mostram o número de canções filtradas no cálculo com fid (freqüência inversa de documentos) e sem fid.

The Thrill Is Gone, B.B. King (blues)

\begin{tabular}{|l|l|}
\hline Sem fid & Músicas filtradas \\
\hline rock & 1 \\
\hline guitar & 9 \\
\hline classic & 7 \\
\hline soul & 30 \\
\hline electric & 18 \\
\hline jazz & 27 \\
\hline $60 s$ & 28 \\
\hline $50 s$ & 38 \\
\hline delta & 39 \\
\hline rhythm & 34 \\
\hline & \\
\hline Total & 231 \\
\hline
\end{tabular}

\begin{tabular}{|l|l|}
\hline Como fid & Músicas filtradas \\
\hline soul & 30 \\
\hline delta & 39 \\
\hline guitar & 9 \\
\hline 50 s & 38 \\
\hline jazz & 27 \\
\hline 60 s & 28 \\
\hline rhythm & 34 \\
\hline psychedelic & 41 \\
\hline classic & 7 \\
\hline electric & 18 \\
\hline & \\
\hline Total & 271 \\
\hline
\end{tabular}

These Days, The Black Keys (blues)

\begin{tabular}{|l|l|}
\hline Sem fid & Músicas filtradas \\
\hline rock & 3 \\
\hline indie & 9 \\
\hline alternative & 6 \\
\hline garage & 29 \\
\hline folk & 38 \\
\hline british & 37 \\
\hline pop & 24 \\
\hline 00s & 26 \\
\hline
\end{tabular}

\begin{tabular}{|l|l|}
\hline Como fid & Músicas filtradas \\
\hline folk & 38 \\
\hline indie & 9 \\
\hline garage & 29 \\
\hline british & 37 \\
\hline rel-mnth & 49 \\
\hline classic & 39 \\
\hline experimental & 43 \\
\hline rock & 3 \\
\hline
\end{tabular}


Apêndice II

\begin{tabular}{|l|l|}
\hline american & 23 \\
\hline classic & 39 \\
\hline & \\
\hline Total & 234 \\
\hline
\end{tabular}

\begin{tabular}{|l|l|} 
singer-songwriter & 41 \\
\hline 2010 & 35 \\
\hline & \\
\hline Total & 323 \\
\hline
\end{tabular}

Für Elise, Ludwig van Beethoven (classical)

\begin{tabular}{|l|l|}
\hline Sem fid & Músicas filtradas \\
\hline classical & 4 \\
\hline romantic & 9 \\
\hline instrumental & 15 \\
\hline classic & 17 \\
\hline klassik & 12 \\
\hline baroque & 40 \\
\hline relaxing & 29 \\
\hline russian & 45 \\
\hline german & 33 \\
\hline impressionist & 43 \\
\hline & \\
\hline Total & 247 \\
\hline
\end{tabular}

\begin{tabular}{|l|l|}
\hline Como fid & Músicas filtradas \\
\hline classical & 4 \\
\hline baroque & 40 \\
\hline russian & 45 \\
\hline instrumental & 15 \\
\hline impressionist & 43 \\
\hline romantic & 9 \\
\hline french & 42 \\
\hline classic & 17 \\
\hline german & 33 \\
\hline relaxing & 29 \\
\hline & \\
\hline Total & 277 \\
\hline
\end{tabular}

Clair de lune, Claude Debussy (classical)

\begin{tabular}{|l|l|}
\hline Sem fid & Músicas filtradas \\
\hline classical & 11 \\
\hline romantic & 22 \\
\hline instrumental & 23 \\
\hline klassik & 23 \\
\hline classic & 28 \\
\hline impressionist & 43 \\
\hline classigal63 & 47 \\
\hline classics & 41 \\
\hline baroque & 42 \\
\hline french & 44 \\
\hline
\end{tabular}

\begin{tabular}{|l|l|}
\hline Como fid & Músicas filtradas \\
\hline classical & 11 \\
\hline romantic & 22 \\
\hline classicao & 49 \\
\hline classigal63 & 47 \\
\hline instrumental & 23 \\
\hline impressionist & 43 \\
\hline french & 44 \\
\hline baroque & 42 \\
\hline classics & 41 \\
\hline classic & 28 \\
\hline
\end{tabular}


Apêndice II

\begin{tabular}{|l|l|} 
& \\
\hline Total & 324 \\
\hline
\end{tabular}

\begin{tabular}{|l|l|} 
& \\
\hline Total & 350 \\
\hline
\end{tabular}

I Walk The Line, Johnny Cash (country)

\begin{tabular}{|l|l|}
\hline Sem fid & Músicas filtradas \\
\hline classic & 5 \\
\hline folk & 18 \\
\hline soundtrack & 27 \\
\hline 60 s & 20 \\
\hline 70 s & 28 \\
\hline singer-songwriter & 23 \\
\hline americana & 17 \\
\hline pop & 18 \\
\hline 50 s & 36 \\
\hline male & 13 \\
\hline & \\
\hline Total & 205 \\
\hline
\end{tabular}

\begin{tabular}{|l|l|}
\hline Como fid & Músicas filtradas \\
\hline soundtrack & 27 \\
\hline female & 42 \\
\hline 70 s & 28 \\
\hline 50 s & 36 \\
\hline folk & 18 \\
\hline outlaw & 37 \\
\hline 60 s & 20 \\
\hline singer-songwriter & 23 \\
\hline roll & 37 \\
\hline rockabilly & 41 \\
\hline & \\
\hline Total & 309 \\
\hline
\end{tabular}

Ours, Taylor Swift (country)

\begin{tabular}{|l|l|}
\hline Sem fid & Músicas filtradas \\
\hline pop & 20 \\
\hline female & 24 \\
\hline modern & 16 \\
\hline american & 28 \\
\hline rock & 30 \\
\hline sad & 38 \\
\hline singer-songwriter & 38 \\
\hline $10 s$ & 39 \\
\hline male & 35 \\
\hline top & 24 \\
\hline & \\
\hline Total & 292 \\
\hline
\end{tabular}

\begin{tabular}{|l|l|}
\hline Como fid & Músicas filtradas \\
\hline female & 24 \\
\hline pop & 20 \\
\hline sad & 38 \\
\hline singer-songwriter & 38 \\
\hline 90 s & 43 \\
\hline 10 s & 39 \\
\hline catchy & 42 \\
\hline cover & 45 \\
\hline american & 28 \\
\hline duet & 48 \\
\hline & \\
\hline Total & 365 \\
\hline
\end{tabular}


Apêndice II

Where the Boats Go, M83 (electronic)

\begin{tabular}{|l|l|}
\hline Sem fid & Músicas filtradas \\
\hline electronic & 2 \\
\hline indie & 10 \\
\hline ambient & 33 \\
\hline electropop & 31 \\
\hline pop & 19 \\
\hline electronica & 31 \\
\hline 10 s & 30 \\
\hline 2011 & 30 \\
\hline synthpop & 37 \\
\hline experimental & 36 \\
\hline & \\
\hline Total & 259 \\
\hline
\end{tabular}

\begin{tabular}{|l|l|}
\hline Como fid & Músicas filtradas \\
\hline ambient & 33 \\
\hline electropop & 31 \\
\hline rel-mnth & 49 \\
\hline shoegaze & 46 \\
\hline synthpop & 37 \\
\hline experimental & 36 \\
\hline atmospheric & 42 \\
\hline electronica & 31 \\
\hline indie & 10 \\
\hline downtempo & 44 \\
\hline & \\
\hline Total & 359 \\
\hline
\end{tabular}

Harder, Better, Faster, Stronger, Daft Punk (electronic)

\begin{tabular}{|l|l|}
\hline Sem fid & Músicas filtradas \\
\hline electronic & 2 \\
\hline dance & 2 \\
\hline electronica & 3 \\
\hline electro & 2 \\
\hline techno & 14 \\
\hline indie & 26 \\
\hline club & 11 \\
\hline french & 38 \\
\hline alternative & 16 \\
\hline 90s & 34 \\
\hline & \\
\hline Total & 148 \\
\hline
\end{tabular}

\begin{tabular}{|l|l|}
\hline Como fid & Músicas filtradas \\
\hline french & 38 \\
\hline indie & 26 \\
\hline 90 s & 34 \\
\hline techno & 14 \\
\hline british & 33 \\
\hline trip-hop & 40 \\
\hline synthpop & 38 \\
\hline electronic & 2 \\
\hline progressive & 33 \\
\hline trance & 24 \\
\hline & \\
\hline Total & 282 \\
\hline
\end{tabular}

Like a Rolling Stone, Bob Dylan (folk) 
Apêndice II

\begin{tabular}{|l|l|}
\hline Sem fid & Músicas filtradas \\
\hline rock & 2 \\
\hline classic & 2 \\
\hline 60 s & 3 \\
\hline psychedelic & 16 \\
\hline 70 s & 4 \\
\hline folk & 26 \\
\hline british & 28 \\
\hline singer-songwriter & 23 \\
\hline blues & 20 \\
\hline pop & 6 \\
\hline & \\
\hline Total & 130 \\
\hline
\end{tabular}

\begin{tabular}{|l|l|}
\hline Como fid & Músicas filtradas \\
\hline folk & 26 \\
\hline british & 28 \\
\hline singer-songwriter & 23 \\
\hline psychedelic & 16 \\
\hline blues & 20 \\
\hline glam & 47 \\
\hline rock & 2 \\
\hline proto-punk & 41 \\
\hline 60s & 3 \\
\hline acoustic & 30 \\
\hline & \\
\hline Total & 236 \\
\hline
\end{tabular}

Skinny Love, Bon Iver (folk)

\begin{tabular}{|l|l|}
\hline Sem fid & Músicas filtradas \\
\hline indie & 9 \\
\hline folk & 12 \\
\hline acoustic & 18 \\
\hline singer-songwriter & 18 \\
\hline mellow & 16 \\
\hline rock & 14 \\
\hline alternative & 16 \\
\hline melancholy & 22 \\
\hline sad & 23 \\
\hline pop & 19 \\
\hline & \\
\hline Total & 167 \\
\hline
\end{tabular}

\begin{tabular}{|l|l|}
\hline Como fid & Músicas filtradas \\
\hline folk & 12 \\
\hline indie & 9 \\
\hline acoustic & 18 \\
\hline singer-songwriter & 18 \\
\hline mellow & 16 \\
\hline melancholy & 22 \\
\hline rock & 14 \\
\hline alternative & 16 \\
\hline sad & 23 \\
\hline lo-fi & 39 \\
\hline & \\
\hline Total & 18 \\
\hline
\end{tabular}

All of the Lights, Kanye West (hip hop)

\begin{tabular}{|l|l|}
\hline Sem fid & Músicas filtradas \\
\hline hip-hop & 13 \\
\hline
\end{tabular}

\begin{tabular}{|l|l|}
\hline Como fid & Músicas filtradas \\
\hline hip-hop & 13 \\
\hline
\end{tabular}


Apêndice II

\begin{tabular}{|l|l|} 
rap & 15 \\
\hline hip & 18 \\
\hline hop & 18 \\
\hline pop & 32 \\
\hline rnb & 27 \\
\hline 2011 & 37 \\
\hline 10 s & 38 \\
\hline 2010 & 40 \\
\hline 2010 s & 38 \\
\hline & \\
\hline Total & 276 \\
\hline
\end{tabular}

\begin{tabular}{|l|l|} 
rap & 15 \\
\hline pop & 32 \\
\hline hip & 18 \\
\hline hop & 18 \\
\hline 2011 & 37 \\
\hline rnb & 27 \\
\hline 2010 & 40 \\
\hline epic & 42 \\
\hline 10 s & 38 \\
\hline & \\
\hline Total & 280 \\
\hline
\end{tabular}

Can I Kick It?, A Tribe Called Quest (hip hop)

\begin{tabular}{|l|l|}
\hline Sem fid & Músicas filtradas \\
\hline hip-hop & 2 \\
\hline rap & 2 \\
\hline $90 s$ & 8 \\
\hline classic & 5 \\
\hline hiphop & 4 \\
\hline school & 15 \\
\hline underground & 18 \\
\hline coast & 9 \\
\hline chill & 20 \\
\hline east & 16 \\
\hline & \\
\hline Total & 94 \\
\hline
\end{tabular}

\begin{tabular}{|l|l|}
\hline Como fid & Músicas filtradas \\
\hline hip-hop & 2 \\
\hline 90s & 8 \\
\hline underground & 18 \\
\hline jazz & 33 \\
\hline funk & 31 \\
\hline gangsta & 33 \\
\hline school & 15 \\
\hline chill & 20 \\
\hline rap & 2 \\
\hline york & 23 \\
\hline & \\
\hline Total & 185 \\
\hline
\end{tabular}

Somebody That I Used To Know, Gotye (indie)

\begin{tabular}{|l|l|}
\hline Sem fid & Músicas filtradas \\
\hline indie & 4 \\
\hline alternative & 3 \\
\hline rock & 11 \\
\hline
\end{tabular}

\begin{tabular}{|l|l|}
\hline Como fid & Músicas filtradas \\
\hline electronic & 19 \\
\hline folk & 35 \\
\hline swedish & 45 \\
\hline
\end{tabular}


Apêndice II

\begin{tabular}{|l|l|} 
electronic & 19 \\
\hline pop & 8 \\
\hline folk & 35 \\
\hline female & 31 \\
\hline british & 38 \\
\hline 2011 & 30 \\
\hline experimental & 37 \\
\hline & \\
\hline Total & 216 \\
\hline
\end{tabular}

\begin{tabular}{|l|l|} 
british & 38 \\
\hline electropop & 40 \\
\hline australian & 43 \\
\hline female & 31 \\
\hline experimental & 37 \\
\hline indie & 4 \\
\hline rock & 11 \\
\hline & \\
\hline Total & 303 \\
\hline
\end{tabular}

I Will Follow You Into The Dark, Death Cab for Cutie (indie)

\begin{tabular}{|l|l|}
\hline Sem fid & Músicas filtradas \\
\hline indie & 5 \\
\hline rock & 7 \\
\hline alternative & 7 \\
\hline acoustic & 22 \\
\hline folk & 27 \\
\hline mellow & 9 \\
\hline singer-songwriter & 26 \\
\hline pop & 9 \\
\hline emo & 22 \\
\hline sad & 17 \\
\hline & \\
\hline Total & 151 \\
\hline
\end{tabular}

\begin{tabular}{|l|l|}
\hline Como fid & Músicas filtradas \\
\hline acoustic & 22 \\
\hline folk & 27 \\
\hline indie & 5 \\
\hline british & 43 \\
\hline singer-songwriter & 26 \\
\hline rock & 7 \\
\hline canadian & 46 \\
\hline electronic & 42 \\
\hline emo & 22 \\
\hline alternative & 7 \\
\hline & \\
\hline Total & 247 \\
\hline
\end{tabular}

So What, Miles Davis (jazz)

\begin{tabular}{|l|l|}
\hline Sem fid & Músicas filtradas \\
\hline piano & 13 \\
\hline saxophone & 21 \\
\hline instrumental & 4 \\
\hline trumpet & 27 \\
\hline bebop & 16 \\
\hline
\end{tabular}

\begin{tabular}{|l|l|}
\hline Como fid & Músicas filtradas \\
\hline trumpet & 27 \\
\hline saxophone & 21 \\
\hline bass & 39 \\
\hline bebop & 16 \\
\hline piano & 13 \\
\hline
\end{tabular}


Apêndice II

\begin{tabular}{|l|l|} 
fusion & 34 \\
\hline swing & 32 \\
\hline bass & 39 \\
\hline bop & 22 \\
\hline sax & 28 \\
\hline & \\
\hline Total & 236 \\
\hline
\end{tabular}

\begin{tabular}{|l|l|} 
fusion & 34 \\
\hline swing & 32 \\
\hline funk & 44 \\
\hline hardbop & 43 \\
\hline sax & 28 \\
\hline & \\
\hline & 297 \\
\hline
\end{tabular}

Strange Fruit, Billie Holiday (jazz)

\begin{tabular}{|l|l|}
\hline Sem fid & Músicas filtradas \\
\hline jazz & 3 \\
\hline female & 12 \\
\hline vocal & 7 \\
\hline swing & 25 \\
\hline soul & 32 \\
\hline 50 s & 34 \\
\hline lounge & 32 \\
\hline easy & 21 \\
\hline 2giveme5 & 35 \\
\hline classic & 28 \\
\hline & \\
\hline Total & 229 \\
\hline
\end{tabular}

\begin{tabular}{|l|l|}
\hline Como fid & Músicas filtradas \\
\hline soul & 32 \\
\hline jazz & 3 \\
\hline female & 12 \\
\hline swing & 25 \\
\hline chic & 49 \\
\hline saxophone & 44 \\
\hline trumpet & 40 \\
\hline 50 s & 34 \\
\hline gershwin & 47 \\
\hline 2giveme5 & 35 \\
\hline & \\
\hline Total & 321 \\
\hline
\end{tabular}

Chop Suey!, System of a Down (metal)

\begin{tabular}{|l|l|}
\hline Sem fid & Músicas filtradas \\
\hline rock & 0 \\
\hline alternative & 0 \\
\hline nu & 9 \\
\hline hard & 3 \\
\hline heavy & 10 \\
\hline metalcore & 26 \\
\hline nu-metal & 17 \\
\hline
\end{tabular}

\begin{tabular}{|l|l|}
\hline Como fid & Músicas filtradas \\
\hline industrial & 30 \\
\hline metalcore & 26 \\
\hline rapcore & 41 \\
\hline political & 41 \\
\hline nu & 9 \\
\hline thrash & 36 \\
\hline nu-metal & 17 \\
\hline
\end{tabular}


Apêndice II

\begin{tabular}{|l|l|} 
industrial & 30 \\
\hline hardcore & 24 \\
\hline $00 s$ & 14 \\
\hline & \\
\hline Total & 133 \\
\hline
\end{tabular}

\begin{tabular}{|l|l|} 
post-grunge & 38 \\
\hline 90 s & 32 \\
\hline hardcore & 24 \\
\hline & \\
\hline Total & 294 \\
\hline
\end{tabular}

Run To The Hills, Iron Maiden (metal)

\begin{tabular}{|l|l|}
\hline Sem fid & Músicas filtradas \\
\hline heavy & 4 \\
\hline hard & 4 \\
\hline 80 s & 14 \\
\hline thrash & 26 \\
\hline classic & 11 \\
\hline power & 16 \\
\hline guitar & 15 \\
\hline nwobhm & 40 \\
\hline nu & 42 \\
\hline alternative & 32 \\
\hline & \\
\hline Total & 204 \\
\hline
\end{tabular}

\begin{tabular}{|l|l|}
\hline Como fid & Músicas filtradas \\
\hline thrash & 26 \\
\hline nu & 42 \\
\hline nwobhm & 40 \\
\hline ballad & 47 \\
\hline german & 46 \\
\hline 80s & 14 \\
\hline metalcore & 43 \\
\hline alternative & 32 \\
\hline comedy & 46 \\
\hline heavy & 4 \\
\hline & \\
\hline Total & 34 \\
\hline
\end{tabular}

London Calling, The Clash (punk)

\begin{tabular}{|l|l|}
\hline Sem fid & Músicas filtradas \\
\hline 70 s & 23 \\
\hline british & 30 \\
\hline hardcore & 28 \\
\hline political & 30 \\
\hline classic & 7 \\
\hline 80s & 18 \\
\hline ska & 37 \\
\hline 90s & 36 \\
\hline indie & 27 \\
\hline
\end{tabular}

\begin{tabular}{|l|l|}
\hline Como fid & Músicas filtradas \\
\hline british & 30 \\
\hline political & 30 \\
\hline hardcore & 28 \\
\hline 70 s & 23 \\
\hline ska & 37 \\
\hline irish & 47 \\
\hline 90s & 36 \\
\hline proto-punk & 41 \\
\hline oi & 44 \\
\hline
\end{tabular}


Apêndice II

\begin{tabular}{|l|l|} 
punkrock & 26 \\
\hline Total & 262 \\
\hline
\end{tabular}

\begin{tabular}{|l|l|}
$\bmod$ & 49 \\
\hline & \\
\hline Total & 365 \\
\hline
\end{tabular}

Boulevard Of Broken Dreams, Green Day (punk)

\begin{tabular}{|l|l|}
\hline Sem fid & Músicas filtradas \\
\hline rock & 0 \\
\hline punk & 2 \\
\hline alternative & 1 \\
\hline pop & 6 \\
\hline emo & 19 \\
\hline hardcore & 33 \\
\hline indie & 13 \\
\hline 00s & 14 \\
\hline british & 45 \\
\hline catchy & 15 \\
\hline & \\
\hline Total & 148 \\
\hline
\end{tabular}

\begin{tabular}{|l|l|}
\hline Como fid & Músicas filtradas \\
\hline british & 45 \\
\hline emo & 19 \\
\hline 70 s & 45 \\
\hline hardcore & 33 \\
\hline punk & 2 \\
\hline pop & 6 \\
\hline classic & 35 \\
\hline fun & 27 \\
\hline 00s & 14 \\
\hline indie & 13 \\
\hline & \\
\hline Total & 239 \\
\hline
\end{tabular}

Billie Jean, Michael Jackson (pop)

\begin{tabular}{|l|l|}
\hline Sem fid & Músicas filtradas \\
\hline 80 s & 2 \\
\hline pop & 0 \\
\hline soul & 14 \\
\hline disco & 14 \\
\hline female & 29 \\
\hline funk & 27 \\
\hline classic & 8 \\
\hline rnb & 25 \\
\hline party & 11 \\
\hline $90 s$ & 24 \\
\hline & \\
\hline
\end{tabular}

\begin{tabular}{|l|l|}
\hline Como fid & Músicas filtradas \\
\hline female & 29 \\
\hline funk & 27 \\
\hline soul & 14 \\
\hline british & 38 \\
\hline motown & 41 \\
\hline disco & 14 \\
\hline rnb & 25 \\
\hline $80 s$ & 2 \\
\hline ballad & 38 \\
\hline 70 s & 35 \\
\hline & \\
\hline
\end{tabular}


Apêndice II

Total

154

Alejandro, Lady Gaga (pop)

\begin{tabular}{|l|l|}
\hline Sem fid & Músicas filtradas \\
\hline pop & 1 \\
\hline dance & 0 \\
\hline electronic & 4 \\
\hline female & 3 \\
\hline electropop & 12 \\
\hline sexy & 16 \\
\hline catchy & 8 \\
\hline party & 3 \\
\hline 2010 & 24 \\
\hline rnb & 29 \\
\hline & \\
\hline Total & 100 \\
\hline
\end{tabular}

Total

263

\begin{tabular}{|l|l|}
\hline Como fid & Músicas filtradas \\
\hline british & 41 \\
\hline indie & 38 \\
\hline 2010 & 24 \\
\hline rnb & 29 \\
\hline 2011 & 37 \\
\hline synthpop & 36 \\
\hline electropop & 12 \\
\hline sexy & 16 \\
\hline disco & 31 \\
\hline rock & 26 \\
\hline & \\
\hline Total & 290 \\
\hline
\end{tabular}

Love on Top, Beyoncé (r\&b)

\begin{tabular}{|l|l|}
\hline Sem fid & Músicas filtradas \\
\hline rnb & 10 \\
\hline pop & 9 \\
\hline soul & 12 \\
\hline female & 7 \\
\hline dance & 19 \\
\hline r\&b & 21 \\
\hline 2011 & 27 \\
\hline british & 38 \\
\hline sexy & 22 \\
\hline hip-hop & 29 \\
\hline & \\
\hline Total & 194 \\
\hline
\end{tabular}

\begin{tabular}{|l|l|}
\hline Como fid & Músicas filtradas \\
\hline rnb & 10 \\
\hline british & 38 \\
\hline soul & 12 \\
\hline pop & 9 \\
\hline hit-boy & 48 \\
\hline jazz & 43 \\
\hline 2011 & 27 \\
\hline dance & 19 \\
\hline hip-hop & 29 \\
\hline tunez & 39 \\
\hline & \\
\hline Total & 274 \\
\hline
\end{tabular}


Apêndice II

We Found Love, Rihanna (r\&b)

\begin{tabular}{|l|l|}
\hline Sem fid & Músicas filtradas \\
\hline pop & 11 \\
\hline 2011 & 18 \\
\hline female & 23 \\
\hline electronic & 35 \\
\hline hip-hop & 41 \\
\hline catchy & 29 \\
\hline soul & 40 \\
\hline rnb & 36 \\
\hline british & 42 \\
\hline electropop & 36 \\
\hline & \\
\hline Total & 311 \\
\hline
\end{tabular}

\begin{tabular}{|l|l|}
\hline Como fid & Músicas filtradas \\
\hline pop & 11 \\
\hline electronic & 35 \\
\hline british & 42 \\
\hline hip-hop & 41 \\
\hline soul & 40 \\
\hline rnb & 36 \\
\hline female & 23 \\
\hline 2011 & 18 \\
\hline electropop & 36 \\
\hline epic & 38 \\
\hline & \\
\hline Total & 320 \\
\hline
\end{tabular}

Come Together, The Beatles (rock)

\begin{tabular}{|l|l|}
\hline Sem fid & Músicas filtradas \\
\hline rock & 2 \\
\hline classic & 2 \\
\hline 60 s & 8 \\
\hline 70 s & 4 \\
\hline british & 18 \\
\hline psychedelic & 14 \\
\hline pop & 5 \\
\hline blues & 21 \\
\hline guitar & 13 \\
\hline folk & 36 \\
\hline & \\
\hline Total & 123 \\
\hline
\end{tabular}

\begin{tabular}{|l|l|}
\hline Como fid & Músicas filtradas \\
\hline british & 18 \\
\hline folk & 36 \\
\hline 60 s & 8 \\
\hline psychedelic & 14 \\
\hline rock & 2 \\
\hline blues & 21 \\
\hline singer-songwriter & 31 \\
\hline glam & 45 \\
\hline metal & 34 \\
\hline 80 s & 28 \\
\hline & \\
\hline Total & 237 \\
\hline
\end{tabular}

Californication, Red Hot Chili Peppers (rock) 
Apêndice II

\begin{tabular}{|l|l|}
\hline Sem fid & Músicas filtradas \\
\hline rock & 0 \\
\hline alternative & 0 \\
\hline indie & 5 \\
\hline 90s & 22 \\
\hline metal & 20 \\
\hline grunge & 20 \\
\hline pop & 6 \\
\hline 00s & 14 \\
\hline hard & 13 \\
\hline british & 37 \\
\hline & \\
\hline Total & 137 \\
\hline
\end{tabular}

\begin{tabular}{|l|l|}
\hline Como fid & Músicas filtradas \\
\hline british & 37 \\
\hline 90s & 22 \\
\hline funk & 40 \\
\hline britpop & 35 \\
\hline metal & 20 \\
\hline experimental & 41 \\
\hline grunge & 20 \\
\hline indie & 5 \\
\hline 00s & 14 \\
\hline mellow & 27 \\
\hline & \\
\hline Total & 26 \\
\hline
\end{tabular}

Viva La Vida, Coldplay (rock)

\begin{tabular}{|l|l|}
\hline Sem fid & Músicas filtradas \\
\hline rock & 0 \\
\hline alternative & 2 \\
\hline indie & 4 \\
\hline pop & 5 \\
\hline british & 23 \\
\hline britpop & 18 \\
\hline electronic & 35 \\
\hline 00s & 12 \\
\hline 90s & 36 \\
\hline happy & 25 \\
\hline & \\
\hline Total & 160 \\
\hline
\end{tabular}

\begin{tabular}{|l|l|}
\hline Como fid & Músicas filtradas \\
\hline british & 23 \\
\hline electronic & 35 \\
\hline $90 s$ & 36 \\
\hline piano & 37 \\
\hline britpop & 18 \\
\hline dance & 31 \\
\hline indie & 4 \\
\hline alternative & 2 \\
\hline acoustic & 34 \\
\hline happy & 25 \\
\hline & \\
\hline Total & 245 \\
\hline
\end{tabular}

\section{Bongo Bong, Manu Chao (reggae)}

\begin{tabular}{|l|l|}
\hline Sem fid & Músicas filtradas \\
\hline roots & 26 \\
\hline
\end{tabular}

\begin{tabular}{|l|l|}
\hline Como fid & Músicas filtradas \\
\hline latin & 35 \\
\hline
\end{tabular}


Apêndice II

\begin{tabular}{|l|l|} 
ska & 25 \\
\hline latin & 35 \\
\hline chill & 22 \\
\hline chillout & 25 \\
\hline world & 32 \\
\hline dancehall & 39 \\
\hline french & 42 \\
\hline jamaica & 39 \\
\hline pop & 31 \\
\hline & \\
\hline Total & 316 \\
\hline
\end{tabular}

\begin{tabular}{|l|l|} 
roots & 26 \\
\hline ska & 25 \\
\hline jewish & 48 \\
\hline dancehall & 39 \\
\hline french & 42 \\
\hline cuban & 47 \\
\hline chillout & 25 \\
\hline world & 32 \\
\hline chill & 22 \\
\hline & \\
\hline Total & 341 \\
\hline
\end{tabular}

Three Little Birds, Bob Marley (reggae)

\begin{tabular}{|l|l|}
\hline Sem fid & Músicas filtradas \\
\hline roots & 11 \\
\hline jamaica & 20 \\
\hline dancehall & 31 \\
\hline chillout & 23 \\
\hline ska & 28 \\
\hline dub & 25 \\
\hline jamaican & 25 \\
\hline $70 s$ & 37 \\
\hline rock & 22 \\
\hline mellow & 31 \\
\hline & \\
\hline Total & 253 \\
\hline
\end{tabular}

\begin{tabular}{|l|l|}
\hline Como fid & Músicas filtradas \\
\hline dancehall & 31 \\
\hline jewish & 48 \\
\hline ska & 28 \\
\hline roots & 11 \\
\hline 70 s & 37 \\
\hline chillout & 23 \\
\hline 90s & 44 \\
\hline jamaica & 20 \\
\hline dub & 25 \\
\hline jamaican & 25 \\
\hline & \\
\hline Total & 292 \\
\hline
\end{tabular}

\section{Lista de Recomendações para Experimento 2}

A lista de recomendações do serviço Last.fm segue abaixo. Ao lado de cada música, indicamos se as tags "bappy" e "piano" foram aplicadas a esta.

0,Viva La Vida,Coldplay HAPPY 
Apêndice II

1, Violet Hill,Coldplay PIANO

2,Strawberry Swing,Coldplay HAPPY

3,Chasing Cars,Snow Patrol PIANO HAPPY

4,Uprising,Muse

5,Run,Snow Patrol PIANO

6,Stop And Stare,OneRepublic PIANO

7,Over My Head (Cable Car), The Fray PIANO HAPPY

8,Creep,Radiohead

9,Karma Police,Radiohead PIANO

10,Drops Of Jupiter,Train PIANO HAPPY

11,Losing My Religion,R.E.M.

12,Feel Good Inc.,Gorillaz HAPPY

13,Guiding Light,Muse

14,Neon Tiger,The Killers HAPPY

15,Every You Every Me,Placebo HAPPY

16,DARE,Gorillaz HAPPY

17,Song To Say Goodbye,Placebo

18,Syndicate, The Fray PIANO

19,Nine In The Afternoon,Panic! At the Disco PIANO HAPPY

20,Look What You've Done,Jet PIANO

21,Grounds For Divorce,Elbow

22,Unwell,Matchbox Twenty HAPPY

23,Anna Molly,Incubus HAPPY

24,Dare You To Move,Switchfoot 
Apêndice II

25,Man on the Moon,R.E.M. PIANO HAPPY

26,All My Own Stunts,Arctic Monkeys

27,Jacksonville,Brandon Flowers

28,Unfinished Business, White Lies

29,All In,Lifehouse

30,I'm Not Over,Carolina Liar PIANO HAPPY

31,Blue Orchid,The White Stripes

32, The Hardest Button to Button, The White Stripes

33,Holy Ghost,White Lies

34,Human, The Killers HAPPY

35,Beautiful Day,U2 HAPPY

36,Use Somebody,Kings Of Leon

37,Hey, Soul Sister,Train HAPPY

38,Sex On Fire,Kings Of Leon

39,Fireflies,Owl City HAPPY

40,Somewhere Only We Know,Keane PIANO HAPPY

41,Secrets, OneRepublic HAPPY

42,Everybody's Changing,Keane PIANO HAPPY

43,For The First Time, The Script

44,The Flood,Take That

45,I'm Yours,Jason Mraz HAPPY

46,Wonderwall,Oasis HAPPY

47,With Or Without You,U2

48,I Gotta Feeling,Black Eyed Peas HAPPY 
Apêndice II

49,Bitter Sweet Symphony,The Verve HAPPY

\section{Lista de Recomendações para Experimento 3}

A lista de recomendações do serviço Pandora.com segue abaixo. Ao lado de cada música, indicamos se as tags "female" e "piano" foram aplicadas a esta.

0,Viva La Vida,Coldplay

1,Love Song,Sara Bareilles PIANO FEMALE

2,Bitter Sweet Symphony, The Verve

3,Chasing Cars,Snow Patrol PIANO

4,You Found Me, The Fray PIANO

5,Lucky,Jason Mraz FEMALE

6,100 Years,Five For Fighting

7,Don't Stop Believin',Journey PIANO

8,Rolling in the Deep,Adele PIANO FEMALE

9,Somewhere Over The Rainbow,Israel Kamakawiwo'ole

10,Look What You've Done,Jet PIANO

11,Linger,The Cranberries FEMALE

12,Apologize,OneRepublic PIANO

13,Intro, The $\mathrm{xx}$

14,Animal,Neon Trees FEMALE

15,I Still Haven't Found What I'm Looking For,U2

16,Closing Time,Semisonic PIANO

17,Somewhere Only We Know,Keane PIANO 
Apêndice II

18,Fix You,Coldplay PIANO

19,The Middle,Jimmy Eat World

20,This Love,Maroon 5

21,With Or Without You,U2

22,Superman (It's Not Easy),Five For Fighting PIANO

23,I'm Yours,Jason Mraz

24,Hey There Delilah,Plain White T's

25, Rhythm Of Love,Plain White T's

26,Human, The Killers

27,Every Breath You Take,The Police

28,Island In The Sun,Weezer

29,Sleeping To Dream,Jason Mraz

30,Won't Go Home Without You,Maroon 5

31,Never Say Never, The Fray PIANO

32,Sunday Morning,Maroon 5 PIANO FEMALE

33,Drops Of Jupiter, Train PIANO

34,Speed of Sound,Coldplay

35,Read My Mind,The Killers PIANO

36,Viva la vida,2CELLOS

37,Starlight,Muse PIANO

38,New Soul,Yael Naim PIANO FEMALE

39,She Will Be Loved,Maroon 5

40,One Headlight, The Wallflowers

41,Life in Technicolor,Coldplay 
Apêndice II

42,Spaceman,The Killers

43,The Heart Of Life,John Mayer

44,Pride (In The Name Of Love),U2

45,Float On,Modest Mouse

46,The Remedy (I Won't Worry),Jason Mraz

47,Smile Like You Mean It,The Killers

48,One,U2

49,Boston,Augustana PIANO 